Impacto das rajadas no desempenho de serviços executados em ambientes em nuvens

Adriana Molina Centurion 

Data de Depósito:

Assinatura:

Adriana Molina Centurion

\title{
Impacto das rajadas no desempenho de serviços executados em ambientes em nuvens
}

\begin{abstract}
Tese apresentada ao Instituto de Ciências Matemáticas e de Computação - ICMC-USP, como parte dos requisitos para obtenção do título de Doutora em Ciências - Ciências de Computação e Matemática Computacional VERSÃO REVISADA.

Área de Concentração: Ciências de Computação e Matemática Computacional

Orientadora: Profa. Dra. Regina Helena Carlucci Santana
\end{abstract}


Ficha catalográfica elaborada pela Biblioteca Prof. Achille Bassi e Seção Técnica de Informática, ICMC/USP, com os dados fornecidos pelo(a) autor(a)

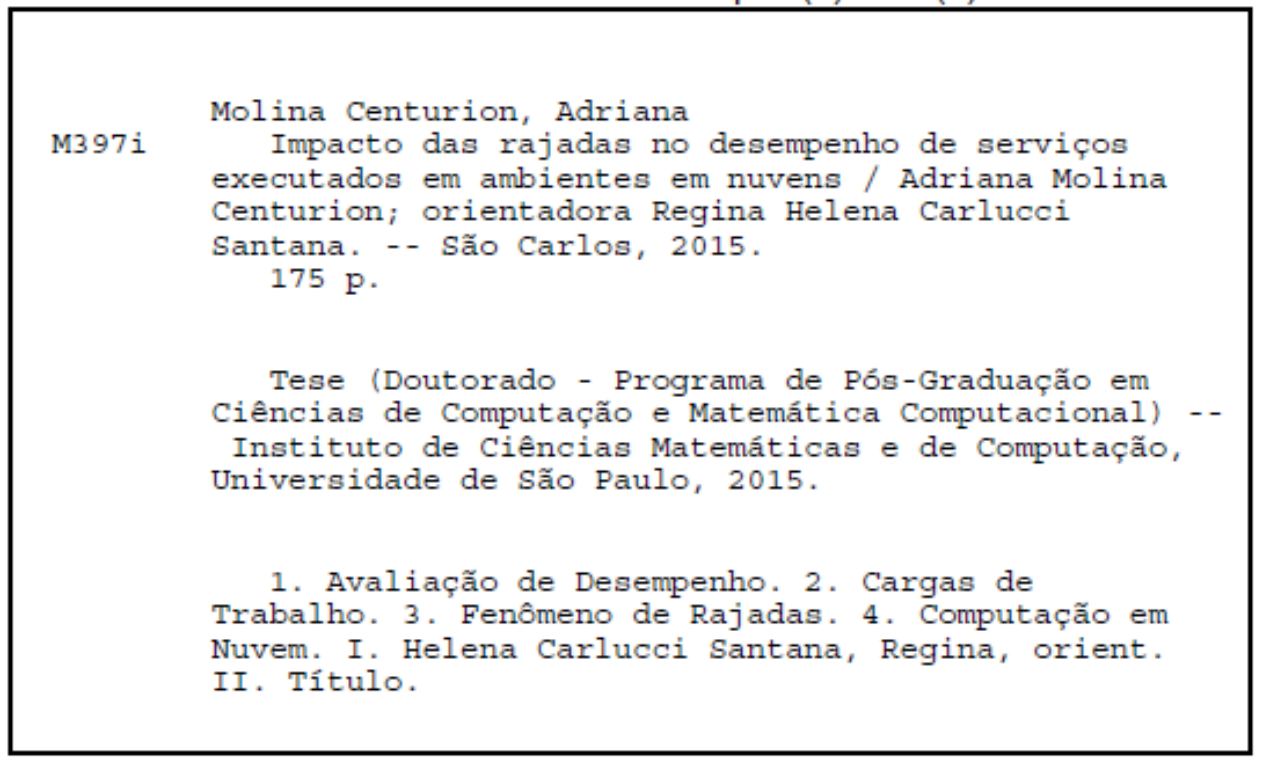


Data de Depósito:

Assinatura:

Adriana Molina Centurion

\section{The impact of bursts in the performance of services executed in cloud environments}

Doctoral dissertation submitted to the Instituto de Ciências Matemáticas e de Computação - ICMCUSP, in partial fulfillment of the requirements for the degree of the Doctorate Program in Computer Science and Computational Mathematics. FINAL VERSION.

Concentration Area: Computer Science and Computational Mathematics

Advisor: Profa.Dra. Regina Helena Carlucci Santana

\section{USP - São Carlos}

June 2015 

Aos meus pais, Evani e Emílio,

com todo amor e gratidão. 



\section{Agradecimentos}

Aos meus pais, Evani e Emílio e aos meus irmãos, Valéria, Fernanda e André, pelo carinho, incentivo e confiança, sem os quais esta conquista não seria possível.

Em especial, à minha orientadora, Prof. Regina Helena Carlucci Santana pela paciência e orientação, tanto na área acadêmica como pessoal e pela incrível capacidade de colocar minhas ideías em ordem. Muito obrigada pelo carinho e confiança a mim depositados e pelos preciosos ensinamentos.

Ao Prof. Marcos José Santana, pelo carinho, pelas sábias palavras de incentivo e pelas lições e ensimanentos, que foram valiosos em vários momentos ao longo deste trabalho.

À Prof. Sarita Mazzini Bruschi pela amizade, pelo apoio e pela grande ajuda na realização deste projeto de doutorado.

Aos meus queridos amigos, Paulo Sérgio F. Eustáquio e Mário H. S. Pardo, que contribuíram muito para o desenvolvimento deste trabalho. Muito obrigada pelo trabalho em equipe, pela amizade e pelos momentos descontraídos que vivenciamos juntos.

À todos colegas, alunos e professores do LaSDPC, que contribuíram com sugestões e críticas sempre construtivas. Ao Instituto de Ciências Matemáticas e de Computação - ICMC, formado por todos os funcionários, pela colaboração no desenvolvimento deste trabalho, que sempre se mostraram disponíveis nos momentos em que os solicitei.

À todos aqueles que contribuíram direta e indiretamente e que, por motivos de correria na finalização eu tenha esquecido de citar nominalmente.

À CNPq pelo apoio financeiro. 



\section{Resumo}

Esta tese apresenta a caracterização de desempenho dos serviços executados em um ambiente em nuvem, quando são consideradas rajadas de diferentes origens, intensidades e variabilidades nas cargas de trabalho. Os resultados mostram que a presença de rajadas no processo de chegada das requisições e/ou nas demandas de serviço, ocasiona uma considerável degradação no desempenho dos serviços e, portanto, devem ser consideradas nos modelos de cargas de trabalhos e nas atividades voltadas para avaliação de desempenho em computação em nuvem. Considerando-se a grande influência das rajadas, é proposta e validada uma metodologia que permite monitorar uma carga de trabalho e determinar a ocorrência de rajadas tanto nas taxas de chegadas de requisições quanto nas demandas de serviços. A metodologia utilizada na condução deste trabalho consta de diferentes modelos de cargas de trabalho com rajadas de diferentes variabilidades e intensidades, desenvolvidos e integrados à arquitetura CloudSim-BEQoS proposta nesta tese. Utilizando-se essa arquitetura é possível executar um conjunto de experimentos que possibilitam a obtenção dos resultados que caracterizam o desempenho dos serviços quando são criadas condições de rajadas nas cargas de trabalho submetidas à nuvem.

Palavras-chave: Avaliação de desempenho, cargas de trabalho, fenômeno de rajadas, computação em nuvem. 



\section{Abstract}

This thesis presents the performance characterization of the services executed in a cloud environment, when bursts are considered from different sources, intensity and variability in the workload. The results show that the presence of bursts in the arrival process of requests and/or in service demands, causes a significant degradation in the performance of services and therefore should belong to the models of workloads and in the activities considered for performance evaluation in cloud computing. Considering the great influence of bursts, a methodology to monitor a workload and predict the occurrence of bursts in both the rates of request arrivals and the service demands is proposed and validated. The methodology used in the conduction of this work consists in different types of workloads with bursts of different variability and intensity, developed and integrated into the CloudSim-BEQoS architecture proposed in this thesis. By using this architecture it is possible to execute a set of experiments that enable the achievement of the results that characterize the performance of services when bursts conditions are created in the workload submitted to the cloud.

Keywords: Performance evaluation, workload, phenomenon of bursts, cloud computing. 



\section{Sumário}

Introdução

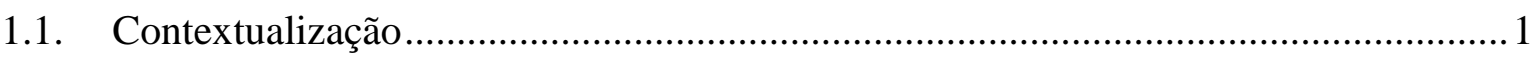

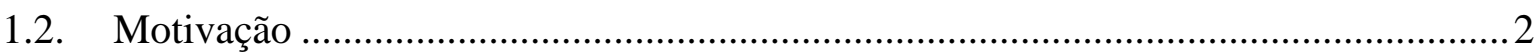

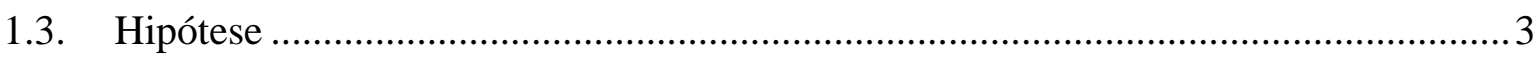

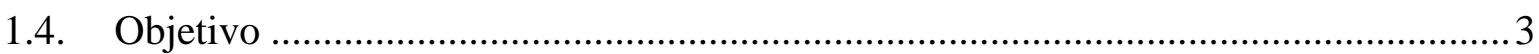

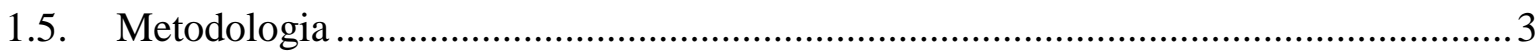

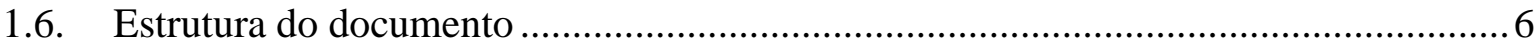

Computação em Nuvem ..................................................................................................................................7

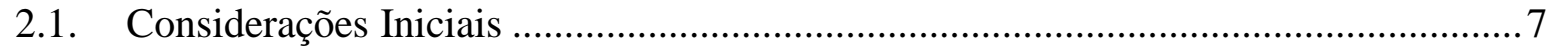

2.2. Definição de Computação em Nuvem .................................................................... 7

2.3. Características Essenciais de Computação em Nuvem............................................... 8

2.4. Modelos de Serviços Computação em Nuvem .......................................................... 9

2.5. Modelos de Computação em Nuvem ..................................................................... 10

2.6. Benefícios e Riscos de Computação em Nuvem .................................................... 12

2.7. Uso de Simulação para Avaliação de Desempenho................................................. 13

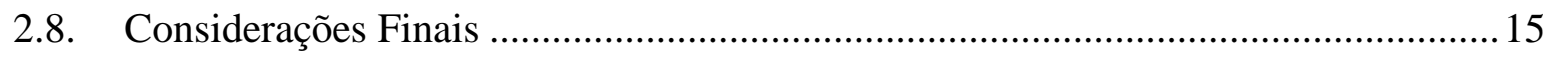

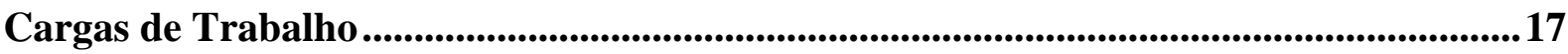

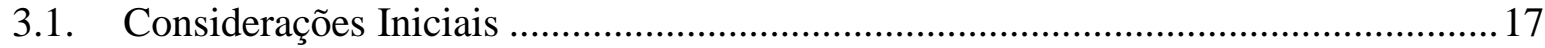

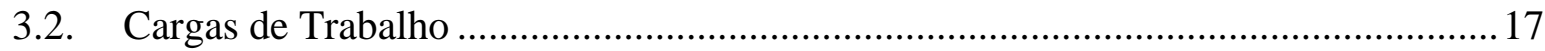

3.2.1. Caracterização de Cargas de Trabalho .............................................................. 18

3.2.2. Modelo de Carga de Trabalho ........................................................................... 19

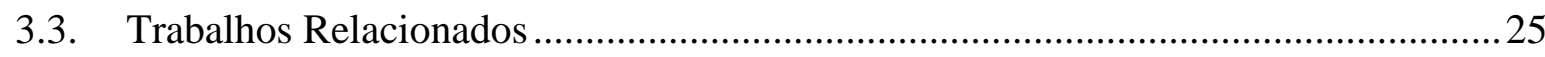

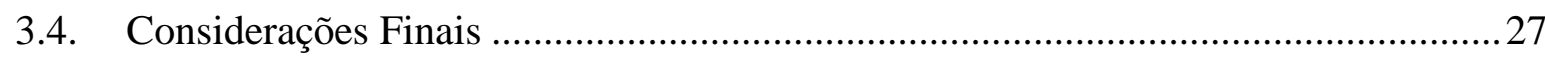

Fenômeno de Rajadas em Cargas de Trabalho ....................................................................29

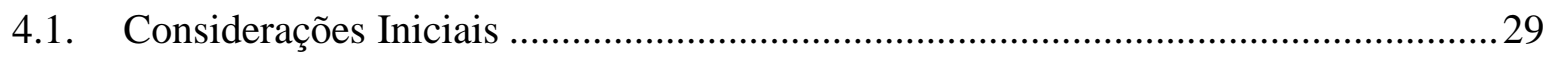


4.2. Fenômeno de Rajadas

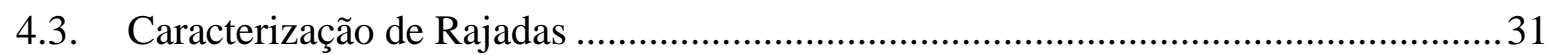

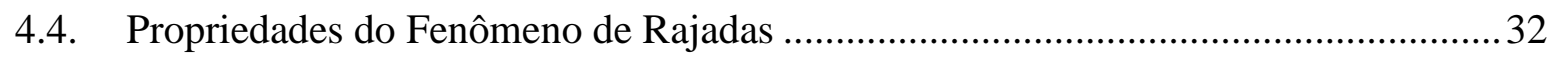

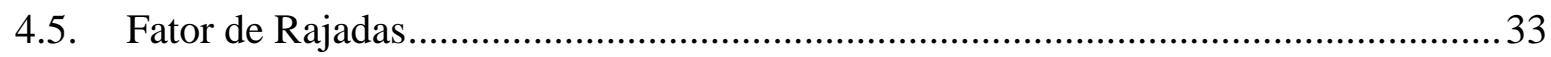

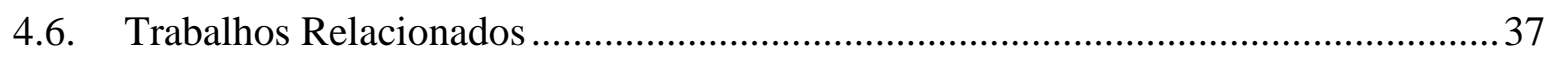

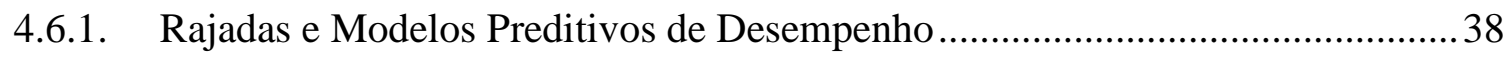

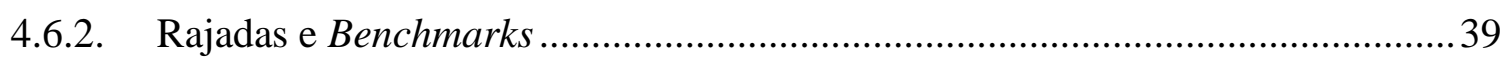

4.6.3. Rajadas e Controle de Admissão/Balanceamento de Carga ............................... 39

4.6.4. Rajadas e Modelos de Custos ...................................................................... 40

4.6.5. Rajadas nos Tempos de Serviços............................................................... 40

4.6.6. Rajadas no Processo de Chegada das Requisições .............................................. 41

4.7. Modelo MAP (Markovian Arrival Process) ........................................................... 42

4.7.1 Descrição Matemática do MAP........................................................................ 43

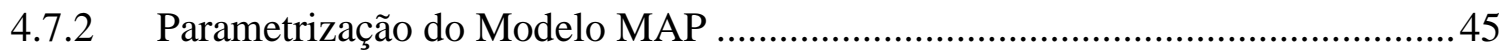

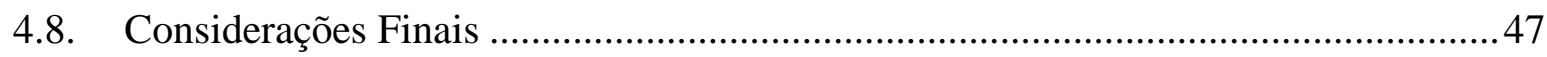

Arquitetura CloudSim-BEQoS: Projeto, Implementação e Estudo de Caso...................... 49

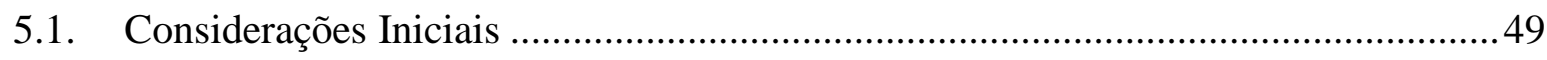

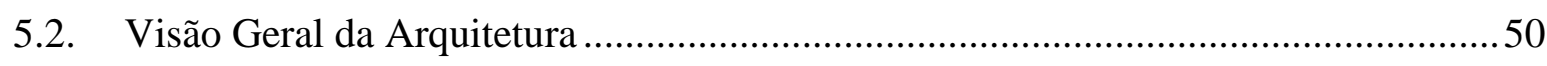

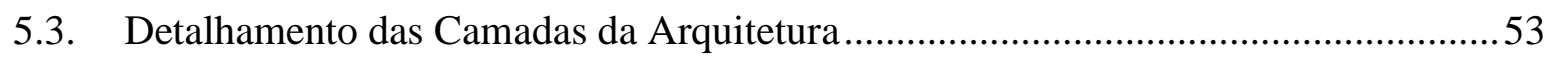

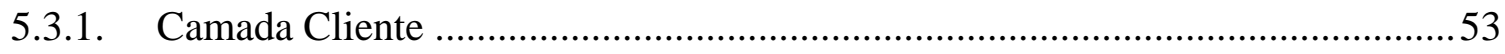

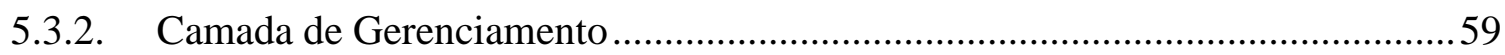

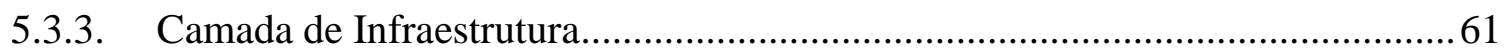

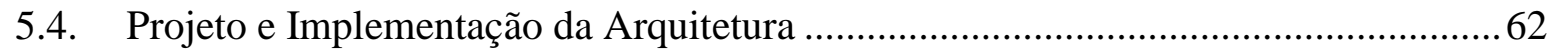

5.5. Estudo de Caso Utilizando CloudSim-BEQoS ............................................................ 64

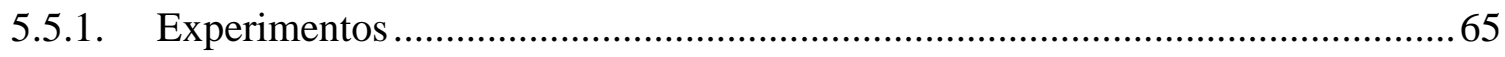

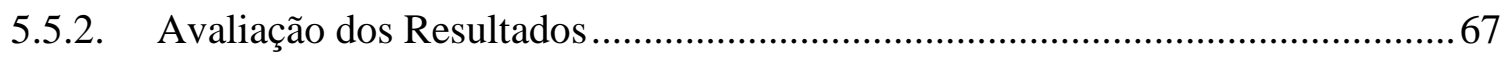

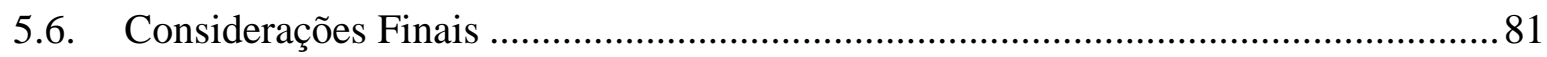




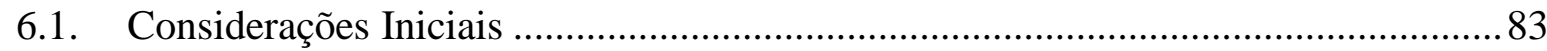

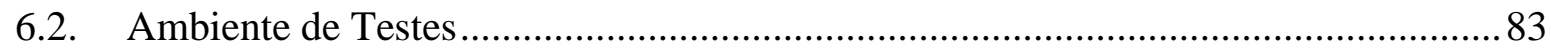

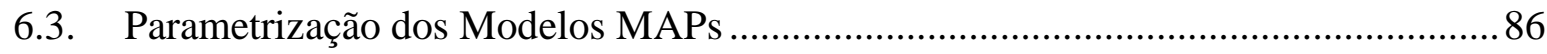

6.3.1 Descrição Matemática das Medidas Principais de um MAP...............................87

6.3.2 Avaliação do Índice de Dispersão ................................................................ 91

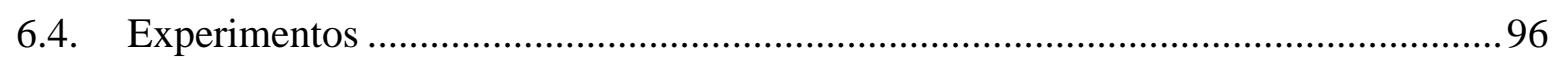

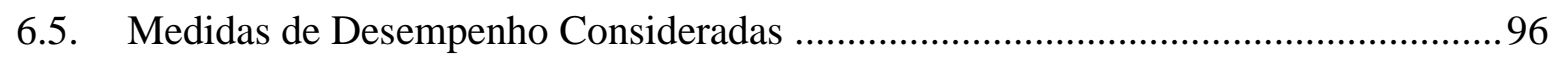

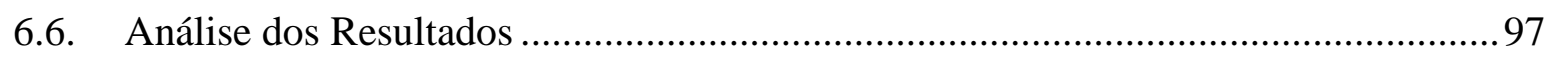

6.6.1 Impacto das Rajadas no Processo de Chegada ...................................................99

6.6.2 Impacto das Rajadas na Demanda de Serviço ................................................. 111

6.6.3 Impacto das Rajadas no Processo de Chegada e na Demanda de Serviço ........ 125

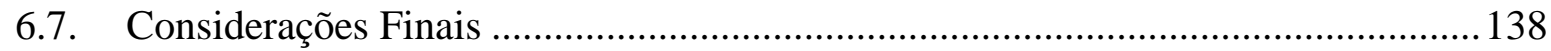

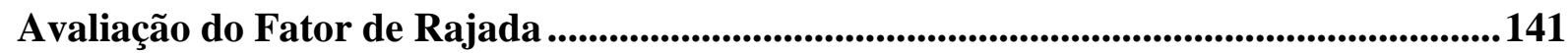

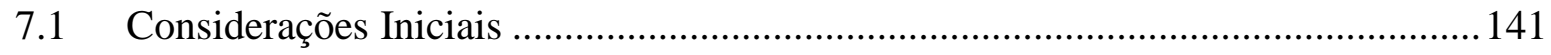

7.2 Fatores de Rajadas e Modelos Preditivos ........................................................... 141

7.3 Metodologia Proposta para o Fator de Rajada ................................................... 144

7.4 Análise Comparativa dos Fatores de Rajada ..................................................... 147

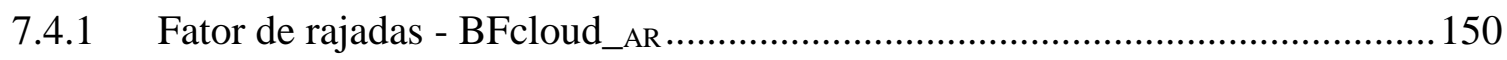

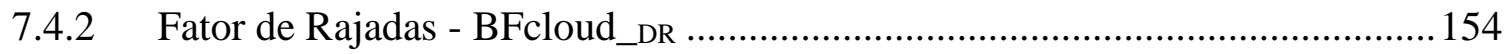

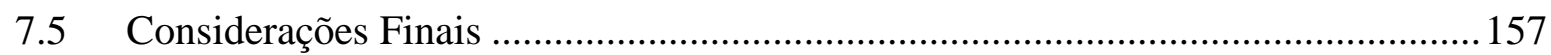

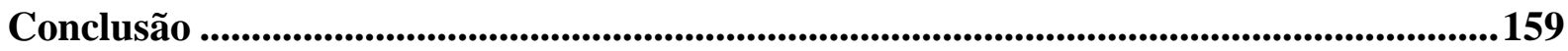

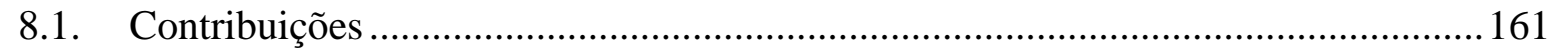

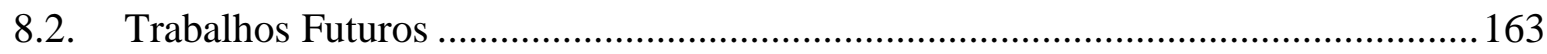

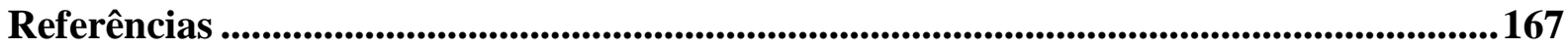





\section{Lista de Figuras}

Figura 2.1 - Modelos de serviços da computação em nuvem, adaptado de Voorsluys et al.(2011)

Figura 2.2 - Modelos de Nuvens baseada nas definições do NIST (Nakamura, 2013)............ 11

Figura 2.3 - Arquitetura do Cloudsim - Adaptado de (Calheiros et al., 2011). ....................... 14

Figura 3.1 - Modelagem de cargas de trabalho (Feitelson, 2014)........................................ 21

Figura 4.1 - Número de requisições chegando ao sistema Web (Menascé et al., 2000)..........30

Figura 4.2 - Taxa de chegada e fator de rajadas: (a) BF1, (b)BF2 (c) BF3, j = 4, (d) BF4, j=4,

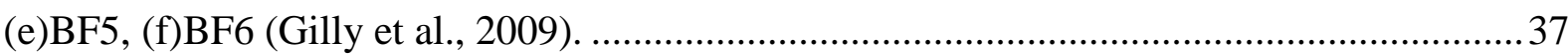

Figura 43 - Exemplo do Markovian Arrival Process com dois estados. ................................ 42

Figura 4.4 - Amostras das taxas de chegadas, adaptado de (Yin et al., 2014)........................ 43

Figura 5.1 - Visão geral da arquitetura desenvolvida........................................................51

Figura 5.2 - Diagrama de sequência para o processamento de um serviço. ............................52

Figura 5.3 - Modos de submissão das requisições implementados na camada cliente............55

Figura 5.4 - Pseudocódigo MAP - para gerar uma amostra de think times............................57

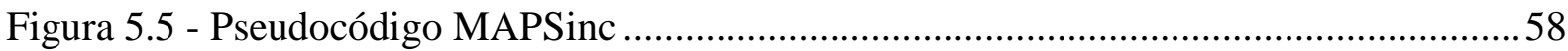

Figura 5.6 - Fluxo de comunicação entre entidades (Calheiros et al., 2011)...........................59

Figura 5.7 - Diagrama de classes do Projeto da Arquitetura. ................................................ 63

Figura 5.8 - Tempo médio de resposta em segundos dos diferentes modos de submissão.......68

Figura 5.9 - Tempo médio do Sistema (em segundos) para os diferentes modos de submissão.

Figura 5.10 - Vazão média dos diferentes modos de submissão .70

Figura 5.11 - Amostras dos tempos de resposta (s) dos diferentes modos de submissão. ........70

Figura 5.12 - Amostras do número de chegadas de requisições dos modos de submissão.......71

Figura 5.13 - Amostras do percentual de consumo dos recursos dos modos de submissão..... 72 Figura 5.14 - Resultados obtidos para cargas de trabalho com e sem rajada e com think times ocorrendo após recebimento de resposta da requisição anterior. 73

Figura 5.15 - Amostras dos tempos de respostas, considerando think times após recebimento da resposta completa da requisição prévia.

Figura 5.16 - Amostras do número de requisições que chegam, monitoradas em intervalos de $7 \mathrm{~s}$, considerando think times após recebimento da resposta completa da requisição prévia.... 75 
Figura 5.17 - Amostras do percentual de consumo de recursos, monitoradas em intervalos de 1s, considerando think times após recebimento da resposta completa da requisição prévia.... 75 Figura 5.18 - Resultados obtidos para - cargas de trabalho com e sem rajada e com think times ocorrendo após submissão da requisição anterior.

Figura 5.19 - Amostras dos tempos de respostas, considerando think times imediatamente após o envio da requisição prévia.

Figura 5.20 - Amostras do número de requisições que chegam, monitoradas em intervalos de $7 \mathrm{~s}$, considerando think times imediatamente após o envio da requisição prévia. 78 Figura 5.21 - Amostras do percentual de consumo de recursos, monitoradas em intervalos de 1s, considerando think times imediatamente após o envio da requisição prévia. 78 Figura 5.22 - Tempos médios de resposta e vazão obtida para os experimentos que consideraram latência de rede entre cliente e Broker homogênea e heterogênea. 79 Figura 5.23 - Tempo médio do sistema - experimentos que consideraram latência de rede entre cliente e Broker homogênea e heterogênea. 80

Figura 5.24 - Amostras dos tempos de espera em fila (s), considerando latência de rede (a) homogênea, (b) heterogênea.

Figura 5.25 - Amostras do número de chegadas de requisições, monitoradas em intervalos de 7 segundos, considerando latência de rede: (a) homogênea, (b) heterogênea. 81

Figura 6.1 - Ambiente de Testes.

Figura 6.2 - Amostras de think times gerados pelos diferentes modelos MAPs (a) MAPIAT1, (b)

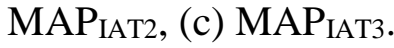
92

Figura 6.3 - Pseudocódigo - Definição dos parâmetros do MAP. 95

Figura 6.4 - Tempos médio de resposta em segundos, para intervalos de chegadas sem e com rajadas - considerando uma nuvem privada.

Figura 6.5 - Tempos médio de serviço, de espera em fila e Latência média de rede para intervalos de chegadas sem e com rajadas - considerando uma nuvem privada. 101 Figura 6.6 - Variável de Resposta Vazão, para intervalos de chegadas sem e com rajadas considerando uma nuvem privada. 102

Figura 6.7 - Amostras de think times geradas durante a simulação 103

Figura 6.8 - Amostras de tempos de resposta monitoradas durante a simulação. 104 Figura 6.9 - Amostras do percentual de consumo dos recursos privados durante a simulação.

Figura 6.10 - Taxa de chegada de requisições \& taxa de demanda de serviço. 106 
Figura 6.11 - Tempo médio de resposta em segundos, para intervalos de chegadas sem e com rajadas - considerando uma nuvem híbrida.

Figura 6.12 - Resultados das variáveis de Repostas: (a) Tempo médio de Serviço, de espera em fila e Latência média de rede, (b) vazão - considerando uma nuvem híbrida 107

Figura 6.13 - Percentual de requisições executadas nas nuvens. 109

Figura 6.14 - Amostras do percentual de consumo dos recursos privados e identificador das VMs alocadas para as requisições ao longo da simulação.

Figura 6.15 - Tempos médio de resposta em segundos, para demandas de serviços sem e com rajadas - considerando uma nuvem privada.

Figura 6.16 - Tempos médio de serviço, de espera em fila e Latência média de rede para demandas de serviços sem e com rajadas - considerando uma nuvem privada. 114 Figura 6.17 - Variável de Resposta Vazão, para demandas de serviços sem e com rajadas considerando uma nuvem privada. 115

Figura 6.18 - Amostras de demandas de serviços geradas durante a simulação. 116

Figura 6.19 - Amostras de tempos de resposta monitoradas durante a simulação.

Figura 6.20 - Amostras do percentual de consumo dos recursos privados durante a simulação.

Figura 6.21 - Taxa de chegada de requisições \& taxa de demanda de serviço. 118

Figura 6.22 - Tempo médio de resposta em segundos, para demandas de serviços sem e com rajadas - considerando uma nuvem híbrida.

Figura 6.23 - Resultados das variáveis de Repostas: (a) Tempo médio de Serviço, de espera em fila e Latência média de rede, (b) Vazão - considerando uma nuvem híbrida.

Figura 6.24 - Percentuais de requisições executadas na nuvem privada e nuvem pública..... 122 Figura 6.25 - Número médio de requisições executadas durante a simulação: total de requisições, requisições com demandas de serviços sem rajadas e com rajadas. 122 Figura 6.26 - Percentual médio de requisições executadas na nuvem privada e pública: (a) com demandas sem rajadas, (b) com demandas com rajadas. 123

Figura 6.27 - Amostras do percentual de consumo dos recursos privados e identificador das VMs alocadas para as requisições ao longo da simulação. 124

Figura 6.28 - Modelos de MAPs implementados: (a) MAP ind $_{\text {, (b) MAP }}$ sinc. 126 Figura 6.29 - Amostras de think times e demandas de serviços geradas durante a simulação.

Figura 6.30 - Tempos médio de resposta em segundos (SR, MAP ind e $\mathrm{MAP}_{\text {sinc) }}$, considerando uma nuvem privada. 
Figura 6.31 - Tempos médio de serviço, de espera em fila e Latência média de rede, para SR, $\mathrm{MAP}_{\text {ind }} \mathrm{e} \mathrm{MAP}_{\text {sinc }}$, considerando uma nuvem privada.

Figura 6.32 - Variável de Resposta Vazão, para SR, MAP ind e MAP ${ }_{\text {sinc, }}$ considerando uma nuvem privada.

Figura 6.33 - Amostras de tempos de resposta monitoradas durante a simulação.

Figura 6.34 - Amostras do percentual de consumo dos recursos privados durante a simulação.

Figura 6.35 - Taxa de chegada de requisições \& taxa de demanda de serviço. 133

Figura 6.36 - Tempo médio de resposta em segundos, para SR, MAP ind e MAP $_{\text {sinc, considerando }}$ uma nuvem híbrida.

Figura 6.37 - Resultados das variáveis de Repostas: (a) Tempo médio de Serviço, de espera em fila e latência média de rede, (b) vazão - considerando uma nuvem híbrida. 135

Figura 6.38 - Percentual de requisições executadas nas nuvens privada e pública. 136

Figura 6.39 - Amostras do percentual de consumo dos recursos privados e identificador das VMs alocadas para as requisições ao longo da simulação. 138

Figura 7.1 - Exemplo do algoritmo e modelo preditivo proposto por Gilly et al. (2012) ...... 142

Figura 7.2 - Monitoramento das cargas de trabalho e cálculo do fator de rajada. 144

Figura 7.3 - Taxa de chegada de requisições e fatores de rajadas, considerando slots estáticos: a) BF1_AR; b) BF2_AR; c) BF3_AR com j=4; d) BF4_AR com j=4; e) BF5_AR; f) BF cloud_AR.. 151 Figura 7.4 - Taxa de chegada de requisições e fatores de rajadas, considerando slots dinâmicos: a) BF1_AR; b) BF2_AR; c) BF3_AR com j=4; d) BF4_AR com j=4; e) BF5_AR; f) BF cloud_AR.. 152 Figura 7.5 - Relacionamento entre as variáveis: taxa de chegada de requisições e BFcloud_AR, considerando: (a) slots estáticos e (b) slots dinâmicos

Figura 7.6 - Taxa de chegada de demanda de Serviço e fatores de rajadas, considerando slots estáticos: a) BF1_DR; b) BF2_DR; c) BF3_DR com j=4; d) BF4_DR com j=4; e) BF5_DR; f) BF 155

Figura 7.7 - Taxa de chegada de demanda de Serviço e fatores de rajadas, considerando slots dinâmicos: a) BF1_DR; b) BF2_DR; c) BF3_DR com j=4; d) BF4_DR com j=4; e) BF5_DR; f) $\mathrm{BF}_{\text {cloud_DR. }}$. 156

Figura 7.8 - Relacionamento entre as variáveis: taxa de chegada demandas de Serviços e BFcloud_DR, considerando: (a) slots estáticos e (b) slots dinâmicos. 157 


\section{Lista de Tabelas}

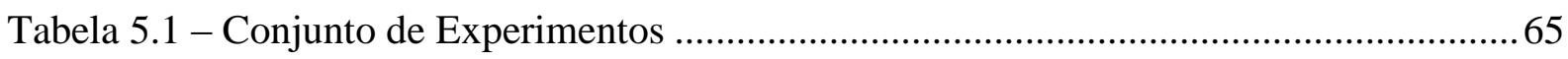

Tabela 6.1 - Configuração dos Servidores dos Provedores de Nuvem ................................... 84

Tabela 6.2 - Parâmetros dos três MAPs avaliados ......................................................................91

Tabela 6. 3 - Medidas de Desempenho - MAPIAT1, MAPIAT2 e MAPIAT3 …........................... 92

Tabela 6.4 - Parametrização dos MAPs para intervalos de chegadas ......................................98

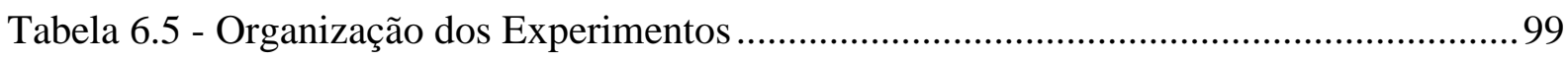

Tabela 6.6 - Parametrização dos MAPs para demandas de serviços. ................................... 111

Tabela 6.7- Organização dos Experimentos .................................................................... 112

Tabela 6.8 - Parametrização dos MAPs para intervalos de chegadas .................................... 126

Tabela 6.9 - Organização dos Experimentos .................................................................. 128

Tabela 7.1 - Modelos de fator de rajada considerados nas avaliações.................................. 148

Tabela 7.2 - Correlação entre o fator de rajada e taxa de chegada de requisições................. 153

Tabela 7.3 -Correlação entre o fator de rajada e taxa de demanda de serviço....................... 157 



\section{Lista de Siglas}

\begin{tabular}{|c|c|}
\hline API & Application Programming Interface \\
\hline $\mathbf{B F}$ & Burstiness Factor \\
\hline CPU & Central Processing Unit \\
\hline СТMC & Continuous-Time Markov Chains \\
\hline EM & Expectation Maximization \\
\hline IaaS & Infrastructure as a Service \\
\hline MAP & Markovian Arrival Process \\
\hline MAPIAT $_{\text {IA }}$ & MAP for Inter-Arrival Time \\
\hline MAPSD & MAP for Service Demand \\
\hline MAP $_{\text {sinc }}$ & MAPs Synchronized \\
\hline MAPind & MAPs Independent \\
\hline MATLAB & MATrix LABoratory \\
\hline MIPs & Millions of Instructions Per Second \\
\hline MI & Millions of Instructions \\
\hline MLE & Maximum Likelihood Estimates \\
\hline NIST & National Institute of Standards and Technology \\
\hline PaaS & Plaftaform as a Service \\
\hline QoS & Quality of Service \\
\hline SaaS & Sofware as a Service \\
\hline SCV & Squared Coefficient of Variation \\
\hline TI & Tecnologia da Informação \\
\hline VM & Virtual Machine \\
\hline
\end{tabular}





\section{Introdução}

\subsection{Contextualização}

A Internet vem se consolidando como um meio de comunicação indispensável e popular. Muitas pessoas, empresas, bancos, instituições de ensino, entre outros, utilizam-se de suas facilidades para fazer negócios ou mesmo trocar informações entre si (Wu e Offut, 2002) (Bozkurt et al., 2010). Com o avanço dos sistemas de informação e a necessidade de se manter todos os processos de negócio integrados, cresce a demanda por tecnologias que possibilitem o desenvolvimento de sistemas que proporcionem maior agilidade nos negócios, redução de custos e maior flexibilidade na oferta de serviços.

A computação em nuvem é uma tendência recente de tecnologia cujo objetivo é proporcionar serviços sob demanda com pagamento baseado no uso (Buyya et al., 2009). De acordo com o NIST (National Institute of Standards and Technology), a computação em nuvem é definida como um modelo que permite ubiquidade, conveniência e acesso sob demanda para um conjunto de recursos compartilhados (redes, servidores e serviços) que podem ser rapidamente entregues com um esforço mínimo de gestão por parte dos usuários (Mell e Grance, 2011).

O modelo de disponibilização de recursos computacionais, em nuvem, ofertada e utilizada na forma de serviço, permite adaptar dinamicamente a capacidade de uma empresa para atender às necessidades dos clientes sem investimentos iniciais para aquisição de hardware e software, licenças e treinamentos dos analistas para manutenção e gerenciamento da nuvem. Em virtude desses benefícios, a computação em nuvem vem se difundindo cada vez mais em empresas de Tecnologia da Informação, como também na comunidade acadêmica. Contudo, alguns ambientes de computação em nuvem estão abertos ao acesso público e portanto, a carga de trabalho pode ser imprevisível e altamente variável, o que dificulta a criação de estimativas de desempenho e garantia de qualidade de serviço (QoS) (Suleiman et al., 2012). 
O oferecimento de QoS é necessário para garantir a satisfação do cliente, mesmo quando a carga de trabalho apresenta uma alta variabilidade na taxa de chegada das requisições e na taxa de serviço. Como a Internet é um ambiente muito dinâmico, prover QoS para clientes em um ambiente de computação em nuvem não é uma tarefa trivial, uma vez que se tem a influência de muitos aspectos do sistema que utiliza esse modelo de implementação (Sakellari e Loukas, 2013) (Batista et al., 2014). Um ponto importante a ser considerado é a natureza imprevisível da carga de trabalho submetida à nuvem, onde os recursos precisam ser monitorados e adaptados continuamente a fim de assegurar um nível adequado de QoS (Cao et al., 2009) (ur Rehman et al., 2015).

\subsection{Motivação}

Conhecer e caracterizar a carga de trabalho é requisito fundamental na avaliação de desempenho e na atividade de planejamento de capacidade de sistemas computacionais (Menascé e Almeida, 2001). A caracterização adequada da carga imposta a um sistema auxilia na identificação de problemas de desempenho, disponibilidade e confiabilidade do sistema.

No contexto de computação em nuvem, dentre o conjunto de características invariantes de carga de trabalho, destaca-se a ocorrência de rajadas (burstiness). Esse fenômeno caracteriza-se pelo aumento súbito de solicitações de serviços submetidas ao sistema, com consequentes picos temporais irregulares na intensidade de chegadas das requisições dos clientes ou na intensidade de demandas de serviços impostas aos recursos da nuvem. Sistemas submetidos a cargas de trabalhos que se apresentam em rajadas, podem apresentar gargalos significativos de desempenho do serviço, e, portanto, precisam ser consideradas no modelo de carga de trabalho.

Vários trabalhos referentes à modelagem de rajadas em cargas de trabalho podem ser encontrados na literatura. (Krishnamurthy et al., 2009) (Rolia et al., 2010) (Mi et al., 2010) (Lu et al., 2010) (Casale et al. 2013). No entanto, a maioria desses trabalhos é voltada para avaliar o desempenho de sistemas baseados em sessão ou aplicações e-commerce baseadas no modelo arquitetural multicamada. Em se tratando de computação em nuvem, existem alguns trabalhos recentes que tratam do fenômeno de rajadas presentes nas cargas de trabalho em ambientes em nuvem, entretanto, de um modo geral esses trabalhos têm um foco mais voltado à alocação, consolidação e provisionamento de recursos na nuvem (Tai et al., 2011) (Luo e Qian, 2013) (Yin et al., 2014) ou ainda, voltados à composição de novos modelos de custos para utilização 
de recursos compartilhados da nuvem (Gmach et al., 2012) (Wang et al., 2012). Não se encontra na literatura um estudo mais profundo referente à caracterização das rajadas nas cargas de trabalho e à definição dos parâmetros do modelo de carga de trabalho considerado.

Percebe-se, portanto, que questões referentes ao estudo e caracterização de rajadas nas cargas de trabalho voltadas para computação em nuvem e à avaliação de sua influência no desempenho dos serviços é um tema pouco explorado e que merece atenção. Desta forma, a análise do impacto das rajadas no desempenho de serviços é o objeto de investigação desta tese.

\subsection{Hipótese}

A hipótese desta tese é que as rajadas influenciam no desempenho dos serviços executados em ambientes em nuvens e, portanto, devem ser consideradas nos modelos de cargas de trabalhos e nas avaliações de desempenho voltados para computação em nuvem. É possível definir-se uma metodologia que permita monitorar uma carga de trabalho e determinar a ocorrência de rajadas.

\subsection{Objetivo}

Para comprovar a hipótese desta tese, o principal objetivo a ser alcançado é viabilizar a avaliação de desempenho dos serviços quando as cargas de trabalho se apresentam em rajadas. Para tanto, alguns objetivos específicos devem ser alcançados:

- Definição de um modelo de carga de trabalho que represente adequadamente as características e propriedades do fenômeno de rajadas;

- Caracterização do desempenho dos serviços quando são consideradas rajadas, de diferentes origens, intensidades e variabilidades nas cargas de trabalho;

- Proposta de uma metodologia que permita monitorar e determinar a ocorrência de rajadas no processo de chegada de requisições e na demanda de serviços.

\subsection{Metodologia}

Para atingir os objetivos citados na Seção 1.4 e para comprovar a hipótese desta tese devem-se analisar os resultados obtidos em experimentos que considerem a presença de rajadas, 
de diferentes origens, variabilidades e intensidades, nas cargas de trabalho e compará-los com os resultados onde o fenômeno de rajadas não é considerado.

Deste modo, a metodologia utilizada para desenvolvimento desta tese possui como base a investigação da literatura e a utilização de ferramentas e APIs (Application Programing Interface) para construção do modelo de carga de trabalho que considere rajadas e implementação de uma arquitetura que permita avaliar o impacto das rajadas no desempenho dos serviços. Assim, a metodologia proposta pode ser dividida em 6 etapas principais:

1. Estudo dos modelos de cargas de trabalho que considerem rajadas propostos na literatura para definição da metodologia adotada nesta tese para modelar as rajadas nas cargas de trabalhos.

2. Com base no estudo realizado na etapa anterior, definir o modelo mais apropriado, considerando:

- A habilidade do modelo em representar as propriedades específicas do fenômeno de rajadas em cargas de trabalho, como variabilidade em diferentes escalas e efeitos de localidade temporal;

- Possibilidade de integrá-lo em ambientes de simulação para avaliação de desempenho dos serviços.

3. Construção de diferentes modelos de carga de trabalho que considerem rajadas nos processos de chegadas das requisições e nas demandas de serviços.

4. Definição de uma metodologia para parametrizar os modelos de cargas de trabalho considerando diferentes níveis de variabilidades e de intensidades.

5. Caracterização do desempenho dos serviços quando são criadas condições de rajadas nas cargas de trabalho submetidas à nuvem. Para a realização desta etapa, as seguintes atividades foram executadas:

- Projeto e implementação de uma arquitetura, CloudSim-BEQoS, utilizando a API do simulador CloudSim, visando incorporar os modelos de carga de trabalho desenvolvidos e viabilizar a avaliação do impacto das rajadas no desempenho dos serviços executados em nuvens.

- Execução de um conjunto de experimentos que possibilite a obtenção de resultados para mostrar a influência das rajadas no desempenho dos serviços executados em uma nuvem privada e híbrida. 
6. Proposta e avaliação de um fator de rajadas que represente com precisão as rápidas variações das taxas de chegadas de requisições e das taxas de demandas de serviços, considerando:

- Estudo dos diferentes modelos de fator de rajadas disponíveis na literatura.

- Definição de um modelo de fator de rajadas que permita detectar a existência de rajadas nas taxas de chegadas de requisições e nas demandas de serviços submetidas à nuvem.

- Análise comparativa considerando os modelos de fator de rajada propostos na literatura e o modelo proposto neste projeto de doutorado, visando avaliar o comportamento de cada um deles em relação à taxa de chegada e validar o modelo para o fator de rajada proposto. Para atingir esse objetivo é realizado um estudo da correlação obtida entre as taxas de chegadas e os fatores de rajadas.

O planejamento de experimentos utilizado nas avaliações de desempenho apresentadas nesta tese, segue, em sua maioria, a abordagem do planejamento fatorial completo. $\mathrm{O}$ planejamento de experimento simples é utilizado em apenas alguns experimentos apresentados no Capítulo 5. O planejamento de experimentos é uma etapa fundamental na avaliação de desempenho de um sistema. Nessa etapa são definidos os fatores ou características que serão avaliadas, verificando quais delas podem influenciar no desempenho do sistema computacional em questão (Jain, 1991). Vários são os termos utilizados durante as etapas de projeto e análise de experimentos. Dentre esses termos, os mais frequentemente usados são:

- Variáveis de resposta: representa o comportamento do sistema avaliado. A variável de resposta é a medida de desempenho do sistema.

- Fatores: são as características do sistema que afetam as variáveis de resposta que se pretende avaliar.

- Níveis: são os valores que um determinado fator pode assumir.

- Interação: mostra a dependência entre os fatores.

A combinação entre os níveis assumidos pelos diferentes fatores de um experimento define os possíveis tipos de planejamento de experimentos: planejamento simples, planejamento fatorial completo e planejamento fatorial parcial (Jain, 1991). No planejamento simples considera-se uma configuração inicial e estabelece-se a variação de um fator de cada vez para verificar como o fator variado, afeta o desempenho do sistema. É um planejamento de fácil implementação, porém não possibilita avaliar a interação entre os fatores. Esse 
planejamento é também utilizado quando se considera apenas um fator, onde não há necessidade de avaliar a interação entre fatores. No planejamento fatorial completo são consideradas todas as combinações possíveis entre os fatores e níveis. Assim, avaliando-se todas as combinações, pode-se determinar tanto os efeitos dos fatores como também verificar as interações entre eles. $\mathrm{O}$ fatorial parcial, por sua vez, consiste em utilizar apenas uma fração do planejamento fatorial completo, ou seja, considera-se apenas parte de todos os experimentos.

\subsection{Estrutura do documento}

Esta tese está organizada em sete Capítulos.

Os Capítulos 2, 3 e 4 apresentam uma revisão bibliográfica contendo os principais conceitos necessários para o desenvolvimento do projeto e os trabalhos relacionados. $\mathrm{O}$ Capítulo 2 apresenta uma revisão sobre computação em nuvem e uma breve descrição do simulador CloudSim. No Capítulo 3 são discutidas maneiras de se definir e caracterizar cargas de trabalho e trabalhos relacionados com cargas de trabalhos voltados para aplicações Web e computação em nuvem. O Capítulo 4 aborda conceitos referentes ao fenômeno de rajadas, à caracterização de rajadas e trabalhos relacionados que tratam aspectos como fatores de rajadas e modelos de rajadas nas cargas de trabalho.

Os Capítulos 5, 6 e 7 apresentam o trabalho desenvolvido nesta tese. O Capítulo 5 mostra o projeto e implementação de uma arquitetura (CloudSim-BEQoS) que possibilita a realização dos experimentos necessários para comprovar a hipótese defendida nesta tese. Nesse Capítulo é apresentada ainda uma avaliação de desempenho para validar em especial os componentes da camada cliente da arquitetura e avaliar o comportamento do sistema quando são submetidas cargas de trabalho distintas. No Capítulo 6 é apresentada a metodologia desenvolvida para definir os parâmetros dos modelos de cargas de trabalho com rajadas propostos nesta tese e avaliações de desempenho, onde é executado uma série de experimentos para avaliar o impacto no desempenho dos serviços quando são consideradas cargas de trabalho com diferentes perfis de rajadas. O Capítulo 7 apresenta o modelo proposto para o fator de rajadas e mostra um estudo comparativo entre o modelo desenvolvido e os modelos matemáticos disponíveis em literatura, mostrando a correlação desses modelos em relação à taxa de chegada (de requisições e de demandas de serviços). Por fim, o Capítulo 8 apresenta as conclusões e os trabalhos futuros que poderão ser desenvolvidos a partir do trabalho apresentado nesta tese. 


\section{Computação em Nuvem}

\subsection{Considerações Iniciais}

O termo computação em nuvem (Cloud Computing) apareceu a partir da evolução natural da Internet e da forma como as aplicações passaram a ser ofertadas aos consumidores, ou seja, na forma de serviços.

Neste Capítulo são apresentados os principais aspectos conceituais que fundamentam a computação em nuvem, bem como suas principais características, os seus benefícios e riscos e também discorre sobre a utilização de simulação para avaliação do desempenho da computação em nuvem.

\subsection{Definição de Computação em Nuvem}

A computação em nuvem é um avanço recente da tecnologia de informação onde tanto a infraestrutura quanto as aplicações são providas como serviços para usuários finais obedecendo um esquema de pagamento por uso (Calheiros et al., 2011).

Muitas definições sobre computação em nuvem podem ser encontradas na literatura. Alguns definem a computação em nuvem sob um aspecto mais técnico-científico, encaixandoa como uma evolução natural da computação distribuída, outros preferem defini-la de um ponto de vista mais econômico, comparando seu impacto no mercado com tecnologias precedentes.

Para Buyya et al. (2009) a computação em nuvem pode ser considerada uma extensão de outros paradigmas, como os da computação em grade e utilitária, acrescentando a capacidade de que as aplicações de negócios podem ser expostas como serviços sofisticados acessados por meio de uma rede (Internet). Zhang et al. (2010) definem computação em nuvem como um modelo de computação que permite o acesso de recursos e informações por meio da Internet, facilitando o uso de infraestruturas e plataformas computacionais, as quais podem ser 
facilmente configuradas e reconfiguradas de acordo com as necessidades dos consumidores. $\mathrm{O}$ conceito de computação em nuvem para Armbrust et al. (2010) envolve tanto as aplicações fornecidas como serviços por meio da Internet quanto ao hardware e ao software presentes em grandes data centers que fornecem esses serviços.

Dentre todas as definições de computação em nuvem, a definição do NIST (National Institute of Standards and Technology) (Mell e Grance, 2011) é a mais completa: "Computação em Nuvem é um modelo para acesso conveniente, sob demanda, e de qualquer localização, a uma rede compartilhada de recursos de computação (isto é, redes, servidores, armazenamento, aplicativos e serviços) que possam ser prontamente disponibilizados e liberados com um esforço mínimo de gestão ou de interação com o provedor de serviços".

De acordo com o NIST (Mell e Grance, 2011), a arquitetura de computação em nuvem é composta de cinco características essenciais, três modelos de serviços e quatro modelos de implementação. Nas próximas Seções essas características e modelos serão apresentados.

\subsection{Características Essenciais de Computação em Nuvem}

Partindo da definição sobre computação em nuvens especificada pelo NIST (Mell e Grance, 2011), o modelo de computação em nuvens é composto de cinco características essenciais:

- Autoatendimento sob demanda: um consumidor pode dispor de capacidade computacional, como processamento, armazenamento, tempo de rede, conforme necessário e sem a necessidade de interação humana com cada prestador de serviço.

- Acesso amplo à rede: recursos são disponibilizados e acessados por clientes heterogêneos utilizando quaisquer tipos de plataforma, como por exemplo, telefones celulares, tablet, notebooks, e estações de trabalho.

- Agrupamento de recursos: os recursos computacionais do provedor são agrupados para atender múltiplos consumidores com diferentes recursos físicos e virtuais atribuídos dinamicamente à medida que a demanda do consumidor é alterada.

- Elasticidade eficiente: os recursos podem ser provisionados e liberados elasticamente, em alguns casos automaticamente, para se ajustar a necessidade, crescente ou decrescente de cada consumidor. Para o consumidor, os recursos disponíveis para provisionamento parecem ser ilimitados e podem ser requisitados em qualquer quantidade e a qualquer momento. 
- Medição de serviço: os recursos da nuvem são controlados e otimizados automaticamente, sendo que seu uso é medido a partir de um nível de abstração apropriado para o tipo de serviço. A utilização dos recursos pode ser monitorada, controlada e descrita em relatórios, o que proporciona transparência tanto para o provedor quanto para o consumidor.

\subsection{Modelos de Serviços Computação em Nuvem}

Os modelos de serviço de nuvem computacional, definidos pelo NIST, configuram-se em três camadas, sendo elas (Mell e Grance, 2011) (Voorsluys et al., 2011):

- Software como um Serviço (Software as a Service (SaaS)): A capacidade computacional fornecida ao consumidor é destinada à utilização de aplicativos executando em uma infraestrutura de nuvem. As aplicações podem ser acessadas através de dispositivos com pouca capacidade computacional (como tablets, celulares, smartphones, etc), e também através de computadores convencionais. Neste modelo, o cliente não controla e nem administra a infraestrutura de nuvem, sendo possível controlar somente configurações restritas ao aplicativo. Exemplos de aplicações incluem: Google Apps para aplicações pessoais, Facebook, Youtube, Twitter, entre outros.

- Plataforma como um Serviço (Platform as a Service (PaaS)): Oferecer os serviços de nuvem como plataforma significa prover aos desenvolvedores uma base sobre a qual pode desenvolver as suas aplicações. Prover uma plataforma significa colocar à disposição do desenvolvedor todos os recursos necessários para o ciclo de vida de software, ou seja, prover os recursos para desenvolver, testar, implantar e hospedar aplicações Web. Assim como no modelo SaaS, o consumidor também não tem controle e gerenciamento da infraestrutura de nuvem, no entanto, pode controlar os aplicativos desenvolvidos e ajustar permissões de acesso ao ambiente do aplicativo hospedado. Pode-se destacar dois exemplos mais conhecidos de PaaS como sendo o Google App Engine (Malawski et al., 2013) e a Windows Azure da Microsoft (Johnson et al., 2013).

- Infraestrutura como um Serviço (Infrastructure as a Service (IaaS)): A capacidade computacional fornecida ao consumidor provisiona processamento, armazenamento, redes e outros recursos computacionais onde o consumidor é capaz de executar softwares 
arbitrários, que podem incluir sistemas operacionais e aplicativos. O cliente não tem controle e nem gerencia a infraestrutura da nuvem, porém tem controle sobre o sistema operacional armazenamento e aplicativos. Provedores de IaaS normalmente oferecem uma infraestrutura virtualizada como o serviço ao invés do hardware real diretamente. Exemplos de serviços IaaS incluem: Amazon Web Services (AWS), Google Compute Engine (GCE), GOGRID, entre outros.

A Figura 2.1 possui a representação dos três modelos de prestação de serviço de nuvens computacionais especificados em camadas, identificando em cada camada as classes de usuários que podem utilizar os serviços, como também exemplos de serviços comerciais que pertencem a cada camada da pilha de modelos de serviços da computação em nuvem (Voorsluys et al., 2011). Quanto mais inferior a camada maior será o nível de detalhamento e de elementos que o usuário obterá acesso.

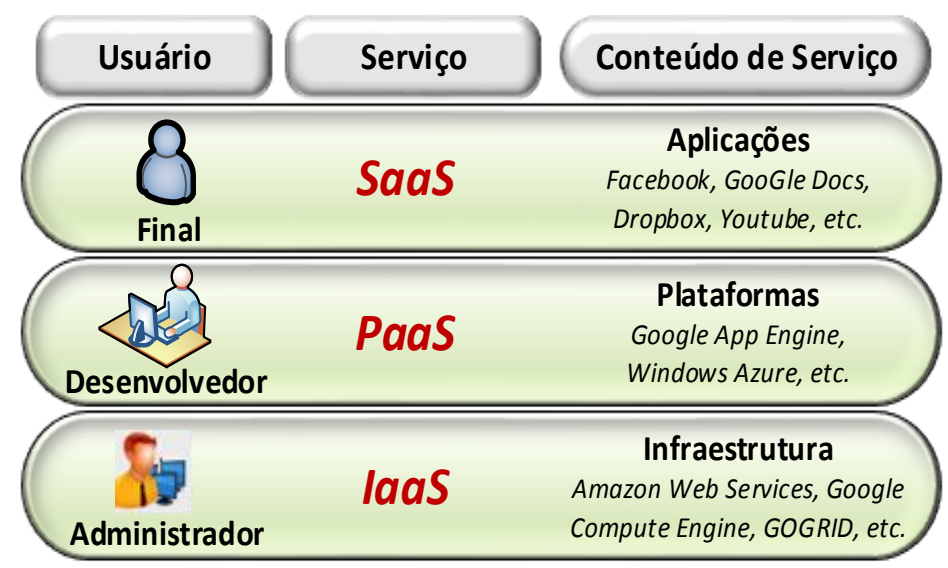

Figura 2.1 - Modelos de serviços da computação em nuvem, adaptado de Voorsluys et al.(2011)

\subsection{Modelos de Computação em Nuvem}

Analisando-se as características de implementação das nuvens que definem as restrições de acesso, podem-se identificar quatro modelos de implementações de nuvens (Mell e Grance, 2011), ilustrados na Figura 2.2:

- Nuvem privada: toda a infraestrutura e serviços disponíveis na nuvem são disponibilizados para uma única organização, independente dos recursos serem próprios ou terceirizados. Os clientes, em sua maioria, são empresas, instituições públicas ou privadas, sendo que a infraestrutura pode ser modificada de acordo com a necessidade dos clientes. 
- Nuvem pública: A infraestrutura de nuvem é provisionada para uso aberto ao público em geral, sendo gerenciada por terceiros. Este modelo de nuvem é interessante para empresas que precisam de serviços flexíveis e temporários para executar uma tarefa, bem como para garantir a redução dos fatores de risco e custo. Os serviços da nuvem podem ser gratuitos ou vendidos pelo provedor da nuvem de acordo com um modelo de negócio considerado pelo provedor.

- Nuvem comunitária: A infraestrutura de nuvem é provisionada para uma comunidade específica de consumidores que têm objetivos comuns, sendo controlada, gerenciada e operada por uma ou mais organizações pertencentes à comunidade.

- Nuvem híbrida: Na nuvem híbrida, a infraestrutura da nuvem é composta pela junção de duas ou mais infraestruturas de nuvem distintas (privada, comunitária ou pública). Este modelo permanece como uma entidade única, porém unidas por tecnologias que padronizam e permitem a portabilidade de dados e aplicações. Uma solução hibrida interessante para provisionamento de aplicações é conhecida como "Cloud-Bursting" (Calheiros et al., 2011). Nesse modelo pode-se utilizar recursos privados mais baratos na maioria das vezes e usar os recursos da nuvem pública apenas durante os períodos de pico de demanda, proporcionando menor custo do que comparado aos cenários onde se utiliza apenas uma nuvem privada (Guo et al., 2012).

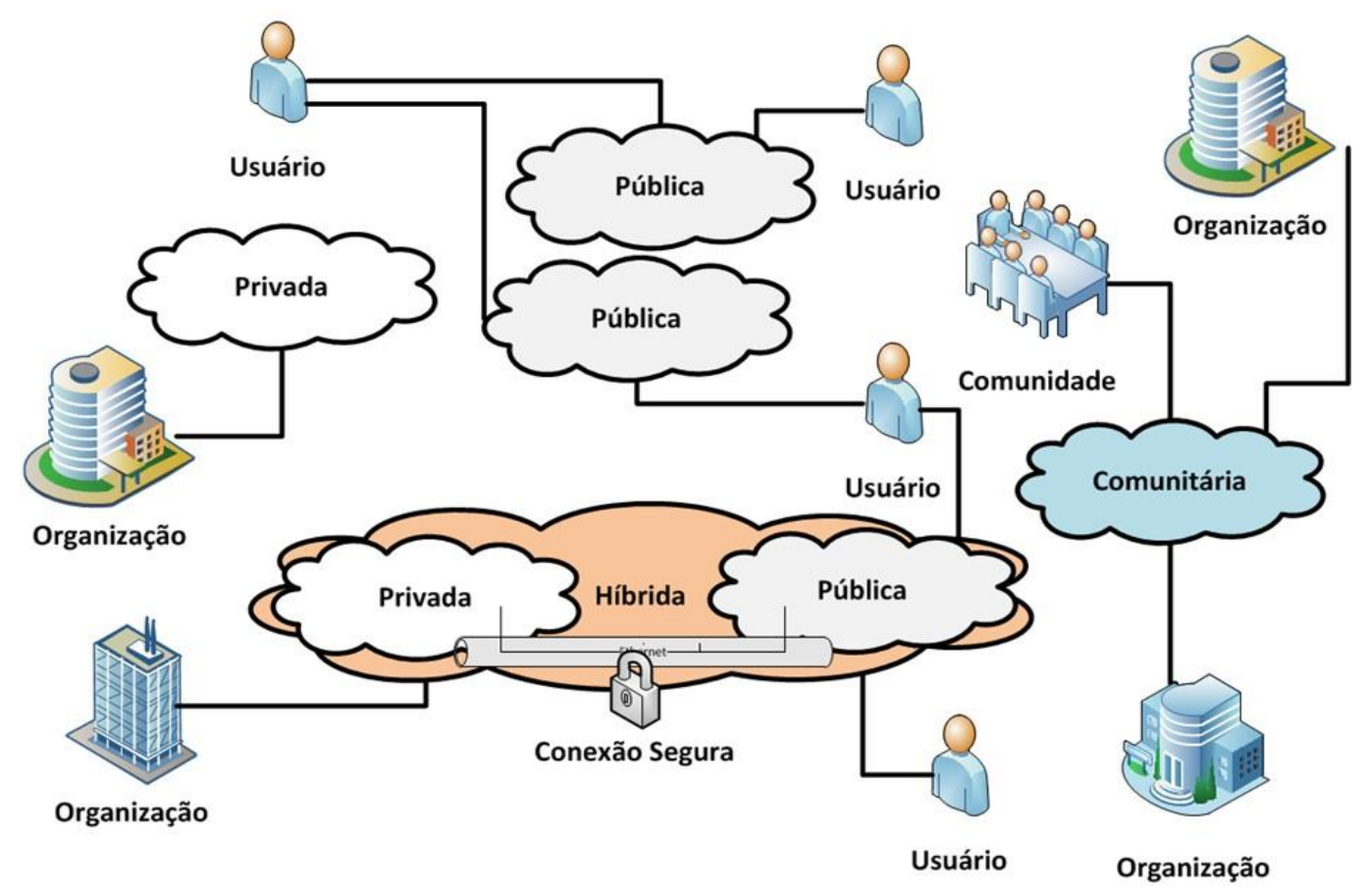

Figura 2.2 - Modelos de Nuvens baseada nas definições do NIST (Nakamura, 2013). 


\subsection{Benefícios e Riscos de Computação em Nuvem}

A computação em nuvem traz diversos benefícios para empresas que desejam migrar seus processos e ofertas de serviços para um servidor localizado fora da instituição. Esses benefícios são apresentados por Zhang et al. (2010):

- Custo inicial reduzido: nos modelos tradicionais, as empresas precisam investir em hardware, software e treinamento dos analistas para manutenção e gerenciamento da nuvem, para hospedar seus processos. Com o advento da computação em nuvem, é viável que empresas migrem seus processos para uma infraestrutura alugada e paguem somente pelos recursos que elas utilizam, tais como ciclos computacionais, tráfego de rede, ou até mesmo pelo número de máquinas virtuais utilizadas;

- Baixo custo operacional: através do modelo de negócios da computação em nuvens os clientes pagam apenas pelos recursos que utilizarem, tais como ciclos computacionais, tráfego de entrada ou saída de dados, armazenamento dentre outros;

- Redução do capital de risco - o cliente apenas contrata o serviço do provedor da nuvem, deixando os riscos fora da organização que contratou o serviço, uma vez que os novos equipamentos são comprados pelo provedor e não pelo cliente. No entanto, para o caso de nuvens privadas, o risco engloba toda a organização;

- Flexibilidade: necessidades temporárias de consumidores podem ser supridas alocando mais recursos em certos momentos, sem a necessidade de investimentos com aquisição de hardware;

- Agilidade e fácil acesso: a implantação de aplicativos novos e existentes no sistema de computação em nuvem é consideravelmente rápida, por isso se torna a plataforma perfeita para implantação das novas aplicações, aumentando a capacidade das já existentes.

Como todo modelo, a computação em nuvens possui riscos a serem considerados. De acordo com Habib et al. (2010), os riscos incluem:

- Riscos de negócios: risco de rejeição ao realocar um aplicativo para uma nuvem, onde os níveis de serviços não são comuns entre os provedores e os clientes;

- Limitações arquiteturais e técnicas: devido às incompatibilidades do novo modelo arquitetural, alguns aplicativos podem não executar na nuvem ou devem ser adaptados para essa arquitetura;

- Questões de conformidade e de regulamentação: consiste em controlar e prover segurança para negócios específicos, clientes ou dados pessoais; 
- Falta de visibilidade: cada provedor possui um nível de transparência, assim como políticas do serviço e dos processos de segurança;

- Latência - não há garantia de uma regularidade do serviço, em virtude que o desempenho do mesmo pode ser influenciado pela latência da rede usada para acessa-lo.

\subsection{Uso de Simulação para Avaliação de Desempenho}

Em virtude das características e benefícios proporcionados pela computação em nuvem, ela vem se difundindo cada vez mais tanto em empresas de Tecnologia da Informação como na comunidade acadêmica. No cenário atual de pesquisa em computação em nuvem, são várias as técnicas empregadas pelos pesquisadores para validar suas proposições e teses. Entre as técnicas adotadas estão a prototipação, benchmarks, monitores, modelos analíticos e simulação (Sakellari e Loukas, 2013).

Em uma situação ideal, tanto os testes de novas aplicações como os experimentos ligados a uma determinada pesquisa seriam executados em provedores reais de nuvem, mas isso nem sempre é possível ou viável. Uma alternativa aos provedores reais são os simuladores. Técnicas de simulação apresentam diversas vantagens, o que torna interessante sua adoção em atividades de planejamento de capacidade, construção de modelos de desempenho e avaliações de desempenho de sistemas computacionais. Dentre essas vantagens destacam-se: executar experimentos repetidas vezes para que os resultados coletados atendam aos requisitos estipulados no planejamento de experimentos (por exemplo, cálculo de médias e intervalos de confiança); ajustar os gargalos do sistema antes de implantar em nuvens reais; flexibilidade na alteração de fatores considerados nos experimentos como: cargas de trabalho de trabalho distintas, estratégias de escalonamento diferentes, modelos de nuvens diversas, entre outras possibilidades (Quiroz et al., 2009).

Um software que vem se destacando em modelagem e simulação de sistemas de nuvem é o CloudSim (Calheiros et al., 2011). O CloudSim é um framework bastante robusto que permite a criação de simulações de ambientes de nuvem pela extensão das classes já existentes em sua API. Com o uso deste framework é possível modelar tanto o sistema quanto o comportamento dos sistemas de Computação em Nuvem, tais como data centers, máquinas virtuais (Virtual Machines - VMs) e políticas de alocação de recursos. O CloudSim adota uma arquitetura de multicamadas modular, possibilitando a gerência dos seus componentes de forma separada. Esses componentes são apresentados na Figura 2.2. 
A camada Código do Usuário, localizada no topo das camadas, expõe as definições dos cenários da simulação relacionados às especificações dos hosts, das aplicações, máquinas virtuais e políticas de escalonamento do Broker. Nessa camada, a entidade Broker além de possuir funções de mediador entre um provedor de serviços $(S a a S)$ e um provedor de nuvem (IaaS), abstrai as funções de um cliente.

A camada CloudSim oferece suporte para a modelagem e a simulação de ambientes computacionais em nuvem virtualizados, incluindo interfaces de gerenciamento dedicadas para máquinas virtuais, memória, armazenamento e largura de banda. A mesma tem a função de gerenciar a instanciação e execução das entidades principais (máquinas virtuais, hosts, data centers e aplicações) durante a simulação. Na camada de Núcleo de Simulação do CloudSim encontram-se os gerenciadores de eventos e as filas utilizadas pelo simulador.

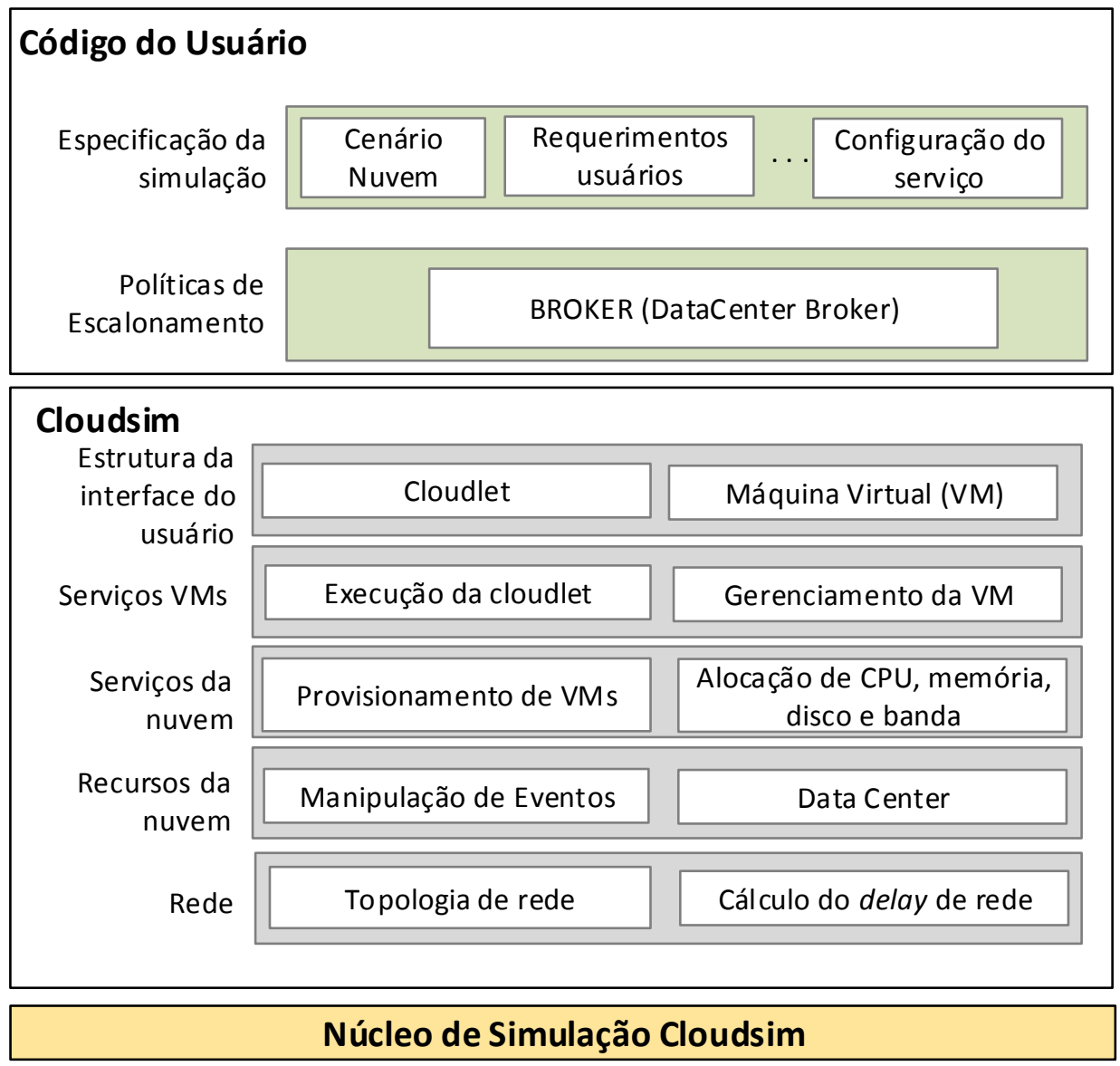

Figura 2.3 - Arquitetura do Cloudsim - Adaptado de (Calheiros et al., 2011).

Para permitir a simulação de diferentes políticas de provisionamento, o CloudSim oferece VMs em dois níveis: de Host e VM. No nível de Host, é possível especificar o máximo de 
poder de processamento que cada VM vai possuir. No nível de VM, é possível especificar o poder de processamento máximo de cada aplicação de serviço individual (unidades de tarefa) que podem ser hospedadas, já que as VMs podem processar várias tarefas ao mesmo tempo dependendo do tipo de política de atribuição. Nesse último nível, o CloudSim implementa duas políticas de alocação de recursos:

Space-shared: Na política Space-shared, quando um recurso é alocado para uma tarefa, o mesmo permanece alocado, sem preempção, até que a tarefa seja finalizada.

Time-shared: Na política Time-shared, quando um sistema é ocupado, há o compartilhamento desse recurso entre várias tarefas que competem pela utilização dos recursos.

Essas duas políticas de provisionamento das VMs e alocação das tarefas nas VMs podem ser combinadas, ou seja, enquanto as VMs seguem uma determinada política, as tarefas podem ser alocadas nas VMs seguindo uma política igual ou diferente. Cada tipo de combinação dos tipos de política permite diferentes rendimentos de tempo e poder de computação. Dependendo das necessidades de um usuário e dos recursos da nuvem poderão se utilizar um tipo de combinação ou outro (Calheiros et al., 2011).

\subsection{Considerações Finais}

Este Capítulo apresentou uma revisão sobre os principais conceitos relacionados à computação em nuvem. Foi apresentado também os benefícios e riscos da utilização em da computação em nuvem e uma breve descrição do simulador CloudSim utilizado no desenvolvimento deste projeto.

O próximo Capítulo aborda maneiras de se definir e caracterizar cargas de trabalho e trabalhos relacionados com cargas de trabalhos voltados para aplicações Web e computação em nuvem. 


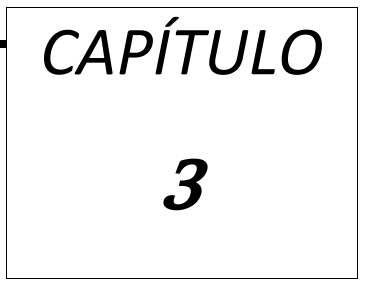

\section{Cargas de Trabalho}

\subsection{Considerações Iniciais}

A avaliação de desempenho tem um papel importante no conhecimento de quão bem um determinado sistema computacional atende às necessidades de uma organização. No contexto de computação em nuvem, a caracterização de desempenho não é uma tarefa trivial uma vez que se tem a influência de muitos aspectos do sistema que utiliza esse modelo de implementação, como provisionamento de serviços sob demanda baseado em técnicas como virtualização, computação distribuída e autônoma (Sakellari e Loukas, 2013) (Batista et al. 2014). O desempenho de um sistema computacional é determinado por suas características, bem como pela composição da carga que estiver sendo imposta a ele (Menascé e Almeida, 2001). Desta forma, a avaliação de desempenho requer o uso de cargas de trabalho representativas para que se consiga produzir resultados confiáveis.

Neste Capítulo é apresentada uma revisão dos conceitos relacionados às cargas de trabalho, onde será discutido o processo envolvido na definiç̧ão e caracterização de cargas de trabalho para um sistema computacional a ser avaliado e também etapas para construção de um modelo de carga de trabalho. No fim deste Capítulo serão apresentados alguns trabalhos relacionados que tratam da caracterização de cargas de trabalho voltados para aplicações Web e computação em nuvem.

\subsection{Cargas de Trabalho}

A carga de trabalho de um sistema refere-se às solicitações feitas por entidades que fazem pedidos de serviços ao sistema (Menascé e Almeida, 2001). Exemplos de cargas de trabalho podem ser instruções enviadas a um processador, transações em uma aplicação ou requisições de serviços para um provedor de serviços. O desempenho de qualquer sistema computacional é determinado por suas características, bem como pela composição da carga que estiver sendo 
processada por ele. A descrição quantitativa da carga é uma parte essencial de qualquer estudo de avaliação de desempenho.

\subsubsection{Caracterização de Cargas de Trabalho}

A caracterização da carga de trabalho é o processo pelo qual se descreve, de forma precisa, a carga total a que um sistema é submetido, considerando seus componentes principais. Deve-se, portanto, determinar o que é importante para cada sistema conforme o tipo de trabalho que estiver sendo executado.

A primeira medida a ser considerada na caracterização de uma carga de trabalho é a identificação do componente básico que é determinado pela natureza do sistema. Um componente básico pode ser um job, uma transação, um processo ou uma requisição. No caso dos serviços web ou serviços em ambientes de nuvens, o componente básico pode ser definido como as requisições recebidas e processadas em um determinado período de tempo.

A escolha das características e parâmetros que descrevem a carga de trabalho depende do propósito do estudo de avaliação. Apesar de cada sistema requerer uma abordagem específica para caracterização da sua carga de trabalho, há algumas questões que precisam ser respondidas e que são aplicáveis para todos os tipos de sistemas (Menascé e Almeida, 2001). Dentre elas destacam-se:

- Definição da carga de trabalho que se pretende caracterizar. Por exemplo, em um ambiente distribuído há diferentes cargas de trabalho que podem ser consideradas. A carga submetida por um computador cliente consiste de uma sequência de comandos e "cliques" realizados pelo usuário. Do lado do servidor, a carga de trabalho pode ser definida como um conjunto de requisições que é recebida durante um período de observação. Outro aspecto que pode ser de interesse refere-se à carga de uma rede, considerando aspectos como distribuição do tamanho e intervalo de chegada entre os pacotes.

- Especificação do nível de descrição da carga de trabalho. Segundo Menascé e Almeida, (2001), a descrição da carga pode ser dividida em três níveis:

- Comercial ou de negócios: considera os planos corporativos e de negócios assim como o modelo de cobrança adotado pela empresa. Esse nível segue uma descrição orientada ao usuário, como por exemplo, número de usuários, transações realizadas por usuário, entre outros. 
- Funcional: considera os programas, aplicações e protocolos usados para processar a carga de trabalho em estudo.

- Físico ou caracterização orientada a recursos: considera a arquitetura e o consumo de recursos físicos como: utilização de CPU, memória, entre outros. A caracterização deve considerar os recursos cujo consumo apresenta um impacto significante no desempenho do sistema.

Nos três níveis podem ser identificados parâmetros importantes para a construção do modelo de carga de trabalho. Por esta razão, é interessante combinar as informações levantadas em cada um deles, a fim de agregar ao modelo um maior conhecimento sobre o ambiente.

- Escolha dos parâmetros que caracterizam o componente básico da carga de trabalho. Como mencionado anteriormente, o primeiro passo para caracterizar uma carga de trabalho é identificar o componente básico que a compõe. Após a identificação do componente básico, deve-se definir os principais parâmetros que a caracterizam. De modo geral, os parâmetros são separados em dois grupos: intensidade da carga de trabalho (WI - Workload Intensity) e demanda de serviço (SD- Service demand). O primeiro parâmetro é associado à intensidade de carga submetida ao sistema, como por exemplo, número de clientes simultâneos e think times, que representa o intervalo de chegada entre duas requisições sucessivas. $\mathrm{O}$ segundo parâmetro está relacionado à demanda de serviço imposta aos recursos (como processador, discos, rede, entre outros) da infraestrutura do sistema. Esses parâmetros são associados, por exemplo, ao tamanho médio dos objetos transferidos para o sistema, tamanho das requisições, taxa de consumo médio de CPU para processamento das requisições, etc.

Conhecer e caracterizar a carga de trabalho é requisito fundamental na avaliação de desempenho e na atividade de planejamento de capacidade de sistemas computacionais. $\mathrm{O}$ conhecimento adquirido nessa tarefa auxilia a identificação de problemas de desempenho, disponibilidade e confiabilidade do sistema. A caracterização de carga é também essencial para a construção de cargas sintéticas, de modelos de cargas de trabalho e para a proposição e validação de benchmarks (Murta e Nascimento, 2007).

\subsubsection{Modelo de Carga de Trabalho}

Cargas de trabalhos representativas podem ser alcançadas através da coleta de dados reais que permitam a criação de modelos estatísticos que representam as principais características do 
sistema analisado (Feitelson, 2014). Nesta Seção são abordadas as formas usuais para representar uma carga de trabalho e os passos envolvidos na modelagem da carga.

Existem dois tipos de cargas de trabalho que podem ser considerados:

Carga real: refere-se à carga observada durante uma operação normal de um sistema real. Uma das formas empregadas para obtenção de dados é através de traces, que são mantidos por alguns sistemas para permitir, principalmente, uma forma de monitoração do comportamento do sistema. Traces são arquivos que registram eventos específicos que ocorreram em um sistema durante o intervalo de tempo monitorado (Menascé e Almeida, 2001). A vantagem de se usar traces é que a carga de trabalho utilizada no experimento será semelhante à carga de trabalho suportada pelo sistema no mundo real. Entretanto, traces normalmente possuem um grande volume de informações, tornando a sua análise uma tarefa complexa.

Carga sintética: este tipo de carga simula a carga real por meio de distribuições, médias e porcentagens que determinam o consumo de todos os recursos envolvidos com a utilização de serviços (Galindo, 2010). A carga sintética é útil principalmente para avaliações baseadas em modelos, como por exemplo, técnicas de simulação. A principal razão da utilização de cargas de trabalho sintéticas é representar ou modelar uma carga de trabalho real (Jain, 1991). Este tipo de abordagem apresenta algumas vantagens. Uma delas é a possibilidade de alterar os parâmetros da carga de trabalho sem afetar a operação normal do sistema, como por exemplo, aumentar a intensidade da carga de trabalho a fim de avaliar o comportamento do sistema (Menascé e Almeida, 2001). Outro aspecto importante é que a avaliação pode ser reproduzida várias vezes de forma controlada e também ser transportada para avaliação de outros sistemas.

A abordagem normalmente utilizada para construir um modelo descritivo da carga é a construção de um resumo estatístico da carga observada. Por exemplo, podem-se sumarizar dados estatísticos da carga de trabalho imposta a um sistema por um determinado período de tempo, através da análise dos registros (traces) de todas as requisições processadas por ele durante o período de tempo observado e determinar a distribuição apropriada dos vários atributos da carga de trabalho. Assim, uma carga de trabalho sintética pode ser gerada de acordo com o modelo construído, conforme ilustrado na Figura 3.1. 


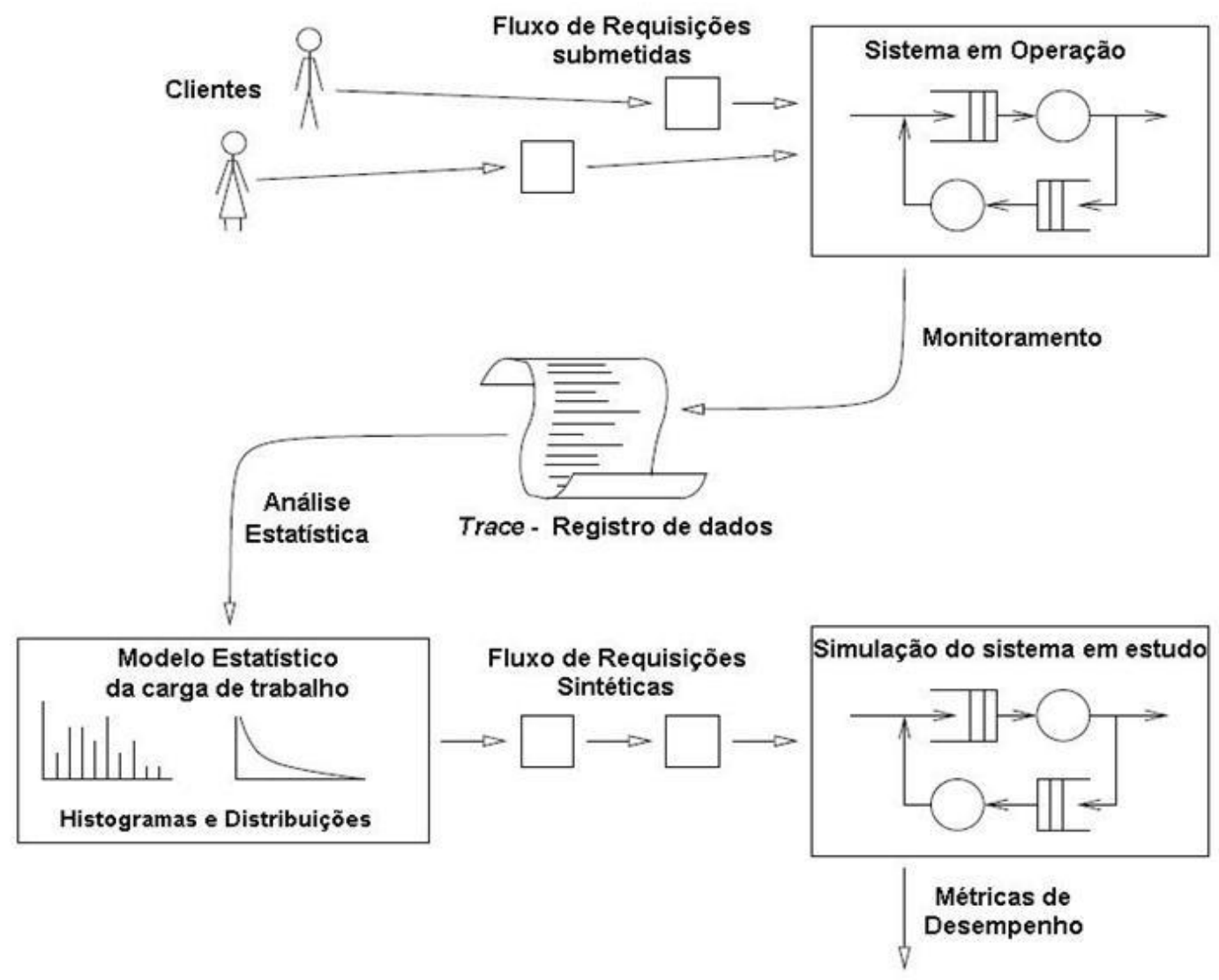

Figura 3.1 - Modelagem de cargas de trabalho (Feitelson, 2014).

O modelo da carga de trabalho pode também ser utilizado diretamente para parametrizar uma análise matemática (Feitelson, 2014). Desta forma, as cargas de trabalho, após serem modeladas, podem ser utilizadas em diversas atividades como seleção de sistemas computacionais, ajuste de desempenho e planejamento de capacidade (Menascé e Almeida, 2001) (Obaidat e Boudriga, 2009).

Existem várias vantagens em se criar um modelo de cargas de trabalho, dentre elas destacam-se (Feitelson, 2014):

- Ajuste da carga: usando um modelo, pode-se ajustar a carga de trabalho para se encaixar a uma determinada situação, como por exemplo, aumentar a intensidade da carga para avaliar o comportamento do sistema mediante um novo cenário considerado.

- Ajuste dos parâmetros: é possível modificar os parâmetros individualmente, com intuito de investigar a influência de cada um, enquanto os outros são mantidos constantes. Isso permite medir a sensibilidade do sistema com diferentes valores de parâmetros. 
- Repetições: Com o uso do modelo é possível repetir os experimentos sobre condições estatísticas semelhantes, mas não idênticas. Isso é necessário, por exemplo, para calcular dados estatísticos dos resultados, como médias, desvio padrão e intervalo de confiança.

- Generalização: modelagem aumenta o entendimento das cargas de trabalho e pode conduzir novos projetos de análise de desempenho baseados nesse entendimento.

A seguir são apresentados os passos necessários para a definição de uma carga de trabalho sintética, que engloba a coleta e filtragem dos dados, seguida do desenvolvimento do modelo que deverá considerar as distribuições que melhor representam a carga. Finalmente devem ser identificadas a correlação, as auto-similaridades e invariantes das características consideradas.

\section{Coleta e filtragem dos dados}

A modelagem de cargas de trabalho é baseada na análise dos dados que compõem esta carga de trabalho. Há duas possibilidades de obtenção desses dados (Feitelson, 2014): utilizar dados disponíveis em um determinado lugar, como por exemplo, registros mantidos em logs de acesso de servidores, ou coletá-los especificamente para criar um modelo de carga de trabalho. Nesta última possibilidade, a coleta dos dados é feita por meio de instrumentação do sistema para monitorar e registrar suas atividades.

Independente da sua origem, os dados após coletados precisam ser cuidadosamente inspecionados, a fim de eliminar possíveis eventos que não representam as características comuns da carga de trabalho do sistema em estudo. A filtragem dos dados é importante, pois os dados podem conter eventos incomuns que não fazem sentido para a caracterização da carga de trabalho (Feitelson, 2014). A decisão do que é incomum, no entanto, pode ser subjetiva e geralmente difícil de ser explicada. Entretanto, considerar tais eventos na caracterização da carga de trabalho implica em correr risco de incluir no modelo de carga uma condição atípica e incomum que provavelmente não ocorrerá novamente.

\section{Modelagem de cargas de trabalho}

A modelagem da carga de trabalho tem como principal objetivo construir um modelo que imite adequadamente a carga de trabalho real (Menascé e Almeida, 2001). Para tanto, a modelagem de cargas de trabalho deve ser representativa da carga de trabalho que um sistema apresenta na prática. Porém, a decisão de quais são as características importantes e que devem 
ser consideradas no modelo, assim como o nível de detalhes que a modelagem deve incluir não é uma tarefa trivial. Pode ser necessário caracterizar completamente todos os atributos importantes da carga de trabalho ou construir um modelo mais compacto e fácil de gerenciar com um número reduzido de parâmetros. Para que o modelo de carga de trabalho proposto possa representar com exatidão uma carga real, alguns aspectos importantes devem ser levados em consideração (Feitelson, 2014). O primeiro desses aspectos é o ajuste das distribuições que representarão a carga.

O modelo da carga de trabalho deve ser composto por uma distribuição ou uma coleção de distribuições dos vários atributos da carga de trabalho. Assim, através de amostras das distribuições é possível construir um modelo de carga de trabalho. Segundo Feitelson (2014), há duas abordagens para encontrar a distribuição que mais se ajuste a um determinado conjunto de dados. Uma delas é limitar a pesquisa para um tipo específico de distribuição. Neste caso, apenas os parâmetros da distribuição precisam ser identificados. Entretanto se o tipo de distribuição é desconhecido, uma abordagem que pode ser adotada é tentar combinar uma sequência de diferentes tipos de distribuição e em seguida selecionar aquela que mais se adéqua ao conjunto de dados ou simplesmente usar uma função de distribuição empírica. Por exemplo, se forem considerados os instantes de tempo em que usuários iniciam novas sessões com um servidor interativo, pode-se considerar que as chegadas são independentes umas das outras e uniformemente distribuídas, constituindo, portanto, um Processo de Poisson. Caso isso seja verdade, pode-se afirmar que o intervalo entre chegadas de novas sessões segue uma distribuição exponencial. No entanto, a análise de cargas de trabalho real, frequentemente, revela que os intervalos entre chegadas não são uniformes e independentes, mas sim chegam em forma de rajadas com alta variabilidade e em diferentes escalas de tempo, em contraste com o modelo Poisson. O fenômeno de rajadas em cargas de trabalho caracteriza-se pelo aumento súbito de solicitações de serviços submetidas ao sistema, com consequentes picos temporais irregulares na intensidade de chegada das requisições ou na intensidade de demandas de serviços impostas aos recursos do sistema (Mi et al., 2010). Neste caso, pode ser interessante adotar uma abordagem diferente para identificar uma distribuição mais apropriada ao modelo, como por exemplo considerar processos estocásticos para modelar a distribuição e a estrutura de autocorrelação (Kriege e Buchholz, 2010). 


\section{Correlações}

A modelagem de cada atributo da carga de trabalho de forma isolada não é suficiente. Uma questão importante que deve ser considerada são as correlações possíveis entre os diferentes atributos e entre diferentes amostras da mesma distribuição. Correlações são importantes porque podem apresentar algum comportamento importante do sistema (Feitelson, 2014). Por exemplo, no escalonamento de jobs em uma máquina com vários processadores o que se conhece é a quantidade necessária de processadores para executar aquele determinado job, mas o tempo de execução é desconhecido. Encontrar uma correlação entre tamanho dos jobs e tempo de execução pode conduzir a escolha de uma política de escalonamento que se ajuste melhor ao comportamento encontrado pela correlação.

\section{Auto-Similaridade (Self Similarity)}

Refere-se às situações em que fenômenos apresentam as mesmas características gerais, mas em diferentes escalas. Nos processos auto-similares observa-se que os conjuntos de dados mantêm um padrão na sua estrutura, mesmo em escalas pequenas. Isso implica que a estrutura contém pequenas réplicas de si mesma, o que explica a origem do nome "auto-similar". Alguns estudos mostram que nas cargas de trabalhos de aplicações Web, o processo de chegada das requisições para o sistema pode ser auto-similar (Barford e Crovella, 1998) (Dick et al., 2014).

\section{Invariantes}

Nas cargas de trabalho existem características comuns, chamadas de invariantes. Em (Arlitt; Williamson, 1996) (Williams et al., 2005) é definido o termo invariante como sendo uma verdade universal, que se aplica à caracterização da carga de trabalho imposta a um sistema e que deve ser representada no processo de construção do modelo. Esses trabalhos analisam a carga de seis servidores Web e apontam dez invariantes, dentre elas: tamanho médio de transferência, tipos de documentos, tempo entre referências para um mesmo documento e distribuição dos tamanhos dos arquivos. Analisando a carga dos seis servidores Web pode-se observar ainda que os tamanhos dos arquivos apresentam uma distribuição de cauda pesada (heavy tail). Uma distribuição de cauda pesada possui esse nome porque a 'cauda' da função não tende rapidamente a zero, ou seja, a probabilidade de variáveis aleatórias com valores grandes é diferente de zero. A distribuição de cauda pesada para os tamanhos dos arquivos em 
servidores Web é apontada como uma provável causa da auto-similaridade no tráfego da Internet (Barford e Crovella, 1998) (Wang et al., 2014).

No contexto de aplicações Web e serviços executados em computação em nuvem dentre o conjunto de características invariantes de carga de trabalho, destaca-se a ocorrência de rajadas (burstiness). Esse tipo de carga de trabalho chega ao sistema com alta variabilidade e pode causar gargalos de desempenho do serviço em ocasiões de difícil previsibilidade (Menascé et al., 2000) (Wang et al., 2003) (Mi et al. 2010) (Casale et al.,2013).

\subsection{Trabalhos Relacionados}

Existem vários trabalhos que abordam caracterização e análise de diferentes tipos de cargas de trabalho. Alguns trabalhos baseiam-se em traces para realizar o estudo de caracterização de cargas visando à análise de desempenho em Servidores Web (Arlitt e Williamson, 1996) (Weber e Hariharan, 2003) (Wang et al., 2003) (Williams et al., 2005) (Silva, 2006) (Bertolino et al., 2008). Pedroso e Fonseca (2006) propõem um modelo para geração de cargas através da classificação e agrupamento dos arquivos encaminhados para um servidor. Os arquivos transmitidos e capturados são separados em classes a partir de sua extensão (HTTP; imagens como Gif, Jpg; Mpeg, dentre outras) e estudados para determinar suas características, como a distribuição de probabilidade do tamanho dos arquivos e o tempo de permanência em cada classe. Nesse trabalho, os dados foram coletados e analisados de dois sistemas: IRCache (projeto do National Laboratory for Apllied Network Research - NLANR: servidores cache, geograficamente distribuídos pelos Estados Unidos, que registram os acessos para toda a Internet) e o servidor da Copa do Mundo de 1998.

Em (Li et al., 2008) é apresentada uma análise detalhada de cargas de trabalho de bibliotecas digitais voltadas para literatura científica. Nesse trabalho foram coletados e analisados logs com registros de dois meses de acesso a uma biblioteca digital de literatura de computação científica, conhecido como CiteSeer, visando analisar correlações temporais entre as sessões estabelecidas pelos usuários e o interesse dos usuários (em termos de consultas e documentos).

Em (Tavares, 2009) é apresentada uma proposta de caracterização de carga de trabalho, dentro do contexto de serviços Web, onde o componente básico para caracterização da carga de trabalho são as mensagens trocadas entre os clientes e provedores de serviço. O nível funcional 
da carga de trabalho é abordado definindo as características dos serviços Web através de uma análise de documentos WSDL (esses oferecem informações de acesso e de construção das mensagens que são utilizadas na execução do serviço). Nesse trabalho foram encontradas algumas invariantes dos serviços Web, como número de operações disponíveis pelo serviço Web, tipos de binding, tipos de codificação e tipos de dados.

Outros trabalhos apresentam temas referentes à carga de trabalho voltados para computação em nuvem (Khan et al., 2012) (Rasheduzzaman et al., 2014) (Di et al., 2013) (Wang et al., 2014). Em (Ali-Eldin et al., 2013) é apresentada uma ferramenta de classificação e análise de carga de trabalho, chamada de WAC (Workload Analysis and Classification tool) para provedores de infraestrutura de nuvem. A ferramenta analisa as cargas de trabalho de diferentes aplicações e baseada nessa análise ele classifica as cargas de trabalho a partir de um conjunto de classes pré-definidas. Essa ferramenta possui dois componentes: o analisador que verifica os dados de uma carga de trabalho para descobrir alguma de suas propriedades estatísticas que possa ser utilizada pelo classificador para encontrar a melhor estratégia de alocação das cargas de trabalho nos recursos da nuvem.

Gonçalves et al. (2014) apresentam uma caracterização e modelagem de padrões de carga de trabalho de um sistema de armazenamento popular em nuvem, conhecido como Dropbox. A caracterização da carga considera várias propriedades dos repositórios do Dropbox, como: tamanho, número e tipo dos arquivos, nível de replicação e dinâmica de alterações, a partir de dados coletados de 333 voluntários. O objetivo dessa proposta é fornecer uma caracterização que possa ser explorada para futuras pesquisas para geração de cargas sintéticas de soluções de armazenamento em nuvem.

O trabalho apresentado em (Alam et al., 2015) fornece uma análise e agrupamento da carga de trabalho baseado em um estudo de um trace contendo 29 dias de registros de acesso a um data center do Google. O objetivo dessa análise foi de apresentar o perfil estatístico das tarefas encaminhadas ao data center, com base no uso dos recursos e classificação dessas tarefas em diferentes tipos de agrupamento. Existem outros trabalhos que seguem a mesma linha e usam o mesmo trace disponibilizado pelo Google para analisar o uso de recursos e o comportamento da carga de trabalho, como status das tarefas, quantidade de tarefas por jobs, tamanho dos jobs e tempos de serviços. Esses trabalhos são apresentados em (Liu e Cho, 2012) (Rasheduzzaman et al., 2014).

Há ainda outros trabalhos que tentam modelar rajadas no processo de chegada das requisições ou rajadas impostas nas demandas de serviços do sistema (Krishnamurthy et al., 
2009) (Rolia et al., 2010) (Mi et al., 2010) (Lu et al., 2010) (Casale et al., 2013). Conforme será visto no Capítulo 4, a maioria desses trabalhos são voltados para avaliar o desempenho de sistemas baseados em sessão ou sistemas de multicamadas utilizadas em aplicação de $e$ commerce. Existem alguns trabalhos recentes que abordam cargas de trabalho com rajadas voltados para ambientes em nuvem. Entretanto, esses trabalhos têm um foco mais voltado na alocação, consolidação e provisionamento de recursos na nuvem (Tai et al., 2011) (Luo e Qian, 2013) (Yin et al., 2014) ou ainda, voltados na composição de novos modelos de custos para utilização de recursos compartilhados (Gmach et al., 2012) (Wang et al., 2012). Alguns desses trabalhos serão apresentados na Seção 4.6 do Capítulo 4.

\subsection{Considerações Finais}

Entender e caracterizar a carga de trabalho é uma etapa importante na avaliação de desempenho e na atividade de planejamento de capacidade de um sistema computacional. A caracterização adequada da carga imposta a um sistema auxilia na identificação de problemas de desempenho, disponibilidade e confiabilidade desses sistemas.

Neste Capítulo foi apresentada uma breve descrição sobre processo de caracterização e modelagem de cargas de trabalho e também foram apresentados alguns trabalhos, disponíveis em literatura, relacionados à caracterização e análise de diferentes tipos de cargas de trabalho, voltados para aplicações e serviços Web e serviços executados em computação em nuvem.

No projeto de doutorado proposto nesta tese, a caracterização da carga de trabalho tem como foco principal a ocorrência de rajadas e, portanto, no Capítulo 4 este assunto será abordado em maiores detalhes, incluindo uma descrição dos principais trabalhos relacionados encontrados na literatura especializada. 


\section{Fenômeno de Rajadas em}

\section{Cargas de Trabalho}

\subsection{Considerações Iniciais}

A avaliação de desempenho de sistemas, com muitos clientes, com vários servidores e máquinas virtualizadas que são provisionadas dinamicamente e interconectados através da rede, como é caso da computação em nuvem, depende fortemente das características da carga de trabalho que são submetidas. Uma das características encontrada nas cargas de trabalho voltadas para aplicações Web e serviços executados em ambientes de nuvens, é a tendência de se observar rajadas no processo de chegada das requisições ou mesmo na demanda de serviço. Rajadas no processo de chegada estão relacionadas aos intervalos de tempo entre chegadas sucessivas de requisições, enquanto que rajadas presentes na demanda de serviço estão associadas às demandas impostas aos recursos do sistema, como CPU, servidores, máquinas virtuais, etc., resultante das solicitações de serviços encaminhadas à nuvem.

Este Capítulo tem como objetivo apresentar conceitos e propriedades referentes ao fenômeno de rajadas e discutir os trabalhos relacionados voltados para modelagem de rajadas em cargas de trabalho. Além disso, serão apresentados diferentes modelos propostos na literatura para a medida do fator de rajada, que têm sido utilizados como uma das métricas consideradas em modelos preditivos de desempenho.

\subsection{Fenômeno de Rajadas}

O comportamento da demanda na forma de rajadas é um fenômeno de carga de trabalho encontrado em diferentes situações e, em especial, em aplicações Web e serviços executados em computação em nuvem. O desempenho do serviço é afetado por essa carga de trabalho que apresenta alta variabilidade em um determinado espaço de tempo. Sistemas submetidos a cargas 
de trabalho que se apresentam em rajadas podem afetar severamente o desempenho de um provedor de serviços, conduzindo para uma significante sobrecarga dos servidores, aumento descontrolado nos tempos de respostas e no pior caso, indisponibilidade do serviço (Mi et al., 2010).

Vários estudos mostram que as requisições submetidas pelos clientes chegam em forma de rajadas (Barford e Crovella, 1998) (Calzarossa et al., 2000) (Menascé et al., 2000) (Wang et al., 2003) (Mi et al., 2010) (Lu et al., 2013) (Casale et al., 2013) (Yin et al., 2014). Wang et al. (2003) mostram como a capacidade do serviço pode ser afetada pela ocorrência do fenômeno de rajadas através da análise de registros de logs de uma página de e-commerce. Nesse trabalho, observou-se que as rajadas de requisições submetidas ao sistema representam um dos principais motivos para os gargalos encontrados nos tempos de resposta. Em (Menascé et al., 2000) também é apresentado um estudo do processo de chegada das requisições em uma página de $e$ commerce. Menascé et al. (2000) mostram a quantidade de requisições chegando ao sistema em diferentes escalas de tempo, conforme apresentado na Figura 4.1.
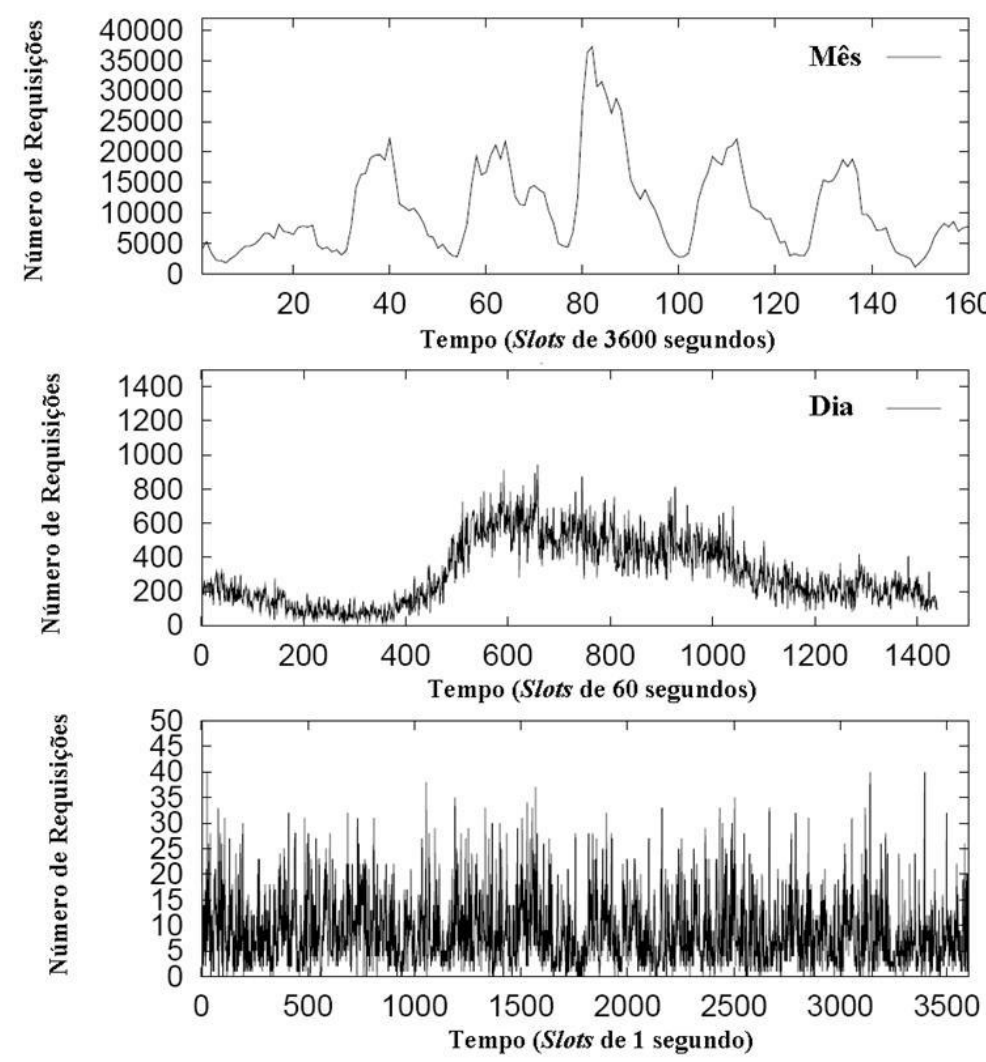

Figura 4.1 - Número de requisições chegando ao sistema Web (Menascé et al., 2000). 
Os resultados obtidos nesse trabalho revelam rajadas e alta variabilidade no processo de chegada das requisições e a importância de se considerar rajadas no modelo de cargas de trabalho, visto que elas podem degradar o desempenho e a vazão (throughput) do sistema se não levadas em consideração.

\subsection{Caracterização de Rajadas}

A caracterização de séries temporais com rajadas requer técnicas para descrição estatística que consigam capturar a natureza imprevisível e altamente variável dos processos de chegadas das requisições. As pesquisas voltadas para cargas de trabalho que se apresentam em rajadas, não são recentes. Trabalhos referentes às análises de tráfego de dados em redes de computadores por volta dos anos 1970 e 1980 (Kleinrock, 1976) (Shoch e Hupp, 1980) mostravam que os processos de chegada dos pacotes eram altamente variáveis, os pesquisadores frequentemente se referiam à esses modelos de comunicação como "rajadas" (bursty). No entanto, poucos se preocuparam em definir o conceito de rajadas. A maioria se referenciava ao termo de "rajadas" quando a distribuição dos intervalos de tempo entre chegadas de pacotes apresentavam maior variabilidade do que processos de Poisson. A imprecisão em torno do conceito de rajadas decorria da dificuldade em caracterizar de forma significativa os diferentes tipos de variabilidade encontradas na estrutura de chegadas dos pacotes.

Diante dessa imprecisão na definição de rajadas, Gusella (Gusella, 1991), apresentou um estudo, em 1991, sobre a variabilidade dos intervalos de tempo entre chegadas de pacotes e propôs um modelo para definir o conceito de rajadas e caracterizar a variabilidade dos processos de chegada de pacotes. Segundo Gusella (1991), a variabilidade encontrada em cargas de trabalho que se apresentam em rajadas pode ser caracterizada pelo Índice de dispersão. Para tanto, considera-se uma sequência de valores (como think times ou tempos de serviços), $\left\{\mathrm{X}_{1}\right.$, $\mathrm{X}_{2}, \mathrm{X}_{3}, \ldots, \mathrm{X}_{\mathrm{n}}$ \} com uma variabilidade quantificada pelo Quadrado do Coeficiente de Variação ou SCV (Squared Coefficient of Variation), que pode ser obtido pela equação 4.1:

$$
S C V=\operatorname{var}\left(X_{n}\right) / E[X]^{2}
$$

Onde $\operatorname{var}\left(X_{n}\right)$ é a variância da sequência de valores e $\mathrm{E}[\mathrm{X}]^{2}$ é a média da sequência de valores elevado ao quadrado. Considere ainda que a diferença em magnitude entre valores consecutivos $\left(X_{t}\right.$ e $\left.X_{t-k}\right)$, pode ser medido pelo coeficiente de autocorrelação $\left(\rho_{\mathrm{k}}\right)$, de forma que a posição 
desses valores no trace se distanciem em $k$ deslocamentos (lag) no tempo. A notação matemática do coeficiente de autocorrelação é dada pela equação 4.2:

$$
\rho_{\mathrm{k}}=\mathrm{E}\left[\left(\mathrm{X}_{\mathrm{t}}-\mu\right)\left(\mathrm{X}_{\mathrm{t}-\mathrm{k}}-\mu\right)\right] / \sigma^{2}
$$

Sendo $\boldsymbol{\mu}$ a média das variáveis e $\boldsymbol{\sigma}^{2}$ é a variância das variáveis aleatórias no trace. Em estatística, o coeficiente de autocorrelação é uma medida que informa o quanto o valor de uma variável aleatória é capaz de influenciar seus vizinhos. Assumindo que o SCV e $\rho_{\mathrm{k}}$ não mudam ao longo do tempo, então o índice de dispersão (I) pode ser quantificado pela equação 4.3:

$$
\mathrm{I}=\operatorname{SVC}\left(1+2 \sum_{\mathrm{k}=1}^{\infty} \rho_{\mathrm{k}}\right)
$$

A presença do quadrado do coeficiente de variação e coeficiente de autocorrelação na equação de $I$ é suficiente para caracterizar diferentes níveis de variabilidades presentes nas cargas de trabalho com rajadas. Nesse trabalho, Gusella (1991) mostra que o índice de dispersão é uma ferramenta valiosa e adequada para capturar a variabilidade nos processos de chegada dos pacotes e mostra que o índice de dispersão $I$ tem uma propriedade importante, que garante que o valor de $\boldsymbol{I}$ cresça proporcionalmente à variabilidade e correlações. Essa medida também tem sido utilizada como um indicador clássico para representar rajadas em séries de tempo para avaliação de desempenho de sistemas baseados no paradigma arquitetural multicamada (Mi et al., 2010) (Casale et al., 2013) e de computação em nuvem (Ali-Eldin et al., 2014) (Yin et al., 2014).

\subsection{Propriedades do Fenômeno de Rajadas}

As rajadas no processo de chegada das requisições apresentam algumas propriedades específicas desse tipo de carga de trabalho. Segundo (Mi et al., 2010), as funções de distribuição clássicas existentes como Poisson, Zipf, Pareto e exponencial são incompatíveis com a noção de rajadas, pelas seguintes razões:

- Localidade temporal: em situações de rajadas, o processo de chegada das requisições provenientes de diferentes clientes não acontece em instantes de tempos aleatórios, mas sim de forma condensada em curtos períodos ao longo do tempo. Além disso, a probabilidade de se enviar uma requisição dentro deste período é muito maior do que fora dele. Esse comportamento é inconsistente com as distribuições clássicas mencionadas que são amplamente utilizadas em atividades de avaliação de desempenho de arquiteturas Web. 
- Variabilidade em diferentes escalas: A variabilidade dos picos de tráfego causados pelas rajadas é uma característica relevante a ser considerada na avaliação de desempenho de um sistema. O modelo da carga de trabalho precisa não apenas criar picos de intensidade variável no processo de chegada das requisições, mas também criar flutuações dentro dele. Esse nível de variabilidade requer uma distribuição mais estruturada para representar o processo de chegada das requisições.

- Agregação: Os clientes agem de modo agregado, ou seja, o processo de chegada das requisições e os think times não podem ser gerados de forma aleatória e independentes uns dos outros para capturar as características essenciais desse tipo de carga de trabalho.

\subsection{Fator de Rajadas}

O fator de rajada (BF - Burstiness Factor), é uma medida importante que determina a ocorrência de rajadas em cargas de trabalho. Essa medida tem sido utilizada em alguns trabalhos (Menascé e Almeida, 2001) (Menascé et al., 2004) (Gilly et al., 2009) (Suchacka, 2011) (AlGhamdi et al., 2011) (Gilly et al.,2012) como uma das métricas consideradas em modelos preditivos de desempenho para dar uma estimativa da tendência da taxa de chegada de requisições no sistema em relação à taxa de chegada média.

O conceito de fator de rajadas foi inicialmente estudado por Menascé e Almeida (1998) (2001), que definiram esse fator como sendo a fração de tempo em que as taxas de chegada das requisições excedem a taxa média. Essa definição requer conhecimento da taxa média de chegada das requisições para um servidor, representada por $\boldsymbol{\mu} \lambda$, medida durante alguns intervalos de tempos ou slots de $\mathbf{0}, \mathbf{1}, . . ., \boldsymbol{k}-\mathbf{1}$.

Para um slot $\boldsymbol{k}$, a taxa de chegada correspondente é representada por $\lambda_{\mathbf{k}}$. Se $\boldsymbol{\lambda}_{\mathbf{k}}>\boldsymbol{\mu} \boldsymbol{\lambda}$, ou seja, se a taxa de chegada das requisições do slot $\boldsymbol{k}$ exceder a taxa média de chegada de requisições resultantes durante o período de tempo observado, então o slot é considerado um intervalo com rajadas. Dado $\boldsymbol{m}$ slots, o fator de rajadas, representado pelo parâmetro $\boldsymbol{b} \boldsymbol{f}$, pode ser definido como a relação entre o número acumulativo de slots que satisfaçam a condição $\boldsymbol{\lambda}_{\mathbf{k}}$ $>\boldsymbol{\mu} \lambda$, chamado de $\mathbf{k}^{+}$e o número atual de slots, $\boldsymbol{k}$, representado pela equação 4.4 :

$$
b f_{1}(k)=\left(\frac{K^{+}}{K}\right)
$$


Assim, o parâmetro $b f$ pode ser usado para indicar o fator de rajadas, podendo assumir valores entre 0 e 1, e geralmente é representado em porcentagem, de $0 \%$ a $100 \%$, indicando a intensidade da rajada.

Em (Gilly et al., 2009) são propostos seis fatores diferentes de rajadas com o objetivo de compará-los e selecionar um deles para incluí-lo em um modelo preditivo, usado em um algoritmo de balanceamento de carga adaptativo para monitorar a taxa de chegada das requisições em servidores Web. Esse algoritmo foi projetado para evitar situações de sobrecargas inesperadas causadas pelas rajadas. Nesse trabalho, os fatores são analisados e comparados, a fim de detectar as rajadas no processo de chegada das requisições. O primeiro fator adotado, chamado de BF1 segue a abordagem proposta por (Menascé e Almeida, 2001), mencionada anteriormente. Segundo um estudo apresentado nesse trabalho, o fator de rajadas BF1, tem a habilidade de modelar os picos na taxa de chegada das requisições, entretanto não é capaz de representar as rápidas variações que ocorrem dentro de um mesmo pico. A Figura 4.2(a) ilustra essa observação. Para tanto, os autores propõem algumas modificações no fator de rajadas BF1 para que essas rápidas variações no processo de chegada das requisições sejam representadas mais corretamente (fatores de rajadas BF2, BF3 e BF4). No fator BF2, é feita uma alteração na equação no fator de rajadas para incluir a diferença relativa da taxa de chegada de dois slots prévios, calculada a partir da equação 4.5 :

$$
\begin{array}{r}
b f_{\text {arr_rate }}(k)=\left(\frac{K^{+}}{K}\right)\left(1+\frac{\lambda_{K}-\lambda_{k-1}}{\lambda_{k-1}}\right) \\
\text { Onde } 0<\mathrm{bf}_{\text {arr_rate }}(\mathrm{k})<1
\end{array}
$$

Com esta alteração, o fator de rajadas, apresentado na Figura 4.2(b), segue as variações da taxa de chegada. No entanto, os autores os autores observaram a existência de alguns picos na taxa de chegada que não eram representados pelo fator de rajadas. Desta forma, foi proposto um terceiro fator BF3, incluindo uma penalização (penalisation) ou um acréscimo no fator ao detectar um número consecutivo de slots com rajadas. Essa penalização é limitada ao registro de $\boldsymbol{j}$ slots, sendo $\boldsymbol{\alpha}=\mathbf{0 , 1} \mathbf{j}$, para $\boldsymbol{j} \in 1, \ldots, 10$. A escolha de ter no máximo registros de 10 slots, segundo os autores, é porque se as rajadas detectadas na taxa de chegada forem extremas, então o fator de rajadas será dobrado a cada 10 slots. O fator de rajadas BF3 pode ser obtido pela equação 4.6:

$$
b f_{\text {penali }(j)}(k)=\left(\frac{K^{+}}{K}\right)(1+\alpha)
$$




$$
\text { Onde } 0<\mathrm{bf}_{\text {penalis }(j)}(\mathrm{k})<1
$$

Os autores executaram algumas simulações com diferentes valores de $j$, na Figura 4.2(c) é apresentado o resultado obtido nesse trabalho considerando $\mathrm{j}=4$ e perceberam que este fator também não consegue representar o comportamento da taxa de chegada e que para valores de $j$ maiores, o fator de rajada é excessivamente penalizado, ultrapassando em vários momentos a taxa de chegada.

No quarto fator proposto (BF4) foram consideradas as alterações realizadas no BF2 e $\mathrm{BF} 3$, para incluir a diferença relativa da taxa de chegada das requisições entre dois slots e também o processo de penalização no fator, calculada pela equação 4.7 :

$$
\begin{gathered}
b f_{\text {arr_rate_penalis }(j)}(k)=\left(\frac{K^{+}}{K}\right)\left(1+\frac{\lambda_{K}-\lambda_{k-1}}{\lambda_{k-1}}+\alpha\right) \\
\text { Onde } 0<\text { bf arr_rate_penalis }(j)(\mathrm{k})<1
\end{gathered}
$$

A Figura 4.2(d) mostra os valores obtidos, em uma simulação, para o fator de rajadas BF4 considerando também $j=4$. Neste caso, o fator de rajadas consegue ter uma representação mais próxima das variações que ocorrem em um mesmo pico de chegada das requisições em relação aos anteriores. Porém os autores também perceberam que da mesma forma que o BF3, dependendo do valor escolhido para a variável $\mathrm{j}$, o fator de rajada poderia ser excessivamente penalizado.

Além desses quatro fatores, foram ainda considerados em (Gilly et al., 2009), dois outros fatores de rajadas: o BF5 e BF6. No BF5 é utilizada uma extrapolação linear em ordem para detectar slots com rajadas ao invés da taxa média de chegada das requisições. Nesse caso, é calculada uma estimativa (previsão) da taxa de chegada das requisições para o próximo slot, representada por $\lambda^{\wedge} \mathbf{k}$. Se $\lambda_{\mathbf{k}}>\boldsymbol{\lambda}^{\wedge} \mathbf{k}$, ou seja, se a taxa de chegada das requisições do slot $\boldsymbol{k}$ exceder a taxa de chegada prevista, o slot é considerado um intervalo com rajadas. Considerando $\mathrm{k}^{+}$ como o número de slots com rajadas, o fator de rajadas $\boldsymbol{b}_{\text {extrap }}(\boldsymbol{k})$ pode ser obtido, pelas equações 4.8 e 4.9 , usando a equação do fator de rajada BF1:

$$
\lambda_{k}^{\wedge}=\lambda_{k-2}+\left(\frac{t_{k}-t_{k-2}}{t_{k-1}-t_{k-2}}\right)\left(\lambda_{k-1}-\lambda_{k-2}\right)
$$

Sendo $t_{k}$ o tempo final do slot $\mathrm{k}$. Assim, $k^{+}$é o número acumulativo de slots que satisfaçam $\lambda_{k}>\lambda_{k}^{\wedge}$, sendo $\lambda_{k}^{\wedge}$ a previsão da taxa de chegada do slot $k$ : 


$$
b f_{\text {extrap }}(k)=\left(\frac{K^{+}}{K}\right)
$$

Os resultados obtidos nesse trabalho para esse fator de rajada, mostraram que o BF5 não tem capacidade de representar as rápidas variações da taxa de chegada, conforme pode ser observado na Figura 4.2(e). O último modelo de fator de rajada, o BF6, considerado no estudo de Gilly et al. (2009) foi baseado no modelo proposto em (Wang e Crowcroft, 1993). A principal diferença entre essa proposta e todas as outras anteriores é que o fator de rajadas é calculado para cada requisição que chega ao servidor $W e b$. Considere que $\mathrm{t}(1)$ e $\mathrm{t}(\mathrm{m})$ representa os tempos em que os pacotes 1 e $\mathrm{m}$ chegaram em um servidor e $\mathrm{c}(\mathrm{t}(1), \mathrm{t}(\mathrm{m}))=\mathrm{m}-1$ corresponde ao número de pacotes que chegaram entre $\mathrm{t}(1)$ e $\mathrm{t}(\mathrm{m})$. A expressão usada por Wang e Crowcroft (1993) para representar as rajadas de cada pacote é apresentada na equação 4.10:

$$
b f(m)=t(1)+\frac{c(t(1), t(m))}{\rho_{\min }}-t(m)
$$

Onde $\rho_{\min }$ representa o throughput mínimo: $\rho_{\min }=\min \left(\frac{c(t(1), t(2)}{t(2)-t(1)}, \frac{c(t(1), t(3)}{t(3)-t(1)}, \ldots, \frac{c(t(1), t(m)}{t(m)-t(1)}\right)$.

Nesse caso, as rajadas são expressas em segundos e desta forma, foi necessário realizar uma modificação nesse modelo para aplicá-lo para slots de tempos. Assim, os autores consideraram que $\mu_{\mathrm{b}}(\mathrm{k})$ é a média das rajadas de todos os pacotes que chegaram no slot $k \mathrm{e} \mu_{\mathrm{b}}$ é a média das rajadas de todos os pacotes prévios e então um slot foi considerado com rajadas quando $\mu_{\mathrm{b}}(\mathrm{k})>\mu_{\mathrm{b}}$. O fator de rajada então foi obtido considerando a equação 4.4. Entretanto, como mostra a Figura 4.2(f), esse fator de rajadas BF6, não segue as mudanças da taxa de chegada e em alguns pontos diminui quando a curva da taxa de chegada aumenta.

Neste projeto de doutorado é proposta uma metodologia para a obtenção do fator de rajada, considerando a ocorrência de rajadas não apenas nos processos de chegadas das requisições, mas também nas demandas de serviços que chegam ao sistema. A descrição da metodologia considerada neste projeto é apresentado no Capítulo 7 desta tese. Nesse Capítulo também será apresentada uma análise comparativa entre os modelos propostos para o fator de rajada disponíveis em literatura e apresentados nesta Seção e o modelo proposto neste projeto de doutorado, considerando slots com duração fixa e variáveis. 
a
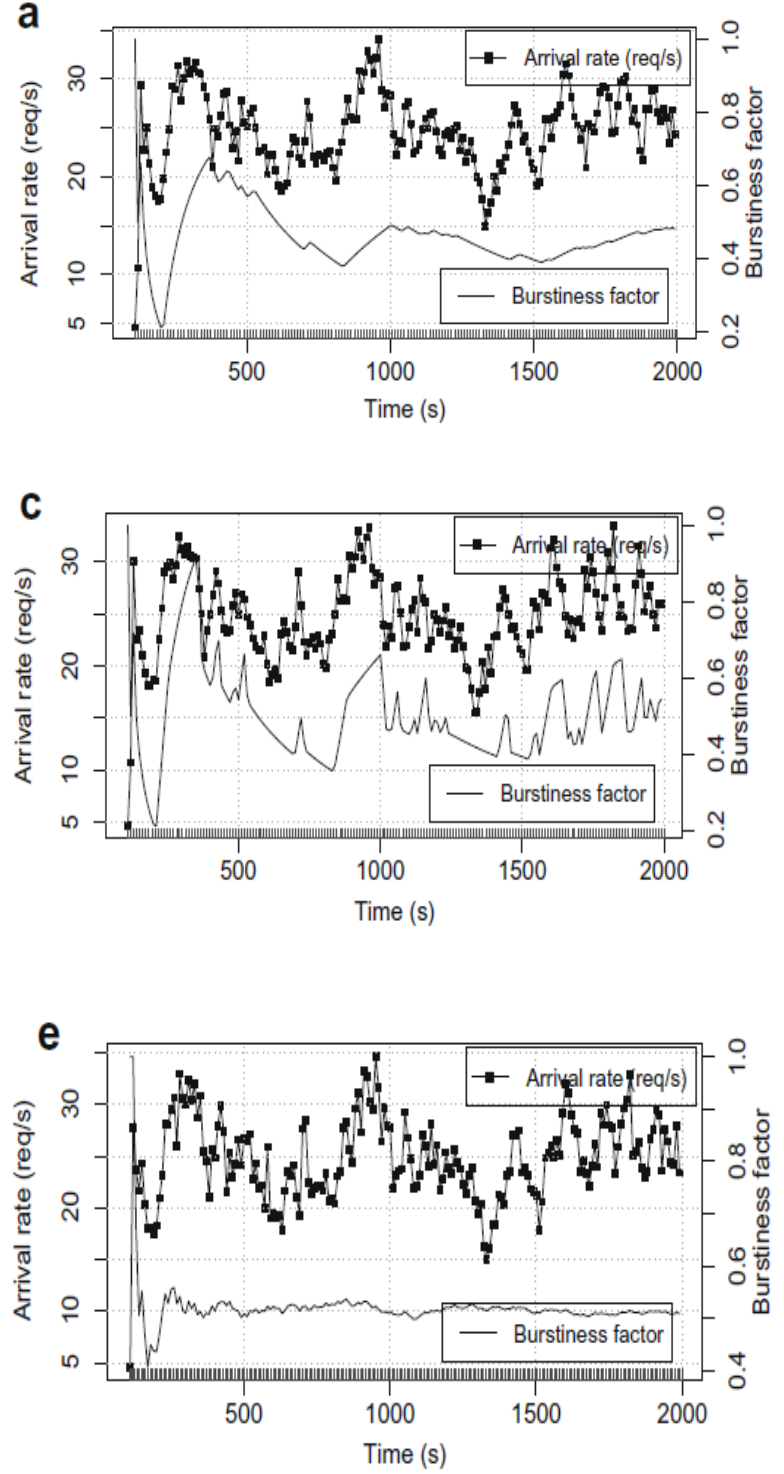

b
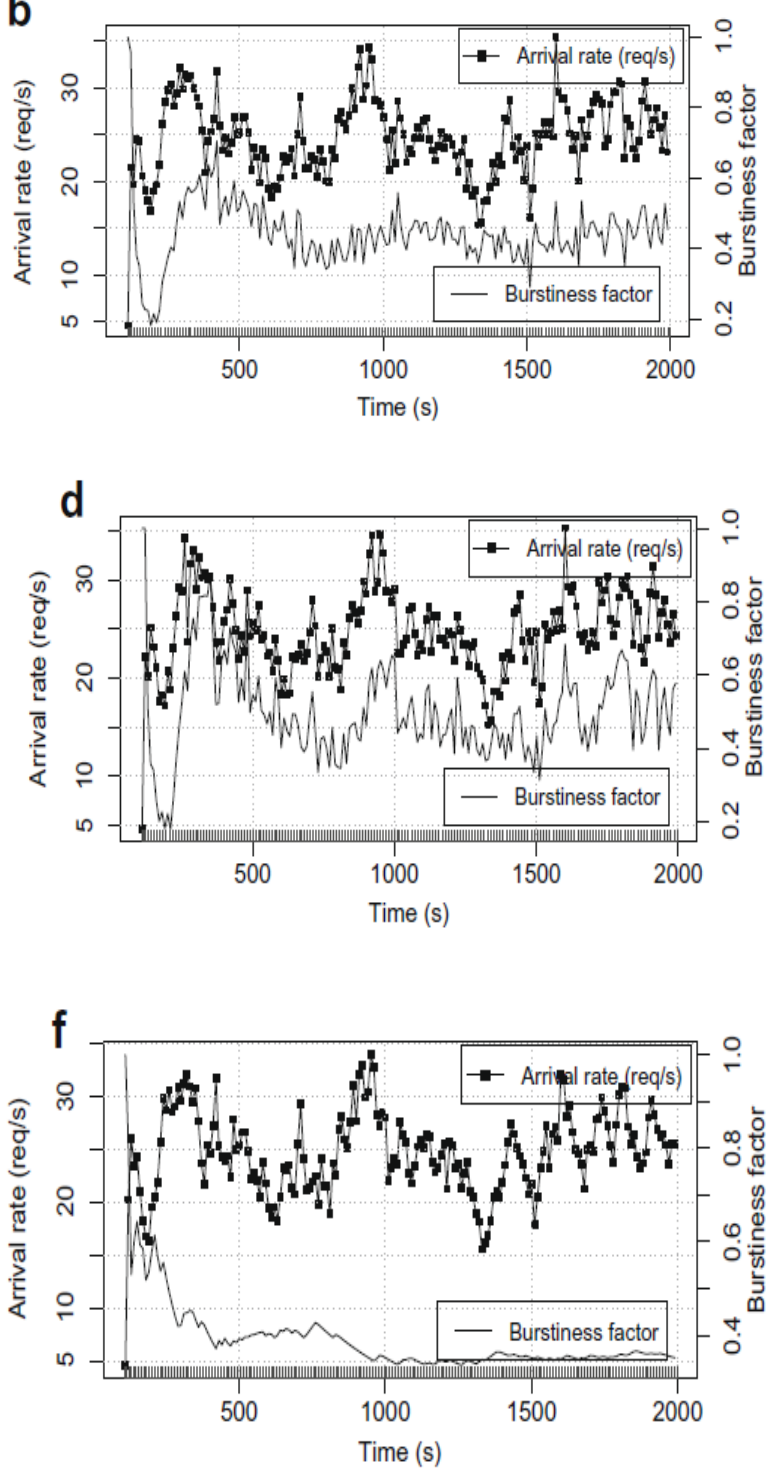

Figura 4.2 - Taxa de chegada e fator de rajadas: (a) BF1, (b)BF2 (c) BF3, j= 4, (d) BF4, j=4, (e)BF5, (f)BF6 (Gilly et al., 2009).

\subsection{Trabalhos Relacionados}

Vários trabalhos encontrados na literatura têm tratado da modelagem de rajadas no processo de chegada das requisições ou sessões ou rajadas impostas nas demandas de serviços do sistema (Krishnamurthy et al., 2009) (Mi, et al, 2008) (Mi et al., 2009) (Mi et al., 2010) (Lu, et al., 2010) (Rolia et al., 2010) (Casale et al. 2009) (Casale et al., 2012). De modo geral, a maioria desses trabalhos são voltados para avaliar o desempenho de sistemas baseados em sessão ou sistemas de multicamadas utilizadas em aplicação de $e$-commerce. Existem alguns trabalhos recentes que tratam do fenômeno de rajadas presentes nas cargas de trabalho executadas em ambientes em nuvem. Entretanto, esses trabalhos têm um foco mais voltado à 
alocação, consolidação e provisionamento de recursos na nuvem (Tai et.al., 2011) (Luo e Qian, 2013) (Yin et al., 2014) ou ainda, voltados à composição de novos modelos de custos para utilização de recursos compartilhados (Gmach et. al., 2012) (Wang et. al, 2012). A seguir são discutidos alguns desses trabalhos.

\subsubsection{Rajadas e Modelos Preditivos de Desempenho}

Em (Krishnamurthy et al., 2009) é proposto um método de média ponderada (WAM Weighted Average Method) para melhorar a precisão dos modelos analíticos de previsão de desempenho para sistemas com rajadas de clientes simultâneos. WAM considera uma distribuição da população de sessões de clientes concorrentes em um sistema para refletir o impacto das rajadas, incluindo distribuições de cauda pesada (heavy-tail) para os parâmetros da carga de trabalho. Esse método é baseado em traces de sessões juntamente com modelos de desempenho, como modelos de redes de filas (QNM - Queuing Network Models e LQM Layered Queuing Models), levando em consideração o impacto causado pelas rajadas no processo de chegada, para estimar o tempo de resposta médio das requisições. Nesse trabalho, é realizada uma validação da proposta usando um estudo de caso envolvendo um benchmark para aplicações e-commerce, conhecido como TPC-W ${ }^{1}$. Os resultados obtidos nesse trabalho indicam que o método proposto melhora a precisão da previsão de desempenho, quando são consideradas rajadas no processo de chegada das sessões, em relação aos modelos de desempenho tradicionais que consideram apenas o número médio de sessões concorrentes.

Em (Yin et al., 2014) é proposto um gerador de carga de trabalho para ser integrado ao benchmark CloudStone (Sobel et al., 2008) voltado para ambientes de nuvens, considerando o modelo MAP (Markovian Arrival Process). O objetivo desse trabalho foi de apresentar, com base nesse gerador, uma metodologia que pode ser utilizada para prever a função de densidade de probabilidade de utilização da CPU, visando apoiar atividades voltadas à otimização de desempenho de sistemas e à tomada de decisões relativas ao provisionamento e escalonamento de recursos. Nesse trabalho, é apresentada uma análise comparativa da utilização de recursos obtidos em um sistema real em relação à utilização de recursos prevista, considerando a presença de cargas de trabalho com rajadas. Com base nos experimentos conduzidos, os autores demonstram a eficácia e precisão da metodologia proposta.

\footnotetext{
${ }^{1}$ TPC-W, definido pelo Transaction Processing Performance Council, é um benchmark que simula as operações de uma livraria eletrônica, utilizando um paradigma arquitetural de 3 camadas, ou seja, um servidor Web, um servidor de aplicação e um servidor de banco de dados.
} 


\subsubsection{Rajadas e Benchmarks}

Casale et al. (2009) (2012) propõem uma metodologia para construção de benchmarks com níveis de rajadas customizadas na demanda de serviço, denominada de BURN (BURtiness eNabling method) para avaliação de desempenho de sistemas baseados em sessões. Nessa metodologia são implementadas duas políticas de submissão de sessões: Prrad para gerar a carga de trabalho tradicional de um benchmark e $\mathbf{P}^{\text {burst }}$ para introduzir rajadas na carga de trabalho (benchmark). A partir de um conjunto de cargas de trabalho pré-existentes, BURN encontra uma política que intercala a sua execução para estressar a aplicação multicamada e gerar rajadas controladas no consumo de recursos do sistema. Nesse trabalho, também é apresentado um caso de estudo envolvendo o benchmark TPC-W para demonstrar a eficiência do método proposto para controlar e predizer rajadas nas demandas de serviços das sessões estabelecidas pelos clientes do sistema.

Em (Rolia et al.,2009) é proposta uma metodologia voltada para modelagem de desempenho de instâncias de serviços de softwares customizados, chamado de BAP Benchmark-driven Algebraic Method. Esse método é baseado em uma abordagem algébrica para modelar a carga de trabalho em atividades como dimensionamento automático de instâncias de serviços customizados e construção automática de testes de validação de desempenho para as instâncias. Uma instância de serviço pode estar configurada em um portal e ser fornecida automaticamente aos clientes. Nesse caso, cada serviço é caracterizado usando um número de benchmarks específicos que podem ser executados e medidos de maneira automática em um ambiente de utilitários compartilhados. Essa abordagem permite um conjunto integrado de métodos, entre eles WAM e BURN, apresentados na Seção 4.6.1 e nesta Seção respectivamente, que suportam modelagem e testes de desempenho e que levam em conta características importantes como rajadas no processo de chegada e na demanda de serviços. Esse trabalho tem foco principal na criação de benchmarks customizados com propriedades específicas que podem ser utilizados para avaliação de desempenho de instâncias de serviços.

\subsubsection{Rajadas e Controle de Admissão/Balanceamento de Carga}

Em (Lu, et al., 2010) é apresentada uma política de controle de admissão baseada em sessão, chamada de AWAIT, visando fornecer um suporte adicional para tratar chegadas de sessões em forma de rajadas. Essa política ajusta a capacidade da fila de sessões bloqueadas em resposta às cargas de trabalho com rajadas submetidas ao sistema, a fim de manter o nível de 
desempenho esperado pelo cliente e minimizar a quantidade de sessões aceitas e abortadas. Nesse trabalho, para validação do algoritmo proposto, as cargas de trabalho com rajadas submetidas para o sistema, são modeladas de acordo com as técnicas implementadas em (Mi et al., 2009) (Mi et al., 2010), usando MAP (Markovian Arrival Process) e índice de dispersão.

Tai et al. (2011) propõeM um novo algoritmo de balanceamento de carga, chamado ARA (for Adaptive Resource Allocation in cloud systems), que tenta, baseado na taxa de chegada de requisições, neutralizar os efeitos das rajadas e melhorar o desempenho dos serviços e a disponibilidade do sistema. Nesse trabalho é adotado o índice de dispersão proposto por Gusella (1991) para detectar variabilidades no tráfego de entrada.

\subsubsection{Rajadas e Modelos de Custos}

Alguns trabalhos também consideram o fenômeno de rajadas, porém são voltados para definição de modelos de custos em computação em nuvem. Em (Gmach et al., 2012) é apresentada uma comparação de dois diferentes modelos de repartição de custos para o fornecimento de serviços em recursos compartilhados (em nuvem), considerando cargas de trabalho em forma de rajadas e recursos ociosos. Seguindo esta mesma linha, em (Wang et al., 2012) são estudados e comparados três modelos de custos, que consideram cargas de trabalho com rajadas. Nesse estudo é utilizado um trace contendo 20 dias de registros de acesso de um data center de uma empresa de Tecnologia da Informação. Após esse estudo, os autores propõem um novo modelo de custo, denominado RO-BURST (A Robust Virtualization Cost Model for Workload Consolidation over Clouds) que além de considerar em seu modelo os picos de utilização dos recursos que surgem em curtos períodos ao longo do tempo (causada pelas rajadas), consideram também políticas de consolidação das cargas para encontrar uma alocação apropriada das cargas de trabalho e ao mesmo tempo minimizar a quantidade de servidores necessários para alocá-las.

\subsubsection{Rajadas nos Tempos de Serviços}

Em (Casale et al., 2013) é apresentada uma metodologia para integrar rajadas originadas nos tempos de serviços em modelos de desempenho em aplicações Multi-Camada (composta de clientes, servidor Front server e um servidor de banco de dados). Essa metodologia é baseada no índice de dispersão do processo de serviço de um servidor, que é inferida pela observação do número de requisições concluídas, considerando os períodos em que os servidores 
mantiveram-se ocupados. O índice de dispersão é usado para derivar um modelo MAP a fim de capturar as rajadas e as variabilidades dos processos de serviços em cada recurso, possibilitando definir modelos de redes de filas usados em modelos preditivos de desempenho.

\subsubsection{Rajadas no Processo de Chegada das Requisições}

Outros trabalhos importantes relacionado ao fenômeno de rajadas em cargas de trabalho são apresentados em (Mi et al., 2008) (Mi et al., 2009) (Mi et al., 2010). No trabalho apresentado em (Mi et al., 2009) (Mi et al., 2010) é proposta uma metodologia para modelar cargas de trabalhos com rajadas no processo de chegada das requisições baseadas em duas técnicas: MAP (Markovian Arrival Process) e índice de dispersão. A metodologia proposta por Mi et al. (2009) (2010) integra um novo módulo para introdução de rajadas no processo de chegada das requisições em um benchmark e-commerce baseado na especificação TPC-W. Esse benchmark implementa os intervalos entre requisições sucessivas (think times) seguindo uma distribuição exponencial. Pelo fato da propriedade sem memória da distribuição exponencial, isso é equivalente a impor que os clientes operam independentemente de suas ações no passado. Think Times exponenciais, conforme comentado na Seção 4.4, são incompatíveis com a noção de rajadas por não conseguir capturar as propriedades específicas de cargas de trabalhos com rajadas, como variabilidade em diferentes escalas de tempo e agregação. Para resolver essa limitação do benchmark TPC-W, o trabalho de Mi et al. (2010) propõe modificar a forma como os think times são gerados para introduzir rajadas no processo de chegada das requisições, usando um MAP de 2 estados. O modelo MAP é parametrizado pela medida de índice de dispersão (I) para regular a intensidade de rajadas no processo de chegada das requisições. Os resultados obtidos nesse trabalho mostraram a importância da avaliação de sistemas em condições de rajadas e como seu desempenho piora à medida que a intensidade de rajadas aumenta.

Em vários trabalhos apresentados nesta Seção 4.6, as rajadas em cargas de trabalho são modeladas como um processo estocástico, utilizando o modelo MAP, para capturar as características e propriedades deste tipo de carga, como alta variabilidade e chegadas de requisições em forma condensada em curtos períodos ao longo do tempo (localidade temporal). Assim, nas próximas Seções serão apresentados o conceito e a descrição matemática do MAP e métodos para parametrização do modelo MAP, disponíveis em literatura. 


\subsection{Modelo MAP (Markovian Arrival Process)}

O MAP pode ser visto como um modelo matemático de séries de tempo e pode ser utilizado para gerar uma sequência de intervalos de chegadas e/ou tempos de serviços. Um processo MAP de 2 estados pode ser modelado de forma que para cada estado $\boldsymbol{i}$ ativo, amostras de think times ou de tempos de serviços são geradas por uma distribuição exponencial com taxa $\lambda_{i}$ associada ao estado $i$ do MAP. A Figura 4.3 ilustra um exemplo de um processo MAP de dois estados para regular a taxa de chegada das requisições no sistema. O estado sem rajadas (Estado SR) é responsável em gerar uma sequência de think times longos, associados aos períodos de tráfego normal. O estado com rajadas (Estado CR) é responsável em gerar uma sequência de think times curtos, implicando que os intervalos de chegada das requisições sucessivas serão menores e, portanto, podendo resultar em rajadas no processo de chegada das requisições.

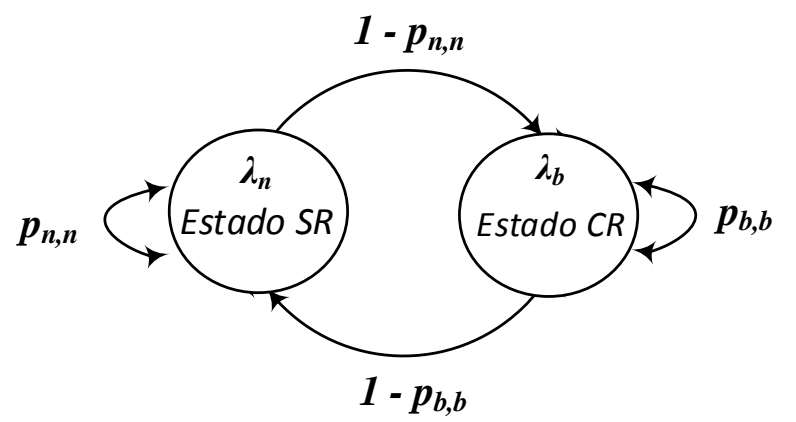

Figura 43 - Exemplo do Markovian Arrival Process com dois estados.

Os think times longos e curtos são gerados com a taxa média de $\lambda_{n}$ e $\lambda_{b}$ respectivamente. Com o intuito de garantir uma correlação entre diferentes eventos, após a geração de uma nova amostra de think times, o modelo tem uma probabilidade $p_{b, b}$, de dois think times consecutivos serem curtos e $p_{n, n}$ de serem longos. As probabilidades $p_{n, b}=1-p_{n, n}$ e $p_{b, n}=1-p_{b, b}$, determinam as mudanças entre os estados. Assim, o modelo consegue capturar a duração dos picos de tráfego e as oscilações de rajadas dentro de um mesmo pico.

Esse comportamento é ilustrado na Figura 4.4, onde picos irregulares na taxa de chegada das requisições surgem nos períodos em que os intervalos de tempos entre chegadas de requisições sucessivas (think times) tornam-se mais curtos e assim causando um aumento da taxa de chegada em curtos períodos ao longo do tempo. 


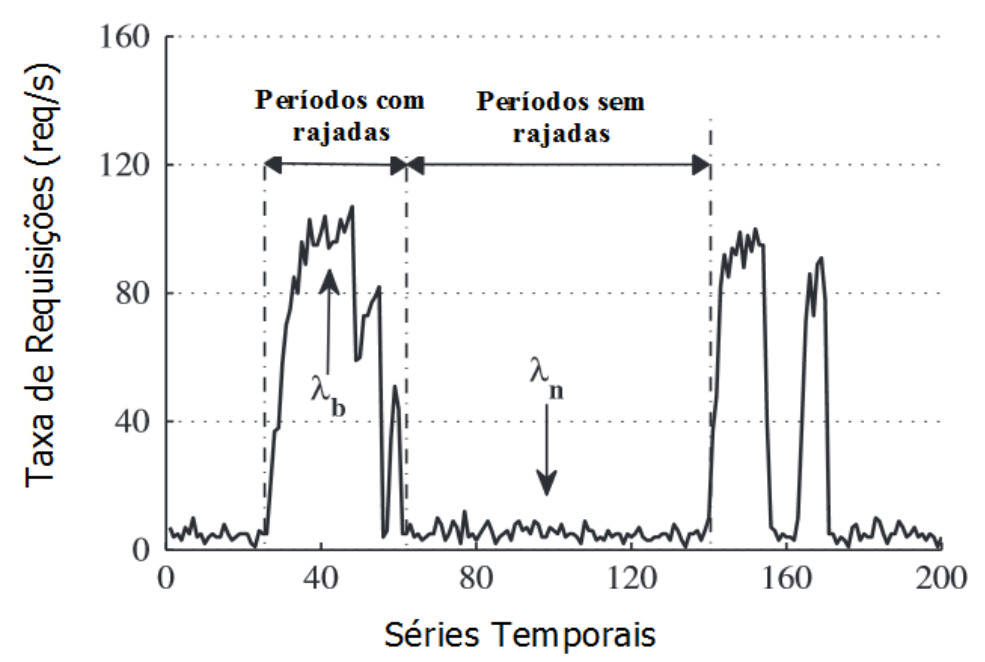

Figura 4.4 - Amostras das taxas de chegadas, adaptado de (Yin et al., 2014).

O processo MAP fornece um modelo matemático que, dependendo de sua parametrização, pode ser adotado para modelar rajadas tanto no processo de chegada das requisições, como também rajadas nas demandas de serviços. Por exemplo, se as amostras geradas pelo MAP são interpretadas como think times, o MAP é modelado para regular a taxa de chegada das requisições. Alternativamente, um MAP pode modelar as demandas de serviços submetidas ao sistema, neste caso as amostras são representadas por demandas de serviço (em Mips) ou por tempos de serviço (Pacheco-Sanchez et al., 2011).

\subsubsection{Descrição Matemática do MAP}

Um processo MAP de ordem $\boldsymbol{n}$ (estados) é definido por duas matrizes quadradas $n \times n$, representadas por D0 e D1, tal que D0 + D1 é o gerador de uma cadeia de Markov de tempo contínuo (Continuous-Time Markov Chains - CTMC). Um CTMC é caracterizado pelo vetor (em regime estacionário) de estado $\pi=\left(\pi^{1}, \pi^{2}, \ldots, \pi^{\mathrm{n}}\right)$ e sua matriz geradora, também conhecida como matriz de intensidade ou gerador infinitesimal.

Consire um processo contínuo irredutível Markov com espaço de estados $\boldsymbol{S}=\{\mathbf{1}, 2, \ldots, \boldsymbol{n}\}$ e matriz geradora $Q_{\text {MAP. }}$ Um processo MAP comporta-se como descrito a seguir (Bolch et al., 2006):

o estado inicial $\boldsymbol{i}_{0} \in \mathrm{S}$ é gerado de acordo com um vetor de probabilidade inicial $\boldsymbol{\alpha}$. Após um tempo $\boldsymbol{t}_{\boldsymbol{i}}$ de permanência no estado $\boldsymbol{i}$, exponencialmente distribuído com parâmetro $\lambda \boldsymbol{i}>\boldsymbol{0}$, 
podem ocorrer duas transições de estado possíveis. Uma delas, referente a transição observável ou efetiva, com probabilidade $\boldsymbol{p}^{\boldsymbol{1}} \boldsymbol{i}$, o MAP passa para o estado $\boldsymbol{j} \in \mathbf{S}$ e uma única amostra (think times ou tempo de serviço) é gerada. A seleção do estado $\boldsymbol{j}$, que pode ser o mesmo $\boldsymbol{j}=\boldsymbol{i}$, é exclusivamente determinada por $\boldsymbol{p}^{\boldsymbol{1}}{ }_{i j}$. Por outro lado, com a probabilidade $\boldsymbol{p}_{i j}^{\boldsymbol{0}}$, ocorre uma transição escondida, onde o processo MAP entra no estado $j$, porém não é gerada uma amostra (tem apenas o efeito de mudança de estado), neste caso $\boldsymbol{j} \neq \boldsymbol{i}$. A Figura 5 ilustra, por meio de um diagrama de transição, ambos os tipos de transições de um MAP com dois estados. As probabilidades $\boldsymbol{p}_{i j}$ e $\boldsymbol{p}_{j i}$ indicam transições escondidas e $\boldsymbol{p}_{i j}$ e $\boldsymbol{p}_{j i}$ indicam transições efetivas ou observáveis.

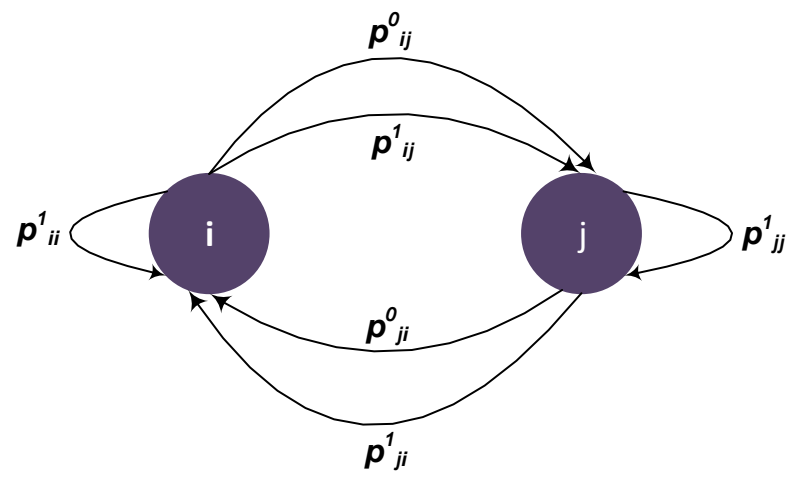

Figura 5. Diagrama de Transição de um $\mathrm{MAP}_{2}$.

$\mathrm{O}$ processo MAP pode então ser caracterizado pelos parâmetros $\left\{\lambda, \mathrm{P}_{0}, \mathrm{P}_{1}\right\}$, sendo que $\lambda=\left(\lambda_{1}, \lambda_{2}, \ldots, \lambda_{n}\right)$ e $\mathrm{P}_{0}$ e $\mathrm{P}_{1}$ determinam as mudanças de estados, onde a somatória das probabilidades de transição de um estado é igual a 1:

$$
\sum_{j=1 ; j \neq i}^{n} p^{0} i j+\sum_{j=1}^{n} p^{1} i j=1, \quad \text { para } 1 \leq i \leq n
$$

A partir da definição das variáveis:

$$
\begin{array}{ll}
D 0_{i j}=\lambda_{i} p_{i j}^{0} & , 1 \leq i \leq n, 1 \leq j \leq n, i \neq j \\
D 0_{i i}=-\lambda_{i} & , 1 \leq i \leq n \\
D 1_{i j}=\lambda_{i} p_{i j}^{1} & , 1 \leq i \leq n, 1 \leq j \leq n
\end{array}
$$

Ou seja: 


$$
\begin{aligned}
D 0 & =\left(\begin{array}{cc}
-\lambda_{i} & \lambda_{i} p_{i j}^{0} \\
\lambda_{j} * p_{j i}^{0} & -\lambda_{j}
\end{array}\right) \\
D 1 & =\left(\begin{array}{ll}
\lambda_{i} p_{i i}^{1} & \lambda_{i} p_{i j}^{1} \\
\lambda_{j} p_{j i}^{1} & \lambda_{j} p_{j j}^{1}
\end{array}\right)
\end{aligned}
$$

A matriz geradora infinitesimal $\boldsymbol{Q}_{M A P}$ da cadeia de Markov de tempo contínuo pode ser obtida pela equação 4.14 :

$$
Q_{M A P}=\mathrm{D} 0+\mathrm{D} 1=\left(\begin{array}{cc}
-q_{i} & q_{i j} \\
q_{j i} & -q_{j}
\end{array}\right)
$$

O vetor de probabilidade em regime estacionário pode então ser calculado usando a equação 4.15:

$$
\pi Q_{M A P}=0, \quad \pi 1=1
$$

A equação 4.16 pode ser usada para obter o vetor $\pi$ para um MAP de 2 estados (Fischer e Kathleen, 1993):

$$
\begin{array}{r}
\pi=\left[\pi_{1}, \pi_{2}\right], \quad \text { sendo: } \\
\pi_{1}=\frac{1}{q_{i}+q_{j}} q_{j} \quad, \quad \pi_{2}=\frac{1}{q_{i}+q_{j}} q_{i}
\end{array}
$$

Desta forma, a notação (D0, D1) permite a descrição compacta das propriedades estatísticas, em regime estacionário, das amostras geradas pelo MAP.

\subsubsection{Parametrização do Modelo MAP}

$\mathrm{Na}$ modelagem estocástica, a representação adequada dos processos de chegada e dos tempos de serviço é de grande importância para construir modelos realistas. Ocorre que muitos processos reais incluem alguma correlação o que implica que as variáveis aleatórias que são identicamente e independentemente distribuídas não são suficientes para descrever tal comportamento. Para esses casos devem ser considerados processos estocásticos para modelar a distribuição e a estrutura de autocorrelação (Kriege e Buchholz, 2010). O Markovian Arrival Processes ou MAPs são processos estocásticos que podem ser aplicados para capturar uma grande gama de diferentes comportamentos estocásticos e podem ser utilizados em modelos de redes de filas para representar processos de chegadas e de serviços e na modelagem de rajadas 
em cargas de trabalho baseados em modelos analíticos. No entanto, para que o MAP possa representar esses comportamentos de forma realista é preciso que ele seja parametrizado adequadamente. A definição dos parâmetros do MAP é um importante passo para construção de um modelo de carga de trabalho. Metodologias voltadas para definição dos parâmetros do modelo MAP têm sido propostas na literatura recentemente e é um tema que continua sendo um desafio para a comunidade científica (Bause et al., 2009) (Bucholz et al., 2010).

Algumas abordagens tentam encontar uma parametrização do MAP usando o algoritmo de Maximização de Expectativas ou EM (Expectation Maximization) para maximizar as probabilidades de acordo com um trace disponível (Breuer, 2002) (Klemm et al., 2003). O algoritmo EM busca fazer uma estimativa de parâmetros para modelos estatísticos, onde os parâmetros encontrados são estimativas por máxima verossimilhança ou maximum likelihood estimates (MLE). Entretanto, o uso de algoritmos EM para parametrizar MAPs baseados em traces requer um enorme esforço, visto que para definir parâmetros de um MAP é necessário que os traces contenham grande quantidade de registros (como intervalos de chegadas ou tempos de serviços), de modo que seja possível capturar com exatidão a autocorrelação na estrutura do trace (Bucholz et al., 2010).

Outras abordagens, primeiro analisam algumas medidas de um trace, como momentos de ordem superior, momento conjunto (joint moment) ou coeficiente de autocorrelações $\left(\rho_{k}\right)$ em $k$ deslocamento no tempo e em seguida, define os parâmetros de um MAP de acordo com essas medidas (Telek e Horváth, 2007). Nessa abordagem, diferente da anterior, a parametrização torna-se independente do tamanho do trace. Há ainda metodologias que consideram apenas medidas de coeficiente de autocorrelação (Casale et al., 2008) para definir a parametrização de um MAP.

Em Casale et al. (2008) é apresentada uma coleção de scripts Matlab, chamada de KPCToolbox, para automaticamente definir a parametrização do MAP baseado em cargas de trabalho reais por meio de traces. O KPC-Toolbox adquire como entrada os intervalos de chegadas ou tempos de serviços registrados no trace e busca automaticamente a melhor parametrização do MAP que caracterize as autocorrelações encontradas na estrutura desse trace. O KPC-Toolbox por possuir uma coleção de scripts voltados para cálculos das medidas de um MAP, permite analisar medidas importantes como a média $\left(\lambda^{-1}\right)$, índice de dispersão (I), vetor de probabilidade em regime estacionário $(\pi)$, quadrado do coeficiente de variação $(\mathrm{SCV})$, coeficiente de autocorrelação $\left(\rho_{\mathrm{k}}\right)$, entre outras. Esse toolbox foi utilizado como uma ferramenta de apoio para a parametrização dos modelos MAPs implementados neste projeto de doutorado. 
A descrição da metodologia proposta para parametrizar os MAPs adotados neste trabalho será apresentada na Seção 6.3.2, no Capítulo 6.

Uma abordagem diferente das mencionadas anteriormente que não é baseada em traces é apresentada em (Mi et al, 2010). Nesse trabalho o modelo MAP é parametrizado pelo índice de dispersão, por meio de um script implementado no Matlab e o MAP Queueing Network Toolbox (Casale e Smirni, 2009). O MAP Queueing Networks é uma classe de modelos de redes de filas fechadas para a análise de sistemas computacionais e comunicações, onde os tempos de serviço são afetados pelas rajadas. Essa classe, assim como o KPC-toolbox, possui uma coleção de scripts para manipulação e análise de medidas de um MAP.

\subsection{Considerações Finais}

Este Capítulo apresentou conceitos sobre o fenômeno de rajadas e os principais trabalhos encontrados na literatura relacionados à modelagem de cargas de trabalho e medidas conhecidas como fator de rajadas, que permitem determinar a ocorrência de rajadas nos processos de chegada das requisições. O estudo bibliográfico permitiu observar a importância de se considerar o fenômeno de rajadas nas cargas de trabalho e também contribuiu para a definição da metodologia adotada, neste projeto de doutorado, para a construção de cargas de trabalho que representem adequadamente o fenômeno de rajadas.

O modelo de carga de trabalho adotado neste trabalho, foi definido com base nas metodologias encontradas na literatura (Mi et al., 2010) (Lu et al., 2010) (Pacheco-Sanchez et al., 2011) (Casale et al., 2013) (Lu et al., 2013) (Yin et al., 2014). Durante a etapa de definição do modelo a ser considerado neste projeto, foi realizado um estudo envolvendo a modelagem de rajadas nos processos de chegada de requisições utilizando o modelo MAP. Este estudo deu origem a um trabalho apresentado em (Centurion et al., 2012). Nesse trabalho, foi apresentada uma avaliação de desempenho voltada para Serviços Web, considerando diferentes características das cargas de trabalho. Dentre essas características destacou-se o fenômeno de rajadas. As rajadas nas cargas de trabalho foram modeladas com base na metodologia proposta por (Mi et al., 2010), utilizando MAP, para regular a taxa de chegada das requisições no sistema e índice de dispersão, para regular a intensidade de rajadas no processo de chegada das requisições. Os resultados obtidos mostraram que o modelo MAP tem a habilidade de representar adequadamente as propriedades específicas desse tipo de carga, descritas na Seção 4.4. Além disso, o estudo constatou a afirmação discutida por alguns autores (Menascé et al., 
2000) (Wang et al., 2003) (Casale et al., 2009) (Mi et al., 2010) sobre a importância de se considerar rajadas no modelo de cargas de trabalho, visto que elas podem degradar o desempenho e tempos de resposta do sistema se não levadas em consideração.

Assim, a partir deste estudo e baseado nos modelos apresentados na literatura, neste trabalho, as rajadas no processo de chegada das requisições e nas demandas de serviços foram modeladas por processos MAPs de 2 estados parametrizados com diferentes níveis de variabilidade e intensidades. A descrição dos modelos considerados é apresentada na Seção 5.3.1 no Capítulo 5.

Assim, no Capítulo 5, serão apresentados o projeto e implementação da arquitetura proposta e os modelos de carga de trabalho que implementam o processo de chegada e demandas de serviços, considerando situações com ou sem rajadas. Em seguida, nos Capítulos 6 e 7, será apresentada uma avaliação do impacto das rajadas no desempenho dos serviços executados em ambientes em nuvens e uma avaliação do modelo proposto para o fator de rajada, considerando rajadas de diferentes origens (intervalo de chegada e demanda de serviço) e de diferentes variabilidades. 


\section{Arquitetura CloudSim-BEQoS: Projeto,}

\section{Implementação e Estudo de Caso}

\subsection{Considerações Iniciais}

Este Capítulo descreve a arquitetura CloudSim-BEQoS (Bursty, Energy, QoS), baseada no simulador CloudSim (Calheiros et al., 2011), descrito na Seção 2.7 e explica com detalhes os principais módulos que a compõem. Essa arquitetura foi projetada visando à possibilidade de:

i) Avaliar a influência das rajadas no desempenho dos serviços,

ii) Fornecer mecanismos ao Broker para que ele atue como um agente de intermediação, de modo a garantir qualidade de serviço (QoS) aos clientes da nuvem,

iii) Disponibilizar políticas de escalonamento, através da diferenciação de serviços baseada em prioridades, a fim de evitar picos de demandas de energia.

Todas essas características englobam temas associados ao projeto de doutorado apresentado nesta tese (modelos de cargas de trabalhos e fator de rajadas) e em mais dois projetos de doutorado do Laboratório de Sistemas Distribuídos e Programação Concorrente (LaSDPC), voltados para construção de um Broker com políticas que garantam QoS e eficiência energética. Assim, a união de todas essas características deu origem a uma arquitetura mais completa, contribuindo desta forma, não apenas com o LaSDPC, mas também com áreas de pesquisas voltadas ao planejamento de capacidade, modelos de desempenho e avaliação de desempenho de sistemas computacionais em nuvem.

A seguir é apresentada uma visão geral da CloudSim-BEQoS e nas Seções 5.3 e 5.4 a arquitetura é detalhada. Na Seção 5.5 é apresentada uma avaliação de desempenho realizada visando exemplificar a aplicabilidade da extensão proposta para o CloudSim e, em especial, os 
componentes da camada cliente da CloudSim-BEQoS. Com o estudo de caso apresentado na Seção 5.5 demonstra-se a possibilidade de avaliar o comportamento do sistema quando são submetidas cargas de trabalho distintas (individuais ou em grupo), que se apresentam ou não em rajadas, de vários clientes concorrentes, localizados ou não em diferentes pontos geográficos.

\subsection{Visão Geral da Arquitetura}

A Figura 5.1 apresenta a visão geral da arquitetura desenvolvida, utilizando a API (Application Programming Interface) do simulador CloudSim (Calheiros et al., 2011). A implementação dos módulos e dos modelos de cargas de trabalho baseia-se na linguagem de programação Java. Como a API do simulador CloudSim utilizada neste projeto é baseada nesta linguagem de programação, sua adoção para a extensão proposta neste trabalho tornou-se atraente. A arquitetura é composta por três camadas: a camada cliente, a de gerenciamento e a de infraestrutura.

$\mathrm{Na}$ camada cliente encontram-se as entidades clientes responsáveis pelo envio concorrente de requisições à nuvem, os diferentes modos de submissão de requisições implementados, que podem ocorrer de forma individual ou em grupo e os modelos de cargas de trabalho com e sem rajadas.

A camada de gerenciamento é responsável pelas tarefas de escalonamento, alocação das requisições nas máquinas virtuais e pelo monitoramento e na camada de infraestrutura é onde encontram-se os recursos físicos dos data centers privado e público. Essas camadas serão detalhadas na Seção 5.3.

Os componentes presentes nas camadas realizam trocas de informações entre si. A Figura 5.2 mostra, de forma resumida, a interação entre os componentes para o processamento de um serviço. 


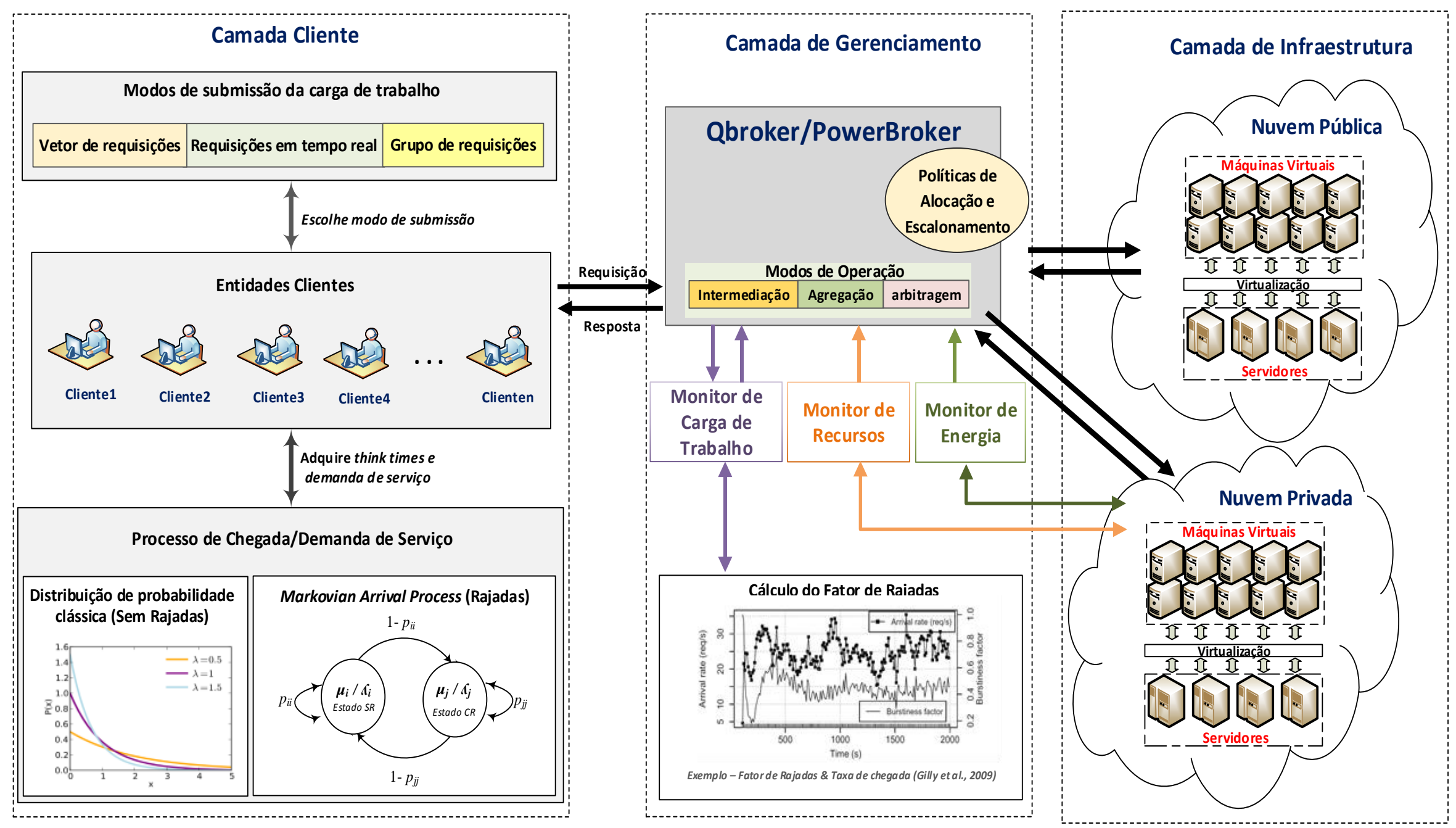

Figura 5.1 - Visão geral da arquitetura desenvolvida. 


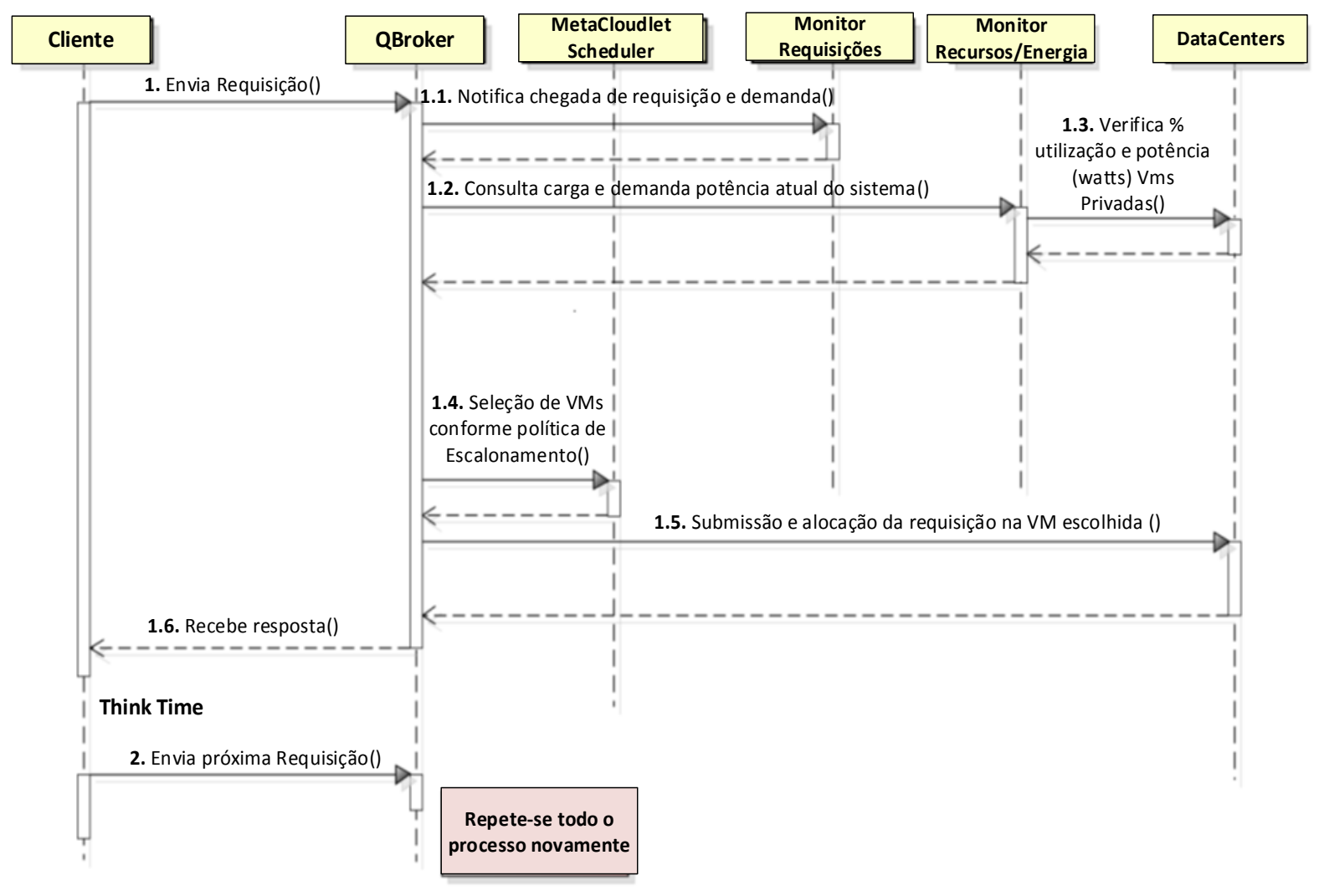

Figura 5.2 - Diagrama de sequência para o processamento de um serviço.

Como mostra o diagrama de sequência, o processo inicia-se com o cliente enviando uma requisição ou um grupo de requisições para serem processadas na nuvem. Essas requisições são recebidas pelo Broker, que realiza algumas operações antes de encaminhá-las aos recursos da nuvem para serem processadas. Inicialmente, o Broker sinaliza ao monitor de requisições a chegada de uma ou um grupo de requisições e também a demanda de serviço (em Milhões de Instruções - MI) requerida por essas requisições. Essas informações são utilizadas pelo monitor de requisições para calcular as taxas de chegadas de requisições e as taxas de chegadas de demandas de serviços, em intervalos de tempo, durante a simulação. Logo após, o Broker se comunica com o monitor de recursos para consultar o percentual de consumo dos recursos do data center privado e com o monitor de energia para verificar o percentual de consumo, em watts, também do data center privado. Baseado na carga atual dos recursos do data center privado e das políticas de escalonamento adotadas (considerando requisições individuais ou em grupos, com ou sem critérios de QoS e/ou diferenciação de serviços) o Broker seleciona uma máquina virtual (VM) ou máquinas virtuais (no caso de grupos de requisições) do data center privado ou público e encaminha a requisição para essa(s) VM(s). Para uma situação onde considera-se requisições individuais ou em grupos independentes, que serão descritos na Seção 
3.5.1, a requisição após ser processada é encaminhada ao Broker, para que este envie a resposta completa ao cliente. Quando considera-se grupo de requisições dependentes, como há uma dependência na sequência de execução das requisições, apenas após todas as requisições serem processadas é que as respostas completas das requisições do grupo são enviadas ao cliente. $\mathrm{O}$ diagrama da Figura 5.2 mostra uma das opções implementadas para o tempo de espera entre o envio de duas requisições sucessivas pelo mesmo cliente. Neste caso após receber a resposta completa, o cliente aguarda um intervalo de tempo (think time) e então envia a próxima requisição à nuvem. Existe ainda outra opção, que será descrita na Seção 5.3.1, onde o think time começa a ser considerado imediatamente após o envio de uma requisição.

\subsection{Detalhamento das Camadas da Arquitetura}

Nesta Seção são apresentadas as principais funcionalidades dos componentes presentes na arquitetura CloudSim-BEQoS.

\subsubsection{Camada Cliente}

Conforme comentado na Seção 5.2, a arquitetura CloudSim-BEQoS foi implementada utilizando o simulador CloudSim. Na API padrão desse simulador, a camada cliente é inexistente. No CloudSim original, a entidade Broker além de possuir as funções de mediador entre o cliente e um provedor de nuvem, também é responsável em abstrair as funções de um cliente. Isso significa que, na API padrão do CloudSim, o Broker é responsável por enviar requisições à nuvem e também resolver questões de escalonamento e alocação da requisição, enviada por ele próprio, para uma VM do data center. Além disso, todas as requisições são submetidas juntas no início da simulação e não durante a simulação, o que não permite o uso de cargas de trabalho mais realistas e que representem adequadamente o fenômeno de rajadas.

$\mathrm{Na}$ arquitetura CloudSim-BEQoS foi implementada uma camada cliente, permitindo modelar diferentes cargas de trabalho a serem submetidas à nuvem durante a simulação. Essa camada, portanto, por estar integrada à API do simulador CloudSim, representa uma contribuição importante para as pesquisas que utilizam o simulador CloudSim para avaliar o desempenho e a capacidade de sistemas computacionais em nuvem.

A camada cliente possui três componentes principais: as entidades clientes, os modos de submissão das requisições e os modelos de carga de trabalho que implementam o processo de chegada e demandas de serviços das requisições, considerando situações com ou sem 
rajadas. A entidade cliente é responsável por enviar requisições sucessivas ao Broker. Existem três modos de submissão das requisições: vetor de requisições, requisições em tempo real e grupo de requisições. A demanda de serviço (em MI) imposta pela requisição é definida durante a sua criação, podendo ser modelada sem ou com rajadas. Da mesma forma, o processo de chegada das requisições pode se apresentar ou não em forma de rajadas, onde os intervalos de tempo entre o envio de duas requisições sucessivas de um mesmo cliente são gerados durante a simulação, logo após o envio da primeira requisição ou após o recebimento completo da requisição prévia. A seguir são descritos os principais componentes da camada cliente.

\section{Modos de Submissão}

Foram implementadas diferentes formas de envio da requisição à nuvem, individuais ou em grupos, sendo elas:

- Vetor de Requisições: este modo é implementado por meio de um array de requisições (cloudlets no CloudSim) que é gerado após a criação de cada instância de cliente, conforme ilustrado na Figura 5.3(a). Depois de instanciado, o cliente envia as requisições de modo sucessivo e sem intervalos, ou pode aguardar intervalos de tempo (think times), a serem modelados com ou sem rajadas. Com esse tipo de cliente pode-se emular vários tipos de aplicações do lado cliente, como por exemplo a transmissão de streams de aúdio ou vídeo, o upload de um arquivo de tamanho grande, envio de mensagens de e-mail, entre outras.

- Requisições em Tempo Real: neste modo de submissão, as requisições são dinamicamente criadas e enviadas, em tempo real, durante a simulação. Esse tipo de cliente possibilita a criação de simulações mais realísticas, pois torna o comportamento do cliente mais próximo do que se espera num ambiente de uso de sistemas de nuvem reais. Este modo de submissão é ilustrado na Figura 5.3(b).

- Grupo de Requisições: este modo de submissão permite que os clientes enviem grupos de requisições a cada vez que submete uma mensagem ao Broker, durante a simulação. É possível configurar a quantidade de requisições que cada grupo terá e definir se essas requisições deverão executar de forma dependente ou independente. Isto é, as requisições em grupos podem possuir ou não dependência na ordem de execução das tarefas dos serviços solicitados. Quando há dependência, a segunda requisição só poderá ser executada após a primeira requisição do grupo finalizar, a terceira apenas após o término da segunda e assim por diante. Quando a dependência não existe, as requisições são executadas assim que encaminhadas a uma VM. Além disso, em cada grupo de requisições, pode-se configurar o 
cliente para solicitar diferentes serviços em cada requisição, de modo que a simulação funcione como se o cliente estivesse pedindo "coleções" de serviços. Desta forma, tal implementação possibilita a simulação de diversos tipos de aplicações cliente que usam grupos de requisições, por exemplo, a solicitação de serviços Web por composição, requisições para execução de tarefas paralelas, entre outras possibilidades.

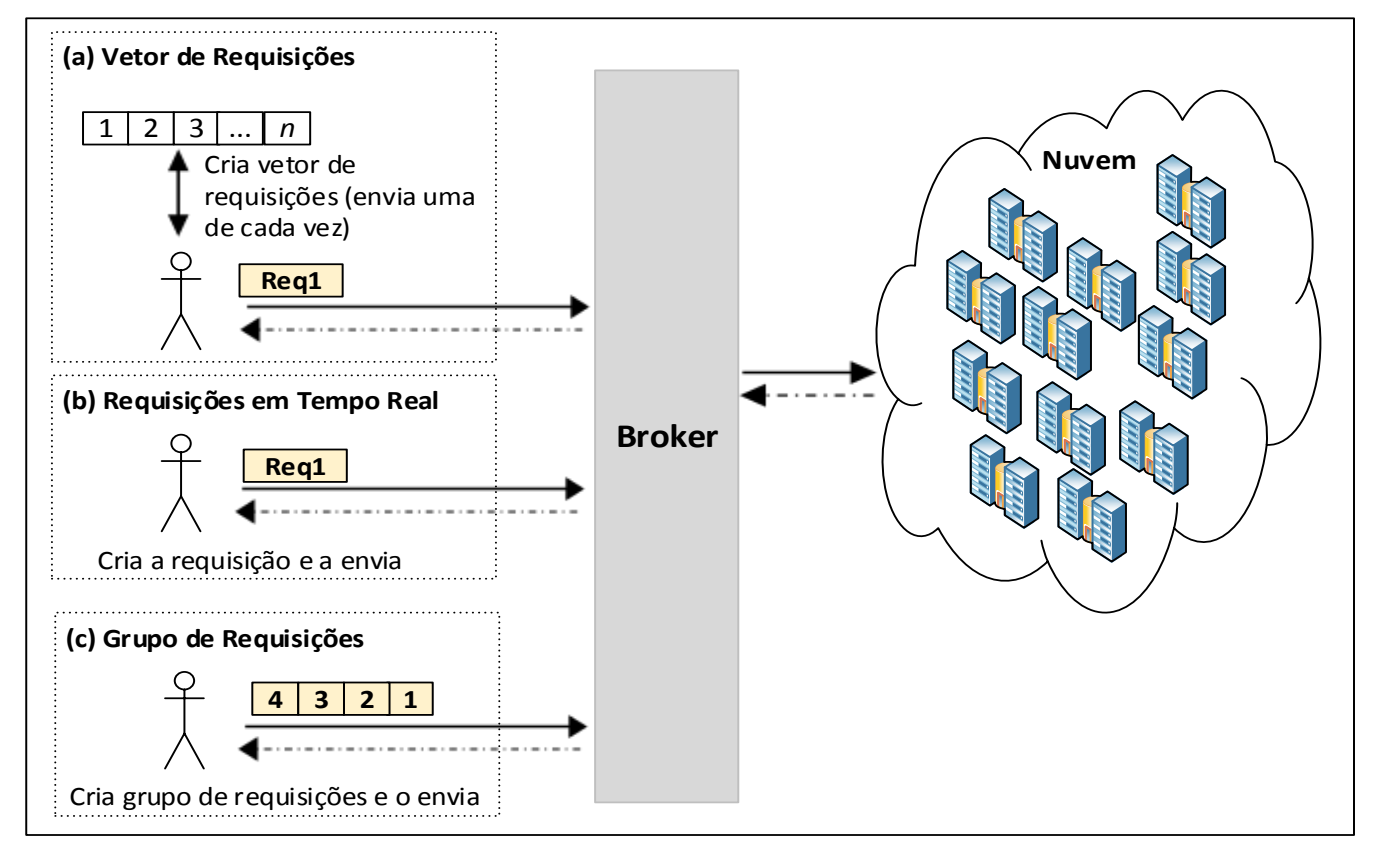

Figura 5.3 - Modos de submissão das requisições implementados na camada cliente.

\section{Modelagem da carga de trabalho}

A carga de trabalho pode ser modelada para representar situações sem e com rajadas no processo de chegada das requisições e/ou nas demandas de serviços impostas aos recursos da nuvem. Como ilustrado na Figura 5.1, na situação sem rajadas o processo chegada e demanda de serviço podem ser gerados por meio do uso de funções de distribuição clássicas (como exponencial, uniforme, Pareto, entre outras).

Para situações onde consideram-se rajadas, a carga de trabalho é modelada com base nas metodologias encontradas na literatura (Mi et al., 2010) (Lu et al., 2010) (Pacheco-Sanchez et al., 2011) (Casale et al., 2013) (Lu et al., 2013) (Yin et al., 2014). Na maioria desses trabalhos, as cargas de trabalho que se apresentam em forma de rajadas são modeladas como um processo estocástico, usando a classe MAP, para capturar as características e propriedades deste tipo de carga, como alta variabilidade e chegadas de requisições em forma condensada em curtos períodos ao longo do tempo (localidade temporal). O MAP, apresentado na Seção 4.7, tem a 
habilidade de fornecer variabilidade em diferentes níveis como também efeitos de localidade temporal. Além disso, esse modelo pode ser facilmente integrado com modelos analíticos, modelos de redes de filas e ambientes de simulação para avaliação de desempenho de sistemas computacionais (Pacheco-Sanchez et al., 2011) (Nelson, 2012).

Desta forma, o modelo de carga de trabalho adotado neste projeto de doutorado e implementado na arquitetura proposta é construído usando três processos MAPs com dois estados para modelar rajadas de origens distintas (no processo de chegada e/ou nas demandas de serviços) e de diferentes níveis de intensidades e variabilidades. As rajadas originadas no processo de chegada das requisições estão relacionadas aos intervalos de tempo entre chegadas de requisições (representadas pelos think times entre o envio de duas requisições sucessivas), enquanto que, as rajadas originadas na demanda de serviço estão associadas às demandas impostas aos recursos do sistema, como memória, CPU, servidores, etc., resultante das solicitações de serviços (expressas no ambiente de simulação em Milhões de Instruções - $M I$ ). Esses três MAPs, nomeados de MAP ${ }_{\mathrm{IAT}}$ (MAP for Inter-Arrival Time), MAPSD (MAP for Service Demand) e MAP sinc (MAPs Synchronized), são usados para respresentar diferentes modelos de carga de trabalho, sendo eles:

- MAPiat: implementa rajadas originadas no processo de chegada das requisições, através da geração de uma sequência de think times longos, associados aos períodos de tráfego normal ou sem rajadas e curtos, associados aos períodos em que os intervalos de chegada das requisições sucessivas tornam-se menores e, portanto, causando um aumento na taxa de chegada das requisições.

- MAPsD: processo responsável por modelar rajadas originadas nas demandas de serviços, onde é gerada uma sequência de tempos de serviços leves, correspondendo a períodos sem rajadas e pesadas, implicando em um aumento na demanda de serviço imposta aos recursos da nuvem em alguns períodos ao longo do tempo de simulação;

- MAPsinc: implementa rajadas originadas tanto no processo de chegada como na demanda de serviço, ocorrendo de forma sincronizada durante a simulação. Existe também a possibilidade de considerar rajadas nas duas origens, mas ocorrendo em escalas de tempos distintas, usando os modelos MAPIAT e MAPSD executados de maneira independente um do outro. Essas duas possibilidades permitem avaliar o impacto das rajadas quando elas se apresentam tanto no intervalo de chegada das requisições como nas demandas de serviços e chegam juntas, no mesmo instante de tempo ou chegam em instantes de tempos diferentes. 
O pseudocódigo, na Figura 5.4, mostra como o processo MAPIAT foi implementado para regular a taxa de chegada das requisições. Nesse modelo, para cada estado $i$ ativo, amostras de think times são geradas por uma distribuição exponencial com taxa $\lambda_{i}$ associada ao estado $i$. Assim, como os estados são alternados entre um e outro, é possível modelar não apenas os picos de tráfego, como também as flutuações das rajadas dentro de um mesmo pico.

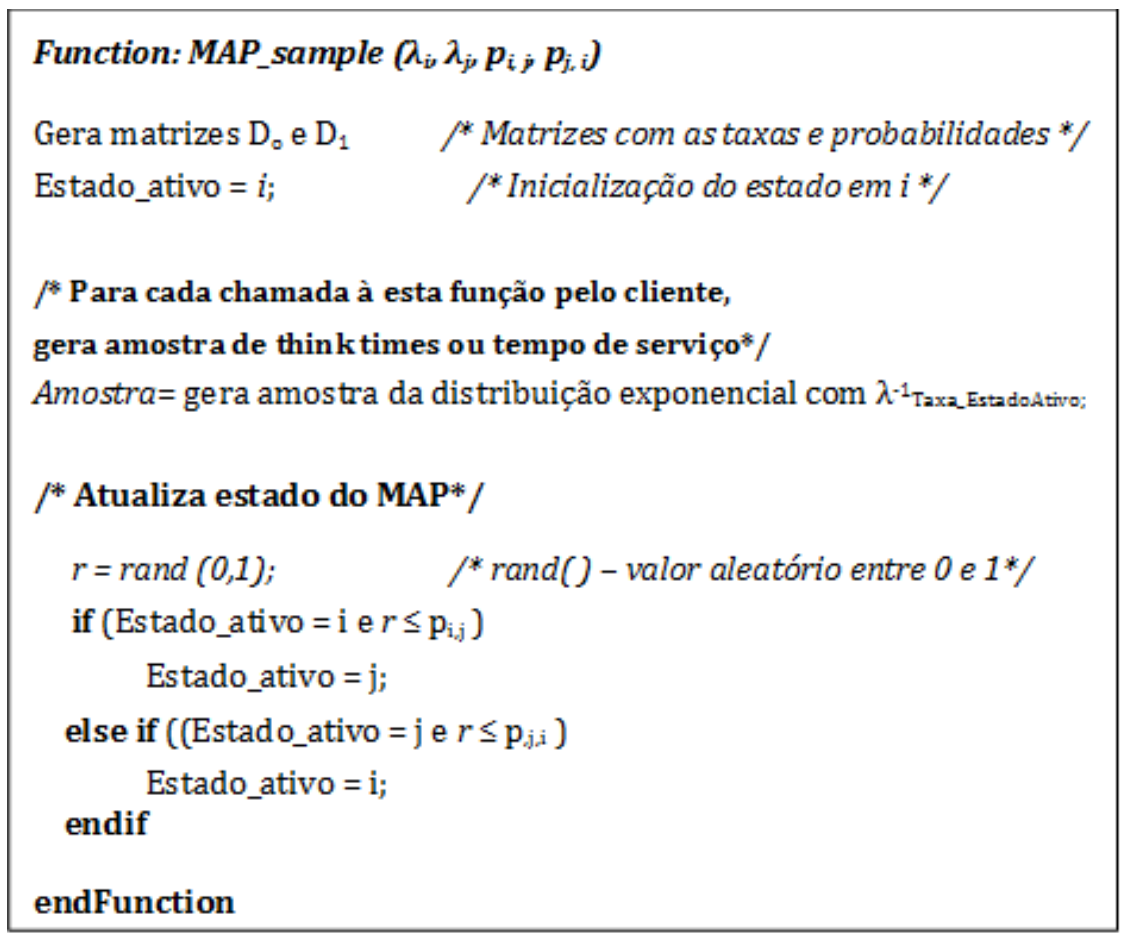

Figura 5.4 - Pseudocódigo MAP - para gerar uma amostra de think times.

O modelo MAPSD segue a mesma implementação apresentada na Figura 5.4, porém os argumentos de entrada correspondem à taxa de chegada dos tempos de serviços do estado $i$ e $j$ : $\left(\mu_{\mathrm{i}}, \mu_{\mathrm{j}}, \mathrm{p}_{\mathrm{i}, \mathrm{j}}, \mathrm{p}_{\mathrm{j}, \mathrm{i}}\right)$ para regular a taxa de serviço que chega à nuvem. A demanda de serviço em MI da requisição é calculada, pela entidade cliente, a partir da amostra de tempo de serviço gerada pelo MAPSD. Por exemplo, se o tempo de serviço obtido é de $t$ segundos para ser executado em uma VM com capacidade de processamento de $c p$ Milhões de Instruções por Segundo (MIPs), então a demanda de serviço pode ser obtida multiplicando-se o tempo de serviço $t$ pela capacidade de processamento da VM $c p$ :

$$
\text { Demanda }=t . c p
$$

$\mathrm{O} \mathrm{MAP}_{\text {sinc }}$ foi implementado seguindo a mesma lógica, porém incluindo uma sincronização nas mudanças dos estados, conforme o pseudocódigo da Figura 5.5. 


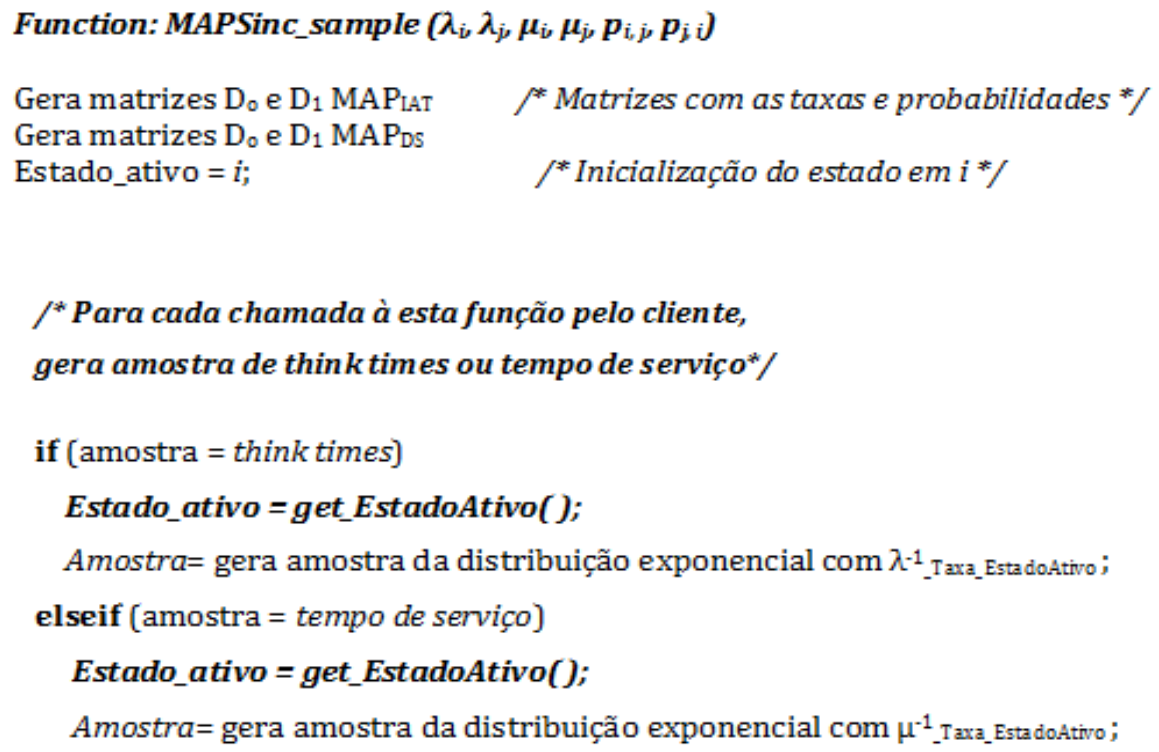

Figura 5.5 - Pseudocódigo MAPSinc

No $\mathrm{MAP}_{\text {sinc }}$ considera-se a implementação de dois modelos: o MAPIAT e o MAPSD que devem executar de modo sincronizado ao longo do tempo. Desta forma, os dois modelos compartilham a mesma variável "Estado_Ativo", garantindo que as mudanças de estados ocorram de forma sincronizada nos dois modelos.

Na camada cliente da arquitetura CloudSim-BEQoS é criado um conjunto de MAPs idênticos que são compartilhados por todas as entidades clientes instanciadas durante a simulação. Isso resolve imediatamente a questão de independência entre requisições de diferentes clientes, visto que uma das propriedades das rajadas refere-se à agregação, ou seja, os clientes devem agir de modo agregado, onde o processo de chegada das requisições não podem ocorrer de forma aleatória e independentes uns dos outros. 


\section{Latência de rede entre Cliente e Broker}

$\mathrm{Na}$ arquitetura CloudSim-BEQoS, foi necessário adicionar uma latência de rede entre o cliente e o Broker, uma vez que essa entidade na API padrão do CloudSim é inexistente. Para tanto, a implementação permite a associação das instâncias dos clientes com qualquer topologia de rede implementada no CloudSim, podendo interagir com o cenário obtendo uma latência fixa por meio dos métodos da classe NetworkTopology ou fazendo parte de um grafo de rede mais complexo por meio do uso da ferramenta Brite (Medina et al., 2001). O simulador CloudSim não conta com entidades reais para a simulação de entidades de rede, como roteadores, em vez disso, a latência que uma mensagem possui entre uma entidade de origem e entidade destino é simulada baseada na informação armazenada em uma matriz de latência (Calheiros et al., 2011). Como ilustrado na Figura 5.6, o cliente cria uma mensagem e a envia para ser processada.

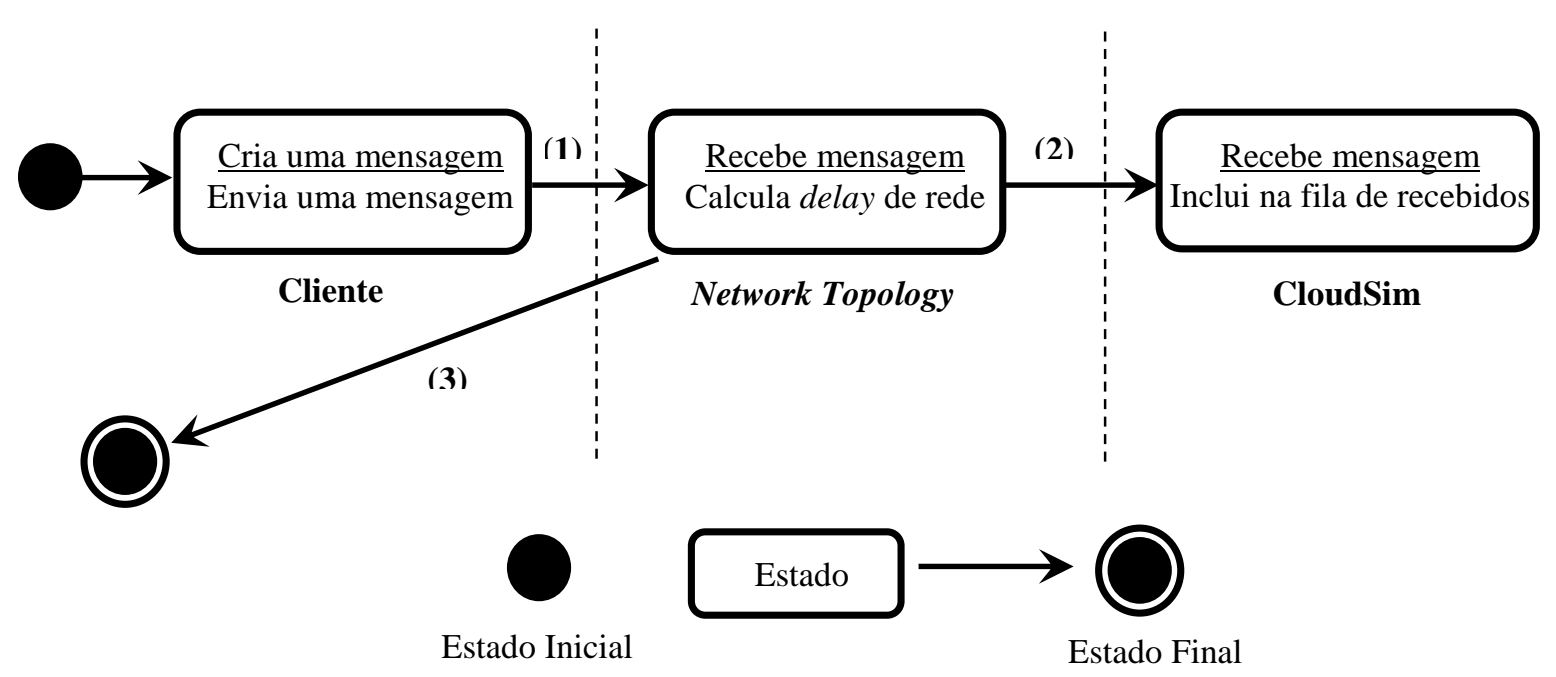

Figura 5.6 - Fluxo de comunicação entre entidades (Calheiros et al., 2011).

Nessa operação é acrescentado ao tempo de simulação o tempo de envio da mensagem (1). A mensagem é recebida e encaminhada para ser processada. O tempo de envio (2) é acrescentado ao tempo de simulação. Por fim, o tempo de entrega das solicitações (3) também é adicionado ao tempo de simulação. Isso significa que um evento da entidade $i$ para a entidade $j$ será enviado apenas pelo gerenciador de eventos do CloudSim, quando o tempo total de simulação atinge o valor de $t+d$, onde $t$ é o tempo de simulação quando a mensagem foi enviada originalmente, e $d$ é a latência de rede entre as entidades $i$ e $j$.

\subsubsection{Camada de Gerenciamento}


A camada de gerenciamento é responsável por tarefas de escalonamento, alocação e provisionamento das requisições nos data centers (executadas pela entidade Broker) e pelo monitoramento das cargas de trabalho e consumo de recursos.

A entidade Broker, nessa camada, atua como um agente de intermediação e possui políticas de escalonamento que tratam de critérios de $Q o S$ e também de classes de prioridade de serviços. O Broker de nuvem se posiciona como um mediador entre os clientes e os provedores de serviço de nuvem. No detalhamento de suas atividades, como agente de intermediação, podem-se citar três modos de operações básicas que foram implementadas na arquitetura CloudSim-BEQoS:

- Intermediação de serviço: Quando há a necessidade do Broker acrescentar um serviço, visando melhorar a qualidade de um já existente (QoS) ou é necessário prover um novo serviço para agregar valor aos consumidores, essa atividade é denominada de intermediação;

- Agregação de serviço: Agregar serviços é uma atividade que exige a combinação ou agrupamento de vários serviços de nuvem. Portanto, esse modo de operação é implementado para tratar de requisições que chegam em grupo. O Broker usa uma lista fixa de vários serviços de diferentes provedores de nuvem para compor uma solução, baseada em critérios de QoS;

- Arbitragem: Similar à agregação de serviços, com exceção de que os serviços que estão sendo agregadas não são fixos, ou seja, o Broker não usa uma lista fixa de vários serviços, ele tem a flexibilidade de escolher os serviços de várias agências ou provedores de serviços, baseado também em critérios de QoS, no momento em que grupos de serviços são solicitados.

O Broker implementado na CloudSim-BEQoS, possui também políticas de escalonamento orientadas à economia de energia, baseada na diferenciação de serviços (esse Broker é nomeado na arquitetura de PowerBroker). Neste caso, as requisições são classificadas com níveis de prioridades diferentes e de acordo com suas prioridades, elas são encaminhas às VMs. Por exemplo, se uma quantidade de 5 requisições, com prioridades mais baixas, chega ao sistema e essas requisições são alocadas em 5 máquinas virtuais, elas serão executadas em paralelo e durante este intervalo de tempo em que as requisições são processadas, pode haver um pico de demanda de potência. Alternativamente, essas 5 requisições podem ser enfileiradas para serem executadas em um única VM. Nessa última situação, os tempos de resposta das requisições são maiores, porém pode-se evitar picos de demanda de potência. Assim, 
dependendo do critério mais relevante ao cliente ou ao provedor de serviços, QoS ou eficiência energética, o Broker seleciona a VM mais adequada para atender uma requisição.

$\mathrm{Na}$ camada de gerenciamento encontram-se também as classes responsáveis pelo monitoramento do sistema. Existem três monitores implementados:

- Monitor de Carga de Trabalho: responsável por monitorar a taxa de chegada das requisições (em requisições por segundo) e a taxa de demandas de serviços (em Milhões de Instruções por Segundo - MIPs) encaminhadas ao Broker. Essas informações são repassadas ao método responsável por calcular a medida referente ao fator de rajada para cada intervalo de tempo definido - BF (Burstiness Factor), podendo ser intervalos de duração fixa ou variável. Essa medida, conforme apresentado na Seção 4.5, determina a ocorrência de rajadas em cargas de trabalho e, portanto, pode ser uma das métricas consideradas em modelos preditivos de desempenho que considerem o fenômeno de rajadas. A descrição da metodologia e o modelo matemático para o fator de rajada proposto neste projeto de doutorado será apresentada no Capítulo 7.

- Monitor de Recursos: responsável por monitorar o percentual de consumo de recursos de um data center (percentual de Mips). O Broker consulta esse monitor para obter o percentual de consumo de recursos antes de alocar uma requisição a uma VM. Desta forma, caso os recursos do data center privado estejam sobrecarregados ou o percentual tenha atingido um limite especificado (como argumento de entrada para a simulação), as requisições passam a ser encaminhadas ao data center público;

- Monitor de Energia: monitora o percentual de demanda de potência (em watts) consumida pelos recursos do data center privado. O Broker também pode consultar esse monitor para selecionar uma VM do data center privado ou público em que uma requisição será processada, baseada nas políticas de escalonamento voltadas para evitar altas demandas de consumo de energia.

\subsubsection{Camada de Infraestrutura}

O ambiente computacional em nuvem implementado adota o modelo de nuvem híbrida, composta de um data center privado e um data center público, como apresentado na Figura 5.1. No modelo em nuvem é implementada a técnica híbrida para provisionamento de aplicações conhecida como "Cloud-Bursting” (Calheiros et al., 2011) (Guo et al., 2012), considerando cenários em que critérios de QoS e prioridade devem ser atendidos. Nesse modelo 
pode-se utilizar recursos privados de menor custo, na maioria das vezes, e usar os recursos da nuvem pública apenas durante os períodos de pico de demanda, proporcionando um custo mais atrativo comparado a cenários onde se utiliza apenas uma nuvem privada ou pública.

\subsection{Projeto e Implementação da Arquitetura}

Nesta Seção são fornecidas informações relacionadas às classes implementadas que envolvem o projeto da arquitetura CloudSim-BEQoS. A visão geral do projeto de diagrama de classes é mostrada na Figura 5.7. Os retângulos representados na cor verde correspondem às classes que foram criadas e os retângulos representados nas cores amarela e azul são as classes da API original do CloudSim. No entanto, as classes de cor azul precisaram ser alteradas para inclusão de novos métodos, parâmetros, variáveis e atributos. As classes criadas são descritas a seguir:

- Cliente: classe responsável em instanciar as entidades clientes e enviar solicitações de serviços ao Broker de acordo com os modos de submissão das requisições (vetor de requisições, requisições em tempo real e grupo de requisições). Essa classe possui métodos para geração de think times e demandas de serviços de acordo com uma função de distribuição (para uma situação sem rajadas) ou geradas pelo processo MAP (para uma situação com rajadas através da referência a um objeto/instância das classes $\mathrm{MAP}_{\mathrm{IAT}}, \mathrm{MAP}_{\mathrm{SD}}$ e MAPsinc).

- MAPIAT: classe responsável em gerar amostras de think times seguindo o modelo MAP de dois estados.

- MAPSD: classe responsável em gerar amostras de tempos de serviços/demandas de serviços seguindo o modelo MAP de dois estados.

- MAPIatSdSinc: classe responsável em implementar rajadas originadas tanto no processo de chegada (think times) como na demanda de serviço (tempo de serviço), ocorrendo de forma sincronizada durante a simulação.

- MetaCloudletScheduler: classe responsável por selecionar as VMs de acordo com políticas de escalonamento orientadas a prioridade, a QoS, por serviços solicitados, por consumo de recursos e de energia e ainda a política de escalonamento Round-Robin.

- Qbroker: classe que representa a entidade Broker, onde são implementados os modos de operação (intermediação, agregação e arbitragem) para atendimento de requisições que chegam de forma individual ou em grupo. 
- PowerQbroker: extende a classe Qbroker, porém com funções orientadas a economia de energia.

- WorkloadMonitor: essa classe executa as funções do monitor de carga de trabalho. Nessa classe encontra-se também o método Burstiness Factor responsável por calcular o fator de rajadas para cada slot de tempo, fixo ou variável, baseado nas taxas de chegadas de requisições e de demandas de serviços.

- ResourceMonitor - classe responsável por monitorar os recursos da nuvem privada para coletar informações sobre o percentual de consumo (em \% de MIPs consumidos) do data center privado.

- PowerMonitor: classe que possui as funções de monitoramento do percentual de consumo de energia, em watts, dos recursos do data center privado.

- PowerIntelXeon2670 e PowerIntelXeon5650: classes com definições referentes ao consumo energético das unidades de processamento dos hosts instalados nos datacenters público e privado respectivamente. Essas informações são utilizadas pelo monitor de energia para calcular o percentual de consumo de energia do data center privado.

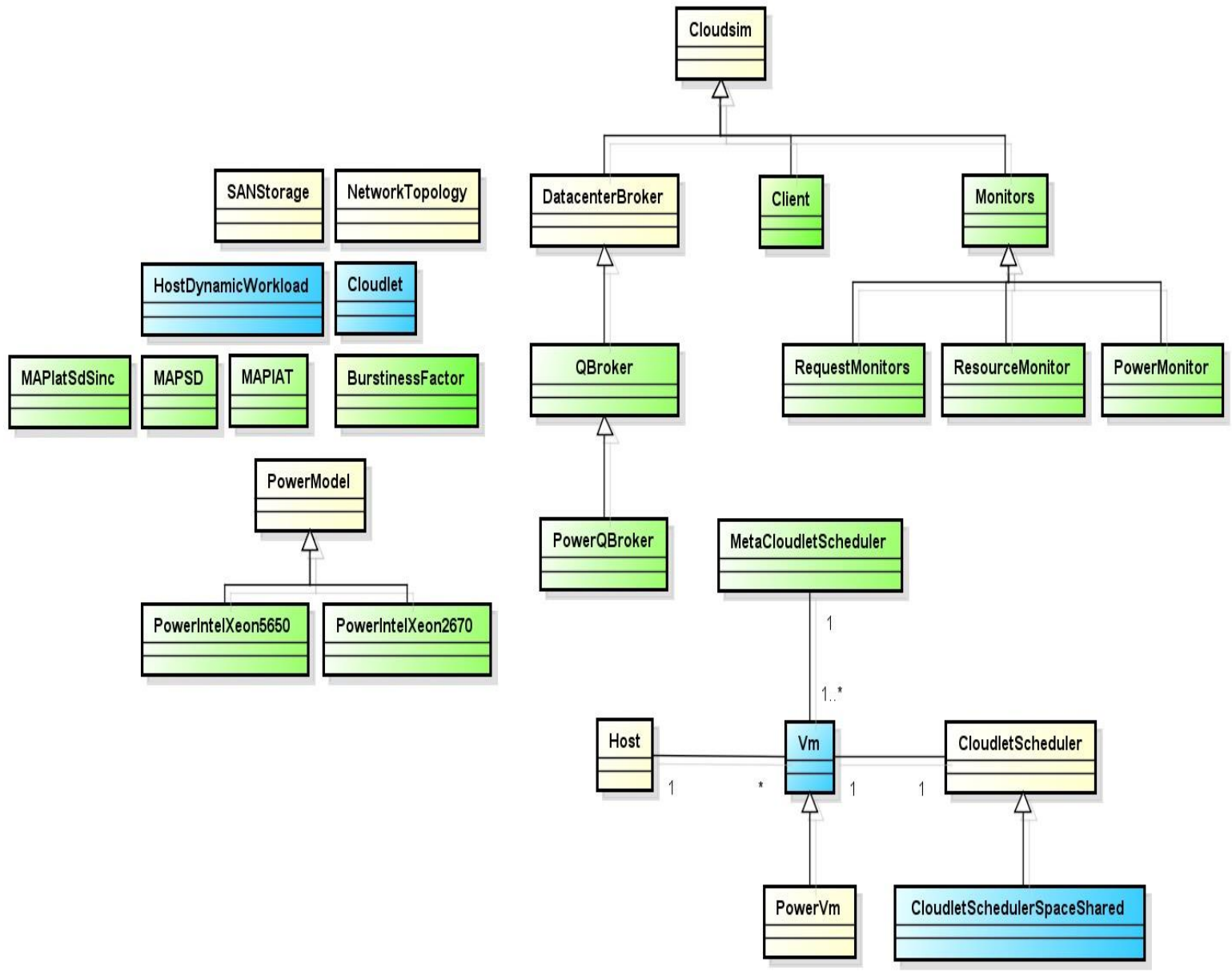

Figura 5.7 - Diagrama de classes do Projeto da Arquitetura. 
As classes já existentes na API do CloudSim que precisaram ser alteradas, foram as seguintes:

- VM: essa classe, a qual modela uma VM e suas configurações físicas, foi acrescentada uma lista de serviços, para que cada VM possa executar um ou mais serviços;

- Cloudlet: essa classe modela as requisições de serviços que são executados no ambiente de computação em nuvem, tais como: aplicações baseadas em contexto, rede social e aplicações baseadas em negócios. Todos os serviços têm instruções pré-atribuidas, por exemplo, tamanho (MI) e sobrecarga da transferência de dados, tanto de entrada como de saída. Foi necessário incluir novos atributos para essa classe, como:

- Identificação do serviço solicitado pela requisição (cloudlet);

- Identificação da prioridade da requisição, classificadas como: sem prioridade, prioridade baixa, média e alta;

- Identificação de grupos de requisições e o tamanho desses grupos;

- Inclusão de parâmetros de QoS (tempo máximo de execução de uma requisição);

- Inclusão do identificador do cliente que enviou a requisição;

- Inclusão do atributo para armazenar o tempo de chegada da requisição no Broker;

- Inclusão do atributo para armazenar o tempo de agendamento futuro para grupo de requisições dependentes.

- CloudletSchedulerSpacedShared: essa classe implementa a política SpacedShared que é uma das formas de compartilhamento dos recursos de processamento entre as requisições de uma VM. Nessa classe foi acrescentado um método para calcular quantos MIPS ainda faltam para finalizar sua execução. Esta informação é usada pelo Broker para determinar o tamanho de fila de uma VM, com objetivo de verificar se esta VM atende os requisitos de QoS de uma nova requisição.

- HostDynamicWorkload: classe de um host que suporta carga de trabalho dinâmica, usada pelo PowerBroker. Essa classe foi modificada para contabilizar a energia gasta pelo host do data center.

\subsection{Estudo de Caso Utilizando CloudSim-BEQoS}

Nesta Seção é apresentada uma avaliação de desempenho realizada para avaliar e exemplificar a utilização da arquitetura implementada e integrada à API do CloudSim. Desta forma, foi executado um conjunto de experimentos com o objetivo de avaliar como o sistema se comporta na presença de vários clientes concorrentes, em pontos geográficos distintos, considerando diferentes modos de submissão das requisições e considerando ainda a presença 
ou não de rajadas no processo de chegada das requisições. Cabe ressaltar que antes de realizar o estudo de caso apresentado nas próximas Seções, a CloudSim-BEQoS foi exaustivamente testada utilizando técnicas de validação para garantir sua eficácia.

\subsubsection{Experimentos}

Os testes realizados neste estudo foram organizados em três conjuntos de experimentos, conforme apesentado na Tabela 5.1. O primeiro conjunto de experimentos refere-se ao modo de submissão das requisições utilizado na simulação, considerando-se os modos de submissão individual das requisições, ou seja, vetor de requisições e requisições em tempo real, submissão de requisições em grupo, considerando requisições dependentes e independentes umas das outras e o modelo de envio das requisições seguindo o padrão da API CloudSim versão 3.0.1. O objetivo desses experimentos não é de comparar os resultados obtidos nos diferentes modos de submissão e sim mostrar como cada modo de submissão pode influenciar nas variáveis de resposta.

Tabela 5.1 - Conjunto de Experimentos

\begin{tabular}{|c|c|c|}
\hline $\begin{array}{l}\text { Conjunto de } \\
\text { Experimentos }\end{array}$ & Fatores & Níveis \\
\hline \multirow{5}{*}{1} & \multirow{5}{*}{ Modos de Submissão } & Vetor de Requisições \\
\hline & & Requisições em Tempo Real \\
\hline & & Grupo de Requisições Depedentes \\
\hline & & Grupo de Requisições Indepedentes \\
\hline & & CloudSim Padrão \\
\hline \multirow{4}{*}{2} & \multirow{2}{*}{ Processo de Chegada das requisições } & Sem Rajada \\
\hline & & Com Rajada \\
\hline & \multirow[t]{2}{*}{ Início do think time } & $\begin{array}{l}\text { Após chegada da Resposta completa da } \\
\text { requisição prévia }\end{array}$ \\
\hline & & Após envio da requisição prévia \\
\hline \multirow{2}{*}{3} & \multirow{2}{*}{ Latência de rede entre cliente e Broker } & Homogênea \\
\hline & & Heterogênea \\
\hline
\end{tabular}

O segundo conjunto de experimentos está associado ao modelo do processo de chegada das requisições, ou seja, sem ou com rajadas. Para a execução desses experimentos considerouse, para a situação sem rajada, a geração da sequência de think times, seguindo uma função de 
distribuição de probabilidade exponencial, com think time médio $\left(\lambda^{-1}\right)$ de 7 segundos e para a situação de cargas de trabalho com rajadas, as sequências de think times foram geradas pelo processo MAP de dois estados com média de 7 segundos e índice de dispersão (I) igual a 4000, com base nos estudos apresentados em (Mi et al., 2010) (Centurion et al., 2012). Para esses experimentos ainda existem duas opções avaliadas, aguardando um intervalo de tempo (think time) para o envio da próxima requisição imediatamente após a submissão da requisição anterior ou apenas após o recebimento da resposta completa da requisição prévia. Esse estudo tem como principal objetivo avaliar o impacto das rajadas, originidas no processo de chegada das requisições, no desempenho dos serviços executados em uma nuvem privada.

O terceiro conjunto de experimentos considera a latência de rede entre o cliente e o Broker. Para esses experimentos são considerados dois cenários: latência de rede homogênea e heterogênea. Desta forma, esse estudo possibilita avaliar o comportamento do sistema quando são considerados clientes em posições geográficas semelhantes ou distintas respectivamente.

O segundo conjunto de experimentos segue o planejamento fatorial completo, enquanto que o primeiro e terceiro conjunto de experimentos por possuir um fator, segue o planejamento de experimento simples. Esses dois tipos de planejamento de experimentos foram comentados na Seção 1.5 do Capítulo 1. Para todos os três conjuntos de experimentos realizados neste estudo, considerou-se uma quantidade de 100 clientes concorrentes responsáveis pela submissão das requisições de serviços distintos durante um tempo de simulação de 5000 unidades de tempo de simulação, representada em segundos no CloudSim. Cada cliente envia uma quantidade fixa de 100 requisições ao longo do tempo de simulação, no caso dos experimentos que adotam os modos de submissão vetor de requisições e grupo de requisições. Para os experimentos que consideram o modo de submissão em tempo real, a quantidade de requisições é variável, uma vez que o processo de envio ocorre durante todo o tempo de simulação. Cada requisição possui um tamanho ou demanda de serviço de 100.000 Milhões de Instruções (MI) para os modos de submissão individual. Para o modo de submissão em grupo, considerou-se grupos de 4 requisições, cada um com tamanho de serviço de 25.000 Milhões de Instruções.

Neste estudo foi considerada a adoção de um data center privado, composto por 10 servidores (hosts) físicos homogêneos, com a seguinte configuração física: seis unidades de processamento ou núcleos de arquitetura x86, com capacidade de processar 10.000 Milhões de Instruções por segundo (MIPS), 24 GB de memória primária, 147 GB de unidades de armazenamento e 16 placas de rede com taxa de transmissão de $10 \mathrm{GBit} / \mathrm{s}$ cada. Da mesma 
forma como os servidores físicos, foram consideradas máquinas virtuais homogêneas, gerenciadas pelo hipervisor Xen (Bhatt e Patel, 2012). Em todos os experimentos foram instanciadas 40 máquinas virtuais (VMs), cada uma com uma unidade de processamento de arquitetura x86 com capacidade para processar 10.000 MIPS, consumindo 4 MB de memória primária. Foram considerados também cinco serviços Web distribuídos de forma aleatória entre as VMs, onde cada VM era responsável pela execução de dois serviços Web distintos.

As variáveis de resposta analisadas neste estudo, considerou algumas medidas voltadas ao desempenho do serviço e do sistema, sendo elas:

- Tempo médio de resposta: intervalo de tempo entre o envio da requisição pelo cliente e chegada da resposta completa processada pela nuvem.

- Tempo médio de sistema: tempo em que a requisição permaneceu esperando na fila das VM para ser atendida mais o tempo de serviço da requisição na VM.

- Vazão (throughput) média: taxa média na qual as solicitações são atendidas pela nuvem privada, medida em requisições por segundo.

Na análise de resultados, Seção 5.5.2 são também apesentadas amostras da quantidade de chegadas de requisições, que foram monitoradas em intervalos de tempo de sete segundos durante a simulação e o percentual do consumo de recursos da nuvem privada, monitorados em intervalos de tempo de um segundo também ao longo da simulação.

\subsubsection{Avaliação dos Resultados}

Nesta Seção são apresentados os resultados obtidos com a execução dos experimentos. Para todos os experimentos foram realizadas 10 repetições utilizadas para determinar a média, o desvio padrão e o intervalo de confiança de $95 \%$ de acordo com a Tabela T-student.

\section{a) Modos de submissão das requisições}

Os resultados referentes aos experimentos que consideram os diferentes modos de submissão da nova entidade cliente e o modo padrão de envio das requisições do simulador CloudSim são apresentados neste item. Na Figura 5.8 são apresentados os tempos médios de resposta para cada um dos experimentos mencionados. 


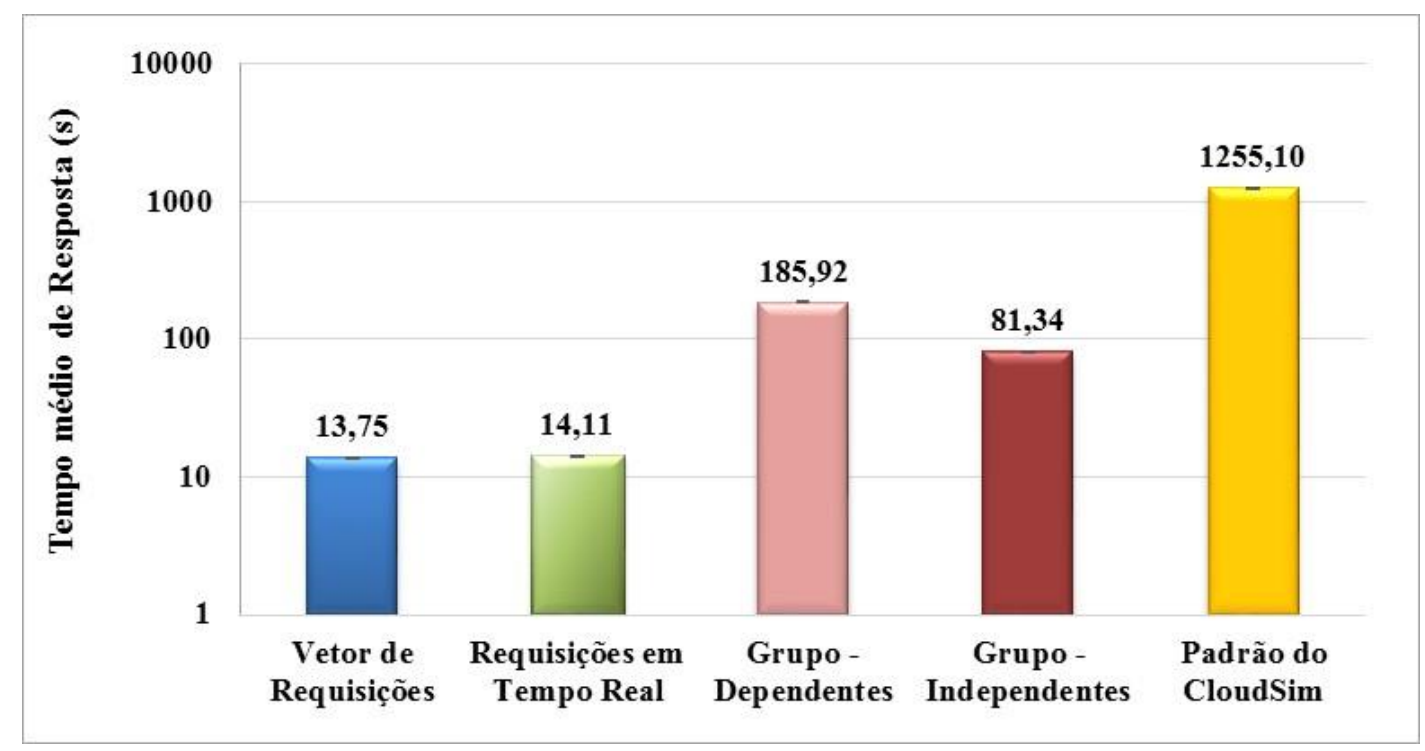

Figura 5.8 - Tempo médio de resposta em segundos dos diferentes modos de submissão

Como pode ser observado, os modos de submissão individuais, vetor de requisições e requisições em tempo real, apresentam resultados muito próximos. Os modos de submissão em grupo, dependentes e independentes, mostram tempos médios de resposta superiores aos modos de submissão individuais, em virtude das requisições serem enviadas em grupo, a fila nos recursos (VMs) torna-se maior. O modo de submissão em grupos dependentes apresenta um tempo médio de resposta maior que os grupos de requisições independentes. Isso ocorre pelo fato que no grupo dependente, as requisições possuem uma ordem de execução, de forma a aguardar o término das suas antecessoras, o que não acontece no grupo independente, onde as requisições não possuem uma ordem e podem executar em paralelo. Ainda na Figura 5.8 destaca-se o tempo médio de resposta usando o modelo de submissão padrão do CloudSim. Nota-se um significativo aumento desta variável de resposta quando comparado aos modos de submissão implementados na camada cliente. Esse aumento no tempo médio de resposta devese ao comportamento padrão do CloudSim, que envia todas as requisições de uma única vez, no início da simulação, provocando uma explosão inicial de demanda.

Os resultados obtidos para a variável de resposta tempo médio do sistema são apresentados na Figura 5.9. Observa-se que para todos os modos de submissão, assim como no padrão CloudSim, o fator que apresenta uma maior influência para a variável de resposta (tempo médio do sistema) é o tempo de fila na VM, enquanto que o tempo médio de serviço da tarefa, por possuir uma demanda de serviço homogênea, não apresentou uma variação significativa. 


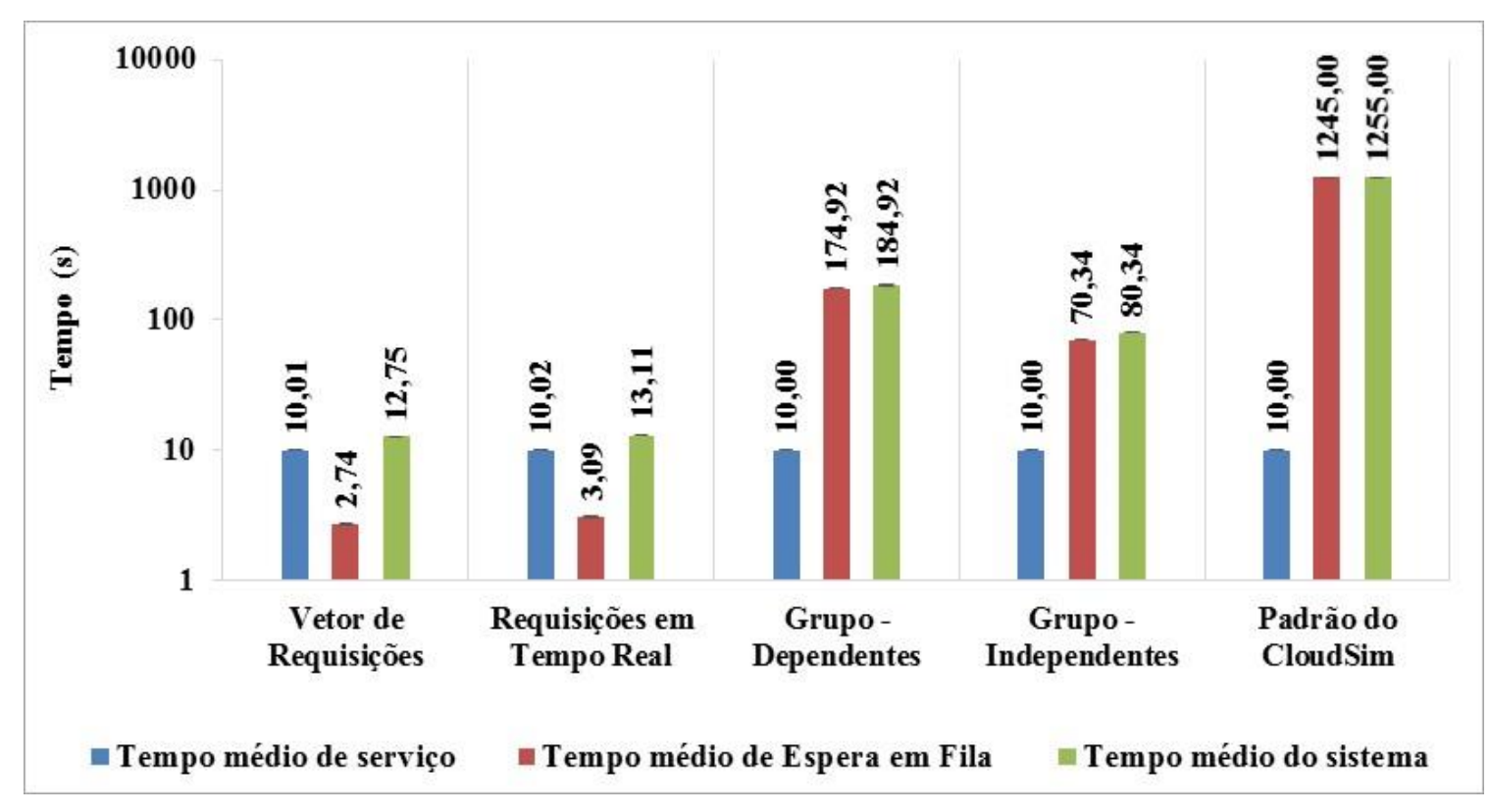

Figura 5.9 - Tempo médio do Sistema (em segundos) para os diferentes modos de submissão.

Na Figura 5.10 são apresentados os resultados da variável de resposta vazão média. É possível verificar que a menor vazão média é referente aos experimentos com clientes de grupo de requisições dependentes (com 1,85 requisições/segundo). A pouca vazão obtida no sistema de nuvem privada justifica-se pelo fato de que grupos dependentes ocasionam um atraso nas respostas devido à sincronização existente entre as requisições do grupo. O modelo padrão do CloudSim, apresenta um pequeno aumento na variável de resposta vazão média, em torno de 0,5\% quando comparado ao resultado obtido para grupos independentes e em torno de $9 \%$ quando comparado ao modo de submissão de requisições em tempo real. Esse resultado foi obtido porque o modo de submissão padrão do CloudSim não possui a latência de rede entre Cliente e Broker e nem o tempo de espera (think time) entre o envio de requisições sucessivas. Entretanto, é importante lembrar que as requisições nesse modelo são enviadas de uma vez só para serem processadas, o que é uma situação improvável que aconteça em serviços executados em ambientes de nuvens reais.

Nas Figuras 5.11, 5.12 e 5.13 são apresentadas amostras de execução de uma das repetições dos experimentos que consideram os modos de submissão individual de requisições (usando requisição em tempo real), em grupo (dependentes ou independentes) ou ainda submetidas conforme o padrão do simulador CloudSim. Na 5.11 são apresentados os tempos de resposta para cada requisição submetida para a nuvem privada. Os resultados obtidos refletem o comportamento já explanado para a variável tempo médio de resposta, onde os 
modos de submissão em grupo apresentam tempos de resposta maiores do que os obtidos para os modos de submissão individual. Além disso, na Figura 5.11 (d), observa-se para o modelo padrão de envio das requisições do CloudSim, que os tempos de resposta tendem a um crescimento linear.

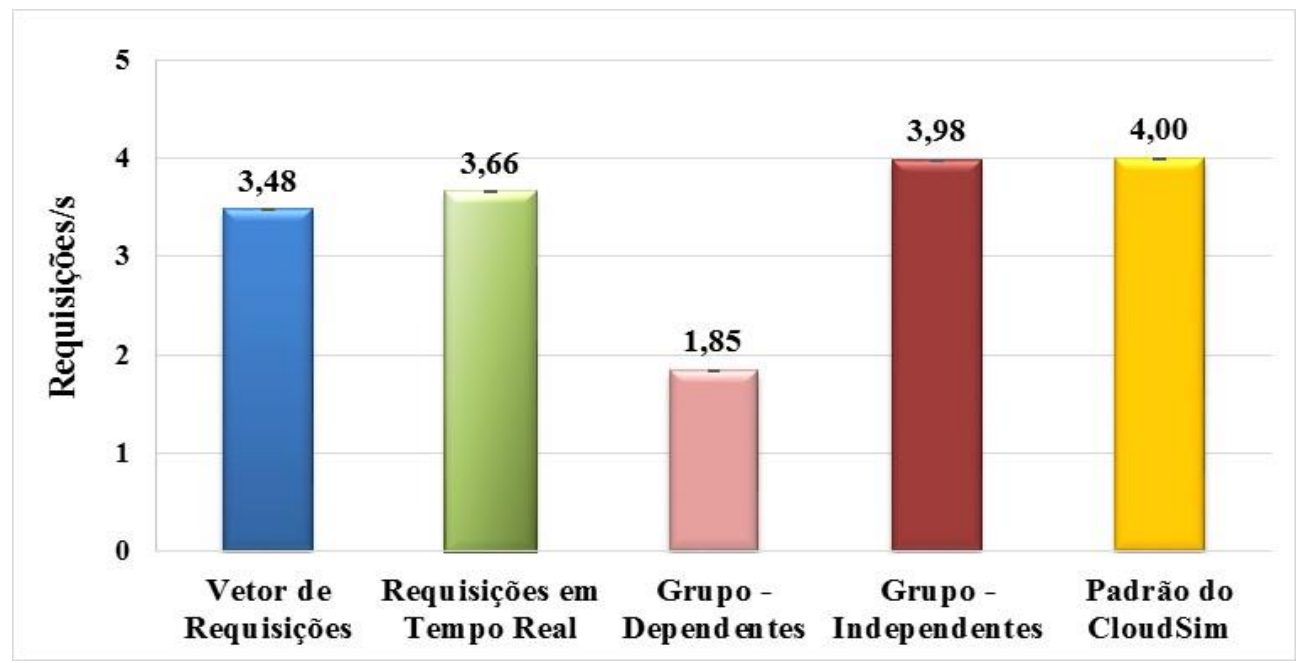

Figura 5.10 - Vazão média dos diferentes modos de submissão

(a) Requisições em Tempo Real

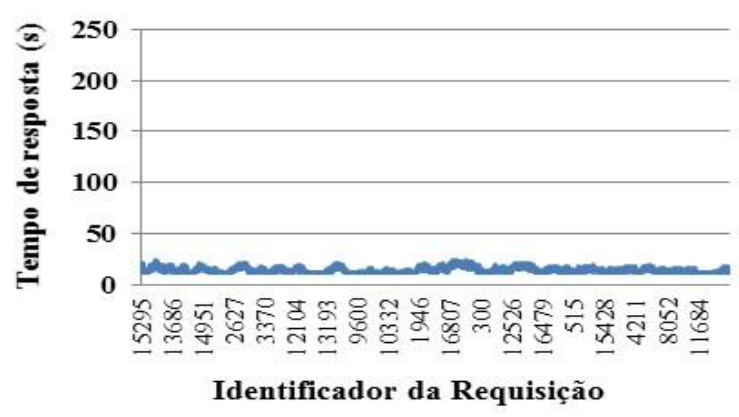

(c) Grupo - Independente

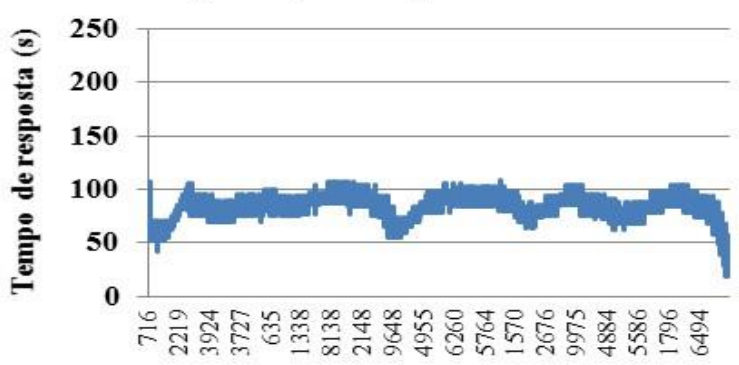

Identificador da Requisição (b) Grupo - Dependente

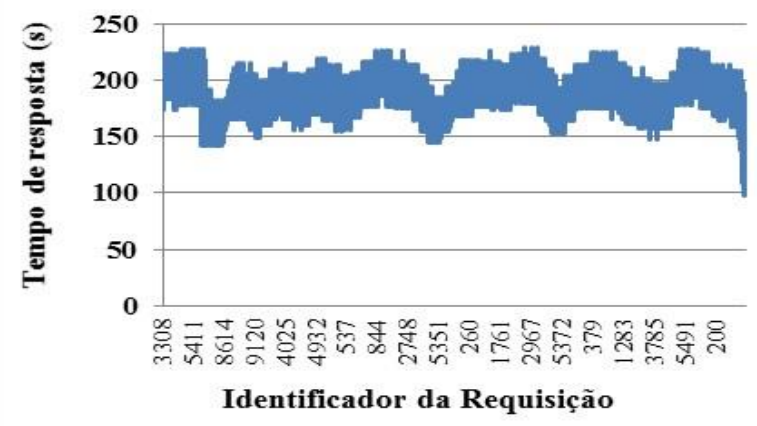

(d) Padrão API CloudSim

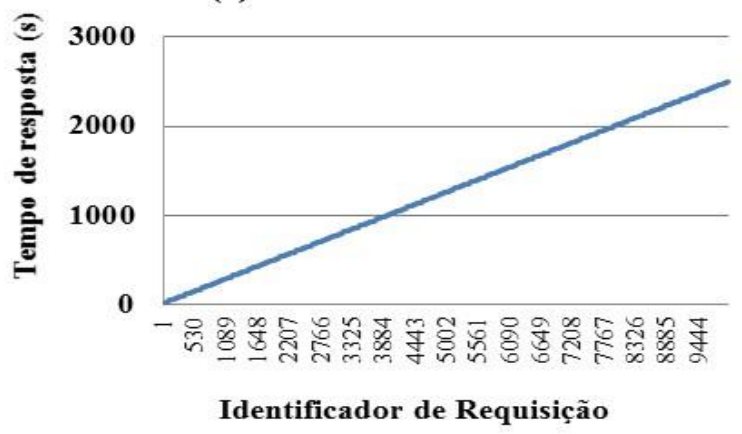

Figura 5.11 - Amostras dos tempos de resposta (s) dos diferentes modos de submissão. 
Na Figura 5.12 são expostos os resultados referentes às amostras da quantidade de chegadas de requisições monitoradas em intervalos de tempo de 7 segundos durante os experimentos de simulação. É possível destacar, conforme a Figura 5.12(c), que o resultado com grupos de requisições dependentes, apresenta uma quantidade de chegada de requisições menor que o grupo independente. Isto se deve pelo efeito causado pela ordenação da execução das tarefas, conforme mencionado anteriormente. Por outro lado, o número de chegadas de requisições nos experimentos com modo padrão CloudSim (Fig. 5.12(d)) apresenta um pico inicial de 10.000 requisições no primeiro instante de simulação e valor zero durante todos os demais instantes de simulação.

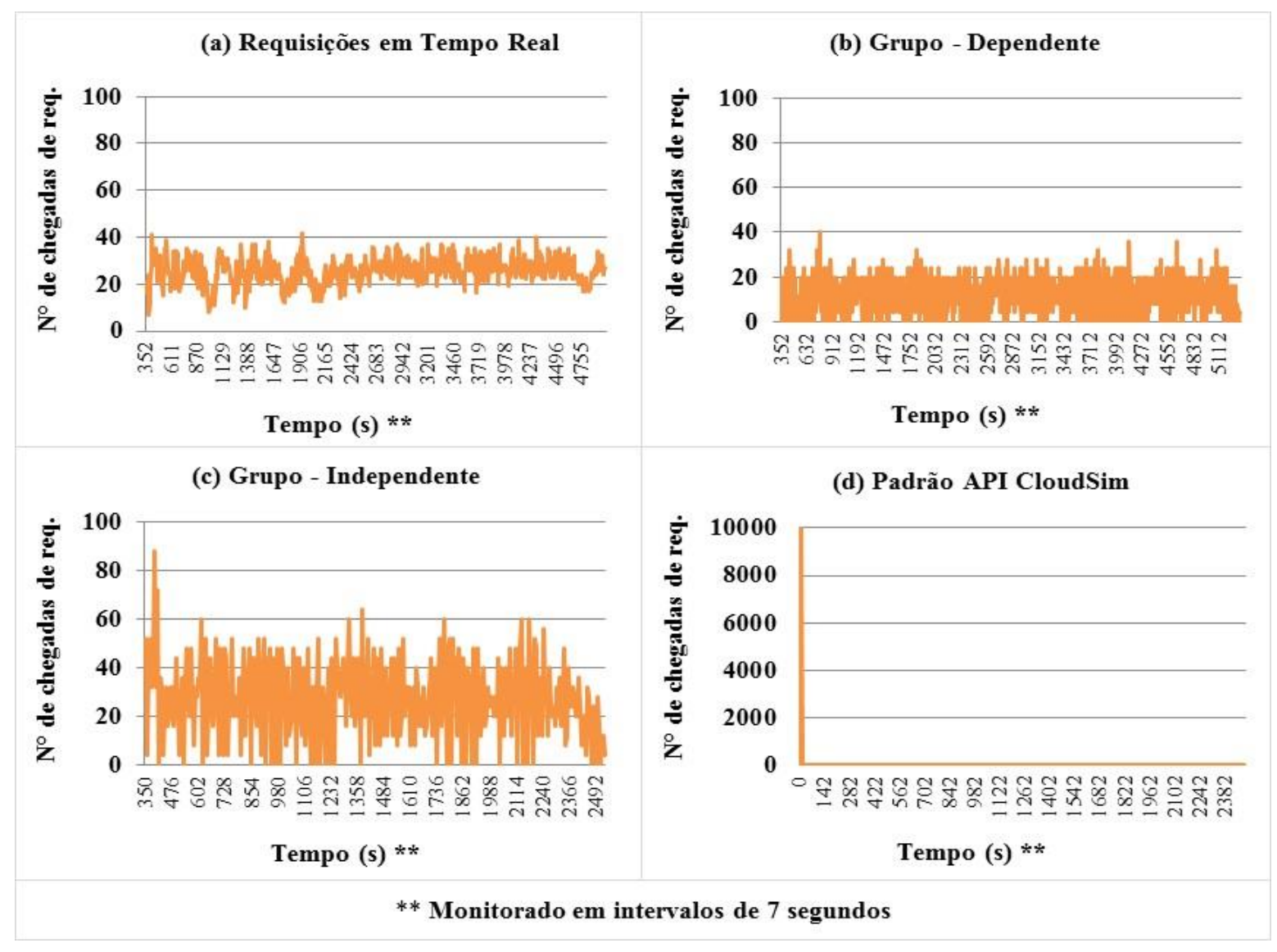

Figura 5.12 - Amostras do número de chegadas de requisições dos modos de submissão.

As amostras de percentual do uso de recursos no sistema de nuvem privada do ambiente simulado são apresentadas na Figura 5.13, os dados foram monitorados em intervalos de tempo de um segundo ao longo dos experimentos de simulação. Para o modo de submissão de requisições em tempo real, na Figura 5.13(a), percebe-se que em vários períodos durante a simulação, o consumo chega a 100\% de utilização. Esse consumo fica ainda mais elevado, 
quando considera-se grupos de requisições independentes (Figura 5.13(c)). Isso acontece devido à execução paralela das requisições. Por outro lado, quando as requisições em grupo possuem dependência (Figura 5.13(d)), há uma redução no percentual de consumo de recursos, devido à sincronização de tarefas que faz com que as VMs fiquem em determinados períodos em regime de espera ociosa. É possível notar também, na Figura 5.13(d), o alto consumo de recursos evidenciado no modo de submissão de requisições padrão do CloudSim. Esse alto consumo é provocado pela grande quantidade de requisições de serviços que são submetidas, sendo todas no mesmo instante de tempo, o que deixa todos os recursos ocupados durante praticamente toda a simulação.

(a) Requisições em Tempo Real

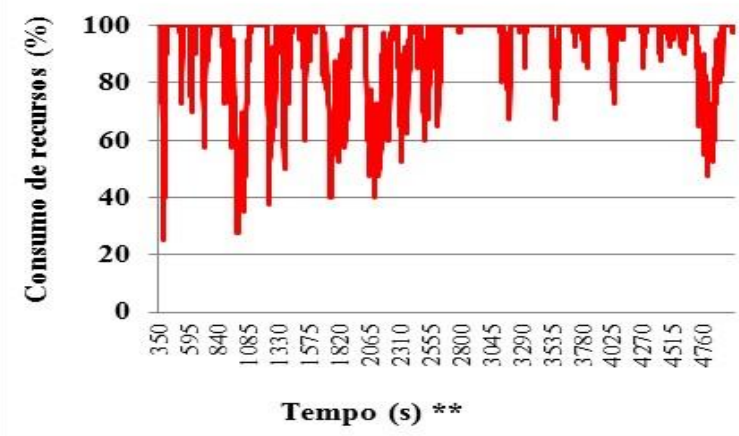

(c) Grupo - Independente

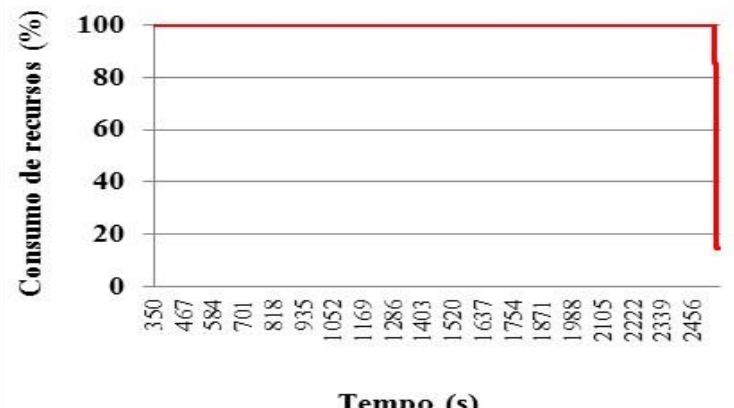

(b) Grupo - Dependente

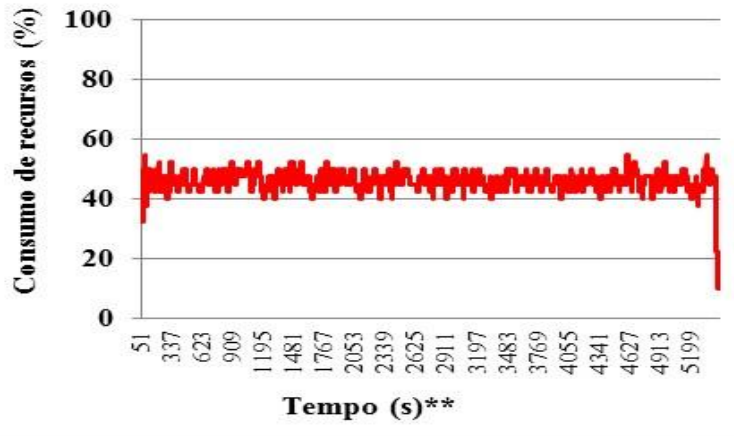

(d) Padrão API CloudSim

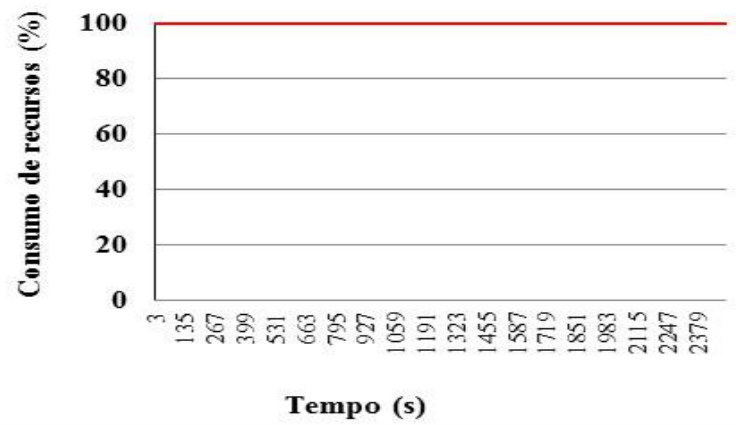

** Monitorado em intervalos de 1 segundo

Figura 5.13 - Amostras do percentual de consumo dos recursos dos modos de submissão.

\section{b) Fenômeno de Rajadas}

Sistemas submetidos a cargas de trabalhos que se apresentam em rajadas podem afetar severamente o desempenho de um provedor de serviços, conduzindo a uma significante sobrecarga dos servidores, aumento descontrolado nos tempos de respostas e no pior caso, indisponibilidade do serviço. Desta forma, um conjunto de experimentos propostos neste trabalho considera situações em que a carga de trabalho se apresenta ou não em forma de 
rajadas. Para esses experimentos, o ambiente de simulação foi configurado para ser executado com o modo de submissão vetor de requisições e latência de rede homogênea de 500 milisegundos entre Cliente e Broker. Além disso, foram consideradas ainda duas configurações distintas para os intervalos de chegadas entre as requisições ou think times. Na primeira configuração considerou-se que os think times acontecem apenas após a chegada da resposta completa da requisição anterior e na segunda configuração os think times ocorrem imediatamente após o envio de uma requisição prévia. Os resultados obtidos com a execução desses experimentos são apresentados a seguir.

\section{Cargas Com e Sem rajadas, com Think Times Aguardando Resposta}

Na Figura 5.14 são apresentados os resultados obtidos para as variáveis de resposta analisadas neste trabalho considerando situações com e sem rajadas de requisições e com think times após a chegada da resposta completa da requisição anterior.

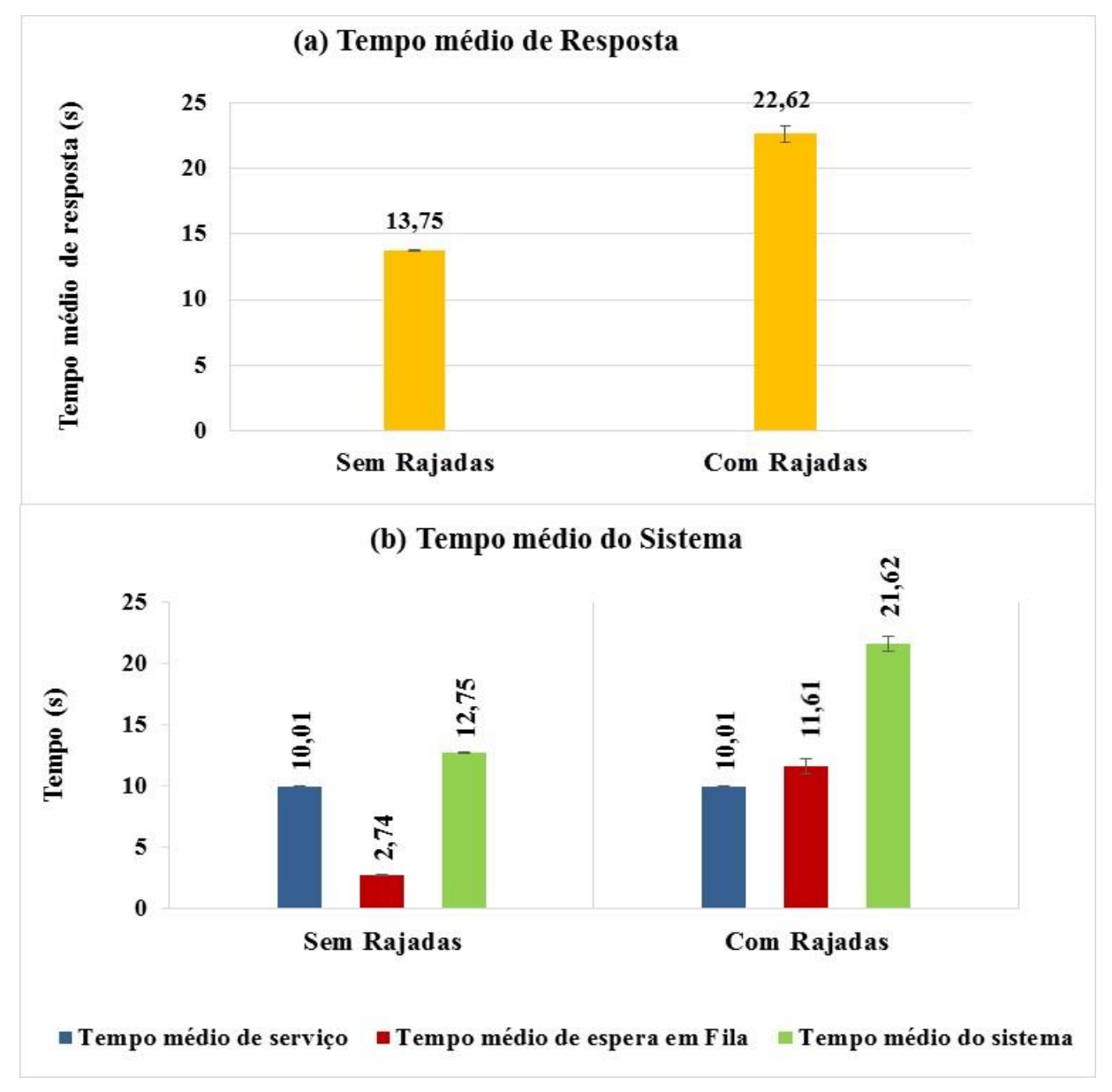

Figura 5.14 - Resultados obtidos para cargas de trabalho com e sem rajada e com think times ocorrendo após recebimento de resposta da requisição anterior. 
O tempo médio de resposta obtido nesses experimentos é ilustrado no gráfico da Figura 5.14(a). Quando são geradas cargas de trabalho com rajadas, há um aumento no tempo médio de resposta em torno de $64 \%$ quando comparado a situações sem rajadas. Isso ocorre, pois em determinados períodos ao longo do tempo, há um aumento inesperado de novas solicitações de serviços, impactando assim, no tempo requerido para atendimento dessas solicitações. Este impacto das rajadas no desempenho do serviço fica ainda mais evidente nos resultados referentes aos tempos médios do sistema, apresentado na Figura 5.14(b). Observa-se que quando a carga de trabalho se comporta em rajadas, há um aumento no tempo médio de espera na fila da VM de mais de $300 \%$ e consequentemente um aumento de aproximadamente $70 \%$ no tempo médio de sistema. Esses resultados confirmam que a presença de rajadas no processo de chegada das requisições apresenta um impacto negativo no desempenho do serviço.

Os gráficos ilustrados na Figura.5.15 mostram os tempos de resposta das requisições enviadas à nuvem privada, em tempo de execução, observados durante a execução de uma das repetições dos experimentos considerados nesta subseção. O intuito dessa comparação é demonstrar como o desempenho pode ser afetado quando as requisições chegam na forma de rajadas. Como pode ser observado no gráfico da Figura 5.15(b), há momentos em que picos fortes e irregulares em diferentes escalas de tempo aparecem quando são criadas condições de rajadas. Este comportamento não acontece com a mesma intensidade nos casos em que não há rajadas no processo de chegada das requisições, como pode ser observado no gráfico ilustrado na Figura 5.15(a).

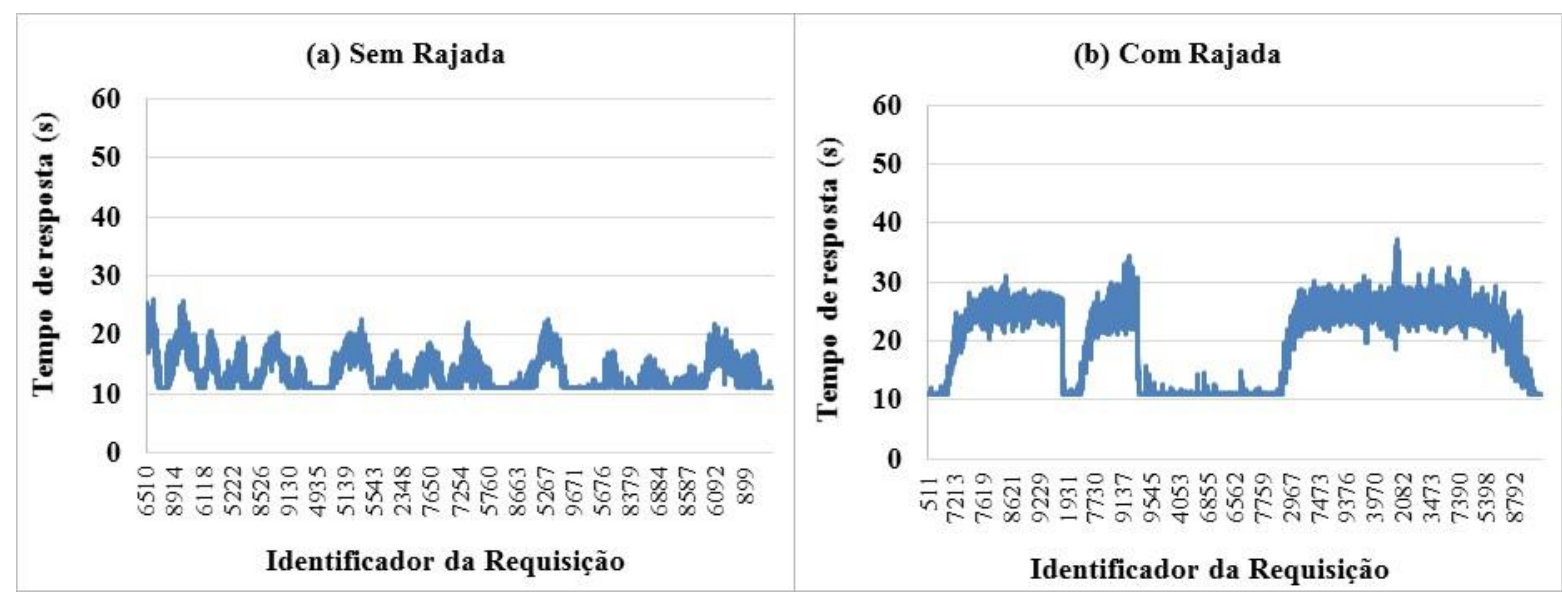

Figura 5.15 - Amostras dos tempos de respostas, considerando think times após recebimento da resposta completa da requisição prévia. 
Nas Figuras 5.16 e 5.17 são apresentadas amostras referentes à quantidade de requisições recebidas pelo Broker e percentual de consumo de recursos da nuvem, respectivamente. Ambas as medições apesentadas na Figura 5.16(b) e 5.17(b), para os casos onde as requisições de serviços chegam em forma de rajadas, observam-se a presença de picos irregulares e de diferentes intensidades e uma maior variabilidade nos resultados obtidos. Quanto aos resultados apresentados para cargas sem rajadas, percebe-se na Fig. 5.17(a) uma sobrecarga no consumo de recursos, entretanto, com menor intensidade quando comparada à sobrecarga imposta aos recursos em períodos em que surgem rajadas.

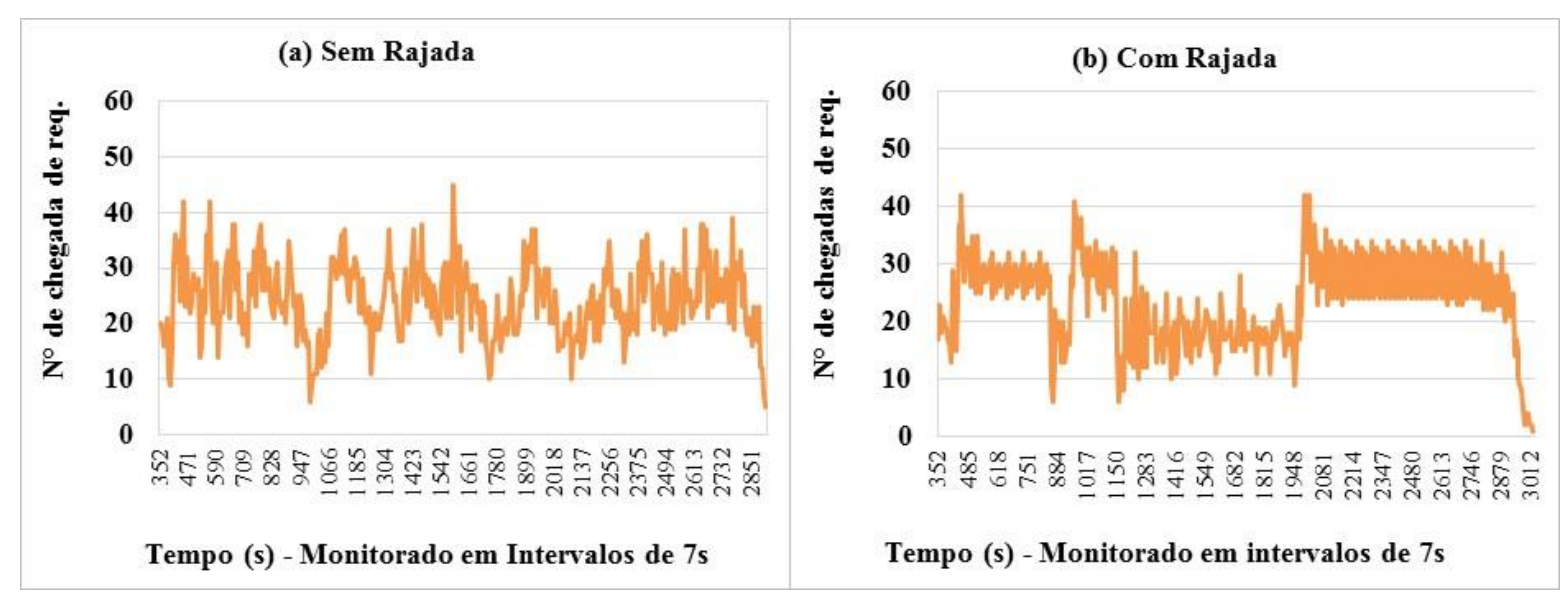

Figura 5.16 - Amostras do número de requisições que chegam, monitoradas em intervalos de $7 \mathrm{~s}$, considerando think times após recebimento da resposta completa da requisição prévia.

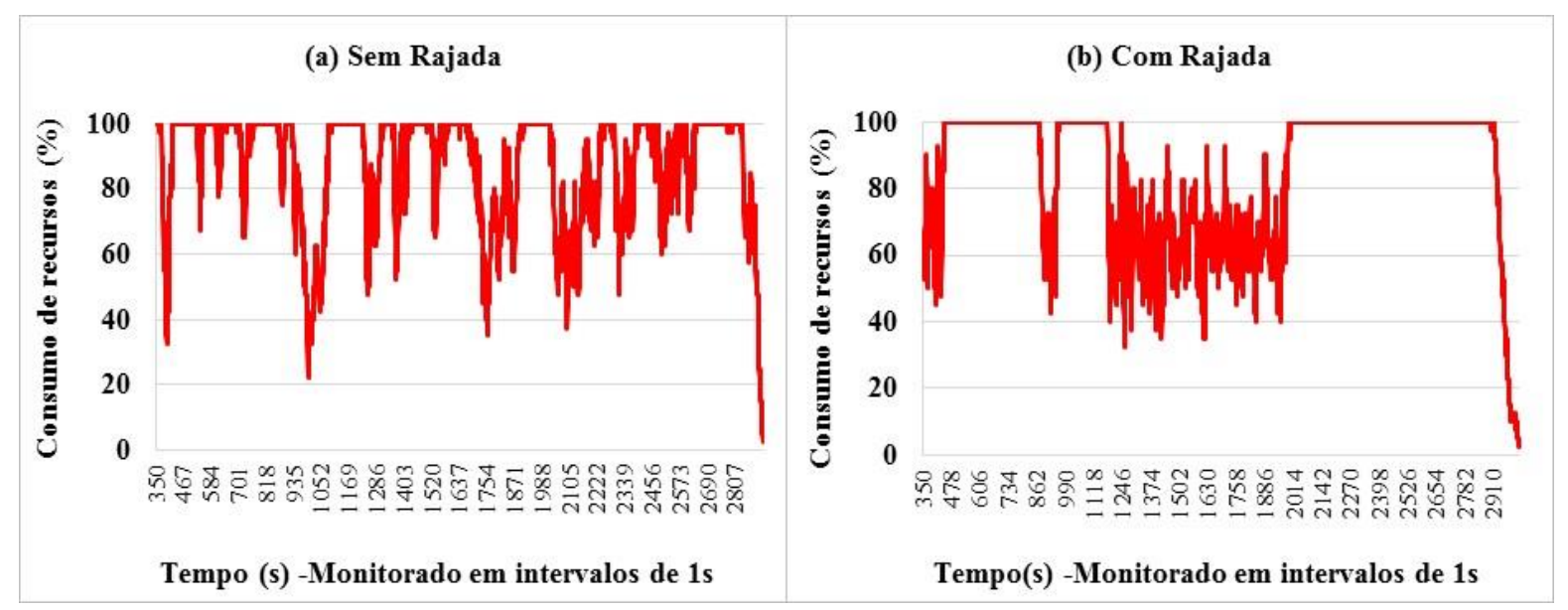

Figura 5.17 - Amostras do percentual de consumo de recursos, monitoradas em intervalos de 1s, considerando think times após recebimento da resposta completa da requisição prévia. 


\section{Cargas Com e Sem Rajadas, com Think Times após o Envio da Requisicão Prévia}

Os experimentos analisados nesta subseção, consideram também modelos de cargas de trabalho que incorporam ou não rajadas no processo de chegada das requisições. Entretanto, para estes experimentos considera-se que os intervalos de chegada entre duas requisições sucessivas não ocorrem após a chegada da resposta completa da requisição anterior, mas sim, imediatamente após o envio da requisição anterior.

De modo similar aos resultados analisados anteriormente, quando são geradas cargas de trabalho com rajadas, os tempos médios analisados tornam-se piores, entretanto com um impacto ainda mais expressivo do que foi observado para as variáveis de resposta analisadas para situações em que os think times aguardam a chegada da resposta. Na Figura 5.18(a), observa-se um aumento em torno de $84 \%$ no tempo médio de resposta, quando considera-se cargas de trabalho com rajadas.

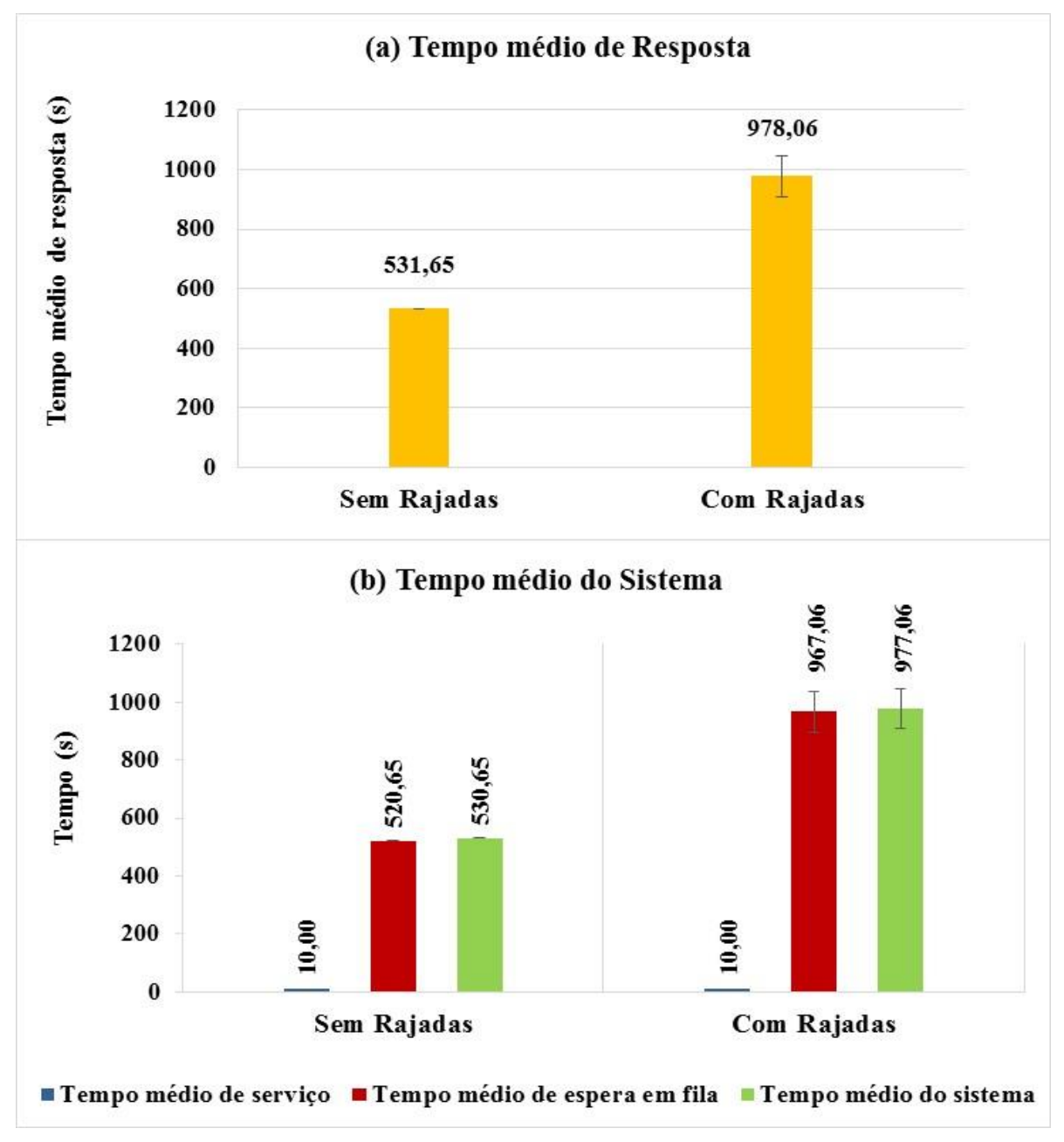

Figura 5.18 - Resultados obtidos para - cargas de trabalho com e sem rajada e com think times ocorrendo após submissão da requisição anterior. 
Ainda para situações com rajadas, na Figura 5.18 (b), há um aumento significativo no tempo médio de espera na fila da VM para atendimento das requisições. Esse impacto mais severo está relacionado à forma com que os think times foram configurados, como esses tempos não aguardam a chegada da resposta das requisições para serem iniciados, o tempo entre o envio de uma requisição e outra se torna menor.

Os resultados ilustrados nos gráficos das Figuras 5.19, 5.20 e 5.21, apresentam amostras, observadas durante a execução de uma das repetições dos experimentos, referentes aos tempos de resposta das requisições, número de requisições recebidas em intervalos de sete segundos e percentual de consumo de recursos, monitorados a cada um segundo. Pode ser observado na Figura 5.19 que, tanto para a situação com rajadas, como sem rajadas, há um aumento dos tempos de resposta das requisições ao longo do tempo. Isso acontece pois, nos experimentos considerados, para cargas sem rajadas o modelo de geração de think times segue uma função de distribuição de probabilidade exponencial com think time médio de sete segundos e para cargas de trabalho com rajadas, as sequências de think times são geradas por uma classe MAP de dois estados, também com média de sete segundos. Assim, o intervalo de chegada entre as requisições, em média, é inferior ao tempo médio de serviço das requisições (tempo de serviço), que conforme mostram os resultados é de dez segundos. Essa situação acaba provocando um acúmulo de tarefas nas filas dos recursos (VMs) e consequentemente, um crescente aumento no tempo de espera em fila que as requisições precisam aguardar antes de serem atendidas e respondidas aos clientes. Nas Figuras 5.20(b) e 5.21(b) nota-se que quando são introduzidas rajadas no processo de chegada das requisições, surgem picos ainda mais severos e de intensidades variáveis na quantidade de requisições que chegam ao sistema e também uma significativa sobrecarga no consumo de recursos que se mantem praticamente durante toda a simulação.

Como pôde ser observado nos resultados apresentados, uma das caraterísticas importantes a ser destacada para as cargas de trabalho em rajadas e é que elas chegam ao sistema com alta variabilidade em um determinado espaço de tempo, causando um impacto no desempenho do serviço. 


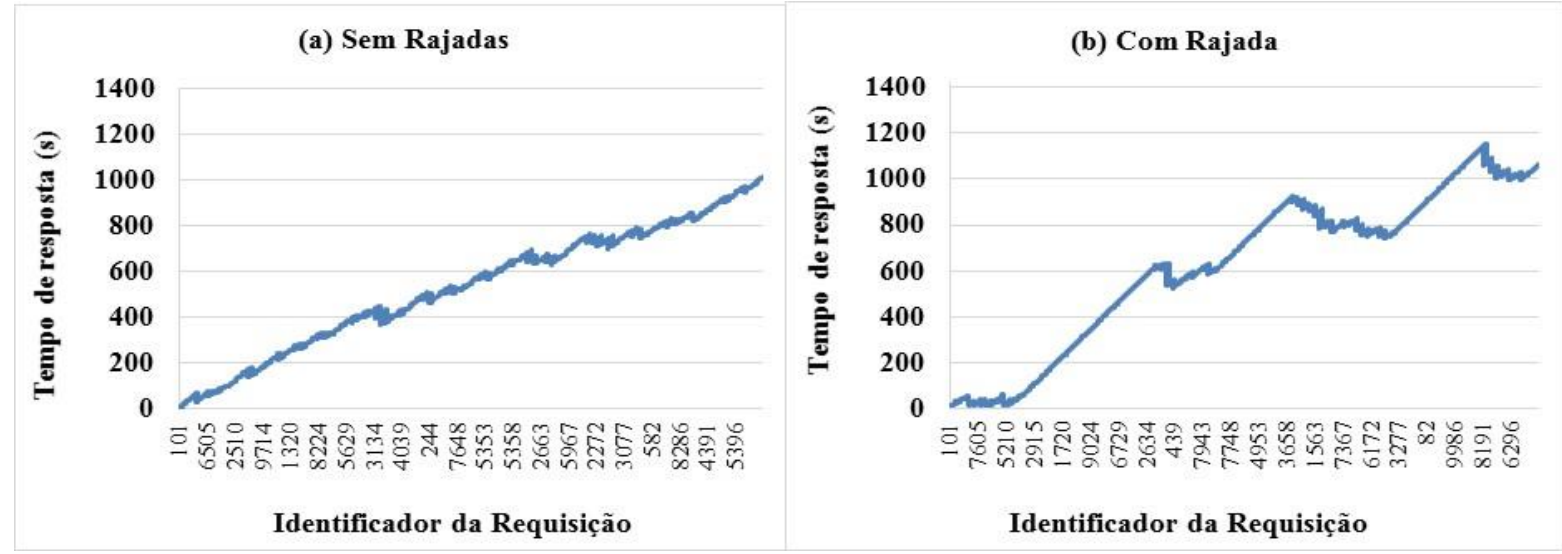

Figura 5.19 - Amostras dos tempos de respostas, considerando think times imediatamente após o envio da requisição prévia.
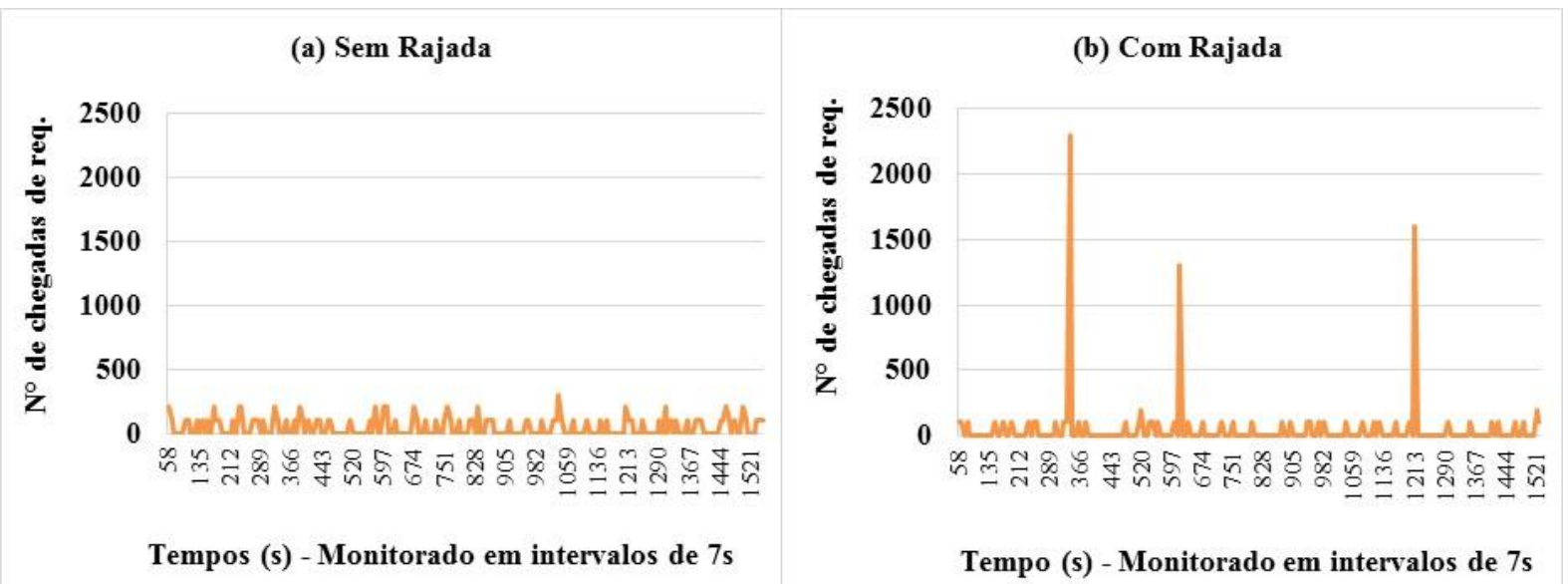

Figura 5.20 - Amostras do número de requisições que chegam, monitoradas em intervalos de $7 \mathrm{~s}$, considerando think times imediatamente após o envio da requisição prévia.
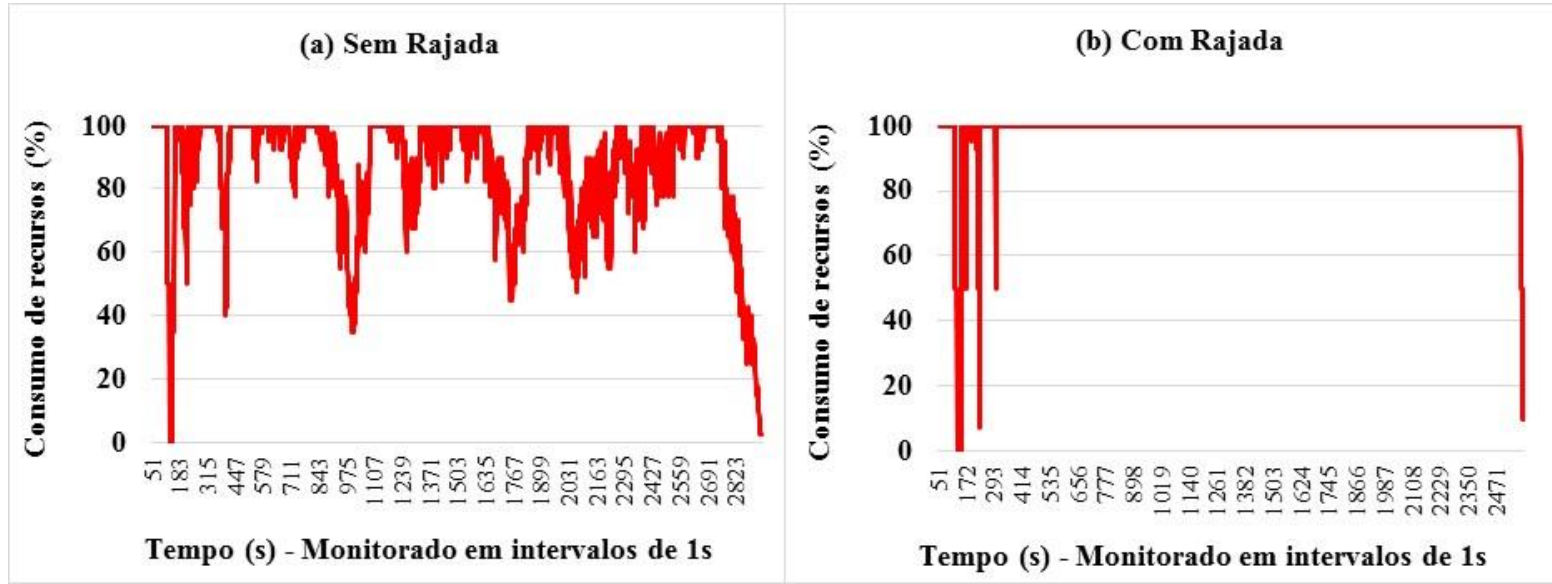

Figura 5.21 - Amostras do percentual de consumo de recursos, monitoradas em intervalos de 1s, considerando think times imediatamente após o envio da requisição prévia. 


\section{c) Latência de rede}

Experimentos de simulação considerando a presença da latência de rede entre as entidades Cliente e Broker são apresentados neste item. Nestes experimentos é considerado o modo de submissão vetor de requisições e os parâmetros adotados para as latências de rede foram: a latência homogênea foi configurada com valor fixo em 500 milissegundos e a latência heterogênea foi configurada através de valores aleatórios gerados no intervalo de 0 (zero) a 2000 milissegundos.

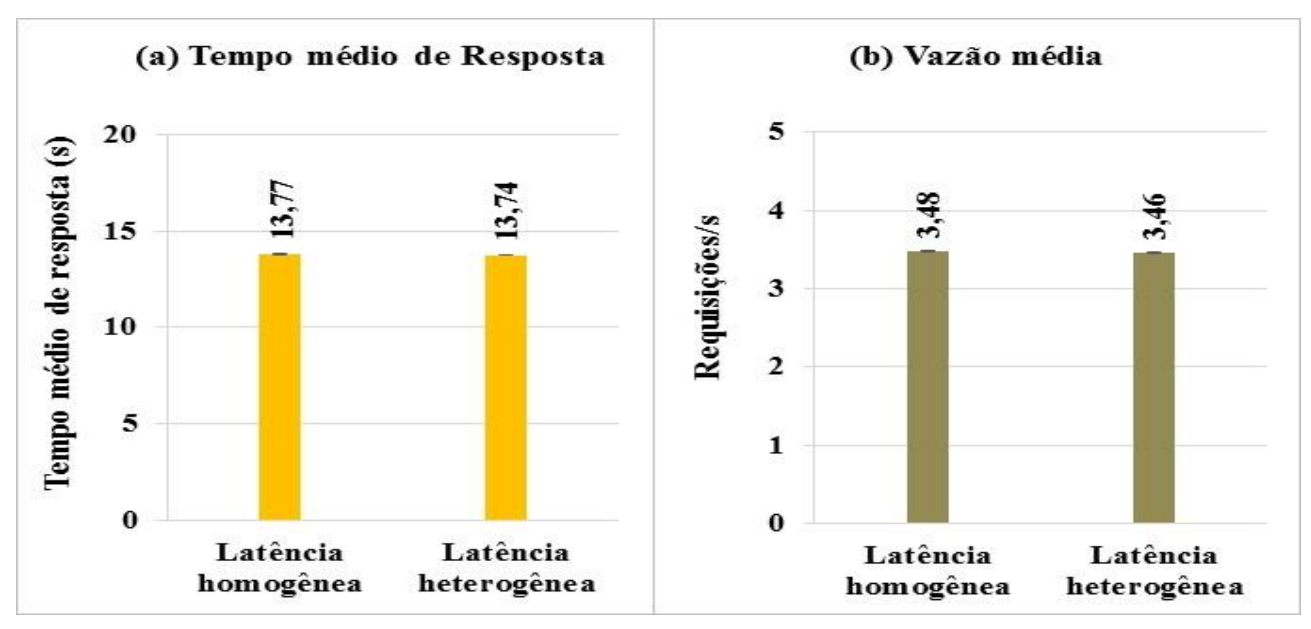

Figura 5.22 - Tempos médios de resposta e vazão obtida para os experimentos que consideraram latência de rede entre cliente e Broker homogênea e heterogênea.

Observa-se, na Figura 5.22(a) que o tempo médio de resposta, quando considerou-se latência de rede heterogênea, apresentou uma ligeira diminuição em relação ao da latência homogênea. Entretanto, a vazão média obtida, apresentada na Figura 5.22(b), foi um pouco menor para situações onde utilizou-se latência heterogênea. Isso ocorreu para ambas variáveis de resposta, pois como a latência média obtida para a configuração heterogênea, ilustrada no gráfico da Figura 5.23, foi maior em relação à latência média obtida para a configuração homogênea (afetando assim a vazão média), as requisições sucessivas foram submetidas à nuvem com um delay um pouco maior, suavizando assim, o tempo médio de espera em fila para serem atendidas (e reduzindo com isso o tempo médio de resposta). Esse comportamento pode ser observado na 5.23, onde são apresentados os resultados obtidos para o tempo médio do sistema (que representa a soma do tempo médio de serviço mais o tempo médio de espera na fila da VM) e a latência média. É possível verificar que o tempo médio de serviço nas VMs são quase constantes, em virtude das tarefas possuírem uma demanda homogênea, assim como os recursos da nuvem também serem homogêneos. Enquanto que, para latência de rede 
homogênea, o tempo médio de espera em fila apresentou um aumento em relação à latência de rede heterogênea.

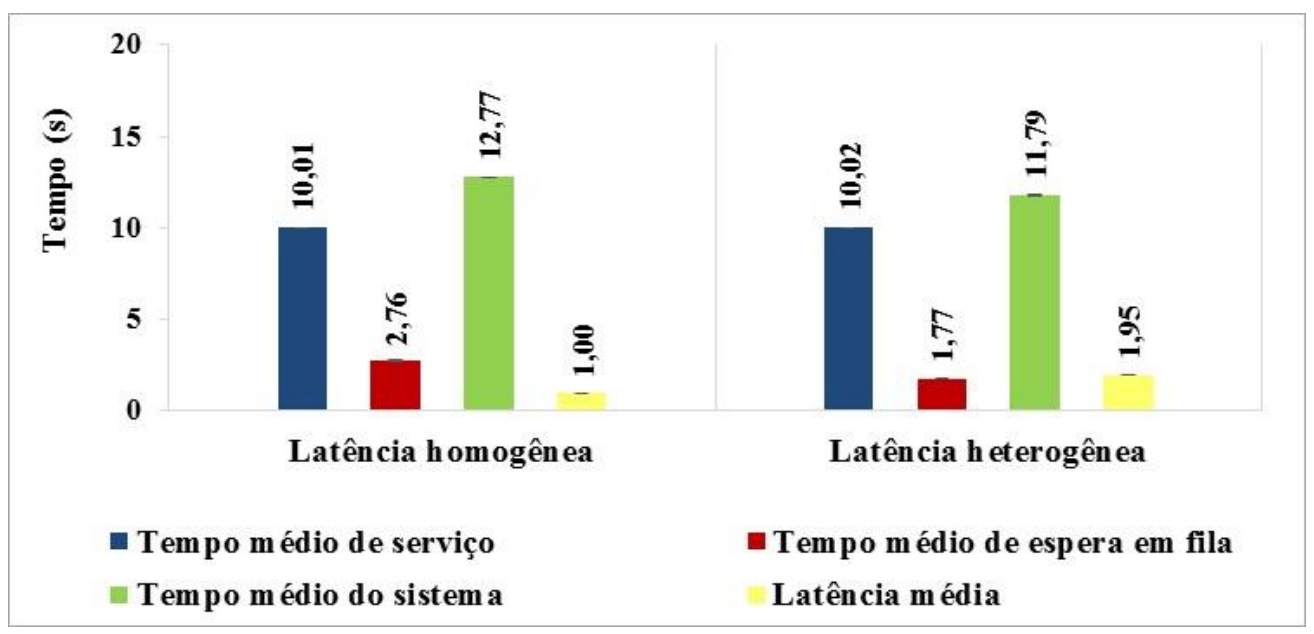

Figura 5.23 - Tempo médio do sistema - experimentos que consideraram latência de rede entre cliente e Broker homogênea e heterogênea.

A Figuras 5.24 e 5.25 apresentam os resultados amostrais dos tempos de espera em fila e a quantidade de requisições que chegam ao Broker, obtidos durante o tempo de simulação, para os experimentos que consideraram latência homogênea e heterogênea. Na Figura 5.24 é possível observar, conforme mencionado anteriormente, que os tempos de espera em fila para latência homogênea apresentam um aumento para a maioria das requisições processadas em relação à latência heterogênea.

(a) Latência Homogênea

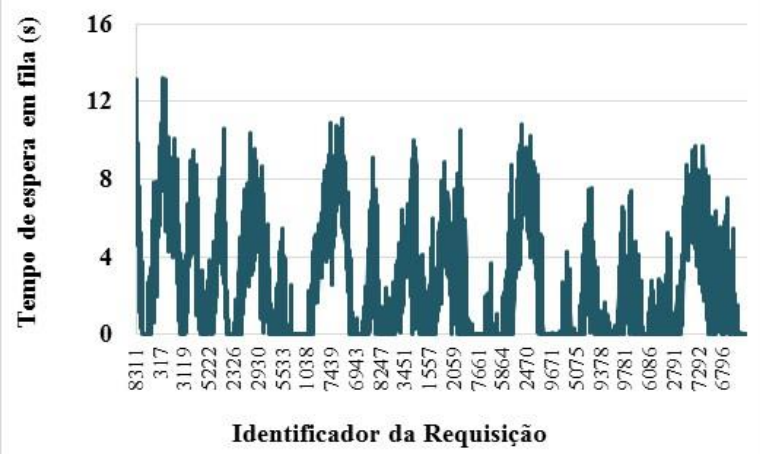

(b) Latência Heterogênea

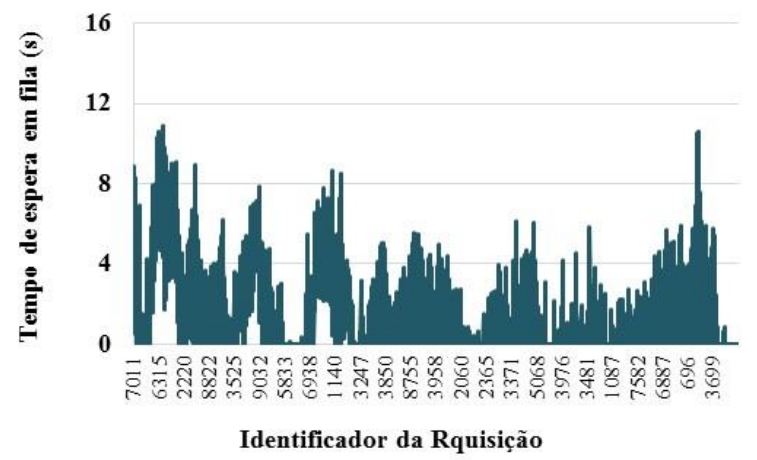

Figura 5.24 - Amostras dos tempos de espera em fila (s), considerando latência de rede (a) homogênea, (b) heterogênea. 


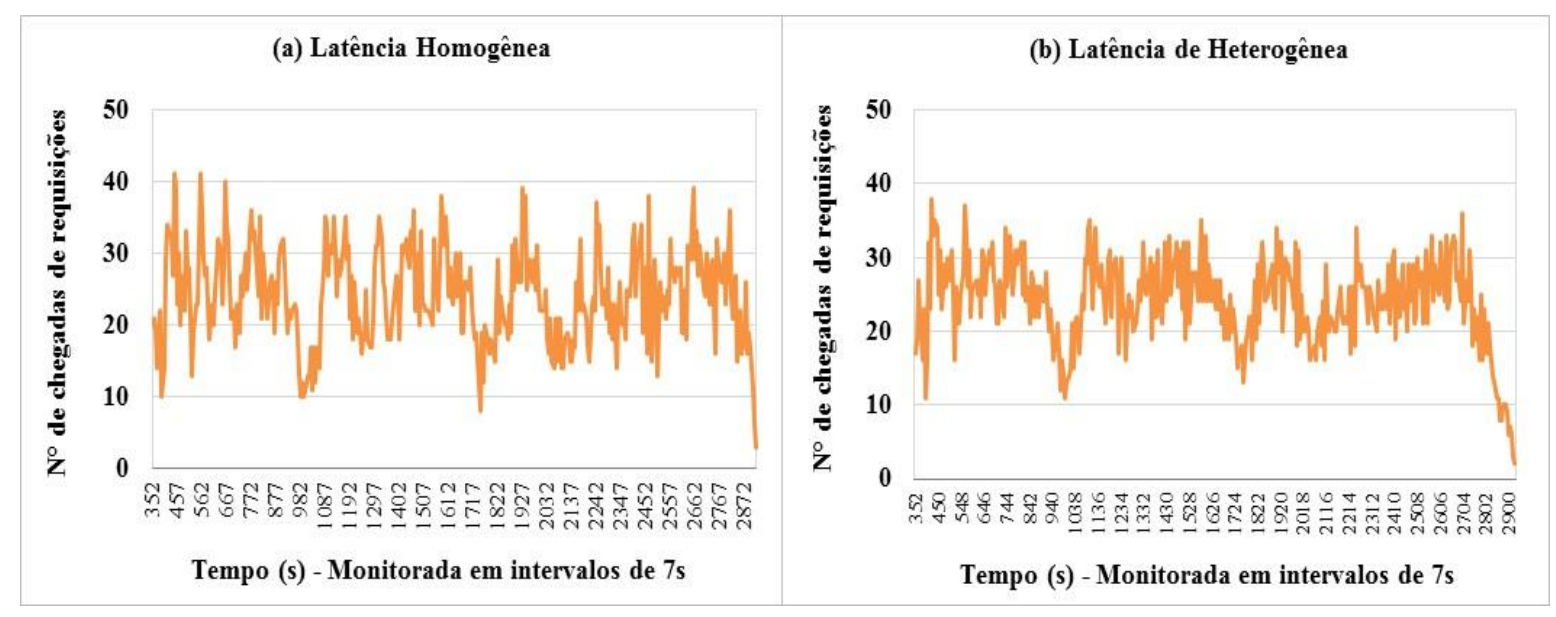

Figura 5.25 - Amostras do número de chegadas de requisições, monitoradas em intervalos de 7 segundos, considerando latência de rede: (a) homogênea, (b) heterogênea.

\subsection{Considerações Finais}

Este Capítulo apresentou a arquitetura CloudSim-BEQoS, incluindo uma descrição detalhada dos seus componentes. Com o desenvolvimento desta arquitetura torna-se possível avaliar o impacto das rajadas no desempenho dos serviços executados em nuvem, através da implementação de diferentes modelos de cargas de trabalho. Além disso, o Broker é projetado para atuar como um agente de intermediação, de modo a garantir critérios de QoS aos clientes da nuvem e evitar picos de demandas de energia, baseado em políticas de escalonamento com diferenciação de serviços.

Foi também apresentada uma avaliação de desempenho com o objetivo de avaliar como o sistema se comporta na presença de vários clientes concorrentes, considerando diferentes modos de submissão das requisições e também o fenômeno de rajadas no processo de chegada das requisições.

Os próximos Capítulos (6 e 7) desta tese focam, particularmente, em um conjunto de experimentos realizados nesta arquitetura. No Capítulo 6 é apresentada uma avaliação de desempenho, com o objetivo de mostrar a influência das rajadas, de diferentes origens e diferentes níveis de variabilidade e intensidade, no desempenho dos serviços executados em uma nuvem privada e em uma nuvem híbrida. No Capítulo 7 é apresentado um estudo comparativo considerando os modelos de fator de rajada disponíveis em literatura e um modelo proposto nesta tese, a fim de avaliar o comportamento de cada um deles e suas correlações com as taxas de chegada, validando o modelo para o fator de rajada proposto neste projeto de doutorado. 


\section{Impacto das Rajadas no}

\section{Desempenho dos Serviços em}

\section{Nuvens}

\subsection{Considerações Iniciais}

Este Capítulo apresenta uma avaliação de desempenho voltada para serviços executados em nuvens privadas e híbridas, considerando a presença de rajadas no processo de chegada de requisições e nas demandas de serviços. As rajadas são modeladas por processos MAPs (Markovian Arrival Process) (Bolch et al., 2006) de dois estados parametrizados com diferentes variabilidades e intensidades.

Neste Capítulo é apresentada a metodologia desenvolvida e utilizada para definir os parâmetros (como taxas dos estados e probabilidades de transição do modelo MAP) com base na média, índice de dispersão e quadrado do coeficiente de variação (SCV - Squared Coefficient of Variation) do MAP. Além disso, são apresentadas avaliações, onde é executado uma série de experimentos para avaliar o impacto no desempenho dos serviços quando são consideradas rajadas de origens distintas, ou seja, originadas no processo de chegada das requisições ou nas demandas de serviços ou ainda rajadas originadas tanto no processo de chegada como na demanda de serviço, ocorrendo em escalas de tempos distintos ou sincronizadas ao longo do tempo de simulação.

\subsection{Ambiente de Testes}

Os experimentos realizados nesta tese baseiam-se em simulações, utilizando o framework de simulação CloudSim versão 3.0.1, proposto por Calheiros et al. (2011), conforme apresentado na Seção 2.7. A figura 6.1 ilustra o ambiente de teste considerado nas avaliações 
de desempenho apresentadas neste Capítulo. A nuvem adotada na simulação considerou a implementação de dois modelos: uma nuvem privada e uma nuvem híbrida (combinação da nuvem privada e da nuvem pública). No modelo híbrido, as requisições são direcionadas à nuvem pública contratada, quando seus recursos privados são insuficientes para atender tal demanda, proporcionando um melhor desempenho aos serviços quando comparado aos cenários onde se utiliza apenas uma nuvem privada. Conforme descrito na Seção 5.3.2, o modelo de nuvem híbrida implementado possibilita que seja parametrizado pelo usuário, antes da simulação iniciar, um percentual de consumo limite dos recursos do data center privado, que se atingido, o Broker passa a encaminhar as requisições para a nuvem pública. Para os experimentos que consideraram o modelo de nuvem híbrido, apresentados na Seção 6.6, esse percentual de consumo limite dos recursos foi parametrizado em $80 \%$. Com a adoção desses diferentes modelos de nuvem é possível avaliar e comparar o impacto das rajadas no desempenho dos serviços quando submetidos a uma nuvem privada ou a uma nuvem híbrida.

Os modelos de nuvem considerados, possuem um data center composto por servidores (hosts) físicos e máquinas virtuais (VM - Virtual Machine). A Tabela 6.1 descreve a configuração física de cada um dos servidores e máquinas virtuais dos provedores de nuvens considerados na execução dos experimentos.

Tabela 6.1 - Configuração dos Servidores dos Provedores de Nuvem

\begin{tabular}{|c|c|c|c|c|}
\hline & \multicolumn{2}{|c|}{ Nuvem Privada } & \multicolumn{2}{|c|}{ Nuvem Pública } \\
\hline & \multicolumn{2}{|c|}{ Servidor $\quad$ VM } & \multicolumn{2}{|c|}{ Servidor $\quad$ VM } \\
\hline Processador & $\begin{array}{l}\text { Intel Xeon } 6 \text { cores } \\
2.66 \mathrm{GHz}\end{array}$ & 1 core $2.66 \mathrm{GHz}$ & $\begin{array}{l}\text { Intel Xeon } 8 \text { cores } \\
2.6 \mathrm{Ghz}\end{array}$ & 1 core $2.6 \mathrm{GHz}$ \\
\hline $\begin{array}{l}\text { Capacidade de } \\
\text { Processamento } \\
\text { (Mips/s) }\end{array}$ & 7.000 MIPs/core & 7.000 Mips & 10.000 MIPs/core & 7.000 Mips \\
\hline $\begin{array}{l}\text { Memória } \\
\text { Principal }\end{array}$ & 24GB & 4GB & $32 \mathrm{~GB}$ & 4GB \\
\hline Disco & $144 \mathrm{~GB}$ & $24 \mathrm{~GB}$ & $2 \mathrm{~TB}$ & $96 \mathrm{~GB}$ \\
\hline $\begin{array}{l}\text { Sistema } \\
\text { Operacional }\end{array}$ & \multicolumn{2}{|c|}{ Ubuntu 14.04} & \multicolumn{2}{|c|}{ Ubuntu 14.10} \\
\hline
\end{tabular}

Cada um dos data centers, privado e público, considerado neste estudo, é composto por 10 servidores (hosts) físicos homogêneos. Da mesma forma como os servidores físicos, no data center privado, são instanciadas 40 máquinas virtuais homogêneas e no data center público são instanciadas 60 máquinas virtuais, também homogêneas, gerenciadas pelo hipervisor Xen 
(Bhatt e Patel, 2012) (Deka e Prashanta, 2014). Para identificar quais VMs pertencem à nuvem privada e à nuvem pública, são atribuídas faixas de numeração diferentes para identifica-las, ou seja, as VMs da nuvem privada são identificadas com uma numeração de 1 a 40 e as VMs da nuvem pública de 1301 a 1360. São considerados também cinco serviços Web distribuídos de forma aleatória entre as VMs, onde cada VM é responsável pela execução de dois serviços Web distintos.

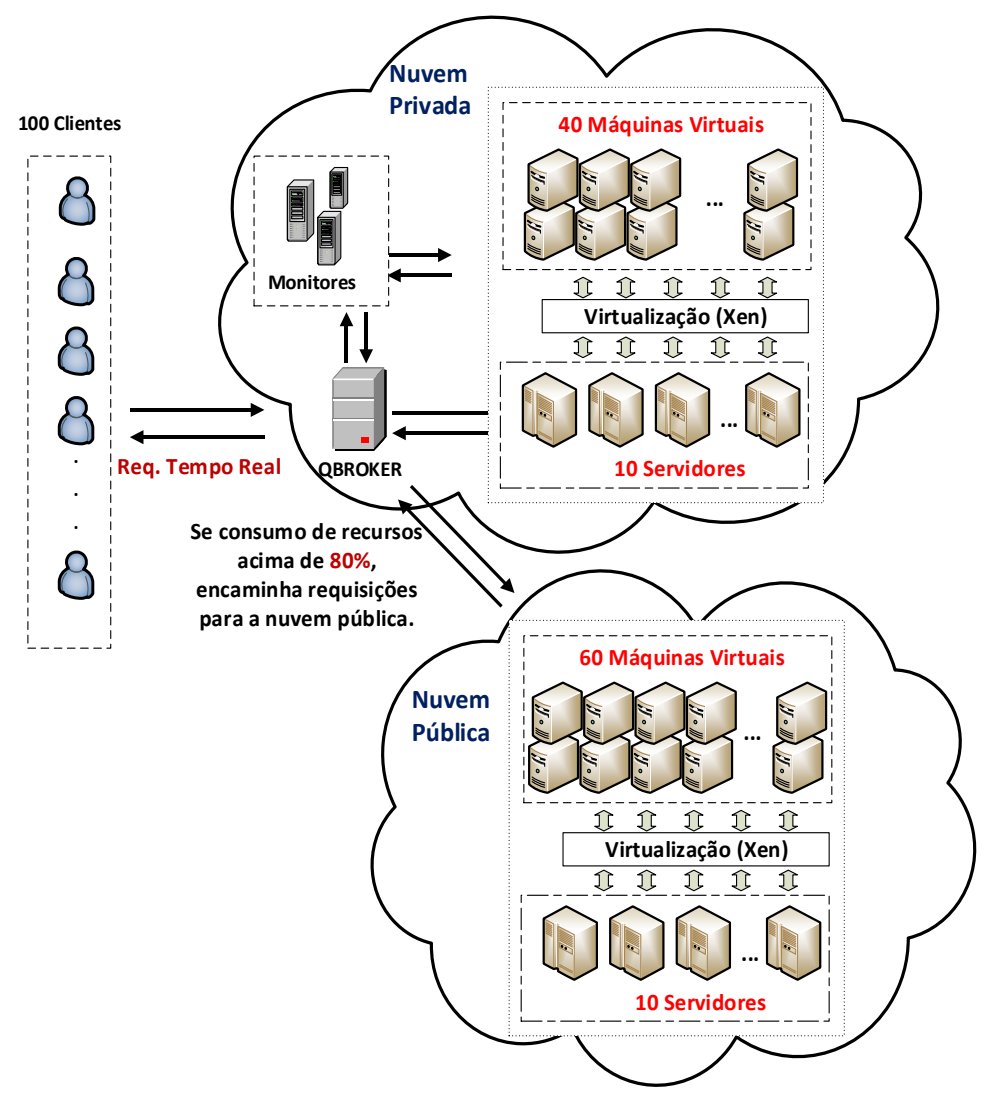

Figura 6.1 - Ambiente de Testes.

A política de alocação de máquinas virtuais adotada é a Space-shared, assim a máquina virtual ocupa uma entidade de processamento ou core, durante todo o tempo de simulação. Para alocar as cargas de trabalho nas máquinas virtuais, também é utilizada a política Space-shared, ou seja, uma vez que uma requisição começa a ser processada, não há possibilidade de preempção.

Para todos os experimentos realizados neste estudo, considera-se uma quantidade de 100 clientes concorrentes responsáveis pela submissão das requisições de serviços distintos, durante um tempo de simulação de 5400 unidades de tempo de simulação, a qual equivale a um intervalo de amostra de simulação (no caso do CloudSim representada em segundos). Da 
mesma forma que para as máquinas virtuais, o serviço da requisição de cada cliente é definido de forma aleatória entre os cinco serviços Web disponíveis.

Quanto às configurações referentes às latências de rede, são definidas latências distintas entre cada cliente e Broker, atribuídas de forma aleatória entre 5 e $500 \mathrm{~ms}$, representando um cenário onde vários clientes concorrentes acessam a nuvem, em posições geográficas distintas. No modelo considerado, o Broker está localizado junto ao provedor de nuvem privada e, portanto, a latência de rede para este caso é considerada nula. A latência de rede entre Broker e provedor de nuvem pública é definida também de forma aleatória entre 20 e $80 \mathrm{~ms}$. Para o caso de nuvem híbrida, foi considerado que a nuvem pública está interconectada ao Broker, através de uma conexão dedicada, com latências mais baixas.

Cada cliente submete requisições ao Broker usando o modelo de submissão de requisições em tempo real, onde o processo de envio ocorre durante todo o tempo de simulação. O modelo de carga de trabalho considera situações em que o processo de chegada das requisições e/ou demandas de serviços chegam ou não em forma de rajadas, sendo que no primeiro caso, as rajadas com diferentes variabilidades e intensidades são modeladas usando o Processo de Chegada Markoviano (MAP - Markovian Arrival Process). A metodologia empregada para parametrizar os modelos MAPs considerados neste trabalho, é descrita na Seção 6.3. Na situação sem rajadas, os intervalos de chegadas e demandas de serviços são gerados seguindo uma distribuição exponencial, com médias de sete segundos, a mesma média considerada na parametrização dos modelos MAPs, e são melhor detalhados na Seção 6.5. A configuração dos think times entre requisições sucessivas, para todos os experimentos, considera a opção implementada na arquitetura desenvolvida, apresentada no Capítulo 5, em que o cliente envia a próxima requisição apenas após aguardar um intervalo de time (think time) contado a partir do recebimento da resposta completa da requisição prévia.

\subsection{Parametrização dos Modelos MAPs}

Nesta Seção, é abordada a metodologia utilizada na definição dos parâmetros ( $\mu_{i}$ ou $\lambda_{i}, \mu_{j}$ ou $\left.\lambda_{j}, p_{i j}, p_{j i}\right)$ dos MAPs utilizados na modelagem de rajadas no processo de chegada das requisições (MAP $\left.\mathbf{P}_{\boldsymbol{I A T}}\right)$ e nas demandas de serviço submetidas à nuvem $\left(\mathbf{M A P} \mathbf{P}_{\boldsymbol{S D}}\right)$, sendo $\left\{\lambda_{i}, \lambda_{j}\right\}$ as taxas de chegadas das requisições considerando um $\operatorname{MAP}_{I A T}$ e $\left\{\mu_{i}, \mu_{j}\right\}$ as taxas de serviços considerando um $\mathrm{MAP}_{S D}$. As probabilidades de transições do estado $i$ para o $j$ e vice-versa correspondem aos parâmetros $\left\{p_{i j}, p_{j i}\right\}$ respectivamente. Esta etapa é de fundamental 
importância para a construção de um modelo de simulação válido, visto que uma parametrização inadequada pode levar a resultados imprecisos. Com base nas metodologias utilizadas para parametrização disponíveis em literatura (Gusella, 1991) (Casale et al., 2008) (Falko et al., 2009) (Mi et al., 2010) (Kriege e Buchholz, 2010), uma abordagem que se destaca é o Índice de dispersão, utilizado para modelar rajadas de uma carga de trabalho, conforme apresentado na Seção 4.3. O índice de dispersão (I), segundo Gusella (1991), tem uma propriedade importante, que garante que o valor de I cresça proporcionalmente à variabilidade e correlações. Assim, ele pode ser utilizado para identificar rajadas em um trace ou para regular a intensidade das rajadas na modelagem de cargas de trabalho (Mi et al., 2010).

Para definir a metodologia empregada na parametrização das classes MAPs, foram executados testes com intuito de verificar se a adoção de apenas uma única medida, o índice de dispersão I, é suficiente para capturar as características das rajadas presentes em uma carga de trabalho. Porém, antes de apresentar os testes realizados, que consideraram três MAPs com parametrizações diferentes, é importante apresentar a definição das principais medidas consideradas na parametrização dos MAPs, assim como as equações utilizadas para obtê-las, que servem de base matemática para entendimento da metodologia utilizada e dos experimentos que serão apresentados no decorrer deste Capítulo. Desta forma, nas próximas Seções serão apresentadas a equações para cálculo da média, índice de dispersão e demais medidas importantes do MAP e os experimentos realizados para definição da metodologia utilizada neste trabalho.

\subsubsection{Descrição Matemática das Medidas Principais de um MAP}

As principais medidas utilizadas para caracterizar as rajadas modeladas por um MAP e que são consideradas na abordagem utilizada para definição dos parâmetros dos modelos MAPs, são descritas a seguir:

- Média: corresponde à média $\left(\lambda^{-1}\right.$ ou $\left.\mu^{-1}\right)$ dos valores gerados pelo MAP (ou seja, $\lambda^{-1}$ : referentes aos intervalos de chegada ou $\mu^{-1}$ : referentes aos tempos de serviços/demandas de serviços).

- SCV: é o quadrado do coeficiente de variação (SCV - Squared Coefficient of Variation) dos intervalos de chegada ou demandas de serviços. Esta medida quantifica a variabilidade de uma sequência de valores aleatórios. Distribuições com SCV $<=1$ são consideradas com baixas variabilidades. Para uma distribuição exponencial, por exemplo, o valor de SCV é 
igual a 1, o que denota uma baixa variabilidade. À medida que o valor de SCV aumenta, mais variável a sequência de valores aleatórios se torna.

- $\boldsymbol{\rho}_{\boldsymbol{k}}$ : representa o coeficiente de autocorrelação. Em estatística, autocorrelação é uma medida que informa as relações entre valores de dados na aproximação do domínio temporal. Matematicamente, as análises do domínio temporal operam no mesmo espaço dos valores dos dados. Em outras palavras, a diferença em magnitude entre valores consecutivos $\left(X_{t}\right.$ e $\left.X_{t-k}\right)$ pode ser medido pelo coeficiente de autocorrelação $\left(\rho_{k}\right)$ em $k$ deslocamento no tempo ( $\boldsymbol{k}$ lags). Desta forma, o valor do coeficiente de autocorrelação quantifica a correlação entre duas variáveis separadas em k deslocamento no tempo. Considerando um MAP de dois estados, o valor de $\rho_{l}$, segundo Mi et al. (2010), deve ter um valor máximo em torno de 0,4, visto que este é valor mais próximo para a autocorrelação máxima que pode ser obtido por um MAP de dois estados.

- Índice de Dispersão (I): corresponde ao índice de dispersão de um modelo MAP, que representa o nível de intensidade das rajadas, que podem chegar em curtos ou longos períodos ao longo do tempo. Quanto maior for valor de I mais severa será a intensidade da rajada e portanto, podendo afetar significativamente o desempenho do serviço. Quando não há rajadas o valor de I é igual ao SCV da distribuição, ou seja, para uma distribuição exponencial, o valor de $\mathrm{I}=\mathrm{SCV}=1$.

A seguir são descritas as equações para cálculo das principias medidas (Bolch et al., 2006) (Casale et al., 2013) apresentadas nesta Seção. As equações consideram um modelo MAP de dois estados para processos de chegadas, assim nas fórmulas aparecem as médias $\lambda_{i} e \lambda_{j}$ dos estados $i$ e $j$ respectivamente. Para um MAP de dois estados para demandas de serviços, as equações são as mesmas, no entanto a média dos estados correspondem às médias dos tempos de serviços/demandas de serviços $\left(\mu_{i}\right.$ e $\left.\mu_{j}\right)$.

Para tanto, considera-se as matrizes $\left\{\mathrm{D}_{0}, \mathrm{D}_{1}\right\}$ do MAP :

$$
\mathrm{D}_{0}=\left[\begin{array}{cc}
-\lambda_{i} & 0 \\
0 & -\lambda_{j}
\end{array}\right] \quad D_{1}=\left[\begin{array}{cc}
\lambda_{i} p_{i i} & \lambda_{i} p_{i j} \\
\lambda_{j} p_{j i} & \lambda_{j} p_{j j}
\end{array}\right]
$$

A matriz geradora infinitesimal $\boldsymbol{Q}_{M A P}$ da cadeia de markov de tempo contínuo pode ser obtido pela soma das matrizes $\mathrm{D}_{0}$ e $\mathrm{D}_{1}$, conforme a equação 6.1:

$$
Q_{M A P}=D_{0}+D_{1}=\left[\begin{array}{cc}
-q_{i} & q_{i j} \\
q_{j i} & -q_{j}
\end{array}\right]
$$


onde a matriz $\left[-q_{i}, q_{i j} ; q_{j i},-q_{j}\right]$ é resultado da soma das matrizes D0 e D1. O vetor de probabilidade em regime estacionário do processo Markov pode ser obtido usando a equação 6.2, que segue a abordagem matemática apresentada em (Fischer e Kathleen, 1993) para o caso de um processo Markov de 2 estados:

$$
\begin{array}{r}
\pi=\left[\pi_{1}, \pi_{2}\right], \quad \text { sendo: } \\
\pi_{1}=\frac{1}{q_{i}+q_{j}} q_{j}, \quad \pi_{2}=\frac{1}{q_{i}+q_{j}} q_{i} \\
\pi Q_{M A P}=0 \quad|\pi|=1
\end{array}
$$

onde $|\boldsymbol{\pi}|$ é a soma dos valores do vetor de probabilidade em regime estacionário $\boldsymbol{\pi}$. Desta forma, o valor de $\pi_{i}$ representa a probabilidade em regime estacionário que os processos de chegadas estejam no estado $\boldsymbol{i}$ e o $\boldsymbol{\pi}_{\boldsymbol{j}}$ representa a probabilidade em regime estacionário que os processos de chegadas estejam no estado $\boldsymbol{j}$.

A média do MAP pode ser obtida através do cálculo dos momentos dos intervalos de chegadas ou das demandas de serviços gerados pelo MAP. Em estatística, os momentos são importantes para caracterizar distribuições de probabilidade, fornecendo características como tendência central, dispersão e assimetria de uma distribuição de probabilidades. Os momentos, para um modelo MAP, podem ser calculados pela equação 6.3, sendo que a média corresponde ao primeiro momento:

$$
E\left[X^{k}\right]=k !\left(\pi D_{1}\right)\left(-D_{0}^{-1}\right)^{-K}\left(\frac{e}{\left(\pi D_{1} e\right.}\right)
$$

onde: $\boldsymbol{e}$ é um vetor coluna com valores 1 de tamanho de $m$ (sendo $m$

$$
=n^{\circ} \text { de estados do MAP, ou seja, } e=[1,1] \text {. }
$$

Portanto, a média do MAP pode ser calculada usando a equação 6.3, considerando k=1, ou seja, $E\left[X^{1}\right]$. Para se obter o quad,rado do coeficiente de variação (SCV), antes é necessário conhecer a variância $\left(\sigma^{2}\right)$ dos valores (intervalos de chegadas e demandas de serviços) geradas pelo MAP. A variância pode ser calculada subtraindo $E\left[\mathrm{X}^{2}\right]$, que corresponde ao segundo momento, pela média do MAP elevado ao quadrado, conforme equação 6.4.

$$
\sigma^{2}=E\left[X^{2}\right]-\left(\lambda^{-1}\right)^{2}
$$


Desta forma, o quadrado do coeficiente de variação (SCV) é então obtido pela equação 6.5 .

$$
S C V=\frac{\sigma^{2}}{\left(\lambda^{-1}\right)^{2}}
$$

Com o SCV calculado é possível obter então o valor do coeficiente de correlação, cuja fórmula é apresentada na equação 6.6.

$$
\rho_{k}=\frac{\left(\left((\lambda \pi)\left(\left(-D_{0}\right)^{-1} D_{1}\right)^{K}\left(\left(D_{0}\right)^{-1} e\right)\right)-1\right)}{S C V}
$$

Sendo $\lambda$ a taxa de chegada média do MAP, que pode ser calculada pela equação 6.7:

$$
\lambda=\pi D_{1} e
$$

Finalmente, o índice de dispersão $I$ é obtido usando a equação 6.8 .

$$
I=1+2\left(\lambda-\left(\frac{\pi D_{1}}{\lambda}\right)(Q e \pi)^{-1}\left(D_{1} e\right)\right)
$$

O Índice de dispersão também pode ser calculado por uma fórmula mais simplificada, apresentado em (Heffes e Lucantoni, 1986) (Mi et al., 2010), com base nas taxas de chegadas e probabilidades de transição de cada estado do MAP, conforme apresentado na equação 6.9.

$$
I=1+\frac{2 \mathrm{p}_{j, i} p_{i, j}\left(\lambda_{j}-\lambda_{i}\right)^{2}}{\left(\mathrm{p}_{j, i}+p_{i, j}\right)\left(\lambda_{j} \mathrm{p}_{j, i}+\lambda_{i} p_{i, j}\right)^{2}}
$$

Nota-se que tanto a equação 6.7 e 6.8 diferem da equação proposta por (Gusella, 1991) para um processo de Poisson, apresentado na Seção 4.3 do Capítulo 4, visto que o índice de dispersão neste caso considera um MAP, e desta forma, a equação deve ser adaptada para este modelo. Em Gusella, 1991, o quadrado do coeficiente de variação, SCV, que quantifica a variabilidade, é usado na equação proposta para o índice de dispersão, enquanto nas equações 6.8 e 6.9 esta medida não é considerada. 


\subsubsection{Avaliação do Índice de Dispersão}

Visto a base matemática para obtenção de $\lambda^{-1}$ ou $\mu^{-1}$, I e demais medidas importantes para entendimento da metodologia utilizada na definição dos parâmetros do MAP, nesta Seção serão apresentados os experimentos realizados com o objetivo de avaliar se as propriedades e características das rajadas presentes em uma carga de trabalho podem ser sumarizadas por um único índice, o índice de dispersão. Os experimentos foram executados na arquitetura desenvolvida, usando o ambiente de simulação CloudSim e considerando as mesmas configurações do ambiente de testes descritas na Seção 6.2, exceto em relação à nuvem, que para este estudo, foi considerado apenas uma nuvem privada. Para tanto, os testes consideram três opções de intervalos de chegadas (think times) entre as requisições sucessivas submetidas pelos clientes à nuvem privada, geradas por três diferentes MAPs de dois estados. Todos os três MAPs, nomeados $\mathrm{MAP}_{I A T 1}, \mathrm{MAP}_{I A T 2}, \mathrm{MAP}_{I A T 3}$, têm parametrizações $\left(\lambda_{i}, \lambda_{j}, p_{i i}, p_{j j}\right)$ diferentes, no entanto, possuem a mesma média $\lambda^{-1}=7$ s e o mesmo índice de dispersão $I=4000$. A Tabela 6.2 apresenta os parâmetros dos três MAPs considerados neste estudo.

Os parâmetros do $\mathrm{MAP}_{I A T l}$, descritos na terceira coluna da Tabela 6.2, segue o trabalho apresentado em (Mi et al., 2010) que modelou as rajadas no processo de chegada usando um MAP de dois estados, com $I=4000$ e $\lambda^{-1}=7 s$. Quanto aos outros dois MAPs (MAPIAT2 e $\mathrm{MAP}_{I A T 3}$ ), para definir seus parâmetros foi utilizado o software MATLAB (MATrix LABoratory), voltado para o cálculo numérico e cálculo com matrizes (Overman, 2011) e o KPC-toolbox (Casale et al., 2008), uma coleção de scripts MATLAB voltados para parametrização e análise de processos MAPs, apresentado na Seção 4.7.2 do Capítulo 4.

Tabela 6.2 - Parâmetros dos três MAPs avaliados

\begin{tabular}{|c|l|c|c|c|}
\hline Parâmetro & \multicolumn{1}{|c|}{ Descrição } & MAPIAT1 & MAPIAT2 & MAP \\
\hline$\lambda_{i}{ }^{*}$ & Taxa do estado $i$ & 0,03443 & 0,07144 & 0,03571 \\
\hline$\lambda_{j}{ }^{*}$ & Taxa do estado $j$ & 192,86055 & 389,99999 & 693,53789 \\
\hline$p_{i i}$ & Probabilidade de permanência no estado $i$ & 0,99880 & 0,99975 & 0,99888 \\
\hline$p_{j j}$ & Probabilidade de permanência no estado $j$ & 0,99962 & 0,99975 & 0,99963 \\
\hline$\lambda^{-1}$ & Média do MAPiat & $7 \mathrm{~s}$ & $7 \mathrm{~s}$ & $7 \mathrm{~s}$ \\
\hline$I$ & Índice de Dispersão & 4000 & 4000 & 4000 \\
\hline$S C V$ & Quadrado do coeficiente de variação & 7 & 3 & 7 \\
\hline$\rho_{1}$ & Coeficiente de autocorrelação (para $K=1$ ) & 0,4 & 0,3 & 0,4 \\
\hline \multicolumn{4}{|r|}{$*$ Aariável $\boldsymbol{i}$ representa o estado sem rajada e $\boldsymbol{j}$ representa o estado com rajada } \\
\hline
\end{tabular}

Assumindo, que o conjunto de valores ( $\lambda^{-1} \mathrm{e}$ I) são conhecidos e já especificados, com auxílio dos scripts do KPC-toolbox, os parâmetros $\left(\lambda_{i}, \lambda_{j}, p_{i i}, p_{j j}\right)$ são definidos por meio de uma 
pesquisa de um MAP que possua uma média e um índice de dispersão (I) que estejam dentro dos valores especificados. Durante esta busca, as médias dos estados e as probabilidades de transição são redimensionadas até que seja encontrado uma parametrização de um MAP com a média definida e com um índice de dispersão que esteja dentro de $1 \%$ do I especificado.

Os gráficos da Figura 6.2 ilustram amostras de 25.000 think times consecutivos gerados pelos $\mathrm{MAP}_{\text {IAT1 }}, \mathrm{MAP}_{\text {IAT2 }}$ e $\mathrm{MAP}_{\text {IAT3 }}$. Observa-se que a carga de trabalho modelada pelo MAP $_{I A T 2}$, na Figura 6.2 (b), apresenta uma variabilidade mais baixa do que as cargas de trabalho modeladas pelo MAP $_{I A T I}$ e MAP $_{I A T 3}$, o que corresponde aos parâmetros de SCV apresentados na Tabela 6.2. Assim, considerando MAPs diferentes, a questão a ser avaliada, portanto, é se o impacto das rajadas modeladas por esses três MAPs serão equivalentes, uma vez que possuem o mesmo índice de dispersão.

(a)

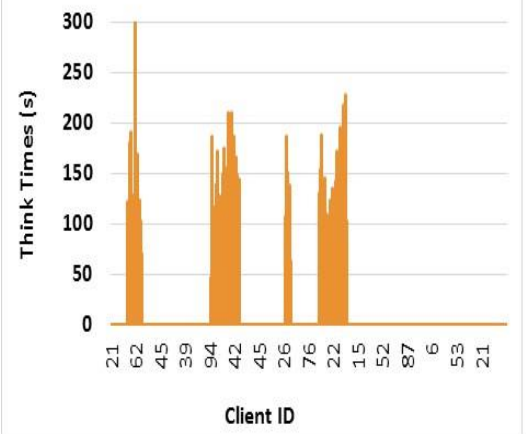

(b)

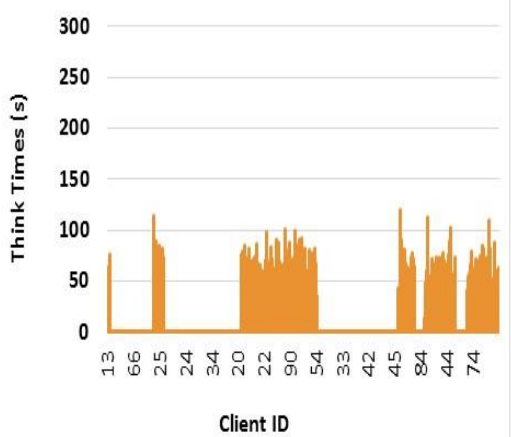

(c)

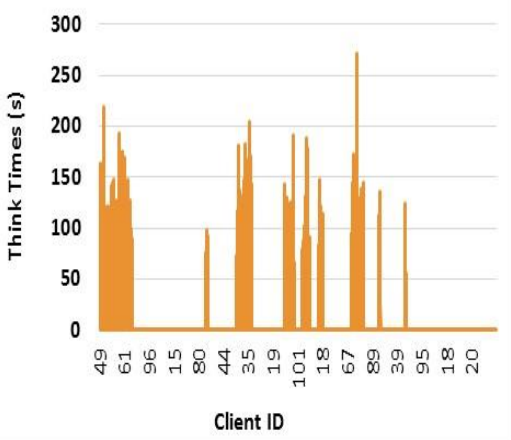

Figura 6.2 - Amostras de think times gerados pelos diferentes modelos MAPs (a) MAPIATI, (b)

$$
\mathrm{MAP}_{I A T 2} \text {, (c) MAP IAT3. }
$$

A Tabela 6.3 apresenta o tempo médio de resposta do cliente (intervalo de tempo entre o envio de uma requisição e a chegada da resposta completa no cliente), o tempo médio de espera em fila e vazão, obtidos com a execução dos experimentos realizados, considerando os três diferentes MAPs.

Tabela 6. 3 - Medidas de Desempenho - MAPIAT1, MAPIAT2 e MAPIAT3

\begin{tabular}{|l|ccc|ccc|ccc|}
\cline { 2 - 11 } \multicolumn{1}{c|}{} & \multicolumn{3}{|c|}{$\begin{array}{c}\text { Tempo médio de } \\
\text { resposta }\end{array}$} & \multicolumn{3}{c|}{$\begin{array}{c}\text { Tempo médio de espera } \\
\text { em fila }\end{array}$} & \multicolumn{3}{c|}{ Vazão } \\
\cline { 2 - 11 } & Média & DesvPad & IC & Média & DesvPad & IC & Média & DesvPad & IC \\
\hline MAP $_{I A T 1}$ & $\mathbf{1 5 , 1 5}$ & 0,21 & 0,13 & $\mathbf{7 , 5 9}$ & 0,21 & 0,13 & $\mathbf{4 , 7 1}$ & 0,09 & 0,06 \\
\hline $\mathrm{MAP}_{I A T 2}$ & $\mathbf{1 3 , 8 2}$ & 0,56 & 0,35 & $\mathbf{6 , 2 7}$ & 0,57 & 0,35 & $\mathbf{5 , 2 6}$ & 0,06 & 0,04 \\
\hline $\mathrm{MAP}_{I A T 3}$ & $\mathbf{1 5 , 1 4}$ & 0,27 & 0,17 & $\mathbf{7 , 6 2}$ & 0,26 & 0,16 & $\mathbf{4 , 7 8}$ & 0,14 & 0,09 \\
\hline
\end{tabular}


Observa-se que para todos os tempos médios (de resposta e de espera em fila) obtidos usando o modelo MAP $\mathrm{M}_{\text {IAT2 }}$ são menores do que os obtidos para os modelos $\mathrm{MAP}_{\text {IATI }}$ e MAP $\mathrm{MAT3}_{\text {IAT }}$ Da mesma forma quando o modelo $\mathrm{MAP}_{I A T 2}$ é considerado na geração das rajadas no processo de chegada, a vazão do sistema é maior do que para os outros dois modelos. Por outro lado, o

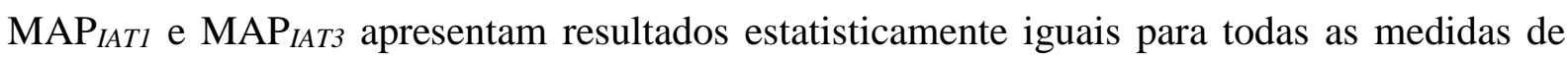
desempenho avaliadas (tempo médio de resposta, tempo médio de espera e vazão). Esses resultados mostram que mesmo considerando modelos MAPs, com a mesma média e índice de dispersão, o impacto das rajadas no desempenho dos serviços não é equivalente. Esse comportamento sugere que o uso de apenas um único índice, o índice de dispersão $I$, não é suficiente para caracterizar as rajadas de uma carga de trabalho, em termos de variabilidade e de intensidade. Outra observação importante é em relação aos resultados obtidos para os $\mathrm{MAP}_{I A T I}$ e MAP $\mathrm{M}_{I A T 3}$, que além da média e do índice de dispersão serem idênticos, nota-se que os dois modelos apresentam mesma variabilidade quantificada pelo quadrado do coeficiente de variação $(\mathrm{SCV}=7)$.

Com base nestes resultados, pode-se concluir que além da média e do índice de dispersão, outra medida deve ser considerada na parametrização do processo MAP para que o modelo consiga representar com exatidão as rajadas de uma carga de trabalho, que corresponde ao quadrado do coeficiente de variação ou SCV. Assim, usando estes dois índices (I, SCV) é possível modelar diferentes perfis de rajadas, com intensidades e variabilidades distintas.

Desta forma, a metodologia utilizada para definir a parametrização dos processos MAPs considerados neste trabalho é feita com base nas medidas $\lambda^{-1}$ ou $\mu^{-1}$, I e SCV, utilizando o software MATLAB e a coleção de scripts do KPC-toolbox. Para tanto, foi implementado um script, para determinar a parametrização $\left(\lambda_{i}, \lambda_{j}, p_{i i}, p_{j j}\right)$ do MAP para modelar rajadas no processo de chegada ou a parametrização $\left(\mu_{i}, \mu_{j}\right.$, $\left.p_{i i}, p_{j j}\right)$ do MAP para modelar rajadas nas demandas de serviços. Esses parâmetros são obtidos a partir dos argumentos de entrada: média - MeanMAP $\left(\lambda^{-1}\right.$ ou $\left.\mu^{-1}\right)$, I, SCV e N, sendo $N$ a quantidade de clientes concorrentes que estarão submetendo requisições ao sistema. Para facilitar o entendimento da abordagem considerada para definir os parâmetros dos MAPs considerados neste estudo e que serão explicados nos próximos parágrafos, a Figura 6.3 apresenta um pseudocódigo do script utilizado para definir os parâmetros do MAP.

Considere que os argumentos de entrada (MeanMAP, $I, S C V, N$ ) são fornecidos pelo usuário e que as médias dos intervalos de chegadas ou tempos de serviços são inicialmente definidos pelas equações 6.10 e 6.11, adaptadas do trabalho de (Mi et al., 2010): 


$$
\begin{gathered}
\mu_{i}^{-1} \text { ou } \lambda_{j}^{-1}=\frac{\text { MinsT }}{f} \\
\mu_{j}^{-1} \text { ou } \lambda_{i}^{-1}=\max \left(f \lambda^{-1}, f N M i n S T\right)
\end{gathered}
$$

sendo MinST o tempo mínimo para um serviço ser completado em uma VM. Este tempo foi definido com base nos experimentos prévios realizados no ambiente de testes preparado e com as mesmas configurações de testes descritos na Seção 6.2, através de medições dos valores dos tempos mínimos para que os serviços fossem processados nas Vms dos data centers. A variável $f>=1$ é um parâmetro livre usado no redimensionamento das médias dos estados $\mu_{\mathrm{i}}{ }^{-1}, \lambda_{\mathrm{i}}{ }^{-1} \mathrm{e}$ $\mu_{\mathrm{j}}^{-1}, \lambda_{\mathrm{j}}^{-1}$.

Assim, assumindo que o valor inicial de $f=1,001$, para um MAP para processos de chegadas, a média do estado $i\left(\lambda_{i}{ }^{-1}\right)$ recebe inicialmente um valor superior para completar as requisições nas VMs (para geração de think times longos), enquanto a média do estado $j\left(\lambda_{\mathrm{j}}{ }^{-1}\right)$ é definida inicialmente para uma média próxima do valor do tempo mínimo para um serviço ser completado (para geração think times curtos). No entanto, para um MAP adotado para modelar rajadas nas demandas de serviços ocorre o inverso, ou seja, a média do estado $i\left(\mu_{i}^{-1}\right)$ recebe um valor próximo do tempo mínimo para um serviço ser completado (para gerar sequências de serviços mais leves) e a média do estado $j\left(\lambda_{j}^{-1}\right)$ recebe inicialmente um valor superior para completar as requisições nas VMs (para gerar sequências de serviços mais pesados). É importante lembrar que as médias dos dois estados são redimensionadas a cada busca por uma parametrização que satisfaçam as medidas especificadas previamente (MeanMAP, I e SCV).

Da mesma forma que as médias dos estados e com base no trabalho de (Mi et al., 2010), as probabilidades de transição do estado $i$ para $j$, podem ser obtidas pela equação 6.12:

$$
p_{i, j}=p_{j, i} * \frac{\text { Mean }_{-i}-\text { MeanMAP }}{\text { MeanMAP-Mean }-j}
$$

Sendo Mean $_{-}$e $\mathrm{Mean}_{-} j$ as médias dos estados i e j respectivamente.

A probabilidade de transição do estado $\mathrm{j}$ para $\mathrm{i}, p_{j, i}$ é definida com uma probabilidade inicial de 0,01. Porém durante a pesquisa os valores $p_{j, i}$ são redimensionados (de forma que: 0 $<p_{j, i}<1$ ) onde para cada iteração é checado o valor do índice de dispersão (I) e do quadrado do coeficiente de variação (SCV). A pesquisa é finalizada quando é encontrado um MAP com 
um I e SCV que estejam dentro de $1 \%$ do índice de dispersão e SCV especificados respectivamente.

\section{Function: FittingMAP (MeanMAP, I, SCV, N)}

\section{Inicializa variáveis e constantes:}

Inicializa minST

$\mathrm{F}=1.0001$;

scvtemp $=0$

Mean $i$

Mean $j$
$/^{*}$ tempo mínimo de um serviço para ser processado na $\mathrm{VM} *$ /

$\int^{*}$ variável usada para redimensionar as médias dos estados */

* variável temporária que recebe valor de scv */

$/{ }^{*}$ média do estado $i: \lambda_{\mathrm{i}}^{-1}$ ou $\mu_{\mathrm{i}}^{-1} *$

${ }^{*}$ média do estado $j: \lambda_{j}^{-1}$ ou $\mu_{j}^{-1} *$

\section{Inicia pesquisa dos parâmetros do MAP com I e SCV especificados:}

While $(([$ scvtemp $-S C V)>0.01 * S C V)] \quad /^{*}$ enquanto $S C V$ for diferente do especificado*

Calcula Mean_i e Mean $j$

D0 $=$ diagonal $([-1 /$ Mean_ $i,-1 /$ Mean_ $j]) ; \quad ~ \%$ Gera matriz DO*

$\mathrm{p}_{\mathrm{ji}}=0.01$;

Calcula $\mathrm{p}_{\mathrm{ij}}$

$\mathrm{P}=\left[1-\mathrm{p}_{\mathrm{ij}}, \mathrm{p}_{\mathrm{ij}} ; \mathrm{p}_{\mathrm{ij}} 1-1-\mathrm{p}_{\mathrm{ji}}\right] ;$

$\mathrm{D} 1=-\mathrm{D} 0 * \mathrm{P}$;

$\mathrm{MAP}=\{\mathrm{D} 0, \mathrm{D} 1\}$

While (map_idc(MAP) $-I$ ) $>0.01 * I$ ) $\quad{ }^{*}$ enquanto I for diferente do especificado*

Inicialize novamente probabilidade $\mathrm{p}_{\mathrm{ji}}$ :

Se Idc > I faça: $p_{j i} /$ rand

Senão faça: $p_{j i}^{*}$ rand

Gera matriz de probabilidades $P$, D1 e MAP novamente

E calcula I para novo MAP

EndWhile

Calcula I, SCV, $\rho_{1}$ do MAP gerado no While acima;

$\mathrm{E}$ faça $\mathrm{F}=\mathrm{F}^{*} 2$ para redimensionar taxas dos estados do MAP; endWhile

$\mathrm{MAP}=\{\mathrm{D} 0, \mathrm{D} 1\}$ endFunction

/*Safda: MAP final gerado com I e SCV especificados */

Figura 6.3 - Pseudocódigo - Definição dos parâmetros do MAP.

Na próxima Seção são definidos os experimentos realizados com o intuito de avaliar o impacto das rajadas no desempenho da execução de requisições em nuvens. 


\subsection{Experimentos}

Os experimentos estão organizados e separados em três conjuntos de experimentos, seguindo o planejamento fatorial completo, para avaliar o impacto das rajadas de diferentes origens, variabilidades e intensidades. Essa separação torna-se interessante, visto a possibilidade de avaliar separadamente o impacto no desempenho dos serviços executados em nuvem, quando a carga de trabalho se apresenta na forma de rajadas de origens distintas, ou seja:

- Rajadas originadas no processo de chegada das requisições, causando um aumento na taxa de chegada de requisições submetidas à nuvem, em alguns períodos ao longo do tempo de simulação;

- Rajadas originadas nas demandas de serviços, provando um aumento de demandas de serviços, também em alguns períodos ao longo do tempo de simulação;

- Rajadas originadas tanto no processo de chegada como na demanda de serviço, ocorrendo em escalas de tempos distintos ou sincronizadas ao longo do tempo de simulação.

O planejamento desses experimentos considera diferentes fatores e níveis os quais serão detalhados na Seção 6.6. Todos os experimentos foram repetidos 10 vezes, cada uma com duração aproximada de 5.400 segundos ou 1,5 hora (no CloudSim a unidade de tempo é representada em segundos), utilizadas para determinar a média, o desvio padrão e o intervalo de confiança de $95 \%$ de acordo com a tabela T-student.

\subsection{Medidas de Desempenho Consideradas}

Os experimentos apresentados na Seção 6.6 foram conduzidos com o objetivo de avaliar aspectos relacionados ao desempenho do serviço. Desta forma foram consideradas as seguintes variáveis de resposta ou medidas de desempenho:

- Tempo médio de resposta: intervalo de tempo entre o envio da requisição pelo cliente e chegada da resposta completa processada pela nuvem.

- Tempo médio de serviço das requisições: representa o tempo de processamento das requisições nas VMs.

- Tempo médio de espera em Fila: corresponde ao tempo em que a requisição permaneceu esperando na fila da VM para ser atendida; 
- $\quad \underline{V a z \tilde{a} o}$ : taxa média na qual as solicitações são atendidas pela nuvem, medida em requisições por segundo.

Além dessas variáveis de resposta mencionadas, foram analisadas ainda a taxa de chegadas de requisições e de chegada de demandas de serviços monitoradas em intervalos de tempo de 14 segundos durante a simulação e o percentual do consumo de recursos da nuvem privada, monitorados em intervalos de tempo de 1 segundo ao longo da simulação. Amostras obtidas em todos esses monitoramentos são apresentadas na próxima Seção.

\subsection{Análise dos Resultados}

Nesta Seção são apresentados os resultados obtidos com a execução dos experimentos. A análise dos resultados consiste na observação das médias referentes ao tempo de resposta, tempo de execução do serviço, tempo de espera em fila e vazão e de uma análise estatística com cálculo dos desvios padrão, intervalos de confiança, considerando uma taxa de erro de $5 \%$.

\subsubsection{Impacto das Rajadas no Processo de Chegada}

Os resultados obtidos na avaliação de desempenho dos serviços executados em nuvem privada e em nuvem híbrida, considerando cargas de trabalho sem e com rajadas no processo de chegada das requisições, são discutidos nesta Seção. Diferentes perfis de rajadas são modelados para representar rajadas de intensidades variáveis (suaves e severas) e com variabilidades em diferentes escalas (moderadas e altas). Desta forma, será possível avaliar como estes diferentes tipos de cargas de trabalho afetam as variáveis de resposta consideradas.

Neste sentido, foram consideradas quatro cargas de trabalho que representem rajadas no processo de chegada das requisições, modeladas por quatro MAPs com parâmetros distintos e com variabilidades e intensidades também diferentes, quantificadas pelo quadrado do coeficiente de variação (SCV) e índice de dispersão (I) respectivamente. A Tabela 6.4 apresenta os quatro MAPs considerados nas avaliações de desempenho apresentada nesta Seção.

Na terceira e quarta coluna da Tabela 6.4, estão descritos os parâmetros de dois MAPs modelados com a mesma variabilidade, $\mathrm{SCV}=3$, mas com intensidades de rajadas diferentes, considerando intensidades mais suaves ( $\mathrm{I}=400)$ e intensidades mais severas ( $\mathrm{I}=4000)$. Os outros dois MAPs, foram parametrizados considerando também a mesma variabilidade, porém mais alta do que nos anteriores ( $\mathrm{SCV}=7$ ) e também com dois níveis de intensidades, suaves ( $\mathrm{I}=400)$ 
e severas (I=4000). Os parâmetros desses dois últimos modelos estão descritos na quinta e sexta coluna da Tabela 6.4.

Tabela 6.4 - Parametrização dos MAPs para intervalos de chegadas

\begin{tabular}{|c|c|c|c|c|c|}
\hline \multirow[b]{2}{*}{ Diagrama } & \multirow[b]{2}{*}{ Parâmetro } & \multicolumn{2}{|c|}{$\mathrm{SCV}=3$} & \multicolumn{2}{|c|}{$\mathrm{SCV}=7$} \\
\hline & & $I=400$ & $\mathrm{I}=4000$ & $I=400$ & $I=4000$ \\
\hline \multirow{6}{*}{$p_{i i}(\underbrace{\left.\begin{array}{c}\delta_{i} \\
\text { Estado SR }\end{array}\right)}_{1-p_{i j}}$} & $\lambda_{i}$ & 0,06978 & 0,07144 & 0,03571 & 0,03443 \\
\hline & $\lambda_{j}$ & 389,7243 & 398,99999 & 693,5379 & 192,86055 \\
\hline & $p_{i i}$ & 0,9978 & 0,99975 & 0,98866 & 0,9988 \\
\hline & $p_{j j}$ & 0,9979 & 0,99975 & 0,99622 & 0,99962 \\
\hline & $\lambda^{-1}$ & $7 \mathrm{~s}$ & $7 \mathrm{~s}$ & $7 \mathrm{~s}$ & $7 \mathrm{~s}$ \\
\hline & $\rho_{1}$ & 0,3 & 0,3 & 0,4 & 0,4 \\
\hline
\end{tabular}

Quanto ao planejamento dos experimentos considerados para avaliar a influência das rajadas originadas no processo de chegada das requisições, foram considerados 2 fatores, um com 5 níveis e outro com dois níveis, conforme apresentado na Tabela 6.5.

O primeiro fator refere-se ao processo de chegada das requisições. Para esse fator são considerados cinco níveis. O primeiro Sem Rajadas, onde os intervalos de tempo (think times) entre chegadas de requisições, de um mesmo cliente, são gerados seguindo uma distribuição exponencial com média de 7 segundos. Os outros quatro níveis consideram processos de chegadas Com Rajadas, incluindo rajadas com variabilidade e intensidades distintas, modeladas usando os MAPs apresentados na Tabela 6.4. Isto é, o segundo e terceiro nível consideram rajadas com variabilidade moderada, ou $\mathrm{SCV}=3$, e intensidades suaves e severas respectivamente. Enquanto que no quarto e quinto nível, os processos de chegada se apresentam em forma de rajadas, com alta variabilidade e com intensidades suaves (quarto nível) e severas (quinto nível).

O segundo fator representa o modelo de nuvem a ser adotado na camada de infraestrutura do ambiente de testes. O primeiro nível desse fator considera um modelo de nuvem privado, com um único data center, enquanto que no segundo nível o modelo de nuvem segue a abordagem híbrida, ou seja, composto por uma nuvem privada e uma nuvem pública. Todos os data centers seguem as configurações descritas na Seção 6.2 deste Capítulo. 
Tabela 6.5 - Organização dos Experimentos

\begin{tabular}{|l|l|}
\hline Fatores & Niveis \\
\hline \hline \multirow{4}{*}{ A- Processo de Chegada das requisições } & Sem Rajadas (SR) \\
\cline { 2 - 2 } & Com Rajadas (CR) - I=400 e SCV=3 \\
\cline { 2 - 2 } & Com Rajadas (CR) - I=4000 e SCV=3 \\
\cline { 2 - 2 } & Com Rajadas (CR) - I=400 e SCV =7 \\
\cline { 2 - 2 } & Com Rajadas (CR) - I=4000 e SCV=7 \\
\hline \multirow{2}{*}{ - Modelo de Nuvem } & Privada \\
\cline { 2 - 2 } & Híbrida \\
\hline
\end{tabular}

A demanda de serviço (em Milhões de Instruções, MI) imposta à nuvem foi modelada, para estes experimentos, considerando demandas sem rajadas. Neste caso, a quantidade de demandas (MI) foi definida para cada requisição, seguindo uma distribuição exponencial com média de 49.000 MI, ou seja, considerando que uma requisição é executada em uma VM com processamento igual a 7.000 MIPs, os tempos de serviço seguem uma distribuição exponencial com média de 7 segundos, a mesma média considerada na distribuição exponencial usada para gerar os intervalos de chegadas sem rajada. A média de 7 segundos foi escolhida para manter um congestionamento baixo nas filas das máquinas virtuais numa situação sem rajada, visto que neste caso, a taxa de chegada $\lambda$ é equivalente à taxa de serviço $\mu$ (Johson e Margalho, 2011).

Os resultados dos experimentos para avaliação do impacto das rajadas no processo de chegada das requisições são apresentados a seguir, sendo no primeiro item (a) os resultados referentes à avaliação de desempenho dos serviços executados em uma nuvem privada e no segundo item (b) executados em uma nuvem híbrida.

\section{a) Serviços executados em uma Nuvem Privada}

Os resultados, referentes ao tempo médio de resposta, obtidos com a execução dos experimentos propostos nesta Seção, são apresentados nos gráficos da Figura 6.4. Os gráficos mostram uma comparação entre os experimentos cuja carga de trabalho considera situações sem e com rajadas para uma quantidade de 100 clientes.

Na Figura 6.4(a) é apresentado o tempo médio de resposta obtido nas 10 execuções do experimento que não considera rajadas no processo de chegada, enquanto que na Figura 6.4 (b) e (c) apresenta-se os resultados dos experimentos que consideram diferentes perfis de rajadas. 
Como pode ser observado, quando são geradas cargas de trabalho com rajadas, há um aumento no tempo médio de resposta quando comparado a situações sem rajadas. Comparando-se a carga sem rajada com a com rajada mais leve considerada neste experimento, observa-se um aumento de $44 \%$ no tempo de resposta. Este aumento é ainda mais acentuado à medida que a variabilidade dos intervalos de tempo (think times) torna-se mais alta e a intensidade das rajadas apresenta-se ainda mais severas, conforme apresentado na Figura 6.4(c), que apresenta o tempo médio de resposta para um cenário onde as rajadas são modeladas através de MAP com variabilidade $\mathrm{SCV}=7$ e I $=4000$ e, neste caso, tem-se um aumento de $75 \%$ no tempo de resposta em relação ao caso sem rajadas. Esses resultados mostram que a presença de rajadas no processo de chegada das requisições, mesmo quando elas chegam de forma mais suave e com variabilidade moderada (Figura 6.4 (b)), ocasiona uma significativa degradação de desempenho percebida pelo usuário.

(a) SR

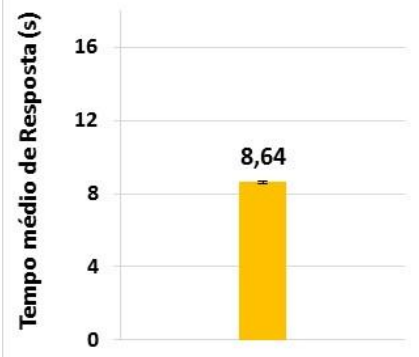

Sem Rajada (SR) (b) $\mathrm{CR}-\mathrm{SCV}=3$

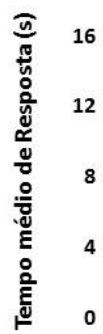

Com Rajada (CR) - I=400 (c) $\mathrm{CR}-\mathrm{SCV}=7$

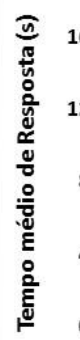

Com Rajada (CR) - I=4000

Figura 6.4 - Tempos médio de resposta em segundos, para intervalos de chegadas sem e com rajadas - considerando uma nuvem privada.

O tempo de resposta, que corresponde ao intervalo de tempo entre o envio da requisição pelo cliente ao Broker e a chegada completa da resposta no cliente, pode ser obtido pela soma do tempo em que a requisição aguardou em fila para ser atendida na VM, mais o tempo de serviço da requisição na VM e mais o tempo de ida e volta para a requisição ser transmitida pela rede do Cliente ao Broker e vice-versa e do Broker à VM do data center e vice-versa (que corresponde à latência de rede total). Desta forma, na Figura 6.5 são apresentados os tempos médios de serviço, tempos médios de espera em fila e latências médias de rede para todos os experimentos avaliados, que consideram o modelo de nuvem privado. Os resultados obtidos permitem identificar qual ou quais dessas etapas (execução, espera em fila e latência de rede) 
apresenta maior influência no aumento dos tempos médios de resposta quando as cargas de trabalhos consideraram o fenômeno de rajadas em seus modelos.

Observa-se que tanto o tempo médio de serviço (que corresponde à média definida de 7 segundos para a distribuição exponencial), como a latência média de rede são estatisticamente iguais, considerando os intervalos de confiança, para todos os experimentos, tanto sem ou com rajadas. No entanto, o tempo médio de espera em fila apresenta um aumento expressivo à medida que as rajadas no processo de chegada se tornam mais rigorosas, como pode ser notado na Figura 6.5, para o experimento que considera um MAP com I=4000 e SCV=7. Para este caso, a fila apresenta um tamanho médio de aproximadamente seis vezes o tamanho da fila observada para as requisições sem rajada. Desta forma, pode-se afirmar que o aumento no tempo médio de resposta, nas situações em que os processos de chegadas se apresentam em rajadas em relação às situações sem rajadas, foi influenciado especialmente pelo aumento no tempo médio de espera nas filas. Isso ocorre, devido ao fato que na presença de rajadas, há um aumento na quantidade solicitações de serviços submetidas à nuvem privada, que chegam de forma condensadas em alguns períodos ao longo do tempo, provocando um maior congestionamento nas filas das VMs.

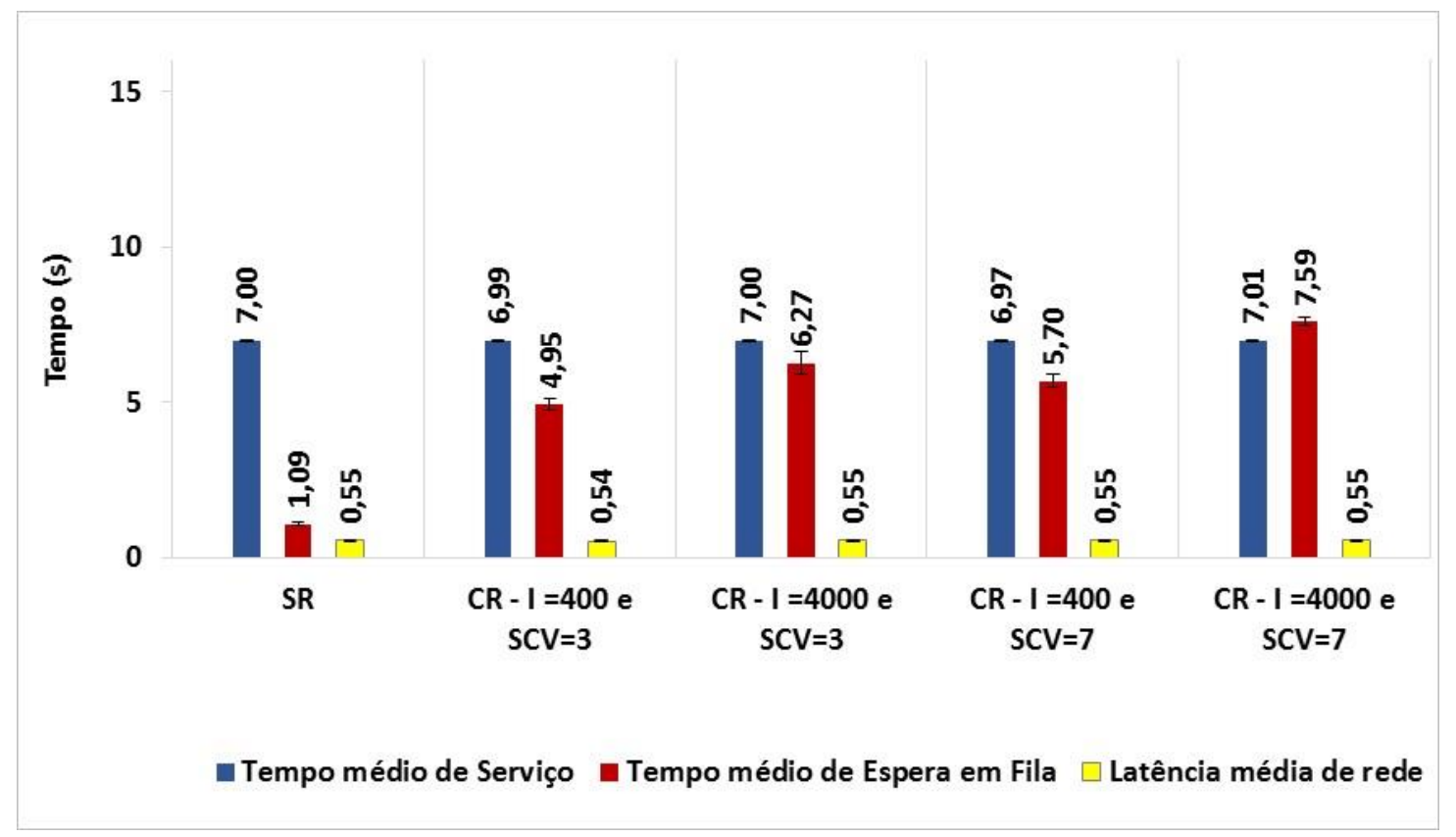

Figura 6.5 - Tempos médio de serviço, de espera em fila e Latência média de rede para intervalos de chegadas sem e com rajadas - considerando uma nuvem privada.

Os resultados obtidos para a variável de resposta vazão, são apresentados na Figura 6.6. Da mesma forma que para o tempo médio de resposta, a vazão é afetada em todos os casos em 
que se considera o fenômeno de rajadas no processo de chegada das requisições quando comparado ao resultado obtido para condição sem rajadas. Observa-se também que as vazões para situações com rajadas de variabilidade moderada $(\mathrm{SCV}=3)$, independente da intensidade considerada (suave e severa) são equivalentes, visto que as médias obtidas para esses experimentos estão inseridas dentro do intervalo de confiança um do outro. Entretanto, para rajadas modeladas com intervalos de tempo entre chegadas, com uma variabilidade mais alta (SCV =7), a vazão torna-se mais baixa, especialmente quando as rajadas chegam com intensidades mais rigorosas ( $\mathrm{I}=4000)$, neste caso observa-se uma queda de $20 \%$ na vazão.

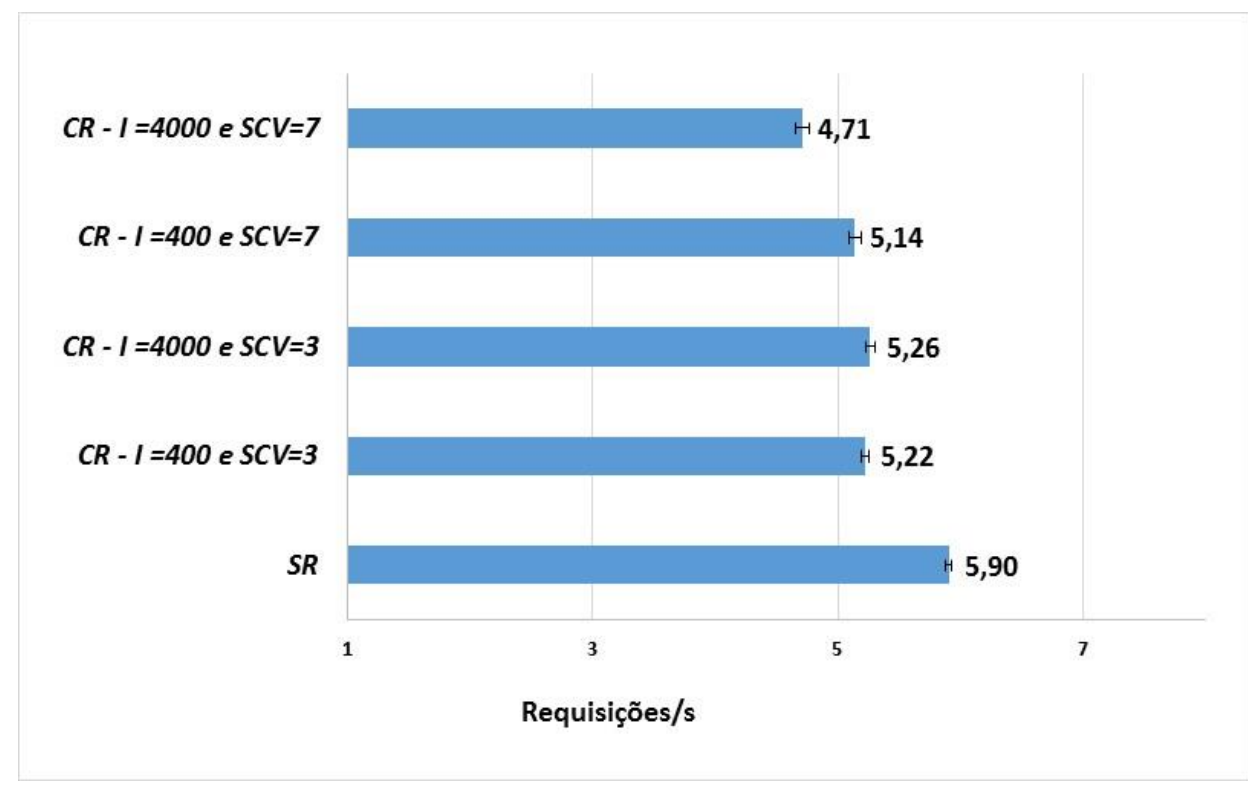

Figura 6.6 - Variável de Resposta Vazão, para intervalos de chegadas sem e com rajadas considerando uma nuvem privada.

Na Figura 6.7 são apresentadas amostras dos think times gerados durante a execução de uma das repetições dos experimentos executados, considerando chegadas de requisições sem e com rajadas para uma nuvem privada. Na situação com rajadas, Figuras 6.7(b-e), observa-se que a sequência de think times gerada se alterna entre uma sequência de think times "longos", associados a períodos de tráfego normal e uma sequência de think times "curtos", implicando que o intervalo de chegada das requisições sucessivas será menor e, portanto, resultando em rajadas de requisições. Pode-se notar também, que para cargas modeladas com MAPs com maior variabilidade, apresentadas nas Figuras 6.7 (d) e (e), além dos intervalos de chegadas apresentarem alta variabilidade, as rajadas de requisições se manifestam em períodos mais longos do que para as outras cargas de trabalho modeladas com MAPs com variabilidade moderada $(\mathrm{SCV}=3)$. Essas rajadas mais fortes, como da Figura 6.7(e), podem provocar um 
impacto mais significado no desempenho dos serviços, conforme pôde ser observado nos resultados obtidos para as variáveis de resposta mencionadas anteriormente.

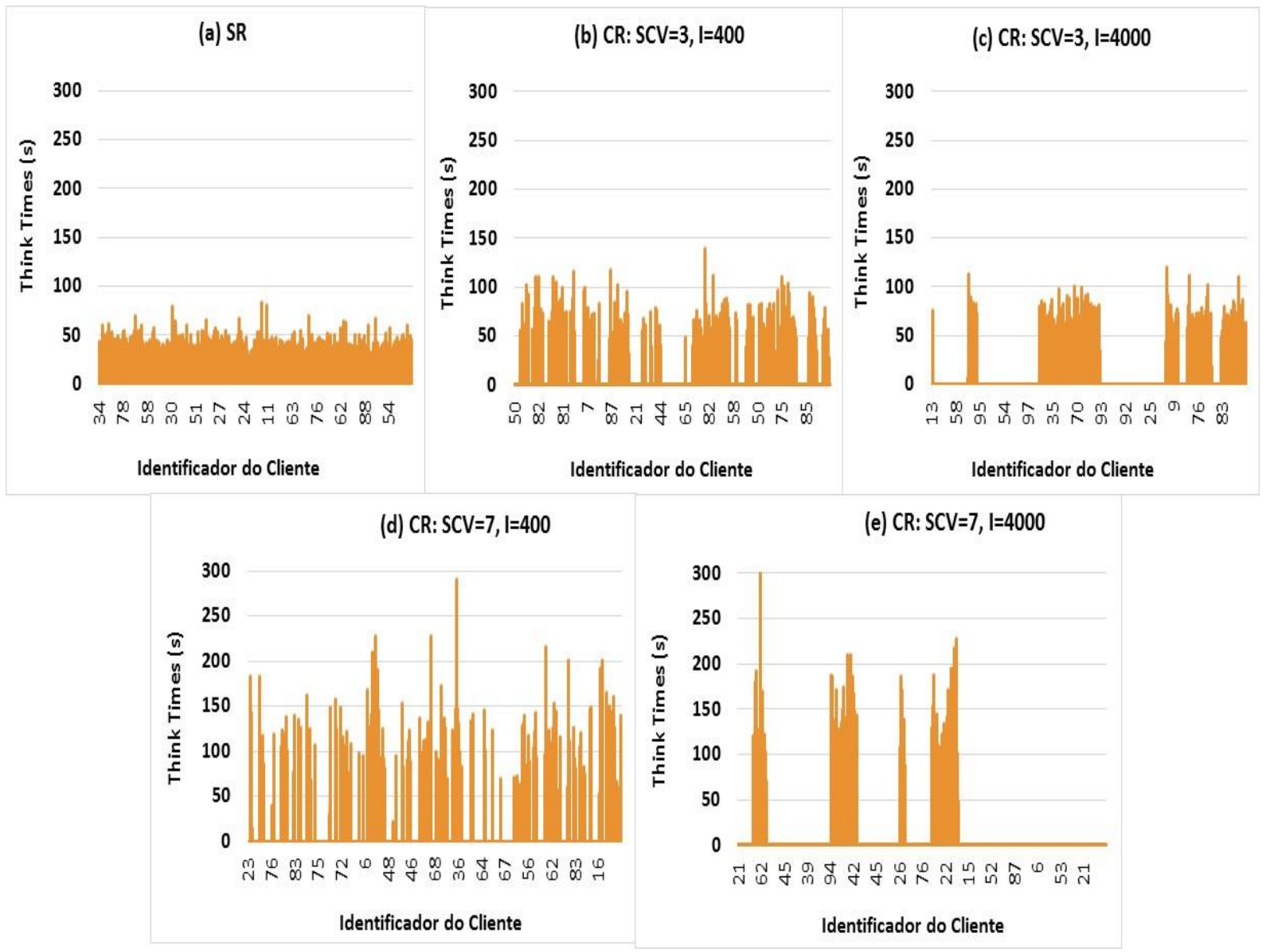

Figura 6.7 - Amostras de think times geradas durante a simulação.

Com a finalidade de comparar o comportamento entre os experimentos que utilizaram cargas sem rajadas e com rajadas, as Figuras 6.8 e 6.9, mostram amostras dos tempos de respostas e dos percentuais de consumo de recursos do data center privado, respectivamente. Essas amostras foram coletadas durante a execução de uma das repetições dos experimentos executados (a mesma repetição observada para as amostras de think times). Percebe-se que quando são criadas condições de rajadas, os tempos de respostas mostram-se superiores, formando picos irregulares em diferentes escalas de tempo, que coincidem aos períodos de rajadas observados nas amostras de think times da Figura 6.7. Nesses períodos de rajadas, notase também que os tempos mínimos de resposta se tornam maiores que os tempos mínimos obtidos para os períodos sem rajadas, fazendo com que os tempos mínimos de resposta se mostrem, como pode ser observado nos gráficos das Figuras 6.8 (b-e), mais distantes de zero. 
Esse comportamento faz com que surjam pequenos espaços vazios, que se acentuam à medida que as rajadas se intensificam.

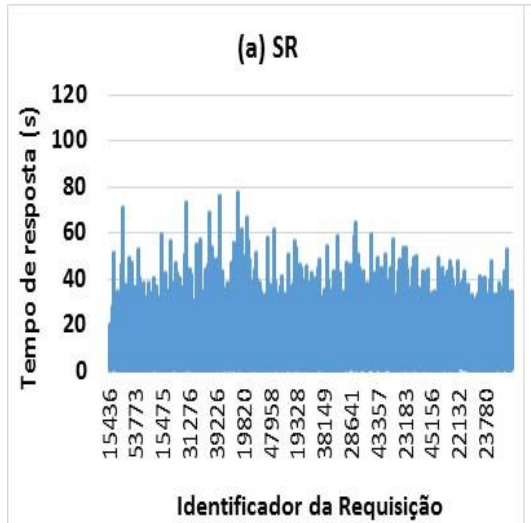

(d) CR : SCV=7, l=400

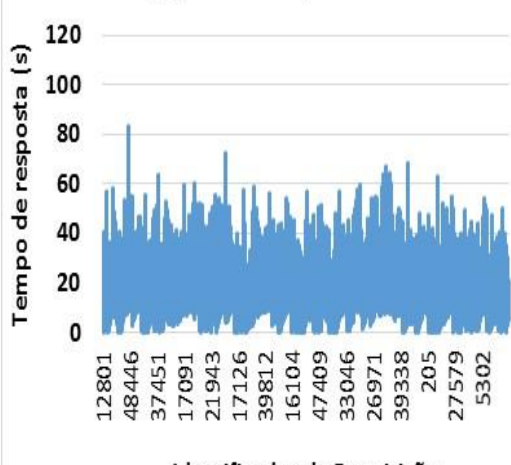

Identificador da Requisição (b) CR : SCV=3, l=400

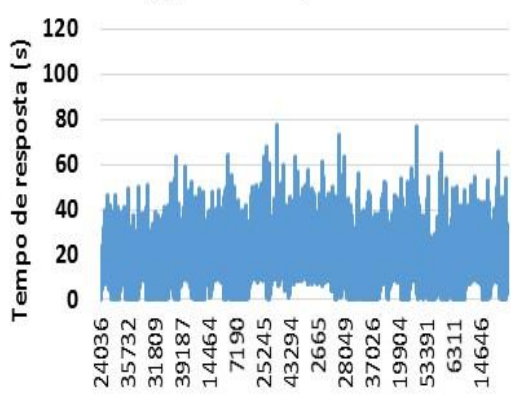

Identificador da Requisição (c) $C R:$ SCV=3, I=4000

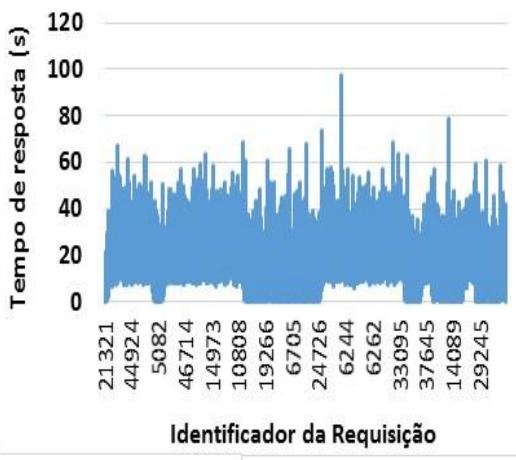

(e) CR : SCV=7, I=4000

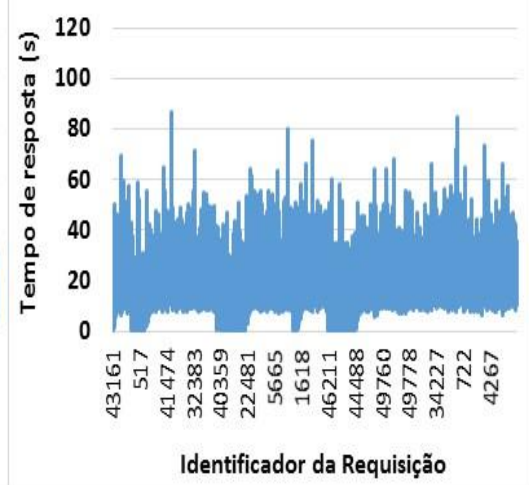

Figura 6.8 - Amostras de tempos de resposta monitoradas durante a simulação.

As amostras de percentual de consumo de recursos do data center privado, monitorados em intervalos de um segundo, são apresentadas na Figura 6.9. Para cenários em que o processo de chegada não se apresenta em rajadas, Figura 6.9(a), nota-se que o percentual de consumo já apresenta uma certa sobrecarga, no entanto, não tão expressiva como observado para os períodos em que o processo de chegada se apresenta em forma de rajadas. Nas Figuras 6.9 (c) e (e), para cargas modeladas por MAPs com $\mathrm{I}=4000$, que representam um perfil de rajada, com intensidades mais rigorosas, surgem picos de $100 \%$ de consumo durante todos os períodos em que as rajadas ocorrem.

Além das amostras dos tempos de resposta e consumos de recursos apresentadas anteriormente, foram ainda analisadas a taxa de chegadas de requisições (em requisições por segundo) e a taxa de chegada de demandas de serviços (em Milhões de Instruções por segundo - MIPs) monitoradas em intervalos de tempo de 14 segundos durante a simulação. A Figura 6.10 apresenta as amostras desses monitoramentos, para os experimentos que consideraram (a) processos de chegadas sem rajadas, e com rajadas de intensidades severas e variabilidades (b) $\mathrm{SCV}=3$ e (c) $\mathrm{SCV}=7$. As duas taxas consideradas, para cada experimento executado, são 
apresentadas em um único gráfico, sendo que o eixo vertical principal corresponde à taxa de chegada de requisições (identificada no gráfico como a linha verde) e o eixo vertical secundário representa a taxa de chegada de demanda de serviço (identificada pela linha laranja).

(a) SR

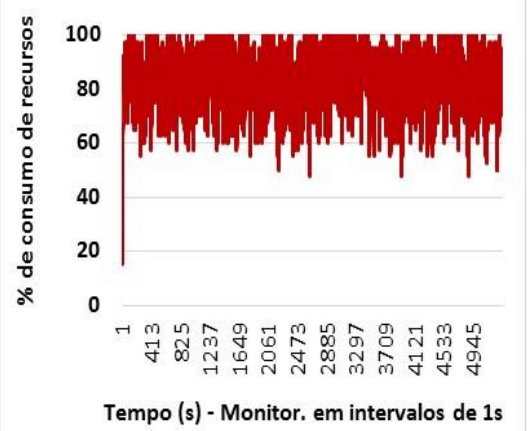

(b) CR: SCV=3, I=400

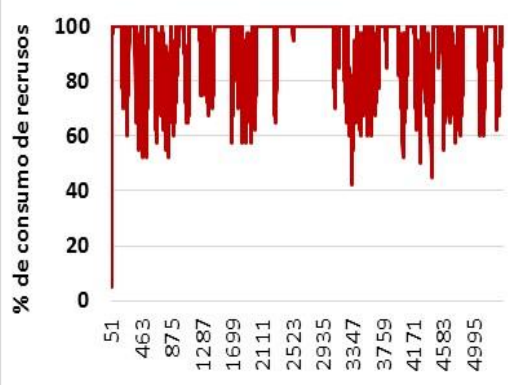

Tempo (s) - Monitor. em intervalos de 1s (d) CR: SCV=7, l=400

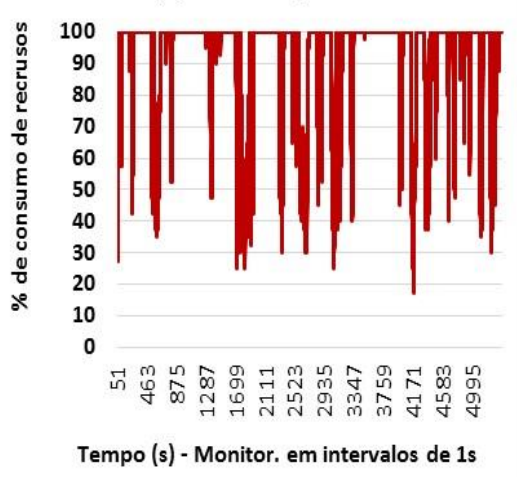

(c) CR: SCV=3, I=4000

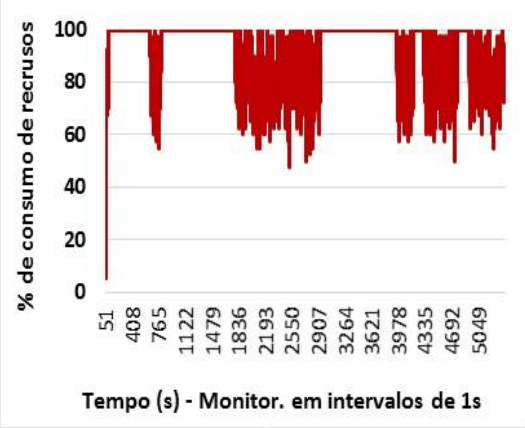

(e) CR: SCV=7, $1=4000$

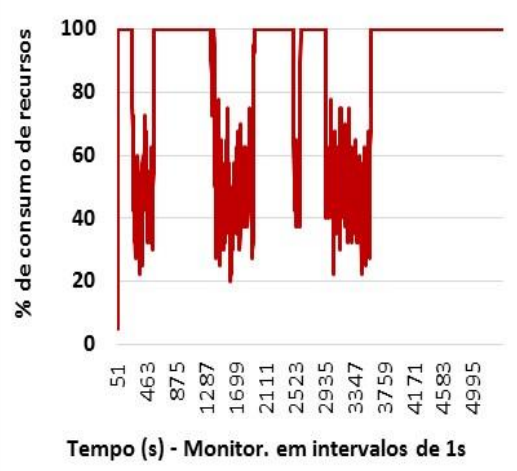

Figura 6.9 - Amostras do percentual de consumo dos recursos privados durante a simulação.

Os experimentos da Figura 6.10 (b) e (c), consideram a geração dos intervalos de chegadas modeladas por MAPs de dois estados, sendo que no primeiro estado, sem rajadas, a taxa de chegada é mais baixa e no segundo estado, com rajadas, as taxas de chegada são mais intensas, sendo estes estados alternados entre um e outro. Da mesma forma, pode ser observado para esses experimentos, que a taxa de chegada de requisições apresenta uma diminuição, durante os períodos em que o modelo encontra-se no estado sem rajadas e um aumento, nos períodos em que o modelo encontra-se no estado com rajadas. Outra observação é que em todos os experimentos da Figura 6.10, a taxa de chegada de demanda acompanha a taxa de chegada de requisições, mesmo nos casos onde o processo de chegada considera rajadas. O que é compreensível, visto que à medida em que há um aumento no número de requisições enviadas ao Broker há também um aumento na quantidade de demanda de serviço que chega para ser processada na nuvem privada. 


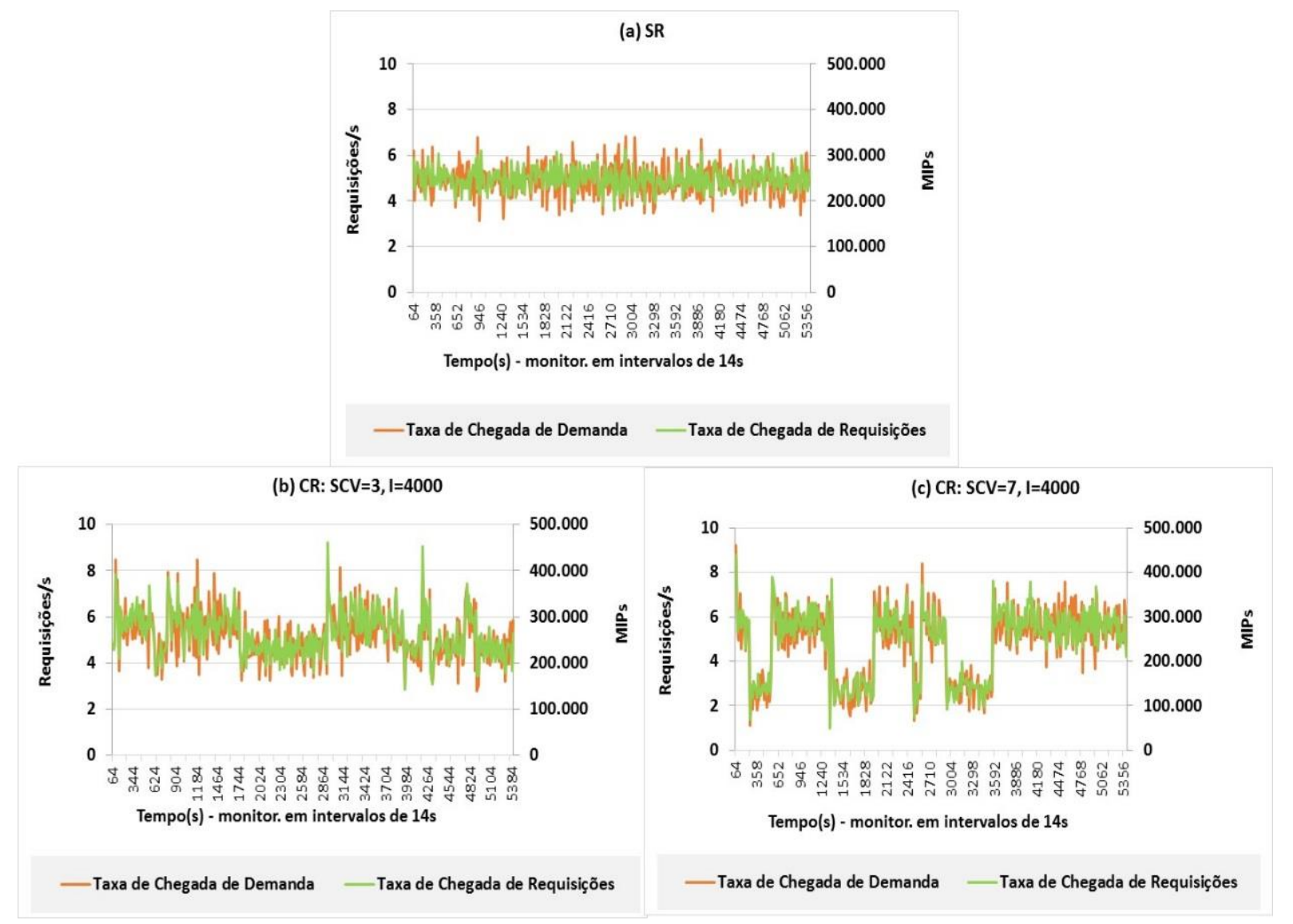

Figura 6.10 - Taxa de chegada de requisições \& taxa de demanda de serviço.

\section{b) Serviços executados em uma Nuvem Híbrida}

Neste item (b), são apresentados os resultados referentes à avaliação de desempenho dos serviços executados em uma nuvem híbrida. A Figura 6.11 mostra os tempos médios de resposta obtidos para os experimentos sem rajadas e para os experimentos que consideram diferentes perfis de rajadas. Os tempos médios de resposta obtidos em todos os experimentos, Figuras 6.11 (a-c), mostram-se muito próximos, porém um pouco maiores quando as requisições chegam em rajadas, apresentadas nas Figuras 6.11 (b) e (c). Assim, pode-se observar que o aumento do tempo de resposta que apresenta um aumento de até $75 \%$ nas nuvens privadas, com a utilização de nuvem hibrida esse aumento passou a ser de $6 \%$.

As demais variáveis de resposta analisadas são apresentadas na Figura 6.12. Na Figura 6.12(a) são apresentados os tempos médios de serviço, de espera em fila e latências médias de rede para todos os experimentos considerados neste item (b). Assim como pôde ser observado para os resultados obtidos nos experimentos que consideraram o uso de uma nuvem privada, os tempos médios de serviço, assim como as latências médias de rede obtidas para todos os experimentos executados, que consideraram nuvem híbrida, são estatisticamente iguais. 


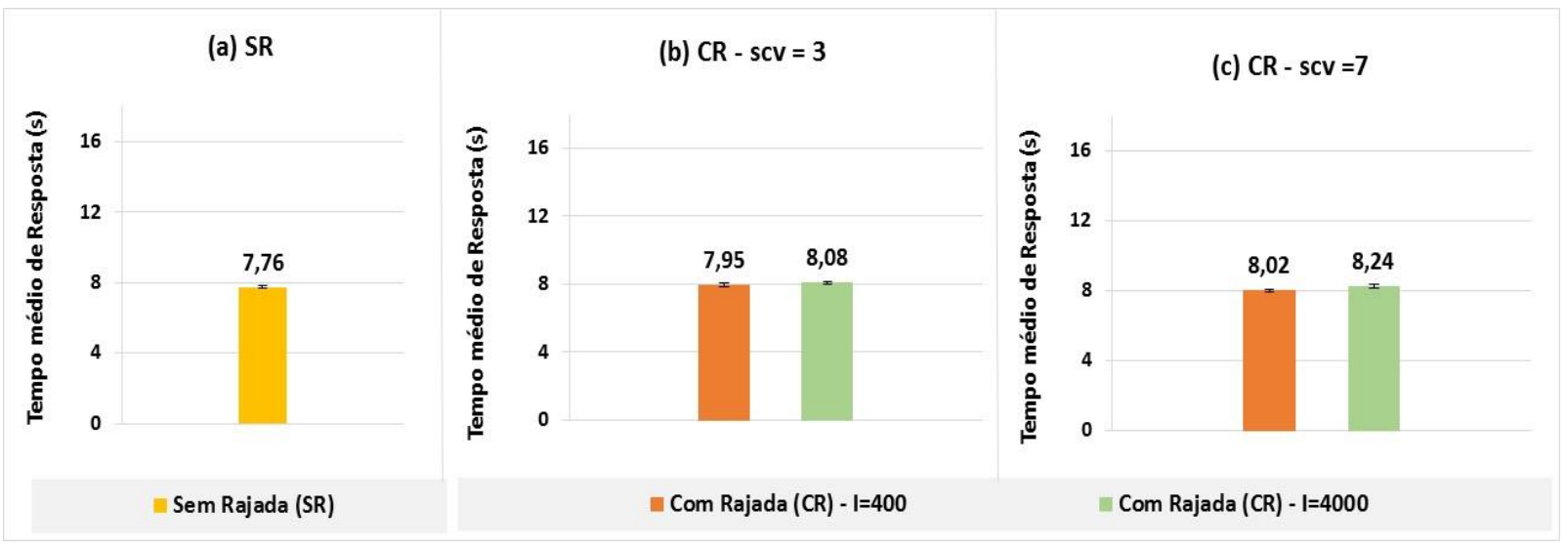

Figura 6.11 - Tempo médio de resposta em segundos, para intervalos de chegadas sem e com rajadas - considerando uma nuvem híbrida.

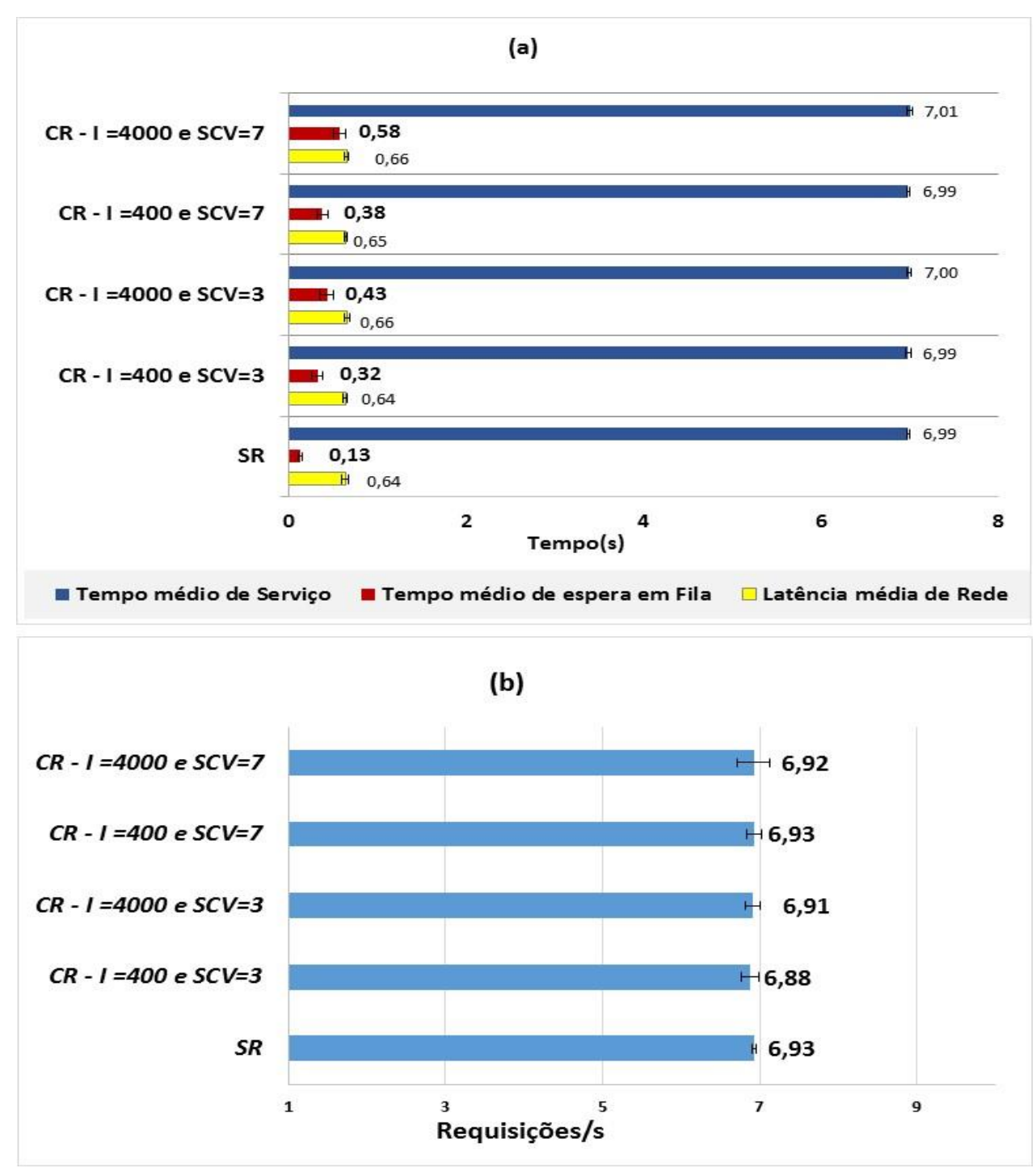

Figura 6.12 - Resultados das variáveis de Repostas: (a) Tempo médio de Serviço, de espera em fila e Latência média de rede, (b) vazão - considerando uma nuvem híbrida 
A latência de rede, embora no cenário de uma infraestrutura de nuvem híbrida tenha uma latência de rede a mais a ser considerada para as requisições serem transmitidas do Broker à nuvem pública e vice-versa, na média ela se manteve igual, mesmo em situações com rajadas onde espera-se que o número de requisições submetidas para a nuvem pública seja um pouco maior que para uma situação sem rajadas. A sobrecarga da latência de rede entre Broker e nuvem pública não é significativa, visto que é considerada uma conexão dedicada para interligálos, conforme descrito na Seção 6.2. No entanto, assim como descrito para os tempos médios de respostas obtidos na Figura 6.11, o tempo médio de espera em fila mostra-se um pouco maior à medida que as rajadas no processo de chegada das requisições se intensificam e se tornam mais variáveis.

Na Figura 6.12(b) são apresentados os resultados obtidos para a variável de resposta, vazão, medida em requisições completadas por segundo. Para essa variável de resposta, os resultados são estatisticamente iguais para todos os experimentos, sem e com rajadas. Isso acontece em virtude do modelo de nuvem híbrida possuir um maior número de recursos para processar as requisições, com capacidade para atender as requisições mesmo em momentos de picos de chegadas.

Esses resultados mostram que o impacto no desempenho de serviços causado pelas rajadas, originadas no processo de chegada, quando se considera o modelo de nuvem híbrido e as configurações dos data centers considerados neste estudo, não é tão significativo quanto observado quando o modelo de nuvem privada é adotado, principalmente quando se leva em conta as métricas de desempenho voltadas para o sistema (vazão). Quando se considera as métricas de desempenho voltadas para o cliente (tempo de resposta e de espera em fila) a influência das rajadas é menor no modelo hibrido, mas significativa. Além disso, ao observar os resultados do percentual médio de requisições executadas na nuvem pública, apresentada na Figura 6.13, percebe-se que há um custo envolvido para minimizar o efeito das rajadas e que deve ser levado em consideração. A Figura 6.13 mostra o percentual médio de requisições executadas na nuvem privada e na nuvem pública para os experimentos que consideram o processo de chegada sem rajadas e com rajadas de diferentes intensidades e variabilidades. Como pode ser notado, quanto maior a intensidade das rajadas e mais alta variabilidade dos intervalos de chegadas, maior é o percentual de requisições que são encaminhas para serem executadas nas VMs da nuvem pública, observando-se um aumento de 3,94 vezes quando se compara requisições sem rajadas com as com rajadas mais severas consideradas neste experimento. Desta forma, a utilização dos recursos da nuvem pública torna-se bem maior e 
consequentemente, considerando que esses recursos são contratados a um preço de recurso/hora, os custos também serão maiores para o provedor de nuvem contratante.

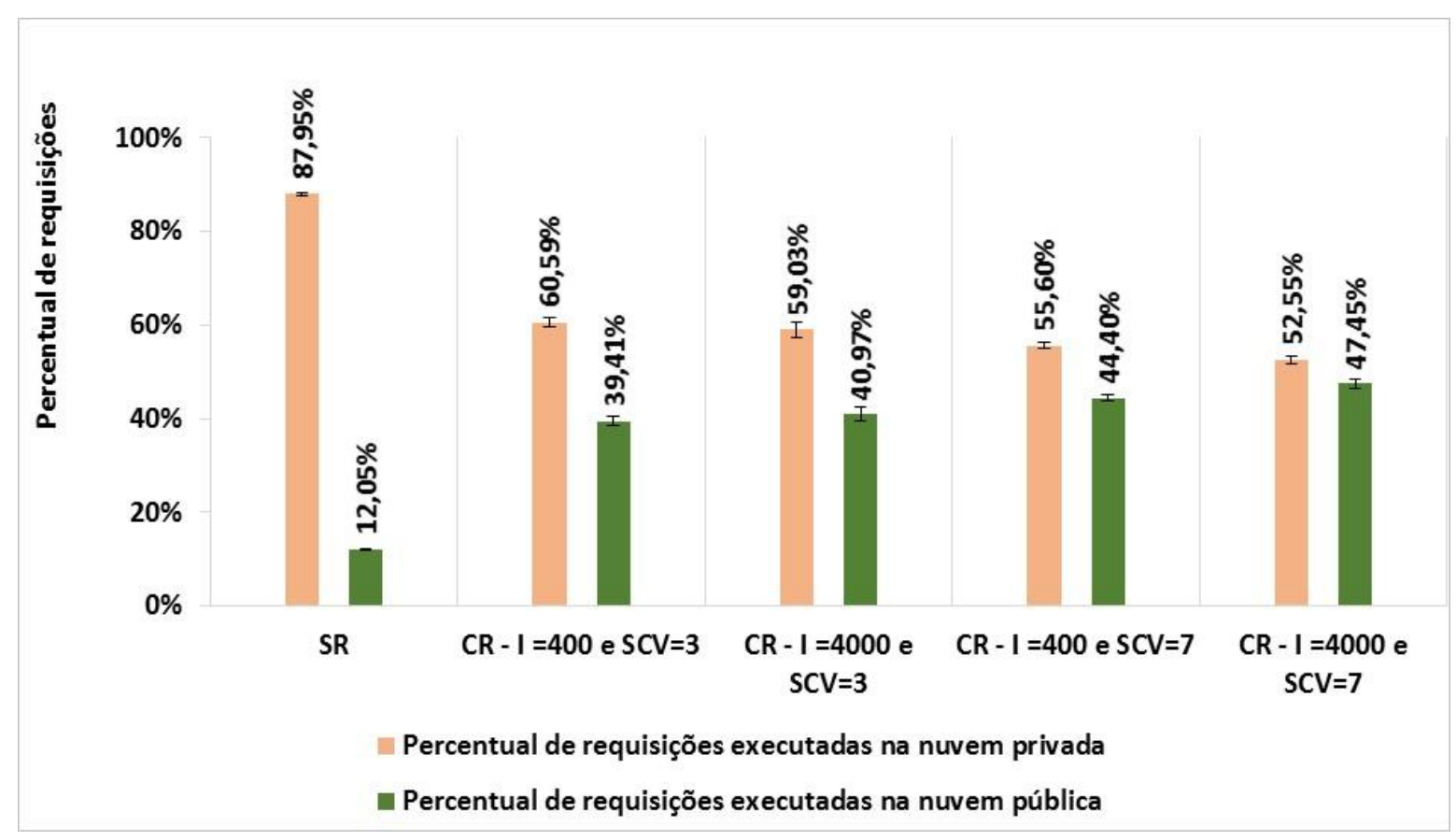

Figura 6.13 - Percentual de requisições executadas nas nuvens.

A Figura 6.14 apresenta os percentuais de consumo de recursos do data center privado e o identificador das VMs alocadas para as requisições no mesmo instante em que o percentual de consumo foi monitorado. As amostras foram coletadas durante a execução de uma das repetições dos experimentos executados, considerando chegadas de requisições sem e com rajadas. Conforme, descrito na Seção 6.2, para os experimentos que consideraram o modelo de nuvem híbrida, foi implementada uma técnica onde as requisições são encaminhadas à nuvem pública contratada, quando os recursos privados atingem um percentual limite de consumo de $80 \%$. Isto é, o Broker antes de alocar uma requisição para uma VM, ele verifica se o percentual de consumo do data center privado é menor que esse limite, caso seja, a requisição é alocada na nuvem privada, caso contrário, a requisição é encaminhada para uma VM da nuvem pública. Neste sentido, os gráficos da Figura 6.14, mostram que no momento em que o percentual de consumo dos recursos da nuvem privada atinge $80 \%$ ou mesmo ultrapassa esse limite, as requisições passam a ser encaminhadas para as VMs da nuvem pública. Esse comportamento pode ser observado nos gráficos, visto que nos momentos de sobrecarga de consumo, representada pela linha vermelha no gráfico, as requisições são alocadas para as VMs, que 
possuem identificadores maiores que 1300 (faixa de identificação usada para identificar as VMs da nuvem pública), representados pela linha azul no gráfico.

(a) $S R$
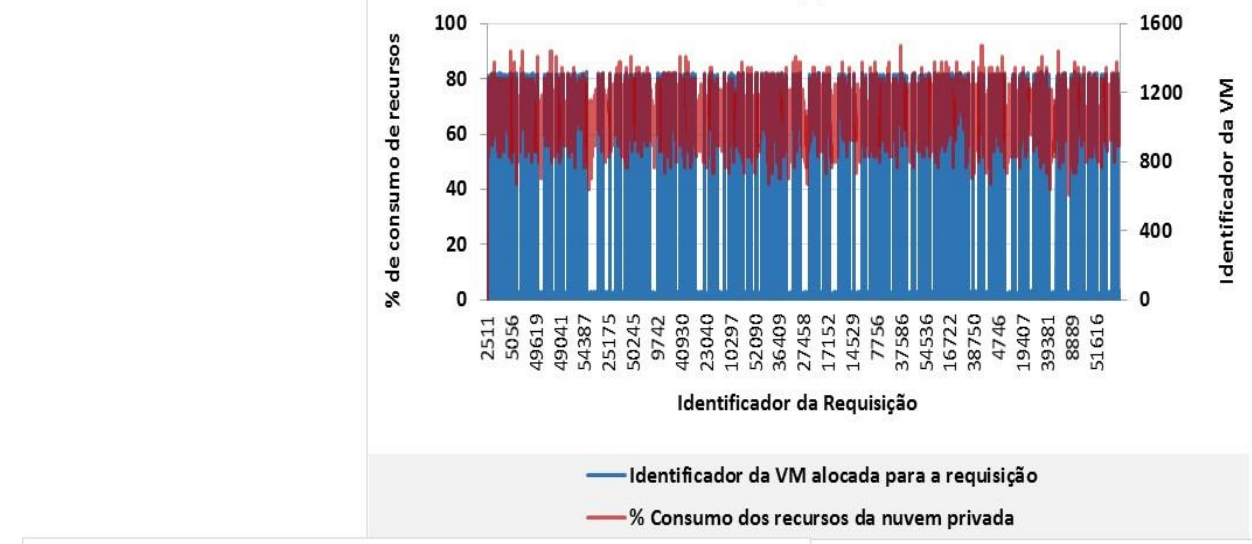

(b) CR: SCV=3, l=400

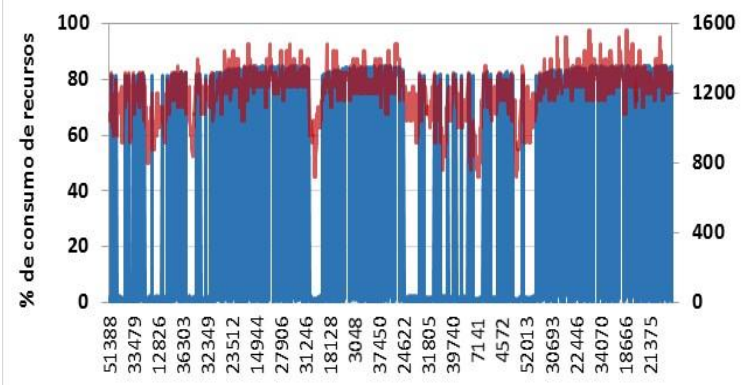

Identificador da Requisição (c) CR: SCV=3, l=4000

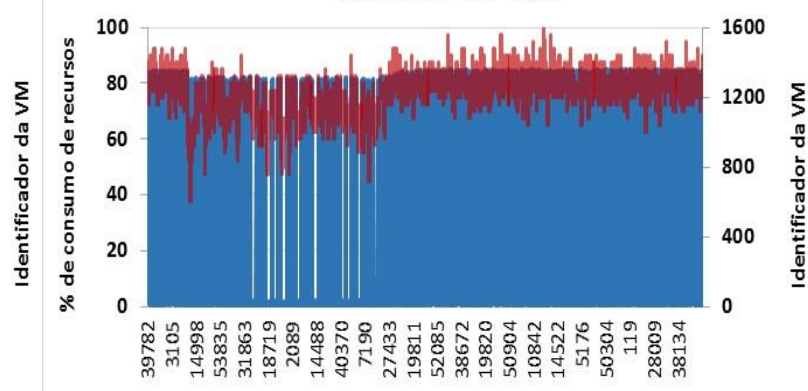

Identificador da Requisição

ara a requisição

—Identificador da VM alocada para a requisição

— Consumo dos recursos da nuvem privada

(d) CR: SCV=7, I=400

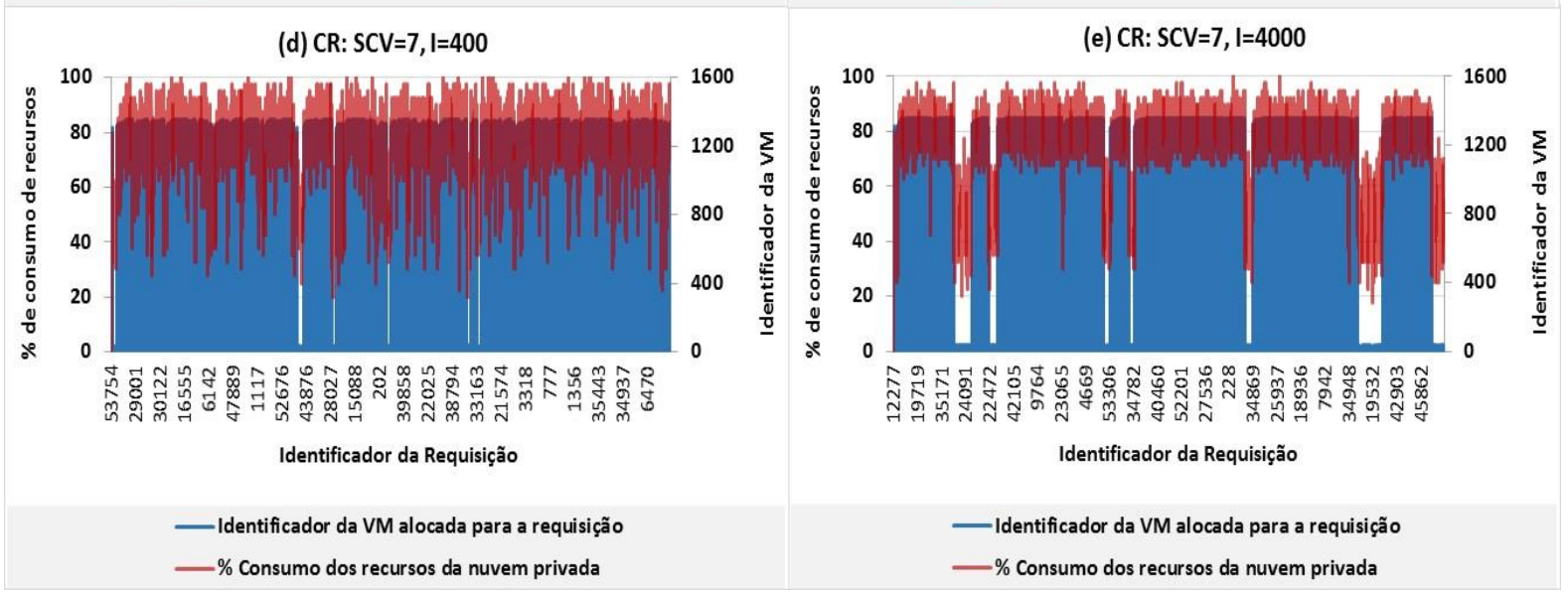

—Identificador da VM alocada para a requisição

— Consumo dos recursos da nuvem privada

Figura 6.14 - Amostras do percentual de consumo dos recursos privados e identificador das VMs alocadas para as requisições ao longo da simulação.

Observa-se também, que o consumo em alguns períodos ultrapassa o limite de $80 \%$, especialmente nos cenários em que foram criadas condições de rajadas. Isso acontece, pois, o Broker observa apenas o consumo dos recursos no momento de alocação da requisição da VM, 
mas não verifica se com a submissão dessa requisição para uma VM privada o consumo o data center privado ultrapassará esse limite. Além disso, na presença de rajadas mais variáveis, como pode ser observado nas Figuras 6.14 (d) e (e), o percentual de consumo tende a ultrapassar esse limite com maior frequência, em virtude dessas rajadas serem mais agressivas.

Entretanto, ao comparar com os percentuais de consumo das amostras apresentadas na Figura 6.9, dos experimentos que consideraram um modelo de nuvem privada, percebe-se, que apesar do processo de alocação das requisições não ser tão otimizado, os percentuais de consumo, para as situações com rajadas, não ficaram em nenhum momento sobrecarregados em $100 \%$ de utilização dos recursos. Outra observação importante é que para os experimentos da Figura 6.14(b-e), onde o processo de chegada considera rajadas de requisições, surgem picos de consumo de recursos irregulares e variáveis em diferentes escalas de tempo, o que não acontece com o experimento da Figura 6.14(a), sem rajadas, que apresenta um consumo dos recursos mais estável, durante todo o tempo de simulação.

\subsubsection{Impacto das Rajadas na Demanda de Serviço}

Esta Seção visa avaliar o impacto da presença de rajadas nas demandas de serviços submetidas em ambientes de nuvens no desempenho dos serviços. Assim como na Seção anterior, são apresentados os resultados obtidos com a execução dos experimentos, considerando chegadas de demandas sem e com rajadas, em nuvem privada e em uma nuvem híbrida. Neste estudo, foram consideradas quatro cargas de trabalho que representem rajadas nas demandas de serviços, modeladas por MAPs diferentes, conforme apresentado na Tabela 6.6.

Tabela 6.6 - Parametrização dos MAPs para demandas de serviços.

\begin{tabular}{|c|c|c|c|c|c|}
\hline \multirow[b]{2}{*}{ Diagrama } & \multirow[b]{2}{*}{ Parâmetro } & \multicolumn{2}{|c|}{$\mathrm{SCV}=3$} & \multicolumn{2}{|c|}{$\mathrm{SCV}=7$} \\
\hline & & $\mathrm{I}=\mathbf{4 0 0}$ & $I=4000$ & $I=400$ & $\mathrm{I}=\mathbf{4 0 0 0}$ \\
\hline \multirow[b]{6}{*}{$1-p_{i j}$} & $\mu_{i}$ & 408,27575 & 39398,99999 & 6 693,53789 & 192,86055 \\
\hline & $\mu_{j}$ & 0,07310 & 0,07144 & 0,03571 & 0,03443 \\
\hline & $p_{i i}$ & 0,9978 & 0,99975 & 0,99622 & 0,99962 \\
\hline & $p_{j j}$ & 0,9979 & 0,99975 & 0,98866 & 0,99880 \\
\hline & $\mu^{-1}$ & $7 \mathrm{~s}$ & $7 \mathrm{~s}$ & $7 \mathrm{~s}$ & $7 \mathrm{~s}$ \\
\hline & $\rho_{1}$ & 0,3 & 0,3 & 0,4 & 0,4 \\
\hline
\end{tabular}


As demandas de serviços foram modeladas considerando perfis de rajadas modeladas por MAPs com um tempo médio de serviço $\left(\mu^{-1}\right)$ de 7 segundos e com variabilidades moderadas $(\mathrm{SCV}=3)$ e altas $(\mathrm{SCV}=7)$ e com intensidades suaves ( $\mathrm{I}=400)$ e severas $(\mathrm{I}=4000)$, da mesma forma que foi considerado para as rajadas originadas no processo de chegada das requisições. Quando são consideradas rajadas nas demandas de serviços, cada requisição que é criada pelo cliente, possui uma demanda de serviço em MI atribuída a ela, conforme foi apresentado na Seção 5.3.1. Essa demanda é definida a partir do tempo de serviço gerado pelo MAP $\operatorname{com} \mu^{-1}=$ 7 segundos, usando a equação 6.13:

$$
\text { demanda }=\text { ts. MipsVM }
$$

onde $\boldsymbol{t}$ s é o tempo de serviço gerado pelo MAP e Mips $\boldsymbol{V M}$ é a capacidade de processamento da VM em Milhões de Instruções por segundo. Ou seja, para um tempo de serviço, por exemplo, de 7 segundos e uma VM de 7.000 MIPs, a demanda de serviço obtida é de 49.000 MI.

Para avaliar a influência das rajadas originadas nas demandas de serviços, os experimentos foram organizados conforme apresentado na Tabela 6.7.

Tabela 6.7- Organização dos Experimentos

\begin{tabular}{|l|l|}
\hline Fatores & Níveis \\
\hline \hline \multirow{4}{*}{ A- Demanda de Serviço das Requisições } & Sem Rajadas (SR) \\
\cline { 2 - 2 } & Com Rajadas (CR) - I=400 e SCV=3 \\
\cline { 2 - 2 } & Com Rajadas (CR) - I=4000 e SCV=3 \\
\cline { 2 - 2 } & Com Rajadas (CR) - I=400 e SCV=7 \\
\cline { 2 - 2 } & Com Rajadas (CR) - I=4000 e SCV=7 \\
\hline \multirow{3}{*}{ B - Modelo de Nuvem } & Privada \\
\cline { 2 - 2 } & Híbrida \\
\hline
\end{tabular}

Neste planejamento de experimento também foram considerados dois fatores: a demanda de serviço das requisições e modelo de nuvem adotada. $\mathrm{O}$ fator demanda de serviço possui cinco níveis, sendo eles:

- Sem Rajadas - onde considera-se demandas de serviços por uma distribuição exponencial com média de 49.000 Milhões de Instruções (MI) ou tempo médio de serviço de 7 segundos.

- Com Rajadas - onde considera-se mais quatro níveis com diferentes perfis de rajadas (segundo a quinto nível). O segundo e o terceiro, considera cargas de trabalhos modeladas 
por MAPs com variabilidade moderada $(\mathrm{SCV}=3)$ e intensidades suaves e severas, respectivamente. Enquanto que, no quarto e quinto nível, considera-se MAPs com uma variabilidade alta $(\mathrm{SCV}=7)$ e com intensidades também distintas.

Todos os experimentos consideraram que o processo de chegadas de requisição não apresenta rajadas e, portanto, os think times são gerados por uma distribuição exponencial com média $\left(\lambda^{-1}\right)$ de 7 segundos, da mesma forma que foi considerado para a demanda de serviço nos experimentos, apresentados na Seção 6.6.1.

\section{a) Serviços executados em uma Nuvem Privada}

Os resultados, referentes ao tempo médio de resposta, obtidos com a execução dos experimentos considerados nesta Seção (item a), são apresentados nos gráficos da Figura 6.15. Como pode ser observado, quando se considera demandas de serviços sem rajadas submetidas à nuvem privada (Figura 6.15(a)), o tempo médio de resposta é significativamente menor comparado aos resultados obtidos com cenários onde as demandas de serviços chegam em forma de rajadas (Figura 6.15(b) e (c)). Os atrasos nos tempos de resposta impostos pelas rajadas são similares aos obtidos no caso analisado na Seção 6.6.1, variando de $45 \%$ para as rajadas mais suaves até $78 \%$ nas rajadas mais severas. Assim como aconteceu para as rajadas originadas no processo de chegada das requisições, o desempenho do serviço é ainda mais afetado negativamente quando as rajadas originadas nas demandas de serviços apresentam variabilidade mais alta $(S C V=7)$ e a intensidade mais severas $(I=4000)$, na Figura 6.15(c).

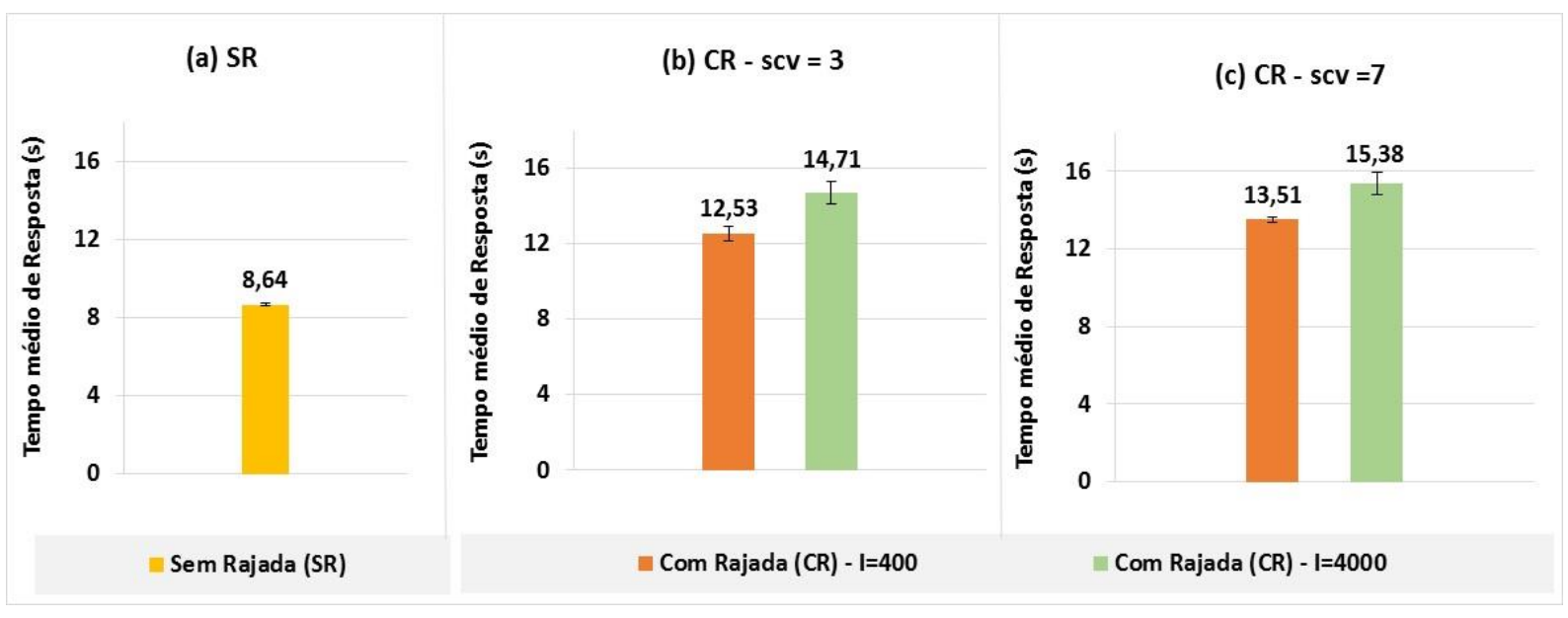

Figura 6.15 - Tempos médio de resposta em segundos, para demandas de serviços sem e com rajadas - considerando uma nuvem privada. 
As variáveis de resposta tempo médio de serviço, tempo médio em que a requisição aguardou em fila para ser atendida na VM e a latência média de rede, que somados correspondem ao tempo médio de resposta, são apresentadas na Figura 6.16. Os resultados mostram que o tempo médio de serviço em todos os experimentos obtidos possuem uma média estatisticamente igual, uma vez que tanto para cenários sem rajadas (que segue uma distribuição exponencial), como com rajadas (que são modeladas por MAPs), o tempo médio de serviço considerado é de 7 segundos. As latências médias de rede também se mantiveram equivalentes em todos os experimentos realizados. No entanto, percebe-se que o tempo médio de espera em fila tornam-se maiores à medida que as rajadas de demandas de serviços chegam à nuvem com maior severidade e variabilidade.

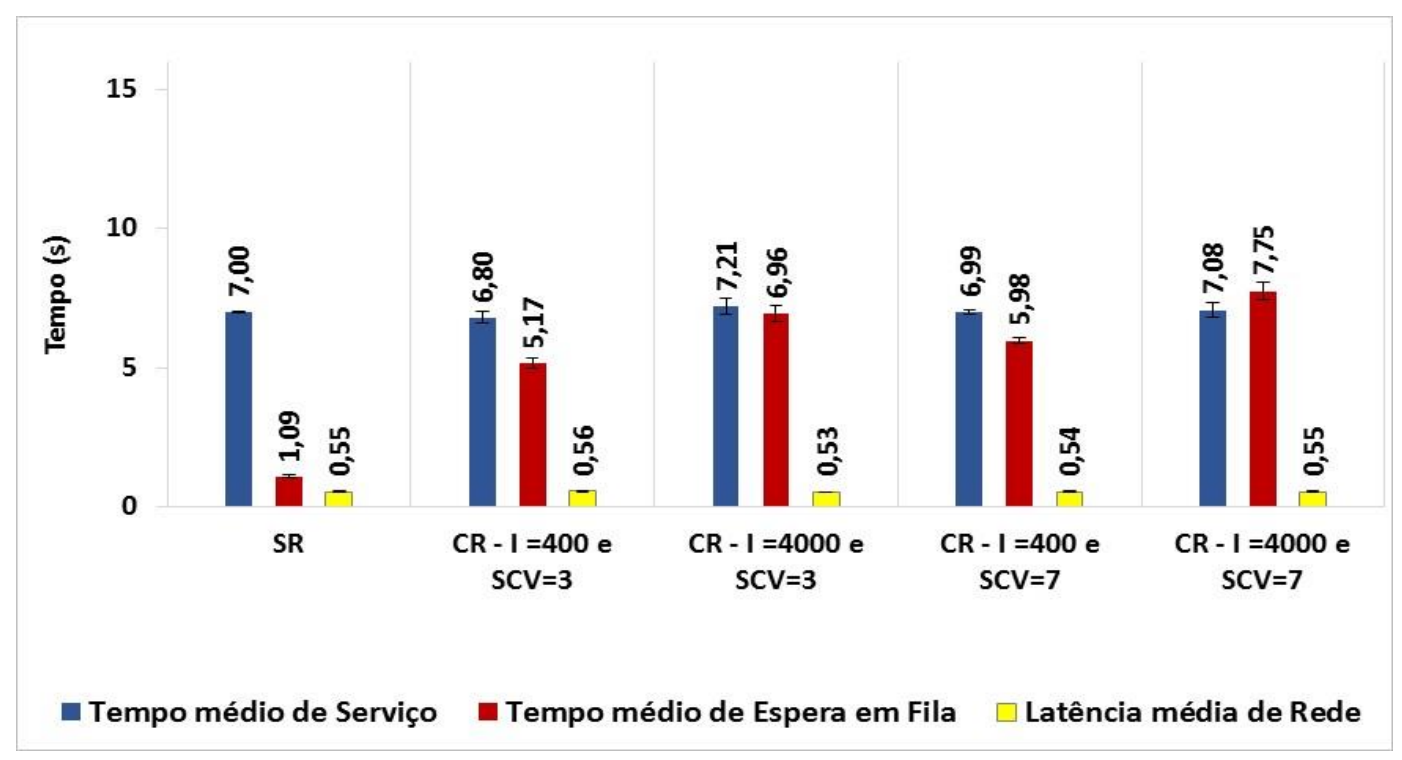

Figura 6.16 - Tempos médio de serviço, de espera em fila e Latência média de rede para demandas de serviços sem e com rajadas - considerando uma nuvem privada.

Os resultados para a variável de resposta vazão, são semelhantes às obtidas para o tempo médio de resposta e tempo médio de espera em fila. Na Figura 6.17 é apresentada a vazão obtida para cada um dos níveis do fator de demanda de serviço, considerando uma nuvem privada. Nota-se que mesmo quando são consideradas rajadas de intensidades mais suaves, há uma degradação da capacidade do sistema, em virtude da sobrecarga imposta aos recursos da nuvem, resultando em uma diminuição de $19 \%$ na vazão observada. No caso mais crítico tem-se uma diminuição de $31 \%$ na vazão do sistema. 


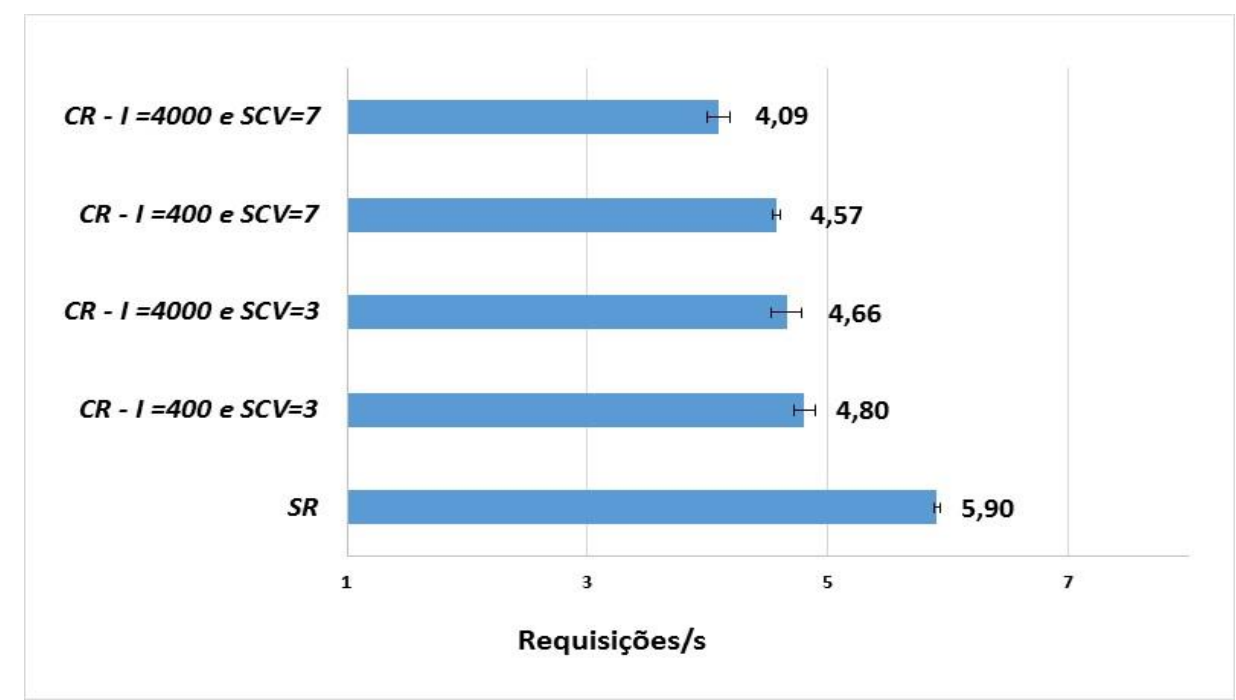

Figura 6.17 - Variável de Resposta Vazão, para demandas de serviços sem e com rajadas considerando uma nuvem privada.

Os gráficos da Figura 6.18 apresentam amostras de demandas de serviços geradas durante a execução de uma das repetições dos experimentos executados, considerando demandas de serviços sem e com rajadas. Diferente dos gráficos de amostras de think times com rajadas apresentados na Figura 6.7 (b-e) da Seção 6.6.1, onde a sequência de think times "longos" corresponde aos períodos de tráfego normal e uma sequência de think times "curtos" corresponde aos períodos de rajadas, para as demandas de serviços com rajadas ocorre o oposto. Ou seja, a sequência de demandas de serviços geradas pelo MAP de dois estados, apresentadas nas Figuras 6.18(b-e), ocorrem da seguinte forma: quando o processo MAP encontra-se no estado sem rajadas, é gerada uma sequência de demandas de serviços mais leves (ou tempos de serviços mais "curtos"), associados a períodos de tráfego normal e quando encontra-se no estado com rajadas, é gerada uma sequência de demandas de serviços mais pesada (ou tempos de serviços mais “longos"), associados a períodos de rajadas de demandas impostas ao ambiente de nuvem. Nas Figuras 6.18 (b) e (c), observa-se que os picos de demandas de serviços, embora bem mais acentuadas do que para demandas modeladas sem rajadas (Figura 6.18(a)), são muito mais suaves do que pode ser notado para demandas modeladas por MAPs parametrizados com variabilidade mais alta (SCV=7), nas Figuras 6.18(d) e (e). Observa-se também que os perfis de rajadas ilustrados nas Figuras 6.18 (d) e (e) apresentam uma característica diferente dos outros modelos com variabilidade mais baixa, isto é, picos de rajadas irregulares e altamente variáveis surgem em curtos períodos ao longo do tempo. Além disso, as rajadas modeladas pelo MAP parametrizado com SCV=7 e I=4000 (da Figura 6.18 (e)), embora tenha uma duração mais curta, o impacto no desempenho dos serviços causada por essas rajadas foi bem mais 
expressivo, conforme pôde ser notado nos resultados obtidos para as variáveis de respostas apresentadas anteriormente.

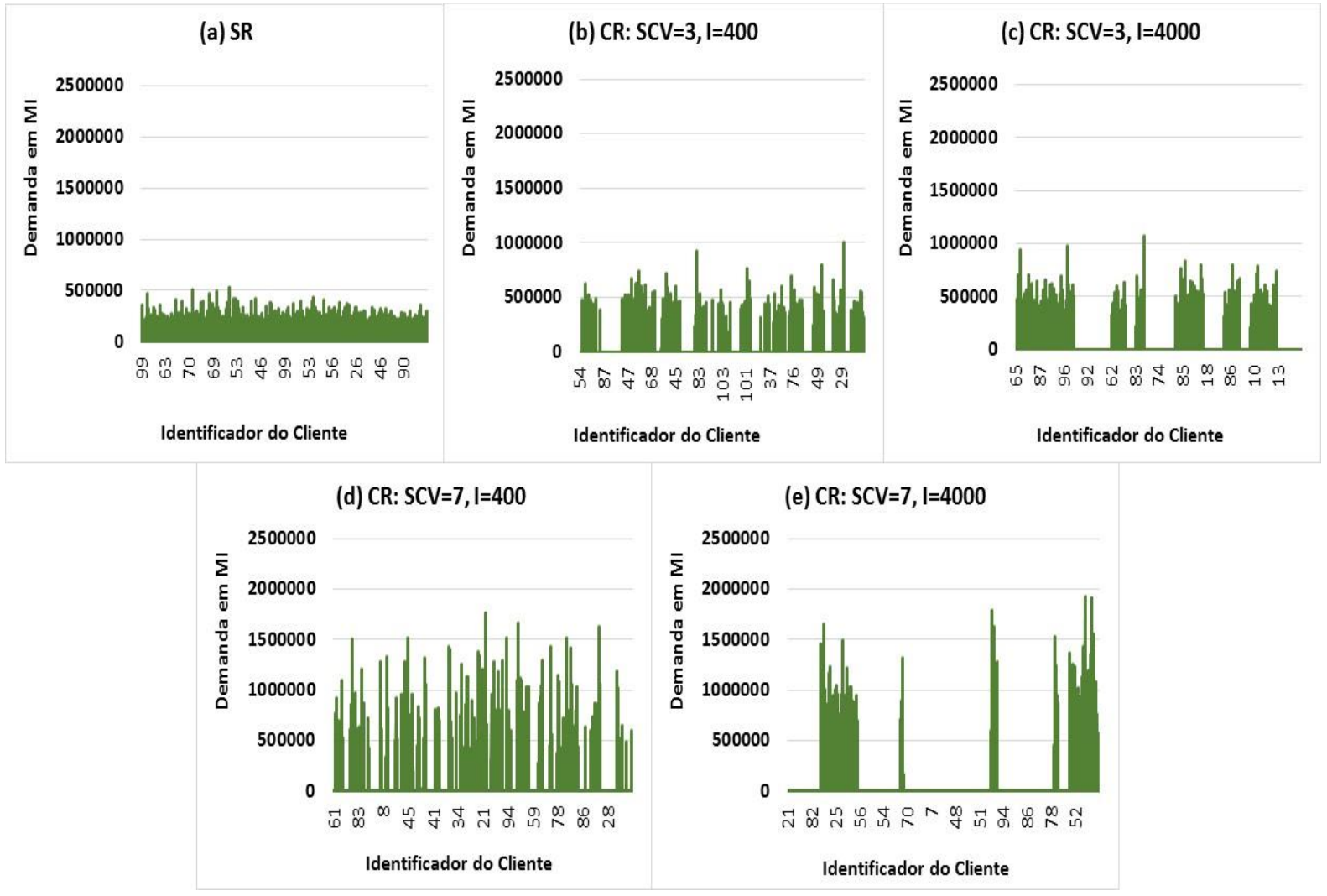

Figura 6.18 - Amostras de demandas de serviços geradas durante a simulação.

As Figuras 6.19 e 6.20 mostram os tempos de resposta das requisições enviadas à nuvem privada e o percentual de consumo dos recursos privados monitorados em intervalos de 1 segundo, respectivamente. Essas amostras, assim como as anteriores, foram coletadas durante a execução de uma das repetições dos experimentos. O intuito dessa comparação é demonstrar como o desempenho pode ser afetado quando as requisições chegam na forma de rajadas. Como pode ser notado no gráfico da Figura 6.19 (b-e), há momentos em que picos fortes e irregulares em diferentes escalas de tempo aparecem quando são criadas condições de rajadas, especialmente para os experimentos apresentados nas Figuras 6.19 (d) e (e) que consideraram uma variabilidade alta na geração das demandas de serviços. Percebe-se, no entanto, que isso não acontece com a mesma intensidade nos casos em que não há rajadas no modelo de carga de trabalho, apresentada na Figura 6.19 (a). Esse comportamento pode ser igualmente observado para as amostras de percentual de consumo apresentadas na Figura 6.20, onde, para situações com rajadas, picos de consumo atingem o máximo de utilização, 100\%, em vários momentos ao longo da simulação. 
(a) $S R$

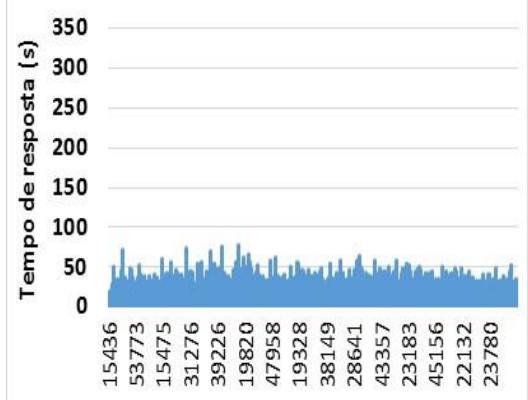

(b) CR: SCV=3, l=400

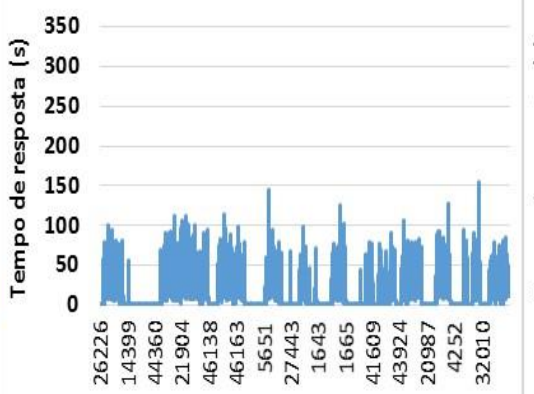

(c) CR: SCV $=3,1=4000$

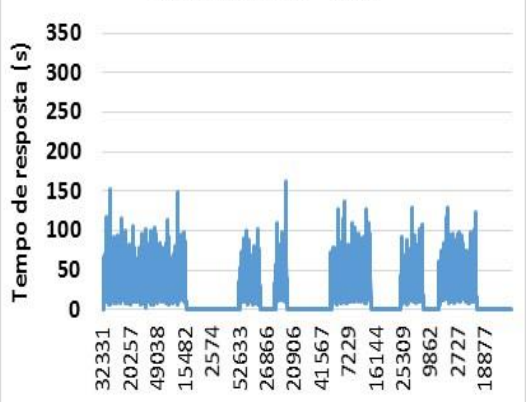

Identificador da Requisição

Identificador da Requisição

Identificador da Requisição

(e) CR: SCV=7, I=4000

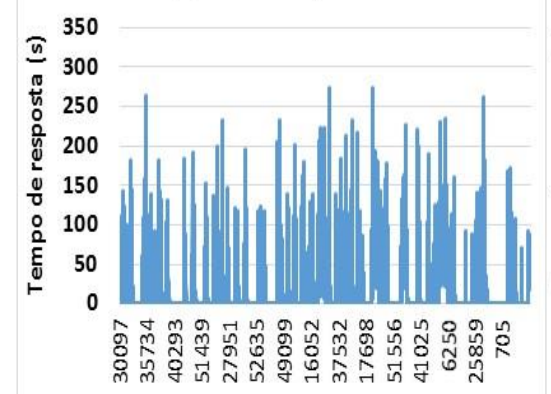

Identificador da Requisição

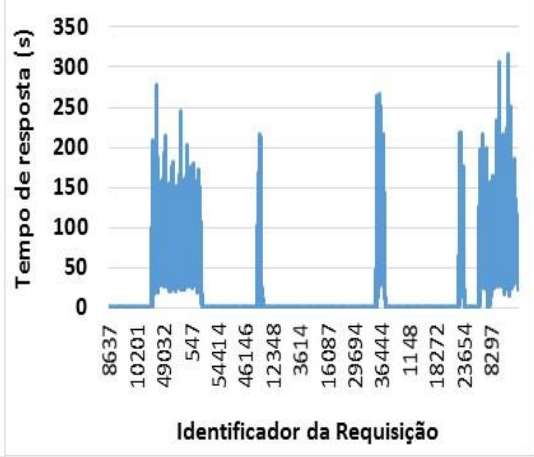

Figura 6.19 - Amostras de tempos de resposta monitoradas durante a simulação.

(a) SR

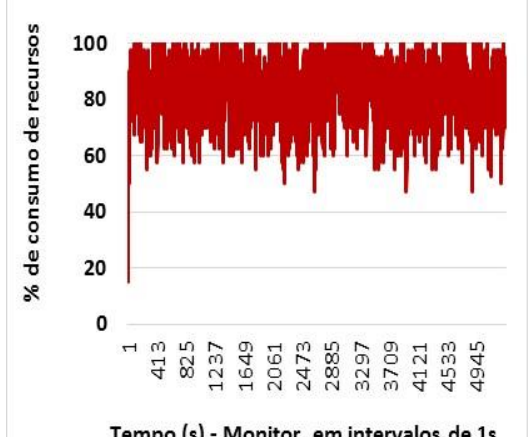

(b) CR: SCV=3, l=400

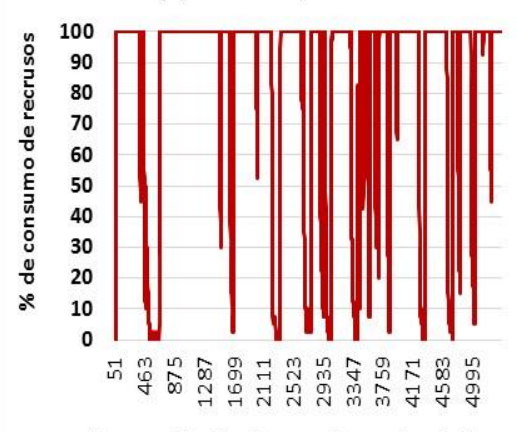

Tempo (s) - Monitor. em intervalos de 1s (c) CR: SCV=3, I=4000

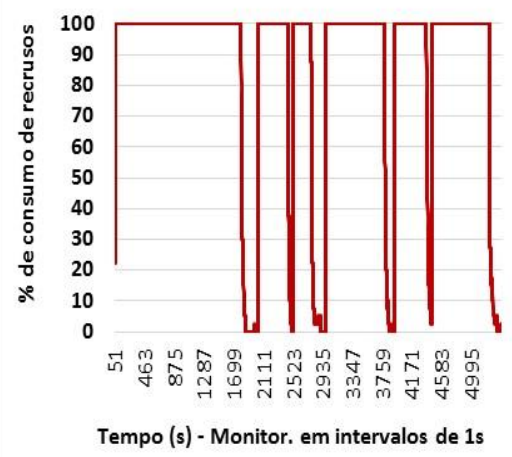

(d) CR: SCV=7, l=4000

(e) CR: SCV $=7,1=4000$
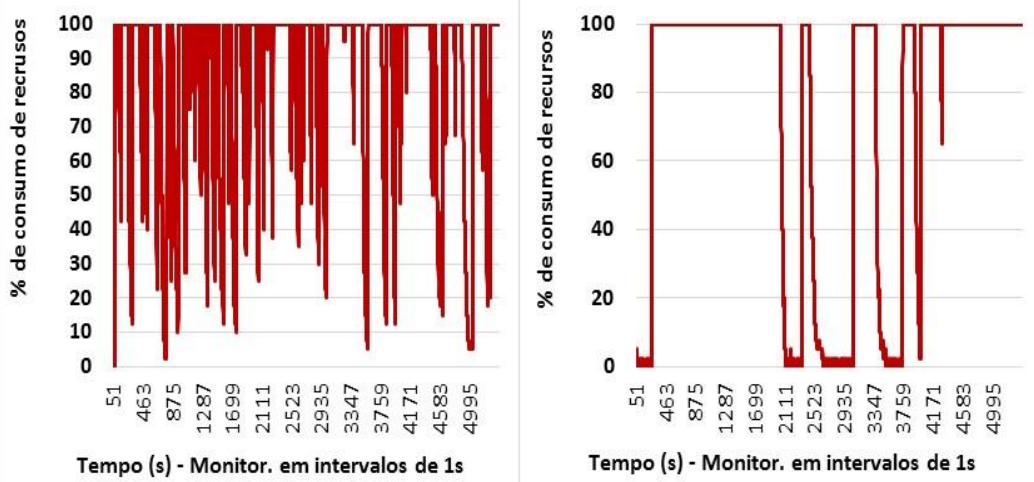

Figura 6.20 - Amostras do percentual de consumo dos recursos privados durante a simulação. 
Além das amostras apresentadas, a Figura 6.21 mostra a taxa de chegada de demandas de serviços, em Milhões de Instruções por Segundo (identificada em laranja nos gráficos), e taxa de chegadas de requisições, em requisições por segundo (identificada em verde nos gráficos), monitoradas em intervalos de tempo de 14 segundos durante a simulação. Esses monitoramentos foram realizados para os experimentos que consideraram demandas de serviços sem rajadas e com rajadas modeladas com intensidades severas ( $\mathrm{I}=4000)$ e com diferentes variabilidades.
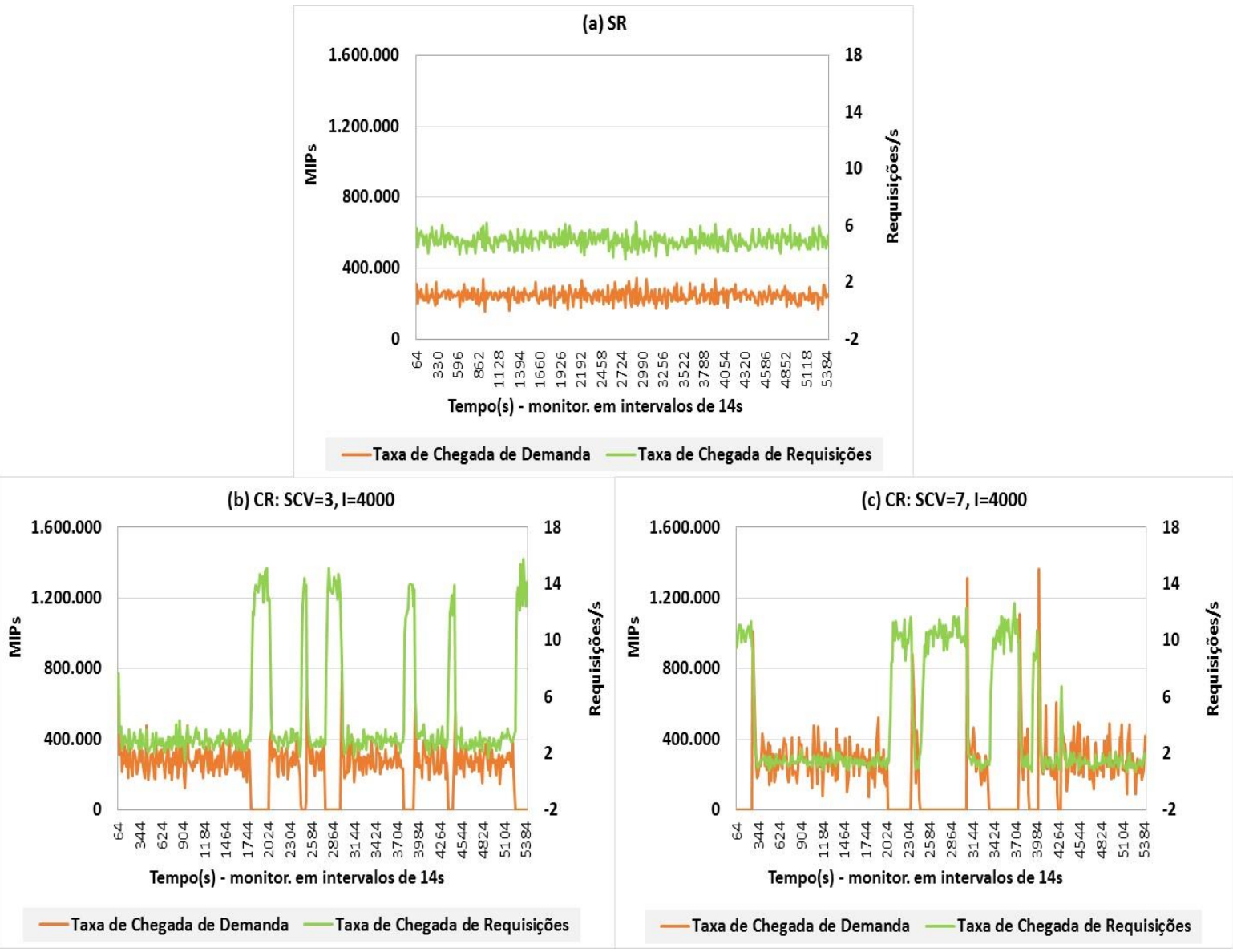

Figura 6.21 - Taxa de chegada de requisições \& taxa de demanda de serviço.

Observando os gráficos da Figura 6.21, percebe-se que a taxa de demanda de serviço sem a presença de rajadas, a Figura 6.21 (a), é bem inferior às taxas de demandas de serviços registradas quando a demanda de serviço se apresenta em forma de rajadas, Figuras 6.21 (b) e (c). Além disso, é possível notar para os experimentos onde as demandas de serviços foram modeladas por MAPs, quando há uma diminuição da taxa de demanda de serviço (períodos sem rajadas), a taxa de chegada de requisições apresenta um aumento. Isso acontece em virtude dos 
intervalos de chegada ou think times ocorrerem após a chegada completa da requisição anterior. Desta forma, quando as requisições submetidas à nuvem apresentam uma demanda mais leve, durante os períodos que as demandas são geradas pelo estado sem rajadas do MAP, as respostas completas dessas requisições chegam com maior rapidez e consequentemente, os intervalos de tempo entre o envio de duas requisições sucessivas tendem a ser menores.

\section{b) Serviços executados em uma Nuvem Híbrida}

Os resultados referentes à avaliação de desempenho dos serviços executados em uma nuvem híbrida são apresentados nesta Seção.

Os tempos médios de resposta obtidos para os experimentos com demandas sem rajadas e com rajadas, considerando uma nuvem híbrida são apresentados na Figura 6.22. Assim como observado para os resultados da Seção 6.6.1(item b), embora os resultados dos experimentos mostrem-se muito próximos, existe ainda uma pequena diferença entre os tempos médios de resposta, sendo que para os experimentos onde as demandas de serviços consideram rajadas em seu modelo, os tempos médios de resposta foram ligeiramente maiores (no máximo 5\% superior ao observado na carga sem rajada) em relação ao experimento onde as demandas não se apresentam em rajadas.

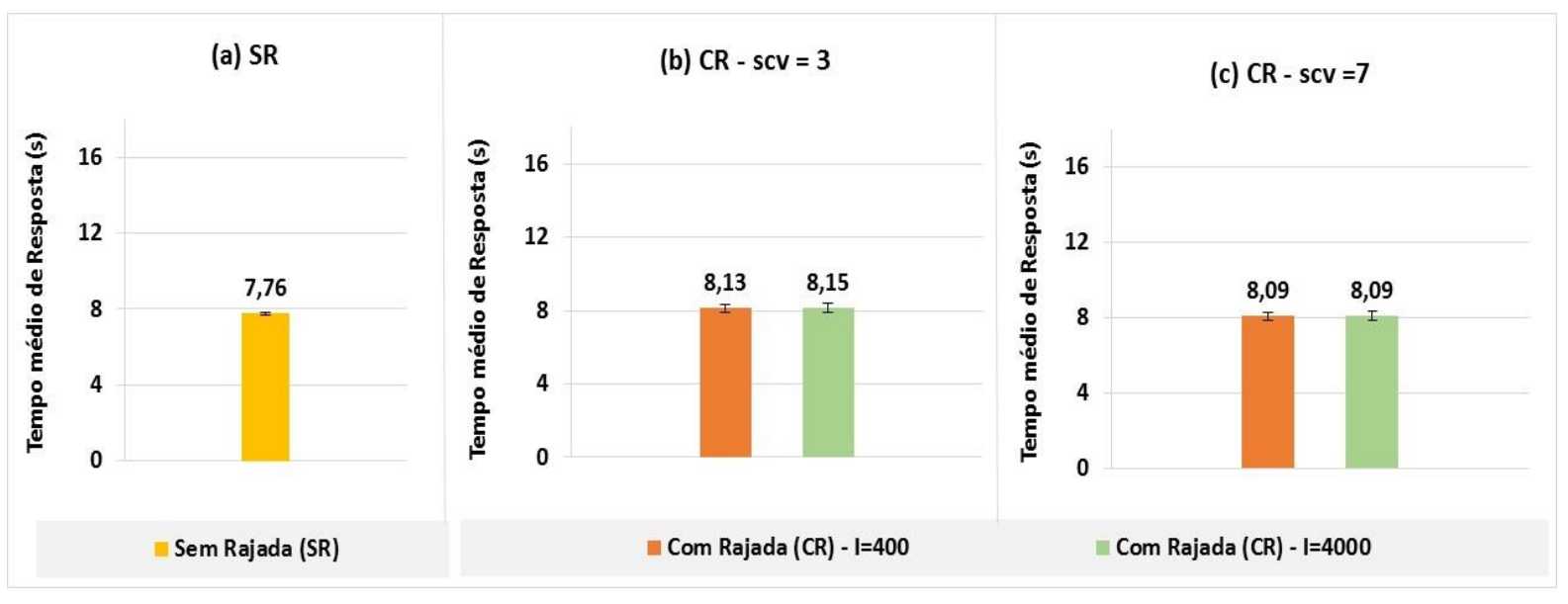

Figura 6.22 - Tempo médio de resposta em segundos, para demandas de serviços sem e com rajadas - considerando uma nuvem híbrida.

Da mesma forma acontece com os tempos médios de espera em fila, apresentado na Figura 6.23(a), que apresentam um pequeno aumento para situações onde as demandas de serviço chegam em rajadas em relação ao experimento sem rajada. Entretanto, entre os 
experimentos com rajadas, independente da intensidade e variabilidade, os tempos médios de espera em fila foram equivalentes. As demais variáveis de resposta da Figura 6.23(a), tempo médio de serviço e latência média de rede, da mesma forma que observado para a nuvem privada, os resultados foram estatisticamente iguais em todos os experimentos. Conforme comentado anteriormente para o tempo médio de serviço, isso ocorre, pois, a média do tempo de serviço considerado é a mesma ( 7 segundos) para o cenário sem rajadas e com rajadas e, portanto, na média o tempo de serviço para todos os casos tende a ser de 7 segundos. Quanto à latência de rede, como o Broker e a nuvem pública são interligados por uma conexão dedicada, a sobrecarga na latência não foi significante.

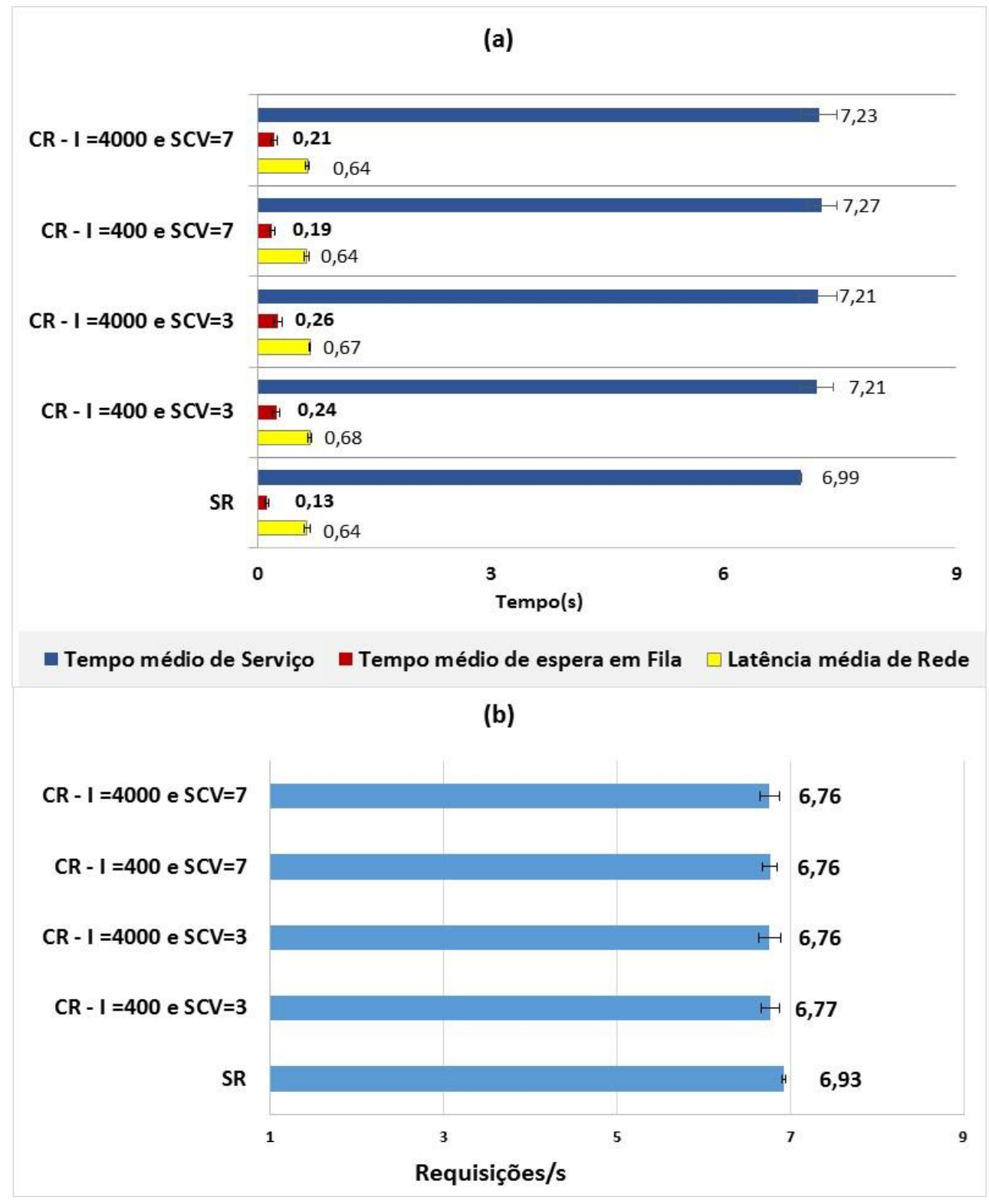

Figura 6.23 - Resultados das variáveis de Repostas: (a) Tempo médio de Serviço, de espera em fila e Latência média de rede, (b) Vazão - considerando uma nuvem híbrida. 
A Figura 6.23(b) apresenta os resultados referentes à vazão obtida em todos os experimentos conduzidos nesta Seção (item b). A vazão, mesmo considerando uma nuvem híbrida com maior capacidade de processamento, é afetada negativamente quando as demandas de serviços se apresentam em rajadas, porém em menor escala do que para uma nuvem privada. Para a nuvem híbrida a vazão apresentou uma queda de 2,3\% entre a carga sem rajada e a com rajada mais amena ( $\mathrm{I}=400$ e $\mathrm{SCV}=3$ ). Na nuvem privada essa queda foi de 18,6\%. Esse comportamento difere-se do observado para as rajadas originadas no processo de chegada de requisições, onde a vazão manteve-se igual em todos os experimentos, sem e com rajadas. Esses resultados mostram, considerando as configurações dos data centers modelados neste estudo, que as rajadas originadas nas demandas de serviços causam uma sobrecarga maior para os recursos da nuvem, mesmo quando considera-se um modelo de nuvem híbrida.

No gráfico da Figura 6.24 é apresentado o percentual médio de requisições executadas na nuvem privada e na nuvem pública para os experimentos que consideram demandas de serviços sem rajadas e com rajadas de diferentes intensidades e variabilidades. Para todos os casos em que as demandas de serviço apresentam rajadas tem-se um aumento no número de requisições executadas na nuvem pública. Esse aumento varia de 19,4\% a 142,4\%. Observa-se que para os experimentos que consideraram um perfil de rajada com uma variabilidade moderada ( $\mathrm{SCV}=3$ ), o percentual de requisições encaminhadas para a nuvem pública é superior aos percentuais obtidos para os experimentos sem rajadas e com rajadas mais variáveis ( $\mathrm{SCV}=7$ ). Pode ser notado também que para os modelos de cargas de trabalho que consideraram rajadas com alta variabilidade, apesar dos percentuais de requisições encaminhadas para as VM públicas (para as duas intensidades consideradas) serem um pouco maiores do para o modelo sem rajadas, são bem mais baixas que para os modelos com rajadas menos variáveis. Isso acontece pois, como pôde ser observado nas amostras de demandas de serviços geradas durante a simulação, na Figura 6.18, os picos de rajadas modelados pelos MAPs que consideraram $\mathrm{SCV}=7$, são mais fortes e variáveis mas surgem em curtos períodos ao longo do tempo. Ou seja, a quantidade de requisições com demandas em rajadas que chegam durante esses períodos, apesar de mais agressivas, é bem menor que para os perfis de rajadas modelados pelos MAPs parametrizados com variabilidade moderada.

Essa afirmação pode ser confirmada, através da Figura 6.25, que mostra a média obtida nas 10 execuções dos experimentos que consideraram modelos de carga de trabalho com rajadas, referente à quantidade total de requisições executadas durante a simulação e desse total, quantas chegaram sem e quantas chegaram com rajadas. Observa-se, para tanto, que a 
quantidade de requisições com demandas que se apresentam em rajadas, para o modelo de rajadas com variabilidade alta, é inferior em relação aos outros modelos.

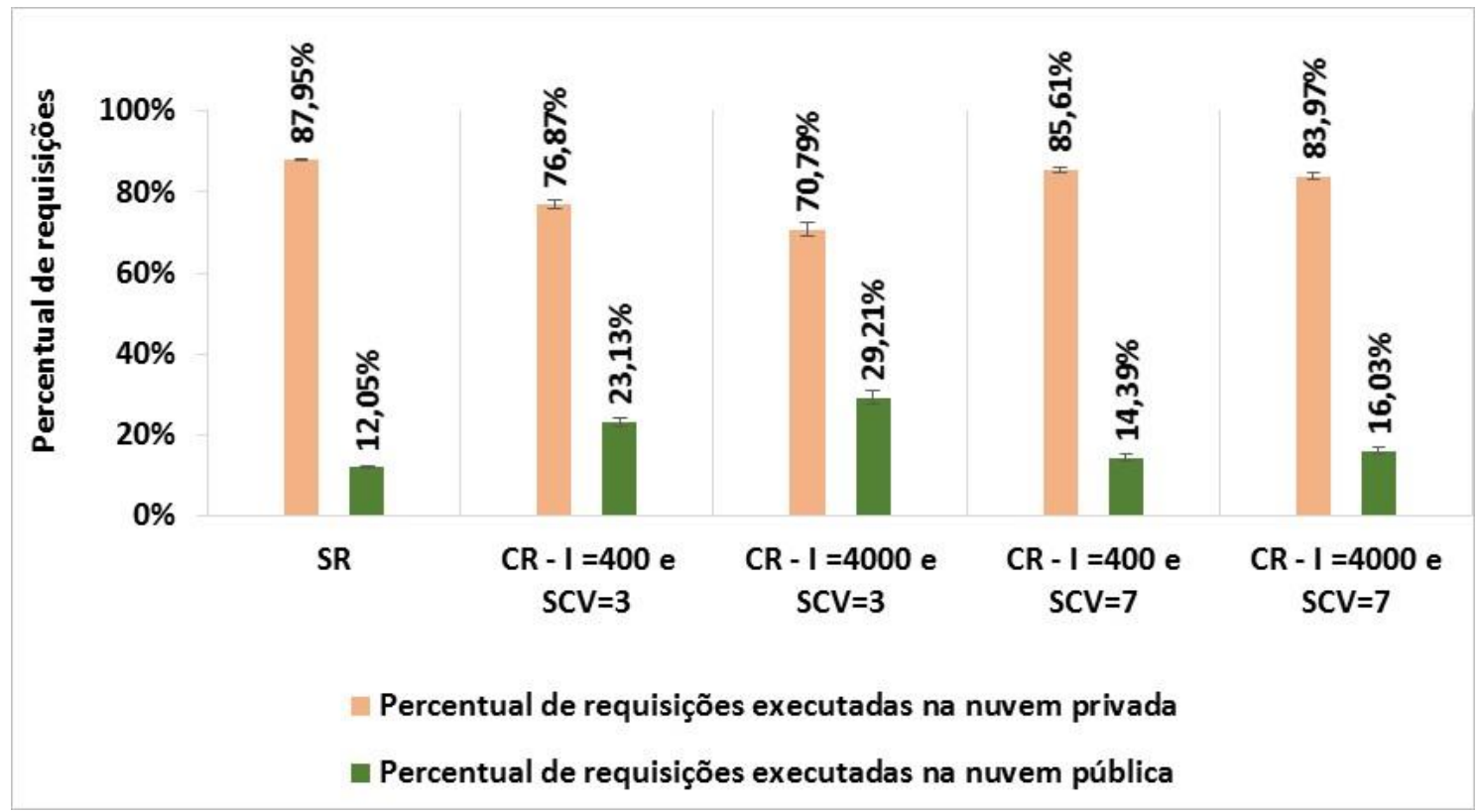

Figura 6.24 - Percentuais de requisições executadas na nuvem privada e nuvem pública.

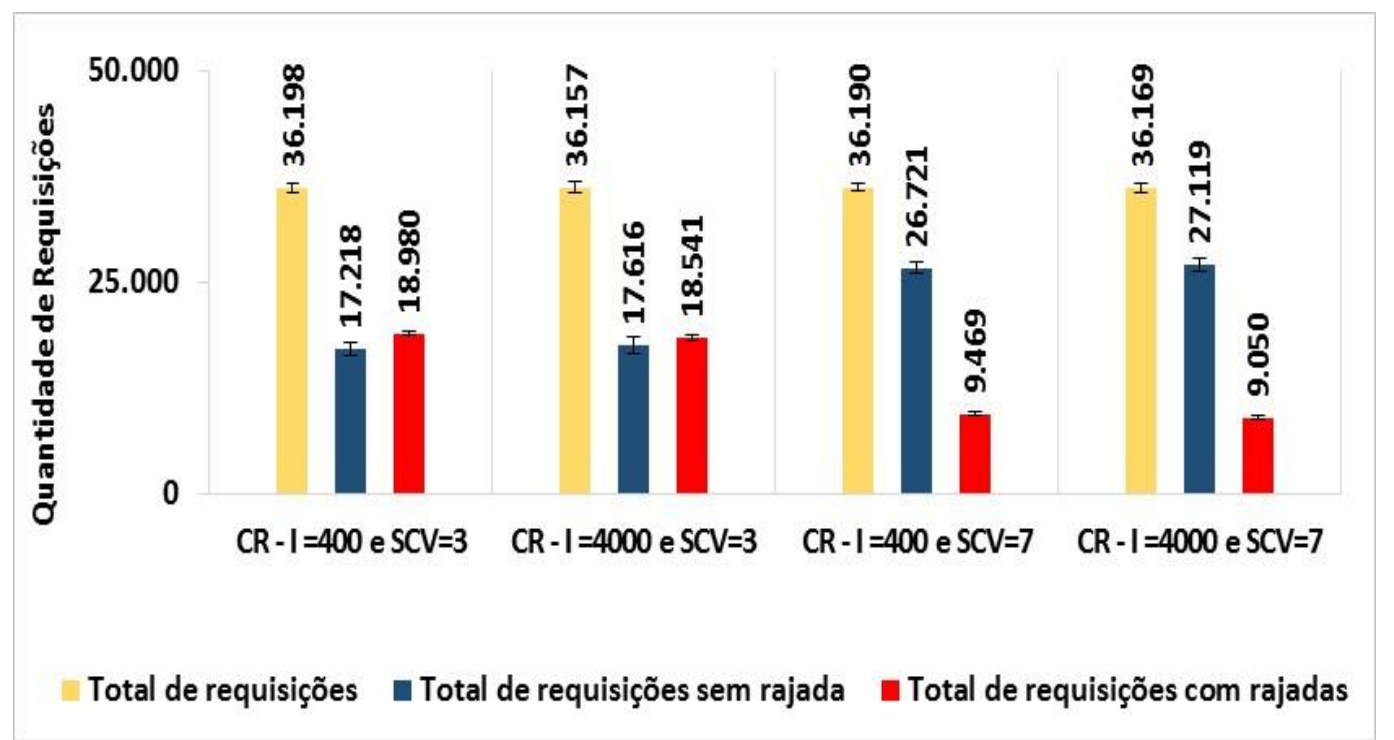

Figura 6.25 - Número médio de requisições executadas durante a simulação: total de requisições, requisições com demandas de serviços sem rajadas e com rajadas.

A Figura 6.26, apresenta um detalhamento em relação a quantidade de requisições executadas na nuvem privada e pública, considerando os experimentos onde as demandas de serviços foram modeladas pelos diferentes MAPs. 


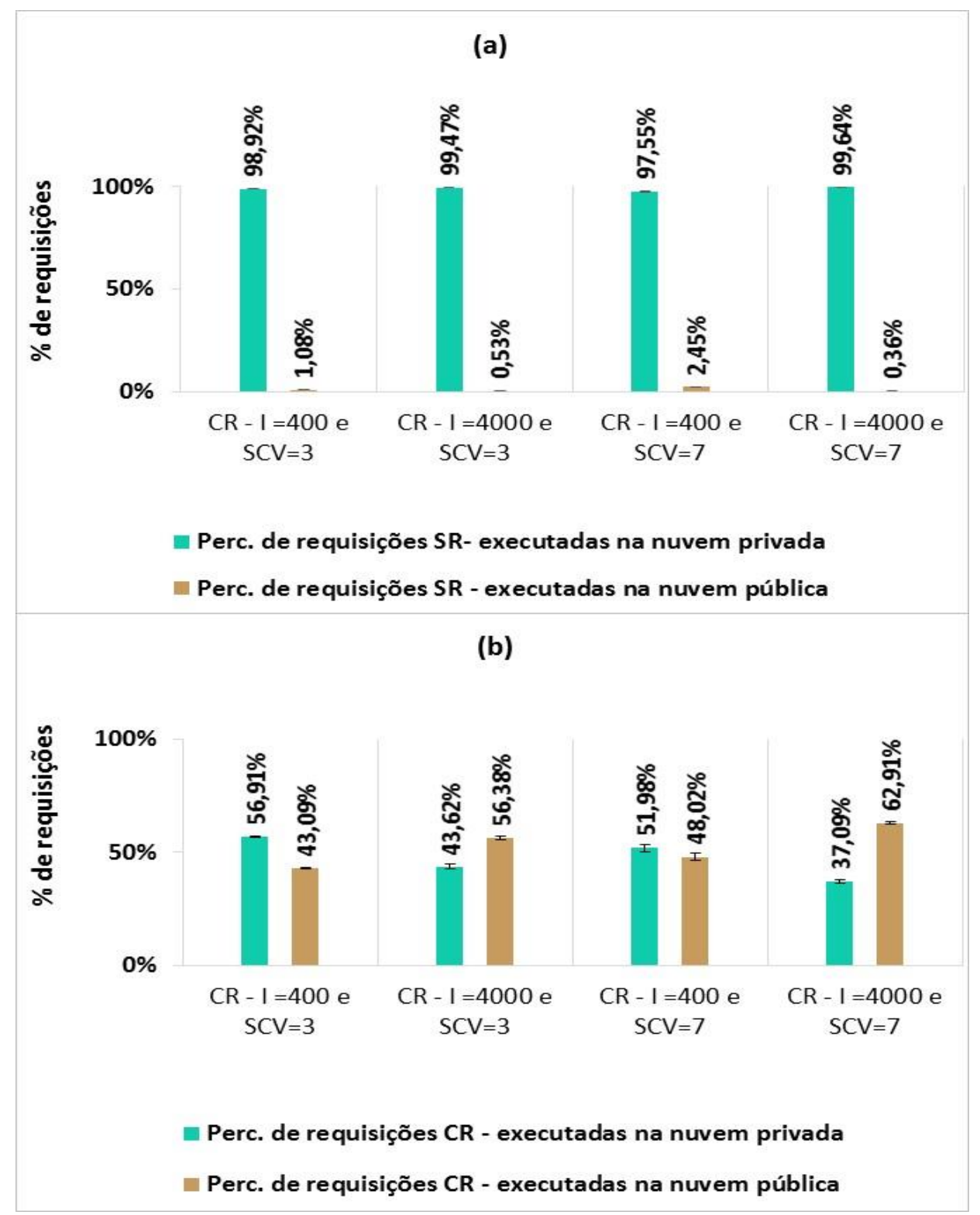

Figura 6.26 - Percentual médio de requisições executadas na nuvem privada e pública: (a) com demandas sem rajadas, (b) com demandas com rajadas.

Na Figura 6.26(a) são apresentados os percentuais de requisições com demandas leves ou sem rajadas (geradas pelos MAPs quando este se encontra no estado sem rajadas) executados em cada nuvem, privada e pública. Na Figura 6.26(b) são apresentados os percentuais de requisições com demandas pesadas ou com rajadas (geradas durante o período que o MAP permaneceu no estado com rajadas) executados na nuvem privada e nuvem pública. Percebe-se na Figura 6.26(b) que, apesar da quantidade de requisições com demandas pesadas que chegam em períodos de rajadas ser menor que para os perfis de rajadas com variabilidade $\mathrm{SCV}=7$, o percentual dessas requisições com demandas pesadas (CR) encaminhadas para a nuvem pública é superior aos percentuais obtidos para os outros perfis, que possuem intensidades equivalentes. 
Esses resultados confirmam mais uma vez que os picos de rajadas para os modelos de carga mais variáveis, apesar de apresentarem uma duração mais curta, chegam de maneira mais agressivas.

(a) SR

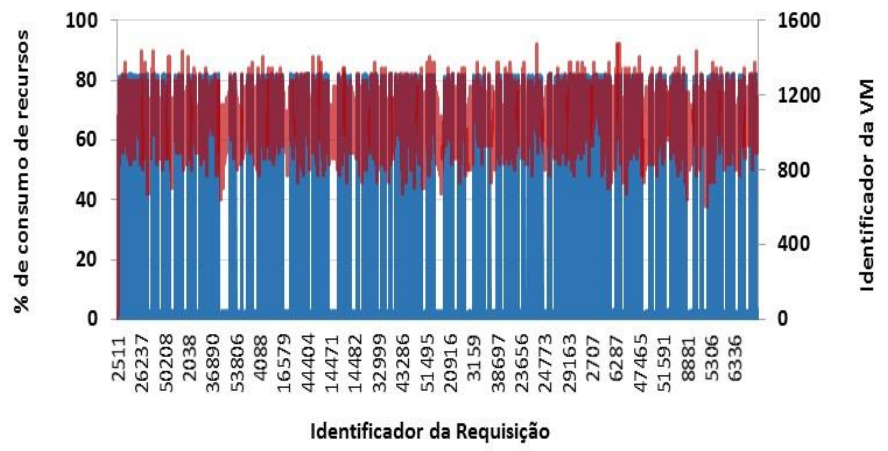

—Identificador da VM alocada para a requisição — $\%$ Consumo dos recursos da nuvem privada

(b) CR: SCV=3, l=400

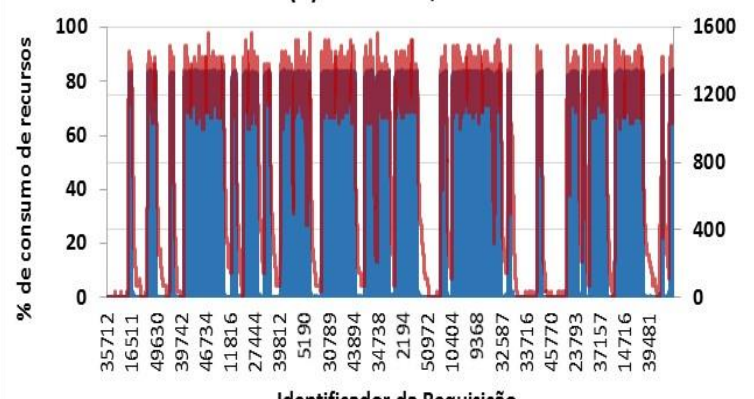

Identificador da Requisição

—Identificador da VM alocada para a requisição

— Consumo dos recursos da nuvem privada

(d) $\mathrm{CR}: \mathrm{SCV}=7, \mathrm{l}=400$

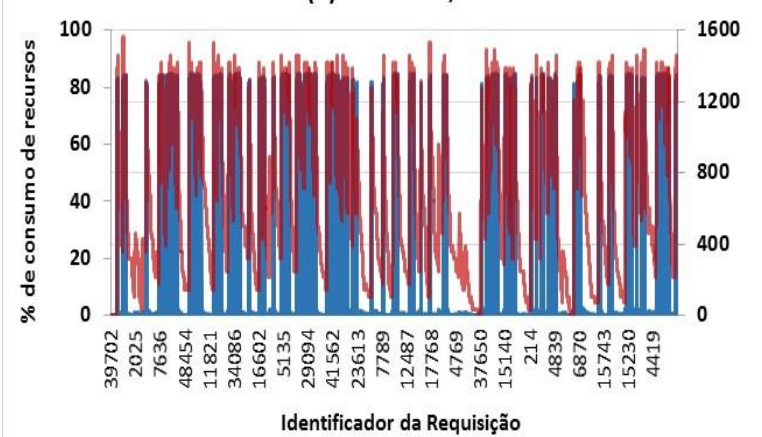

—Identificador da VM alocada para a requisição

— Consumo dos recursos da nuvem privada (c) CR: SCV=3, I=4000

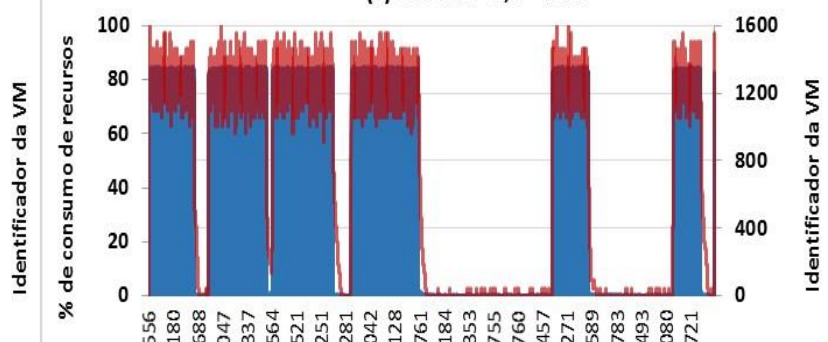

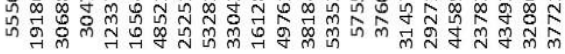

Identificador da Requisição

- Identificador da VM alocada para a requisição

-\% Consumo dos recursos da nuvem privada

(e) CR: SCV=7, l=4000

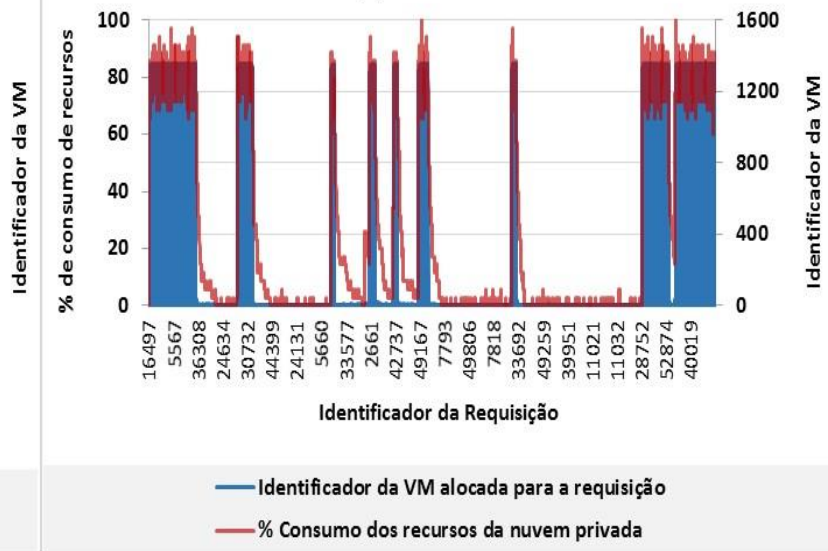

Figura 6.27 - Amostras do percentual de consumo dos recursos privados e identificador das

VMs alocadas para as requisições ao longo da simulação.

Na Figura 6.27 são apresentados os percentuais de consumo de recursos do data center privado e o identificador das VMs alocadas para as requisições, monitorados no mesmo 
momento em que as requisições foram alocadas nas VMs. O percentual de consumo corresponde à linha vermelha no gráfico, enquanto que o identificador da VM alocada para a requisição é representado pela linha azul no gráfico. Na Figura 6.27 (a), apresenta os resultados dos experimentos que consideraram demandas sem rajadas e nas Figuras 6.27 (b-e) mostram os resultados para demandas de serviços que consideraram o fenômeno de rajadas em seus modelos.

Para todos os experimentos, Figuras 6.27 (a-e), quando os recursos privados se tornam mais sobrecarregados, as requisições passam a ser encaminhadas para as VMs da nuvem pública, identificadas por uma numeração a partir de 1300 (percebe-se que nestes momentos, visualmente no gráfico, a linha azul passa a atingir escalas em torno de 1300). Outra observação importante, é que para os cenários onde as demandas de serviços foram modeladas considerando rajadas, Figuras 6.27 (b-e), a sobrecarga no consumo dos recursos ultrapassa o limite de $80 \%$ com maior frequência do que para cenários de demandas sem rajadas. Essa sobrecarga mais elevada é influenciada pelos picos de demandas mais pesadas que são submetidos à nuvem em diferentes períodos de tempo, especialmente quando as rajadas apresentam intensidades mais severas.

\subsubsection{Impacto das Rajadas no Processo de Chegada e na Demanda de Serviço}

Nesta Seção serão apresentados os resultados obtidos com os experimentos que consideraram cargas de trabalho sem rajadas e cargas de trabalho modeladas com rajadas originadas tanto no processo de chegada das requisições como nas demandas de serviços. $\mathrm{O}$ objetivo dessa avaliação é verificar qual o impacto no desempenho dos serviços quando picos de rajadas de diferentes origens (intervalos de chegadas e demandas de serviços) surgem ao longo da simulação.

Para tanto, foram considerados dois modelos de cargas de trabalho com rajadas, nomeados: MAPs independente (MAP ${ }_{\text {ind }}$ ) e MAPs sincronizados (MAP sinc $_{\text {c }}$ ). Os dois modelos são implementados utilizando dois MAPs, um responsável em gerar uma sequência de think times "longos" e "curtos" (MAP iat $)$ e outro responsável em gerar uma sequência de demandas

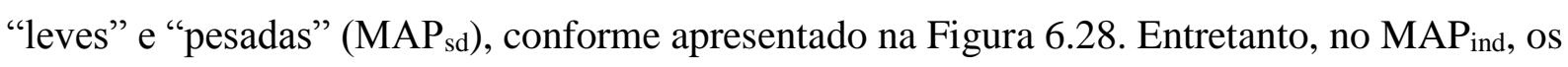
$\mathrm{MAP}_{\text {iat }}$ e $_{\mathrm{MAP}}$ sd executam de forma independente um do outro durante a simulação, ou seja, podem ocorrer momentos em que as rajadas se apresentem apenas no processo de chegada ou na demanda de serviço, ou ainda rajadas podem se apresentar nos dois processos (chegadas e

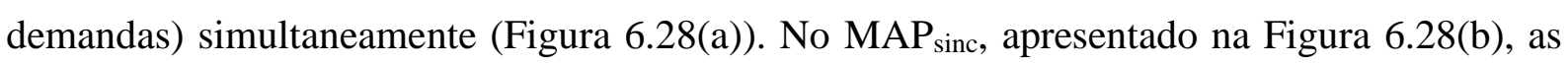


transições dos estados do $\mathrm{MAP}_{\text {iat }}$ e o $\mathrm{MAP}_{\text {sd }}$ ocorrem de maneira sincronizada e desta forma, as rajadas no processo de chegada de requisições sempre ocorrem ao mesmo tempo que as rajadas na demanda de serviço.

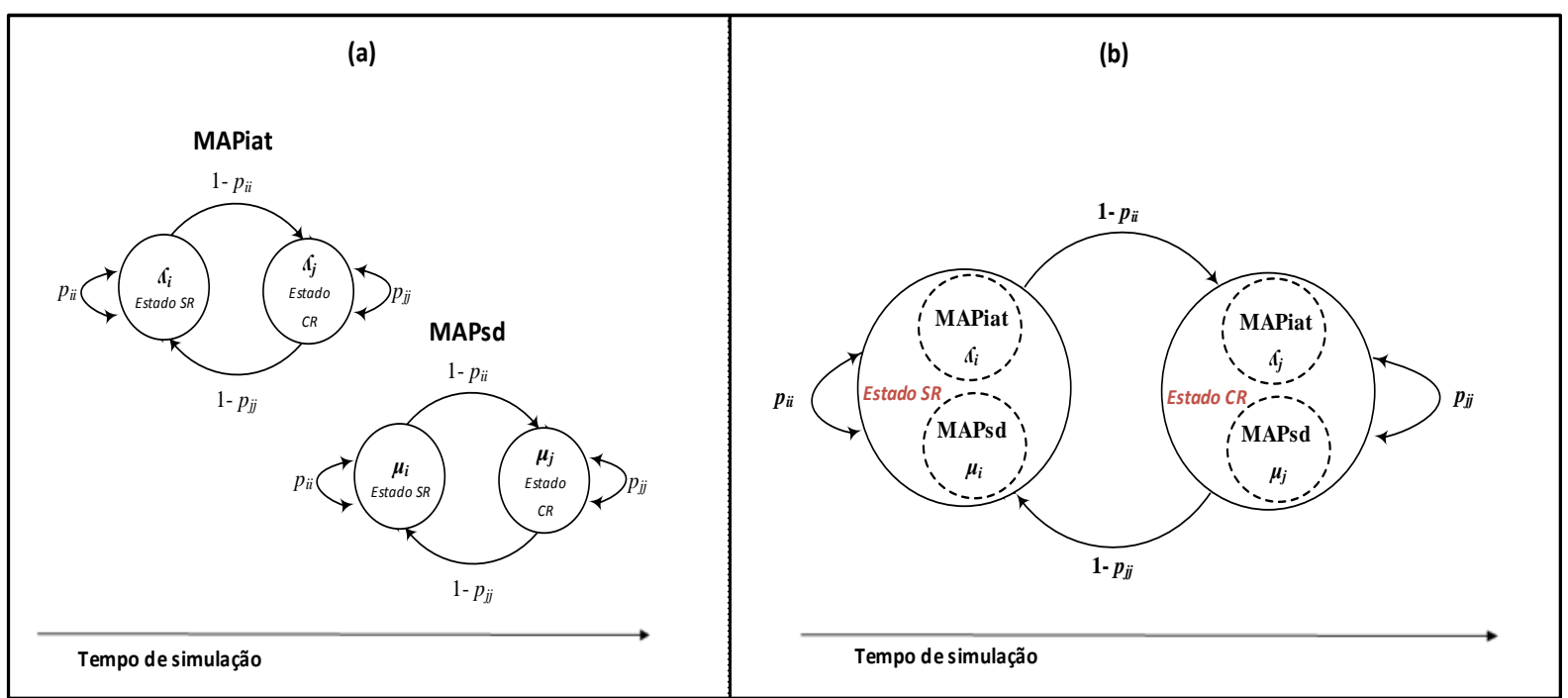

Figura 6.28 - Modelos de MAPs implementados: (a) $\mathrm{MAP}_{\text {ind }}$, (b) MAP sinc. $_{\text {. }}$

Os modelos de rajadas no processo de chegada das requisições (MAP ${ }_{\text {iat }}$ ) e na demanda de serviço $\left(\mathrm{MAP}_{\mathrm{sd}}\right)$ adotados pelos $\mathrm{MAP}_{\text {ind }}$ e $\mathrm{MAP}_{\text {sinc }}$ foram parametrizados considerando uma variabilidade moderada $(\mathrm{SCV}=3)$ e com intensidades distintas, ou seja, suaves ( $\mathrm{I}=400 \mathrm{e}$ $\mathrm{I}=4000$ ), as mesmas parametrizações com $\mathrm{SCV}=3$ consideradas nas avaliações apresentadas nas Seções 6.6.1 e 6.6.2, conforme apresentadas na Tabela 6.8. A variabilidade moderada, $\mathrm{SCV}=3$, foi escolhida pelo fato das probabilidades de permanência ou de transição dos estados serem equivalentes nos dois MAPs, $\mathrm{MAP}_{\text {iat }}$ e $\mathrm{MAP}_{\text {sd }}$, que é uma parametrização necessária para sincronização das mudanças de estados adotado pelo modelo MAP sinc. $_{\text {. }}$.

Tabela 6.8 - Parametrização dos MAPs para intervalos de chegadas

\begin{tabular}{|c|cc|cc|}
\cline { 2 - 5 } \multicolumn{1}{c|}{} & \multicolumn{4}{c|}{ MAPind/MAPsinc } \\
\hline Parâmetros & MAPiat - I=400 & / MAPsd I=400 & MAPiat I=4000 & / MAPsd I=400 \\
\hline \hline $\boldsymbol{\lambda}_{\mathrm{i}} / \boldsymbol{\mu}_{\boldsymbol{i}}$ & 0,06978 & 408,27575 & 0,07144 & 398,99999 \\
\hline $\boldsymbol{\lambda}_{\mathrm{i}} / \boldsymbol{\mu}_{j}$ & 389,72425 & 0,07310 & 398,99999 & 0,07144 \\
\hline $\boldsymbol{p}_{\boldsymbol{i} i}$ & 0,9978 & 0,9978 & 0,99975 & 0,99975 \\
\hline $\boldsymbol{p}_{j j}$ & 0,9979 & 0,9979 & 0,99975 & 0,99975 \\
\hline $\boldsymbol{\mu}^{-\boldsymbol{I}}$ & $7 \mathrm{~s}$ & $7 \mathrm{~s}$ & $7 \mathrm{~s}$ & $7 \mathrm{~s}$ \\
\hline $\boldsymbol{\rho}_{\boldsymbol{I}}$ & 0,3 & 0,3 & 0,3 & 0,3 \\
\hline
\end{tabular}


A Figura 6.29 apresenta as amostras de think times e demandas de serviços coletadas durante a execução de uma das repetições dos experimentos. Cada gráfico corresponde a um modelo de carga de trabalho considerado: sem rajadas - na Figura 6.29(a), com rajadas nos processos de chegadas e demandas de serviços geradas por MAPs independentes - Figura 6.29 (b) e (c) e com rajadas nos processos de chegadas e demandas de serviços geradas por MAPs sincronizados - Figura 6.29 (d) e (e).

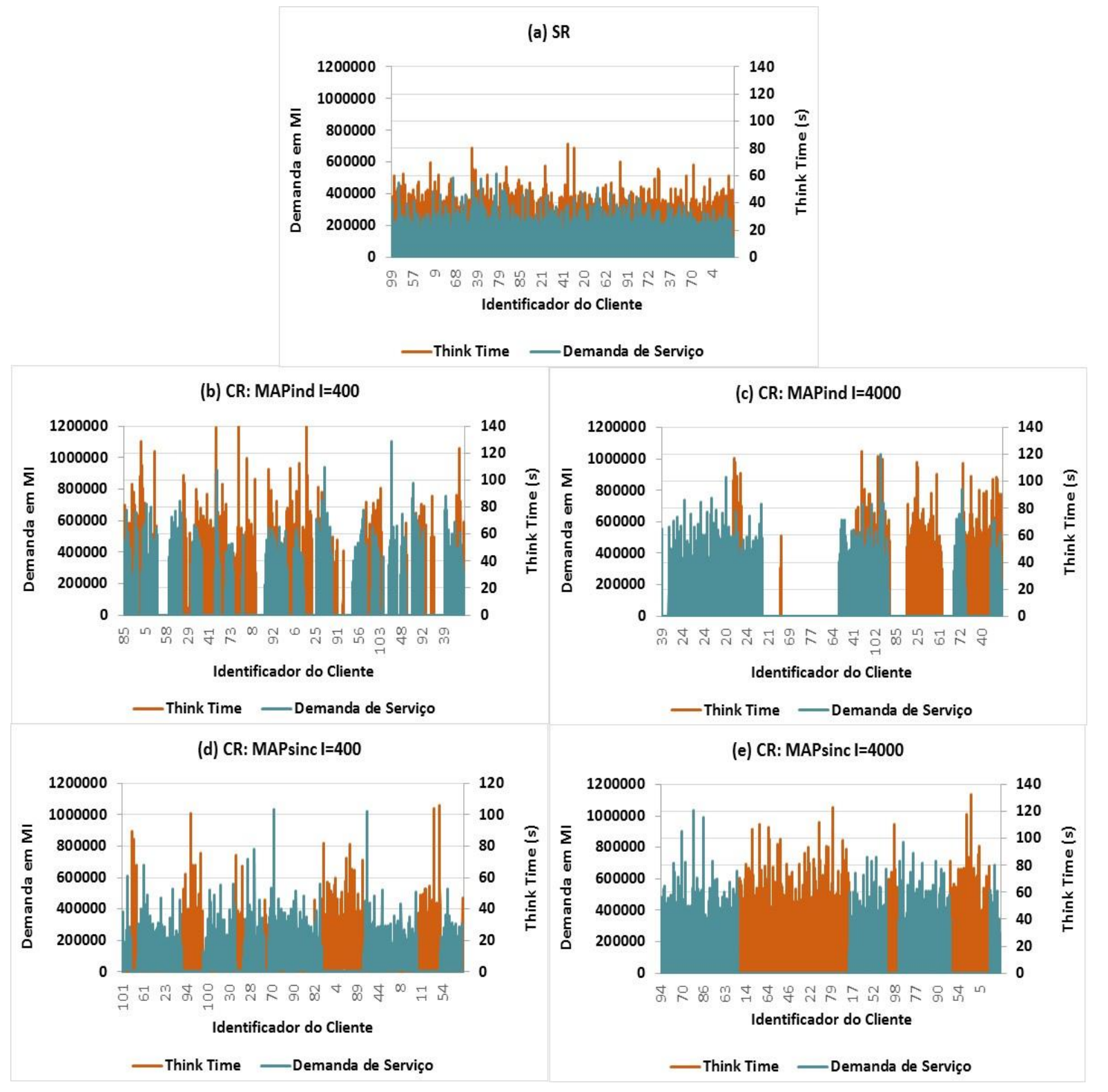

Figura 6.29 - Amostras de think times e demandas de serviços geradas durante a simulação.

Os gráficos mostram que as rajadas se comportam exatamente como descrito anteriormente. Quando o modelo MAP ind é considerado, as rajadas originadas no processo de chegada de requisições (think times) e nas demandas de serviços podem ocorrer simultaneamente ou não ao longo do tempo. No entanto, quando considera-se o modelo 


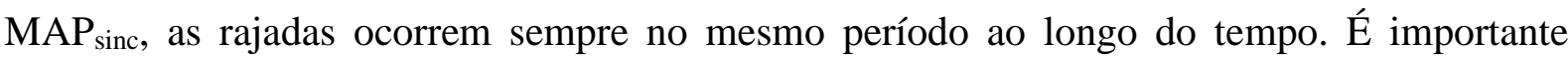
lembrar que as rajadas nos processos de chegada ocorrem quando os think times tonam-se menores (correspondendo aos períodos onde os think times estão próximos da escala de 0,01 segundos), enquanto que as rajadas nas demandas de serviços acontecem nos períodos em que elas se tornam mais pesadas (atingindo escalas mais altas de demandas em MI, conforme pode ser observado no eixo principal à esquerda do gráfico).

Para a realização da avaliação de desempenho apresentada nesta Seção, os experimentos foram organizados conforme apresentado na Tabela 6.9, considerando 2 fatores, um deles com 5 níveis e outro com 2 níveis, da mesma forma que para as avaliações apresentadas nas Seções anteriores.

Tabela 6.9 - Organização dos Experimentos

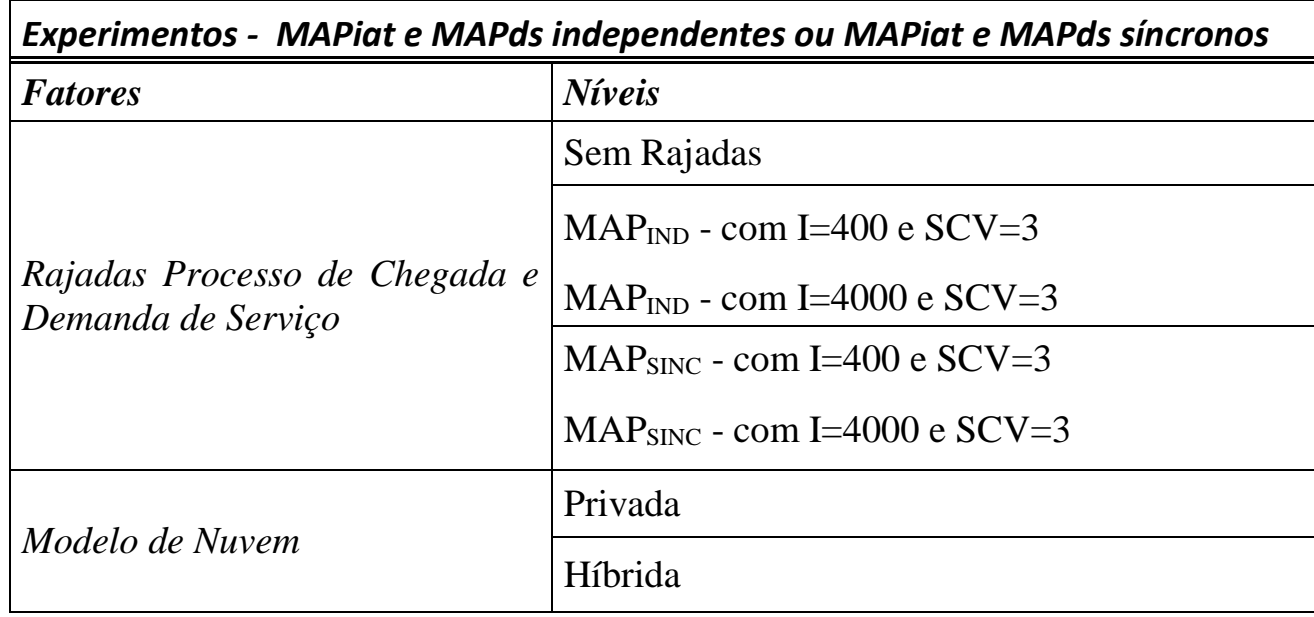

O primeiro fator corresponde ao modelo de carga de trabalho considerado, sendo eles:

- Sem Rajadas -onde os think times e demandas de serviços são geradas por uma distribuição exponencial com média de 7 segundos e de 49.000 Milhões de Instruções (ou de 7 segundos considerando os tempos de serviços) respectivamente.

- Com Rajadas - onde considera-se dois níveis para o modelo MAP ind e dois níveis para o $\mathrm{MAP}_{\text {sinc, }}$ organizados da seguinte forma:

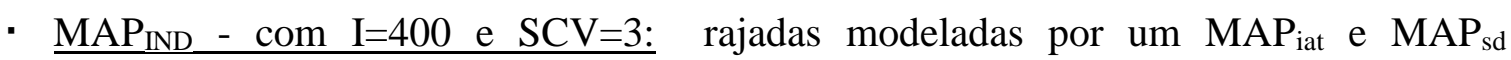
independentes, com a mesma variabilidade e com intensidade mais suaves ( $\mathrm{I}=400)$.

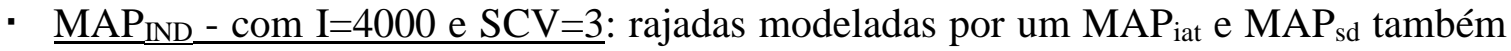
independentes, com a mesma variabilidade e com intensidades mais severas ( $\mathrm{I}=4000)$.

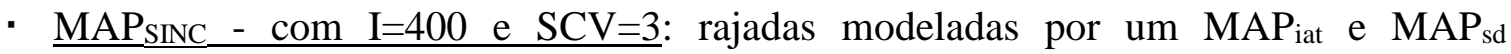
sincronizados, com a mesma variabilidade e com a mesma intensidade ( $\mathrm{I}=400)$. 


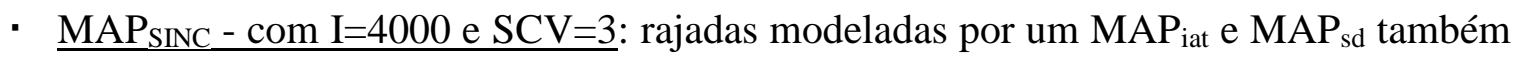
sincronizados, com a mesma variabilidade e com intensidades severas ( $\mathrm{I}=4000)$.

O segundo fator, assim como nas avaliações anteriores, também considera os dois modelos de nuvem, privada e híbrida.

\section{a) Serviços executados em uma Nuvem Privada}

Os resultados das variáveis de resposta para os experimentos apresentados nesta Seção consideram a adoção de uma nuvem privada. A Figura 6.30 apresenta os resultados referentes aos tempos médios de resposta.

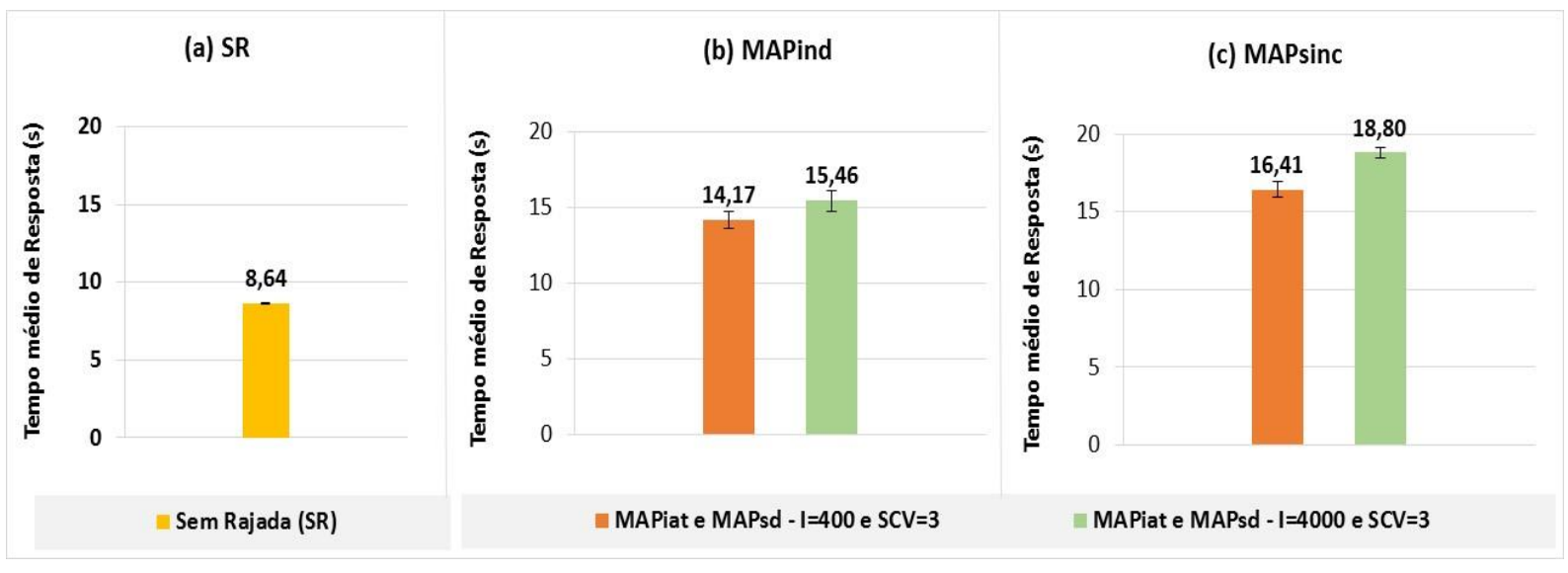

Figura 6.30 - Tempos médio de resposta em segundos (SR, MAP ${ }_{\text {ind }}$ e $\mathrm{MAP}_{\text {sinc) }}$, considerando uma nuvem privada.

Para todos os experimentos apresentados na Figura 6.30 (b) e (c) onde há presença de rajadas provenientes no processo de chegada e nas demandas de serviços, o tempo médio de resposta apresenta um aumento significativo em relação ao experimento onde não são consideradas rajadas no modelo de carga de trabalho, apresentada na Figura 6.30(a). Quando o modelo MAP $_{\text {ind }}$ é utilizado, observa-se um aumento de $79 \%$ para intensidades de rajadas mais rigorosas. O tempo de resposta é ainda mais afetado negativamente, quando se considera o modelo $\mathrm{MAP}_{\text {sinc }}$ com MAP $\mathrm{MAt}_{\text {iat }}$ - MAP $\mathrm{P}_{\text {sd }}$ com intensidades mais severas (Figura 6.30(c)). Neste caso observa-se, para $\mathrm{I}=400$, um aumento de $89 \%$ no tempo de resposta e $118 \%$ para $\mathrm{I}=4000$. Para essa configuração de carga de trabalho, portanto, o impacto no desempenho do serviço é ainda mais expressivo do que observado para os experimentos apresentados nas Seções anteriores, onde considerou-se rajadas originadas ou no processo de chegada (Seção 6.6.1) ou nas demandas de serviços (Seção 6.6.2). 
As variáveis de resposta referentes ao tempo médio de serviço, tempo médio de espera em fila na VM e latência média de rede, são apresentadas na Figura 6.31. Os tempos médios de serviço apresentaram resultados em torno de 7 segundos, que corresponde à média considerada na geração dos tempos de serviços (utilizados na equação 6.10 para o cálculo da demanda de serviço). As latências médias de rede também se mantiveram equivalentes em todos os experimentos realizados, conforme já comentado e justificado nas avaliações das Seções anteriores. Na Figura 6.31, portanto, os tempos médios de espera em fila são as variáveis de resposta que se destacam. Os resultados obtidos, para os cenários onde considerou-se rajadas de diferentes origens no modelo de carga de trabalho, mostram que os tempos médios de espera nas filas das VMs tornam-se muito mais elevados. Esse aumento chega a ser 10 vezes maior para rajadas com intensidades severas modeladas pelo $\mathrm{MAP}_{\text {sinc }}(\mathrm{I}=4000)$ em relação ao tempo médio obtido para uma situação sem rajadas (SR).

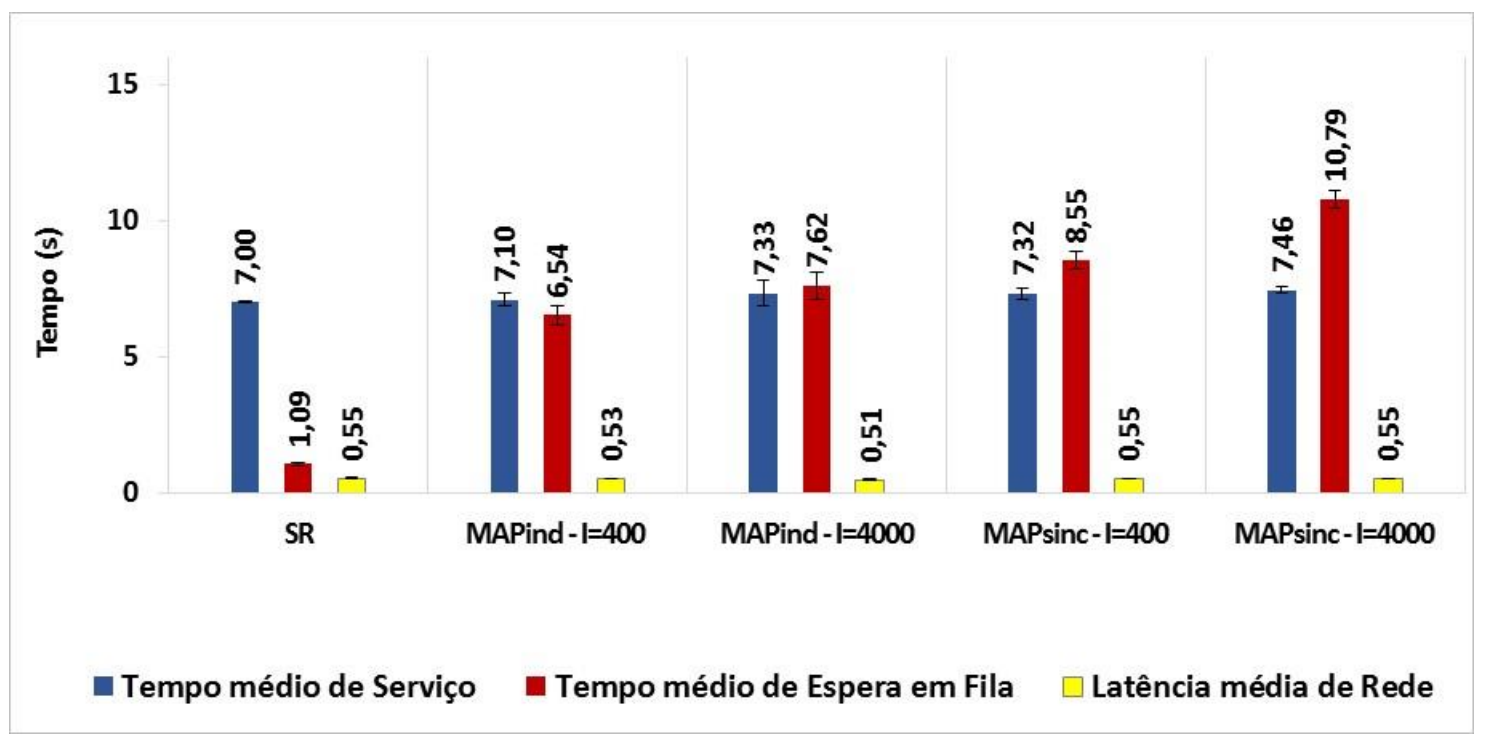

Figura 6.31 - Tempos médio de serviço, de espera em fila e Latência média de rede, para SR, $\mathrm{MAP}_{\text {ind }}$ e $\mathrm{MAP}_{\text {sinc }}$, considerando uma nuvem privada.

Os resultados para vazão média obtida para cada experimento é apresentada na Figura 6.32. Assim como observado para as variáveis de resposta: tempo médio de resposta e tempo médio de espera em fila, a vazão apresentou uma queda para os experimentos com rajadas no processo de chegada e demandas de serviços quando comparados ao experimento sem rajadas. A vazão é ainda mais baixa para situações aonde os intervalos de chegadas e as demandas impostas às VMs chegam em rajadas de forma sincronizadas, especialmente quando essas rajadas apresentam uma intensidade mais severa. Neste caso, a queda da vazão observada é de 
$33 \%$. No caso das rajadas independentes e de intensidade mais leve a queda observada na vazão é de $18 \%$.

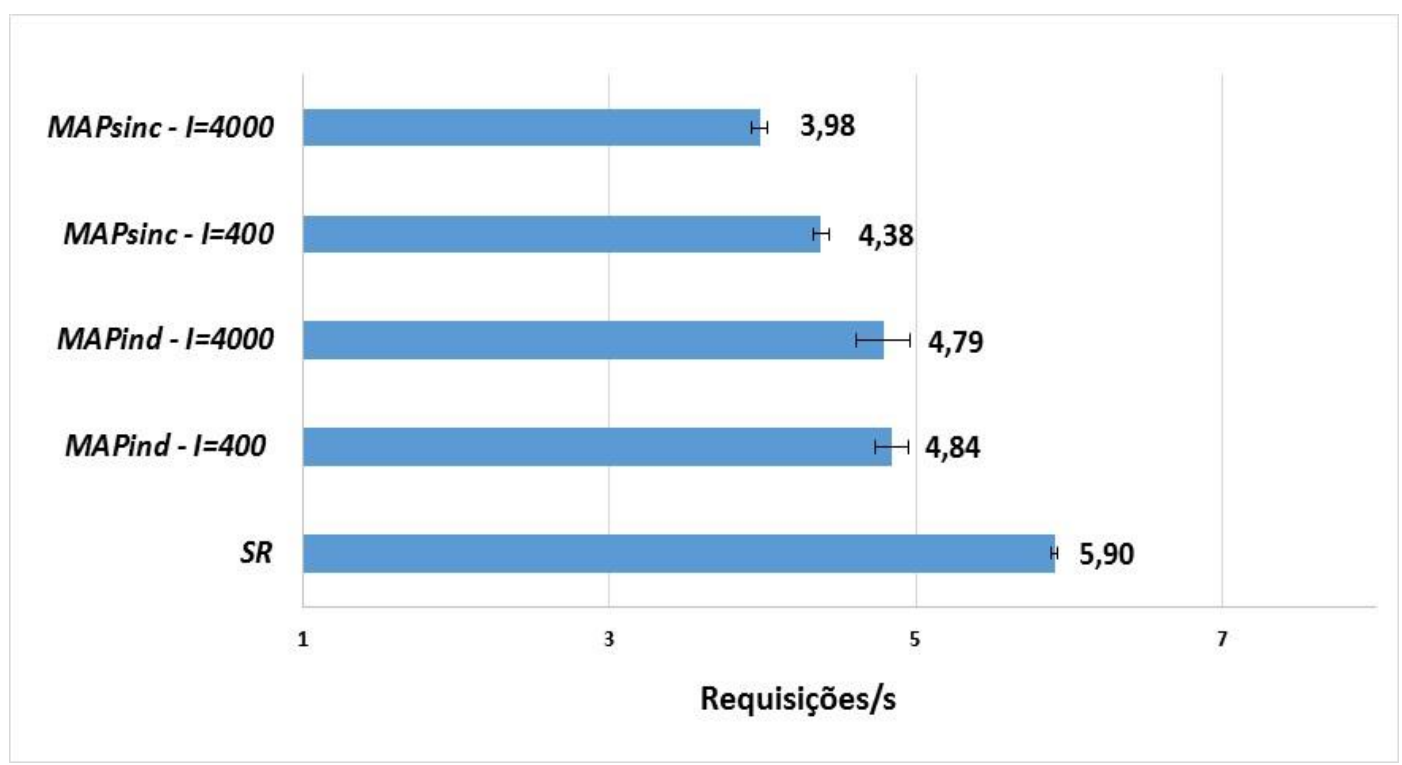

Figura 6.32 - Variável de Resposta Vazão, para SR, MAP ind $_{\text {e }} \mathrm{MAP}_{\text {sinc, }}$, considerando uma nuvem privada.

Além das variáveis de resposta analisadas e apresentadas nas Figuras 6.30 a 6.32, foram coletadas amostras dos tempos de respostas e dos percentuais de consumo de recursos do data center privado monitorados em intervalos de 1 segundos, durante a execução de uma das repetições dos experimentos. Essas amostras são apresentadas nas Figuras 6.33 e 6.34 . Comparando as amostras de think times e demandas de serviços apresentadas na Figura 6.29 (b-e), nota-se que os picos que surgem nos tempos de resposta (Figura 6.33(b-e)), assim como nos percentuais de consumo de recursos (Figura 6.34(b-e)), coincidem com os períodos de rajadas nos intervalos de chegadas e nas demandas de serviços. Além disso, quando são consideradas cargas de trabalho modeladas pelos $\mathrm{MAP}_{\text {iat }}$ e $\mathrm{MAP}_{\mathrm{sd}}$ com intensidades mais rigorosas (I=4000), apresentadas nas Figuras 6.33 e 6.34 (c) e (e), os tempos de respostas assim como o percentual de consumo de recursos apresentam, em alguns períodos ao longo da simulação, picos fortes e mais intensos em ambas variáveis de resposta. 
(a) SR

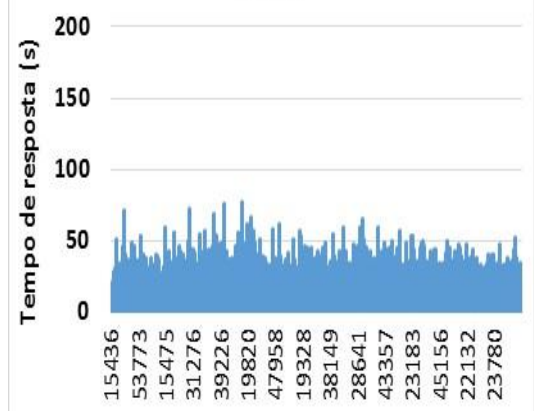

(b) CR: MAPind I=400

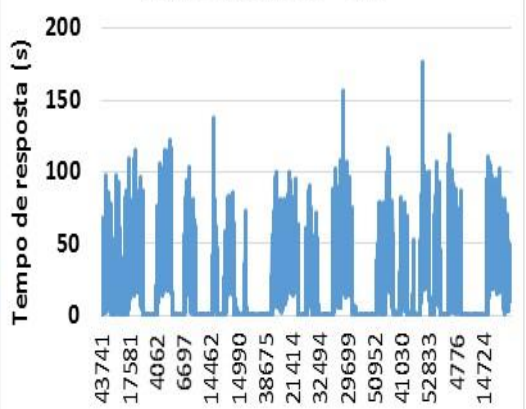

(c) CR: MAPind l=4000

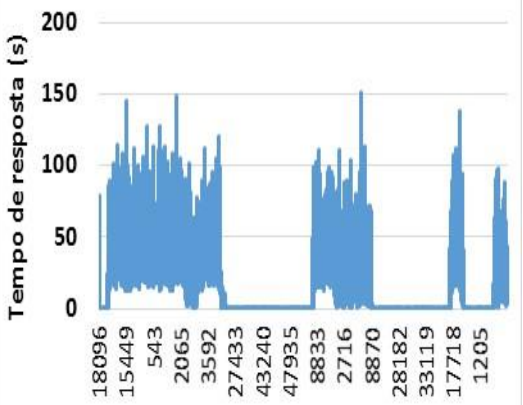

Identificador da Requisição

Identificador da Requisição

Identificador da Requisição

(d) CR: MAPsinc I=400

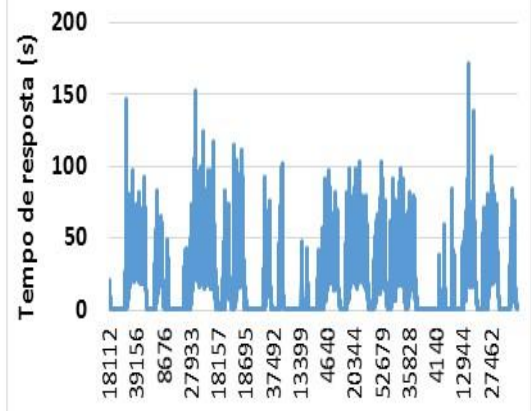

Identificador da Requisição (e) CR: MAPsinc I=4000

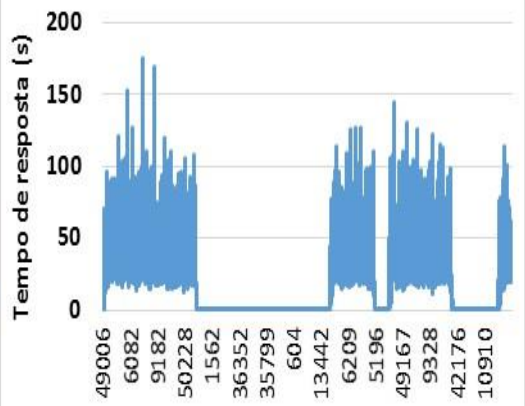

Identificador da Requisição

Figura 6.33 - Amostras de tempos de resposta monitoradas durante a simulação.

(a) SR

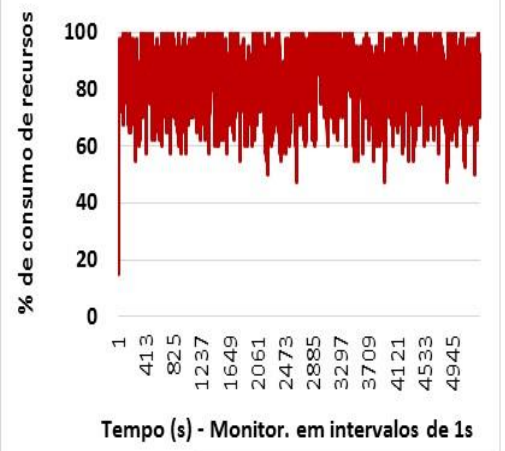

(b) CR: MAPind I=400

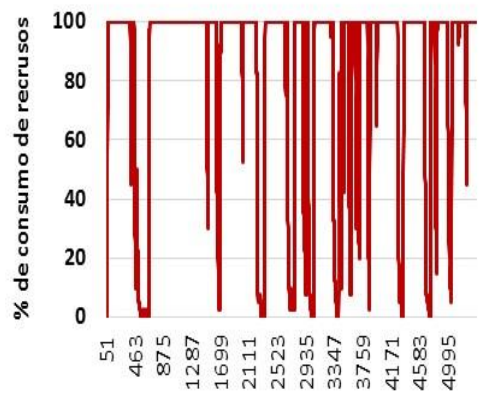

Tempo (s) - Monitor. em intervalos de 1s (c) CR: MAPind l $=4000$

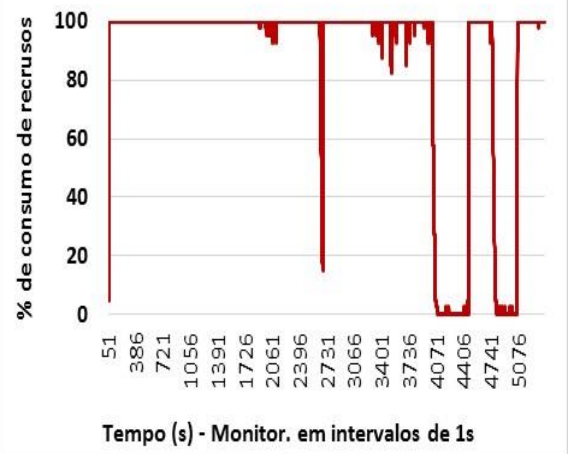

(d) CR: MAPsinc $\mathrm{l}=400$

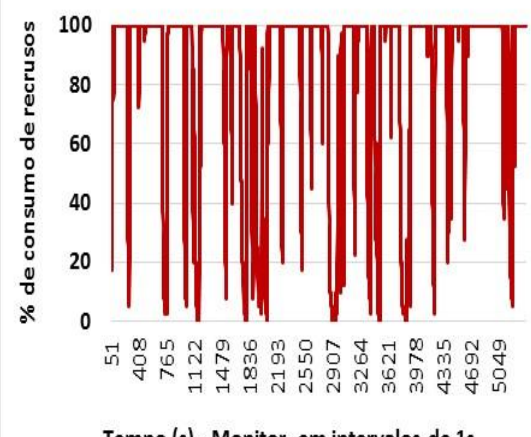

Tempo (s) - Monitor. em intervalos de 1s (e) CR: MAPsinc $1=4000$

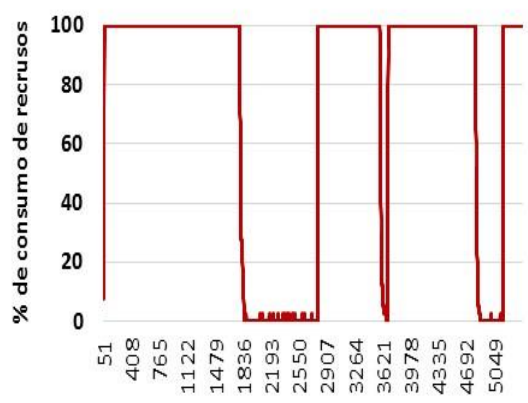

Tempo (s) - Monitor. em intervalos de 1s

Figura 6.34 - Amostras do percentual de consumo dos recursos privados durante a simulação. 
Na Figura 6.35 são apresentadas amostras das taxas de chegadas de requisições (em requisições por segundo) e das taxas de demandas de serviços (em MIPs) para os experimentos

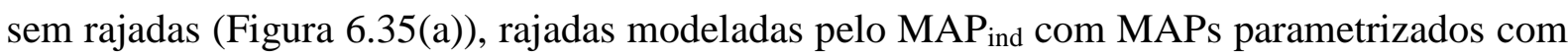
I=4000 (Figura 6.35(b)) e rajadas modeladas pelo MAP $_{\text {sinc }}$ também com MAPs de intensidades severas (I=4000) na Figura 6.35(c).
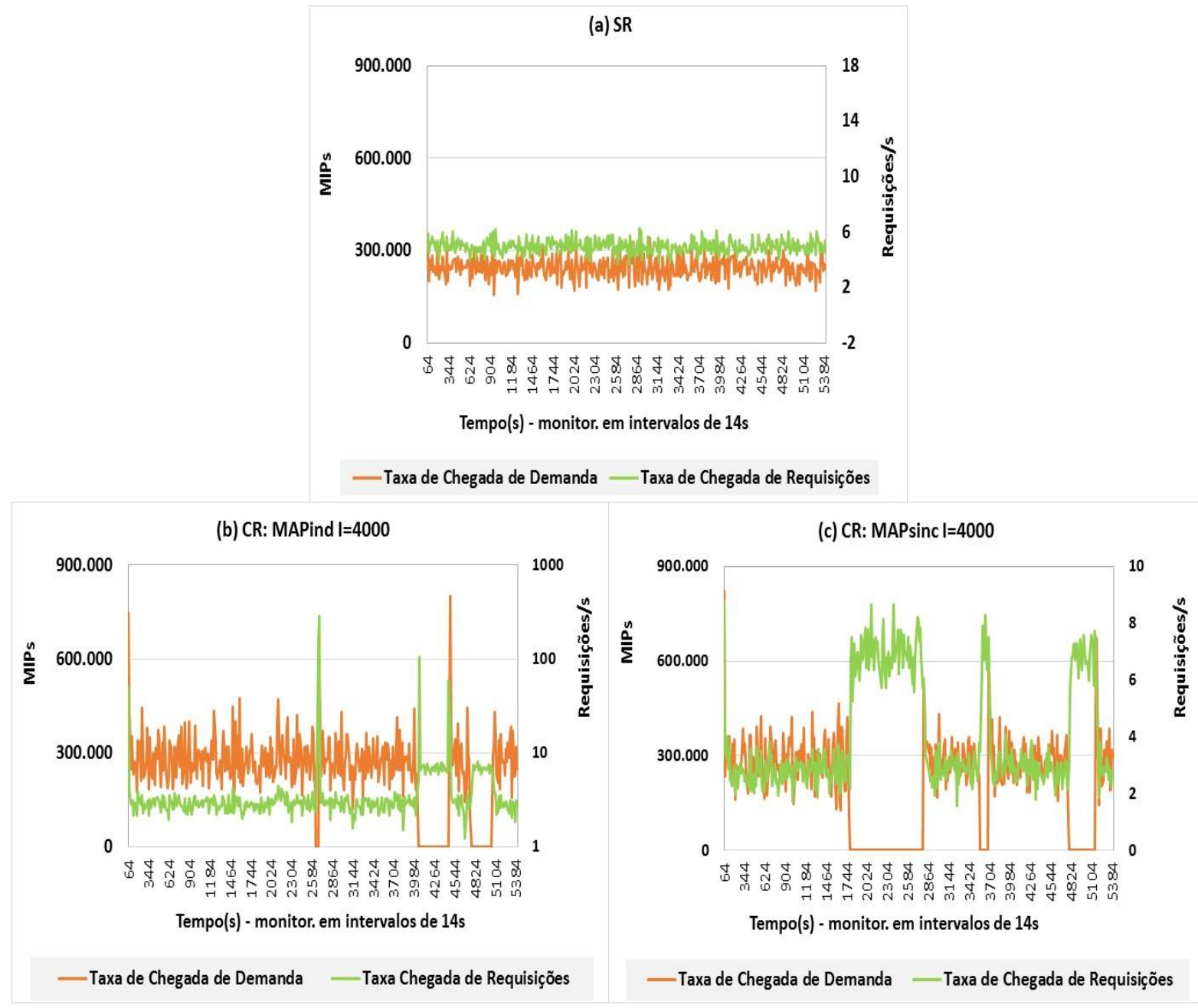

Figura 6.35 - Taxa de chegada de requisições \& taxa de demanda de serviço.

Da mesma forma que foi observado para as taxas de think times e demandas apresentadas na Figura 6.21 da Seção 6.6.2, para as situações com rajadas, nas Figuras 6.35 (b) e (c), quando a taxa de demanda de serviço torna-se mais baixa, a taxa de chegada de requisições apresenta um aumento, mesmo em períodos que o processo de chegada não se apresenta em rajadas. Como comentado na Seção 6.6.2, essa situação ocorre devido aos think times ocorrerem somente após a chegada da resposta completa da requisição anterior. Desta forma, em períodos 
em que as demandas de serviços são mais leves, a resposta completa da requisição chega de maneira mais rápida e consequentemente, o intervalo entre o envio de duas requisições sucessivas de um mesmo cliente tornam-se mais curtos. Outra observação interessante, na Figura 6.35(b), é que em alguns momentos surgem picos altos na taxa de chegada, alcançando valores próximos a 284 requisições por segundo (representado pela linha verde no gráfico). Essas taxas comparativamente mais altas ocorreram, em alguns períodos, onde o modelo $\mathrm{MAP}_{\mathrm{sd}}$ para geração de demandas encontra-se no estado sem rajadas, enquanto o modelo MAP iat para geração dos think times encontra-se no estado com rajadas. Ou seja, o intervalo de tempo entre o envio de requisições sucessivas torna-se ainda menor, uma vez que as requisições com demandas de serviços leves são processadas com maior agilidade e as respostas completas chegam ao cliente também com maior rapidez, conforme mencionado.

\section{b) Serviços executados em uma Nuvem Híbrida}

Neste item são apresentados os resultados referentes à avaliação de desempenho dos serviços executados em uma nuvem híbrida, considerando MAPs independentes e sincronizados.

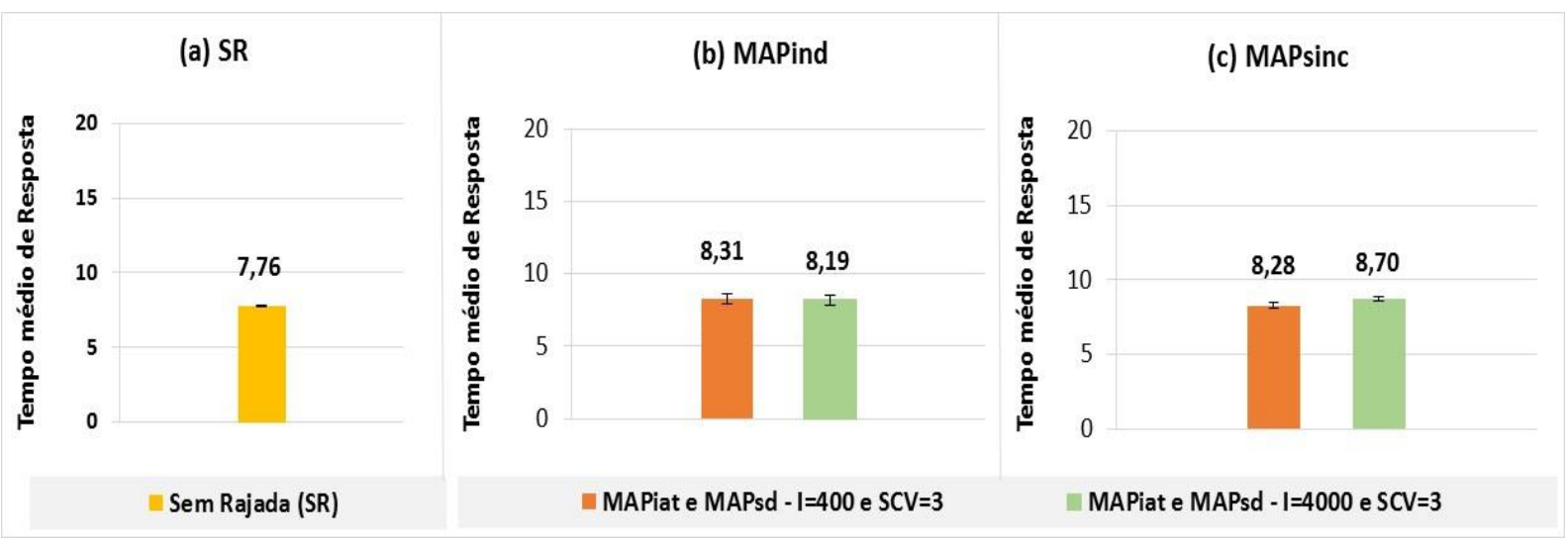

Figura 6.36 - Tempo médio de resposta em segundos, para $\mathrm{SR}, \mathrm{MAP}_{\text {ind }} \mathrm{e} \mathrm{MAP}_{\text {sinc, }}$ considerando uma nuvem híbrida.

A Figura 6.36 apresenta os tempos médios de resposta obtidos para os experimentos que consideraram cargas de trabalhos sem rajadas e para os experimentos que consideraram os modelos de cargas de trabalho $\mathrm{MAP}_{\text {ind }}$ e $\mathrm{MAP}_{\text {sinc }}$, executados em uma nuvem híbrida. Assim como ocorreu nas avaliações apresentadas anteriormente (Seções 6.6.1 e 6.6.2), quando são consideradas cargas de trabalho com rajadas originadas nos processos de chegada e nas 
demandas de serviços (Figuras 6.36 (b) e (c)) os tempos médios de resposta apresentam um pequeno aumento, que variam de 6 a 12\%, em relação ao experimento com cargas sem rajadas (Figura 6.36 (a)). Nota-se ainda que quando as rajadas provenientes nos intervalos de chegadas e nas demandas são mais intensas e ocorrem de maneira sincronizada, o tempo médio de resposta apresenta um aumento de $12 \%$. Esse comportamento se repete para a variável de resposta, tempo médio de espera em fila, conforme pode ser observado na Figura 6.37(a). Ou seja, em situações com rajadas, o tempo médio de espera em fila apresenta um aumento em relação às situações em que a carga é modelada sem rajadas, especialmente quando as rajadas são modeladas com os modelos $\mathrm{MAP}_{\text {iat }}$ e $\mathrm{MAP}_{\mathrm{sd}}$ sincronizados e parametrizados com intensidades severas.

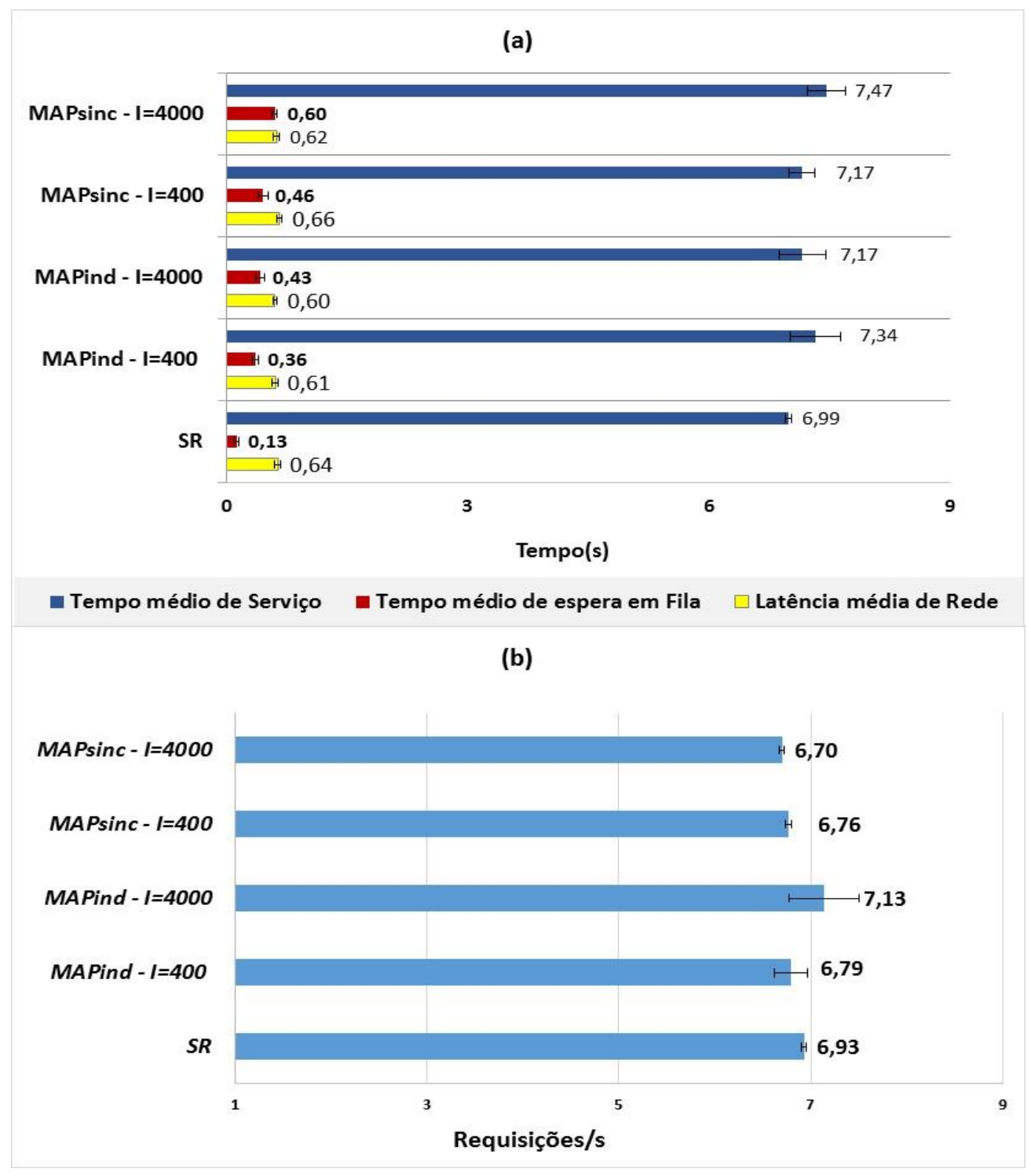

Figura 6.37 - Resultados das variáveis de Repostas: (a) Tempo médio de Serviço, de espera em fila e latência média de rede, (b) vazão - considerando uma nuvem híbrida. 
Em relação à vazão, apresentada na Figura 6.37(b), os resultados obtidos mostram uma queda que varia de 2 a 3\%, quando são consideradas rajadas modeladas por MAPs sincronizados, especialmente quando são parametrizados com intensidades mais rigorosas $(\mathrm{I}=4000)$. Entretanto, a vazão torna-se estatisticamente igual quando considera-se cargas de trabalho sem rajadas e com rajadas modeladas por MAPs independentes, uma vez que a média obtida para esses experimentos estão inseridas dentro do intervalo de confiança um do outro.

Nos experimentos que adotaram o $\mathrm{MAP}_{\text {ind, os resultados obtidos nas repetições }}$ executadas para cada experimento apresentaram uma maior variação, fazendo com que o intervalo de confiança seja um pouco maior em relação aos outros experimentos. Essa variação mais elevada observada nas médias obtidas em cada repetição dos experimentos que consideraram MAP $_{\text {ind }}$ ocorre pois, como os MAPs (MAP iat $_{\text {e }} \mathrm{MAP}_{\text {sd }}$ ) são executados durante a simulação de forma independente, em algumas repetições do experimento, as rajadas originadas em ambos processos (think times e demandas) podem coincidir com maior frequência ou ainda ocorrerem em períodos de tempos distintos. Assim, a vazão obtida para cada repetição pode ser maior ou menor, dependendo da forma como as rajadas se apresentem.

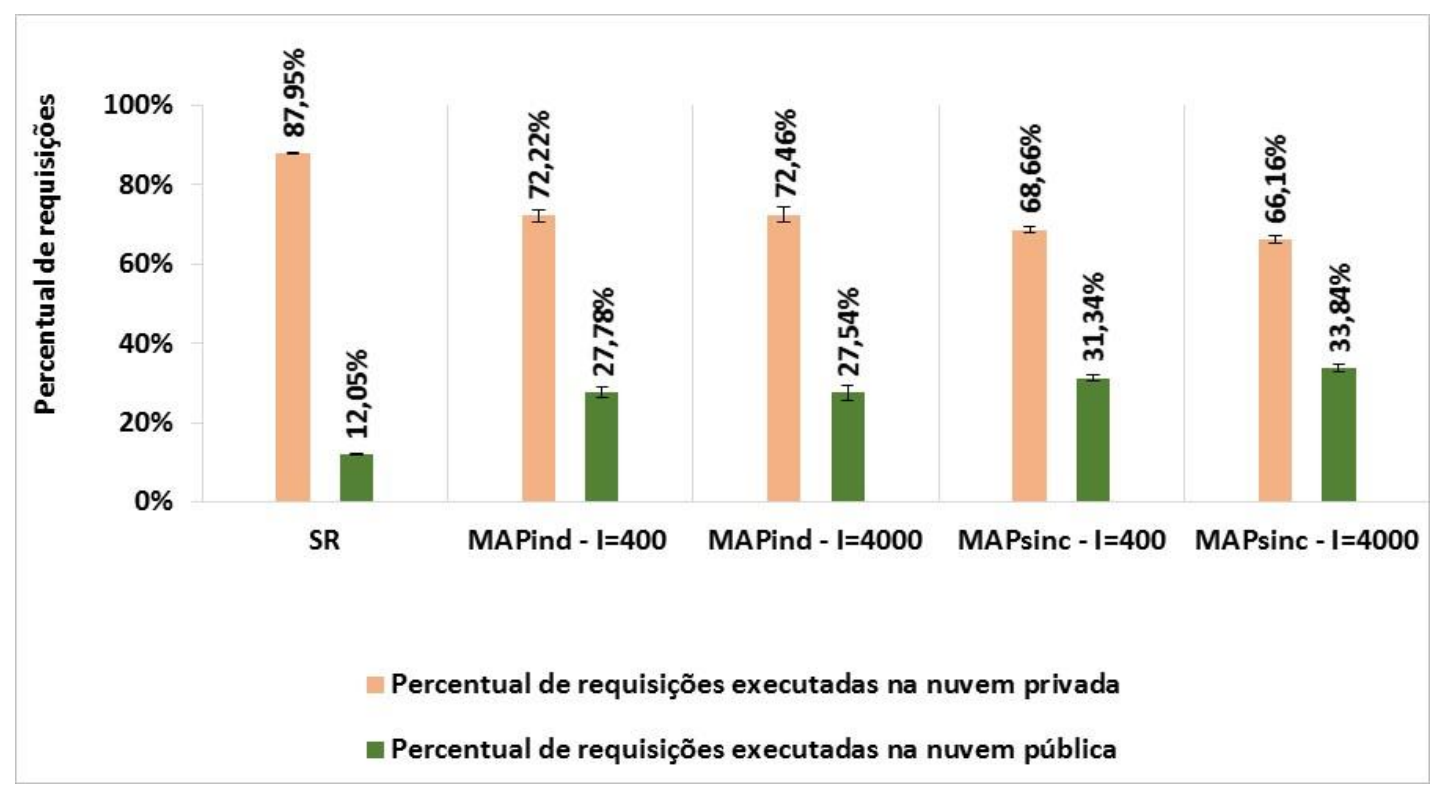

Figura 6.38 - Percentual de requisições executadas nas nuvens privada e pública.

No gráfico da Figura 6.38 é apresentado o percentual médio de requisições executadas na nuvem privada e na nuvem pública para os experimentos considerados nesta Seção. Assim, como observado nos experimentos que consideram modelos de carga de trabalho com rajadas, executados em uma nuvem híbrida, o percentual médio de requisições executadas na nuvem 
pública é significativamente maior que para modelos de cargas sem rajadas. Para as rajadas síncronas com intensidade severa, observa-se que o número de requisições executadas na nuvem pública é 2,81 vezes maior que o observado na ausência de rajadas. Esse aumento de utilização dos recursos públicos mostra mais uma vez, que as rajadas apresentam um impacto no sistema, em termos de quantidade de recursos necessários para atender todas as requisições que são submetidas ao ambiente de nuvem, para que não haja uma degradação mais acentuada no desempenho dos serviços.
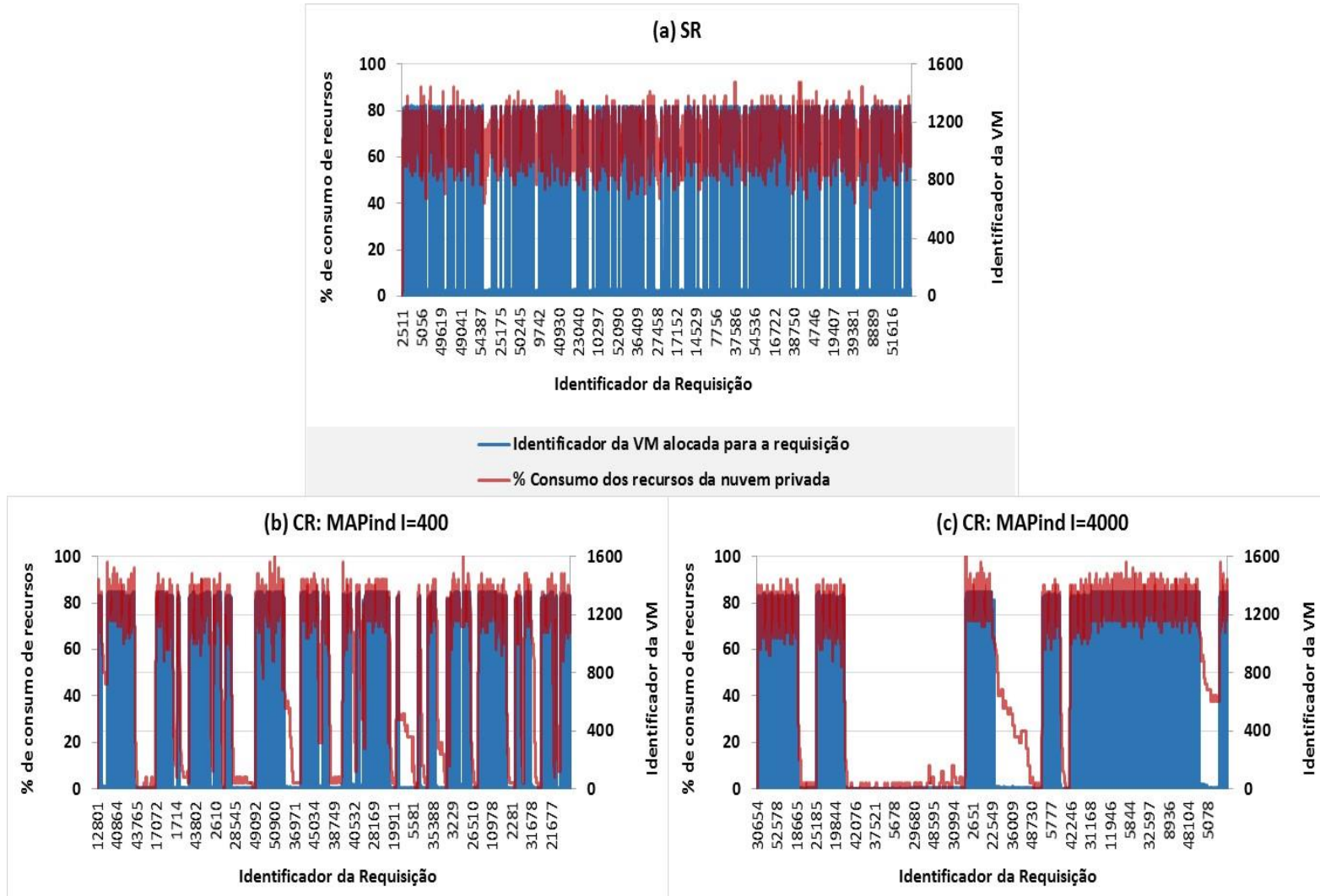

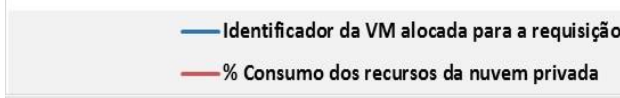

(d) CR: MAPsincl=400

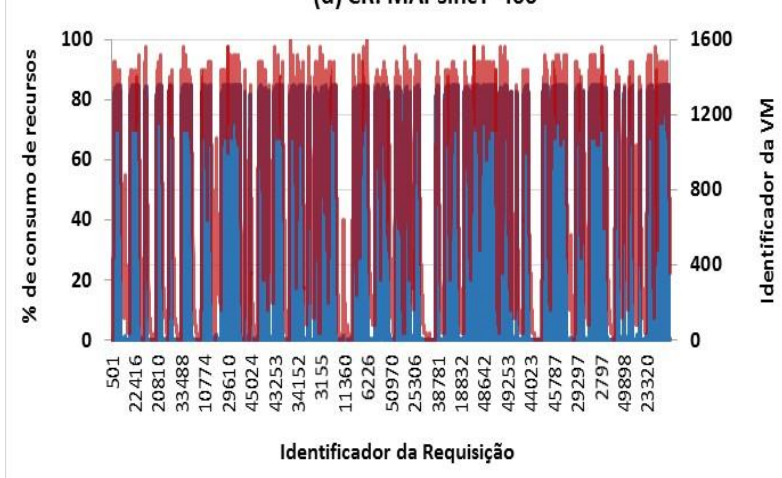

Identificador da Requisição
—Identificador da VM alocada para a requisição — Consumo dos recursos da nuvem privada (e) CR: MAPsinc l=4000

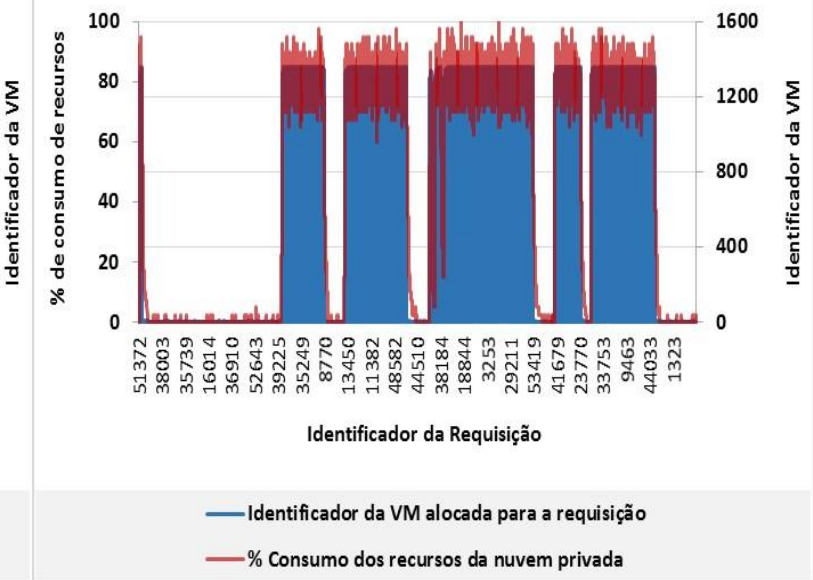

—Identificador da VM alocada para a requisição — Consumo dos recursos da nuvem privada 
Figura 6.39 - Amostras do percentual de consumo dos recursos privados e identificador das VMs alocadas para as requisições ao longo da simulação.

Esse impacto pode também ser percebido na Figura 6.39, onde é apresentado o percentual de consumo dos recursos do data center privado no momento que uma requisição foi encaminhada para uma determinada VM, monitorado durante a simulação. A linha vermelha do gráfico representa o percentual de consumo e a linha azul corresponde ao identificador da VM alocada para a requisição. Nos experimentos, quando os recursos privados apresentam um consumo superior a $80 \%$, as requisições passam a ser encaminhadas para as VMs (identificadas com números a partir de 1300) da nuvem pública. Mesmo para a situação sem rajadas (Figura 6.39(a)), que já apresenta um sobrecarga no consumo de recursos quando considera-se uma nuvem privada (apresentada na Figura 6.34(a)), em vários momentos ao longo da simulação, as requisições são direcionadas às VMs públicas, quando o consumo atinge o limite especificado. Nota-se também que diferente dos experimentos das Figuras 6.39 (b-e), o percentual de consumo, para situação sem rajada, não ultrapassa o limite de $80 \%$ com tanta frequência como ocorre nas situações onde considera-se o fenômeno de rajadas nos modelos de cargas de trabalho. Esse consumo mais elevado que o limite acontece especialmente nos períodos onde há presença de picos fortes e irregulares na utilização dos recursos, causadas pelas rajadas de serviços submetidas à nuvem.

\subsection{Considerações Finais}

Este Capítulo apresentou uma avaliação de desempenho no contexto de serviços executados em ambientes de nuvens, através do desenvolvimento de diferentes cargas de trabalho e considerando a ocorrência de fenômenos de rajadas na chegada de requisições e na demanda de serviço.

Os resultados obtidos nesse estudo mostram que, considerando os fatores, níveis e experimentos adotados nessa avaliação, a presença de rajadas tanto no processo de chegada das requisições quanto nas demandas de serviços, mesmo quando elas chegam de forma mais suave e com variabilidade moderada ocasiona uma significativa degradação de desempenho dos serviços executados em uma nuvem privada. As variáveis de resposta consideradas são ainda mais afetadas negativamente quando as rajadas de diferentes origens (nos intervalos de chegadas e demandas de serviços) e com intensidades mais rigorosas, chegam de maneira sincronizadas ao longo do tempo. No caso de utilização de nuvem privada, os experimentos 
realizados mostraram um aumento acima de $70 \%$ no tempo de resposta quando são consideradas cargas com rajadas.

Quando se considera o modelo de nuvem híbrido, embora o impacto não seja tão expressivo quanto o observado para situações em que modelo de nuvem privada é adotado, também se tem uma influência significativa no desempenho. Para nuvem hibridas observa-se um aumento no tempo de resposta que chega a 7\% quando as rajadas são consideradas. Além disso, ao observar os resultados do percentual médio de requisições executadas na nuvem pública, percebe-se que quando são criadas condições de rajadas, a quantidade de VMs públicas necessárias para atender todas as requisições submetidas à nuvem, torna-se significativamente maior. Em casos de rajadas mais severas, o número de requisições executadas em nuvem pública chega a ser quase quatro vezes maior que o número obtido quando a carga não apresenta rajada. Em consequência, os custos operacionais tendem a ser maiores para o provedor de nuvem disponibilizar recursos suficientes para atender as solicitações de serviços e garantir que o desempenho não seja tão afetado.

Desta forma, pode-se afirmar que as rajadas causam um impacto significativo no desempenho dos serviços executados em nuvem e pode-se constatar também a importância de se considerar rajadas no modelo de cargas de trabalho, visto que elas podem degradar o desempenho do serviço e do sistema se não levadas em consideração. 


\section{Avaliação do Fator de Rajada}

\subsection{Considerações Iniciais}

Visto que a presença de rajadas no processo de chegada das requisições ou nas demandas ocasiona um impacto negativo no desempenho dos serviços executados em uma nuvem, como pôde ser observado nas avaliações de desempenho executadas no Capítulo 6, é importante que o fenômeno de rajadas em cargas de trabalho seja levado em consideração, não apenas na modelagem de cargas de trabalho, mas como também em modelos preditivos de desempenho.

Para tanto, neste Capítulo é proposta uma metodologia para a obtenção da medida conhecida como fator de rajada, que possui a habilidade de determinar a ocorrência de rajadas em cargas de trabalho, podendo, portanto, ser uma métrica a ser incorporada em um modelo preditivo de desempenho que considere a presença de rajadas nas cargas de trabalho. Neste Capítulo também é apresentado um estudo comparativo considerando os modelos de fator de rajada disponíveis em literatura e o modelo proposto neste projeto de doutorado visando avaliar o comportamento de cada um deles em relação à taxa de chegada (de requisições ou de demandas) e suas correlações, como também validar o modelo para o fator de rajada proposto.

\subsection{Fatores de Rajadas e Modelos Preditivos}

No contexto de computação em nuvem, os modelos preditivos de desempenho são fundamentais para apoiar tarefas de gerenciamento dos serviços, para projetar soluções de computação em nuvem, como políticas de balanceamento de carga e de controle de admissão e para planejamento de capacidade do sistema (Pacheco-Sanchez et al., 2011) (Unuvar et al., 2014).

Em ambientes de nuvens, os recursos podem ser provisionados e liberados elasticamente, em alguns casos automaticamente, para se ajustar à quantidade de solicitações e de serviços que 
chegam ao sistema. Além disso, a tarefa de alocação das cargas de trabalho nas máquinas virtuais torna-se mais complexa, especialmente quando elas se apresentam em forma de rajadas, impondo uma maior complexidade no gerenciamento desses processos. Desta forma, há uma necessidade crescente de modelos preditivos de desempenho voltados para a computação em nuvem e que considerem a presença de rajadas nas cargas de trabalho. No entanto, em se tratando de modelos preditivos que levam em consideração o fenômeno de rajadas, poucos trabalhos são encontrados na literatura especializada (Menascé e Almeida, 2001) (Al-Ghamdi et al., 2011) (Krishnamurthy, 2011) (Ghorbani et al., 2014). Um trabalho seguindo esta linha de pesquisa é apresentado em (Gilly et al, 2012). Nesse trabalho é proposto um algoritmo de controle de admissão e balanceamento de carga baseado em um modelo de predição da vazão (throughput). Esse modelo preditivo considera o monitoramento, em intervalos ou slots de tempo, de algumas métricas importantes como: o fator de rajadas, calculado a partir da taxa de chegada de requisições, a utilização de CPU, o tempo de serviço, entre outras. A Figura 7.1 descreve os passos realizados pelo algoritmo proposto por Gilly et al. (2012). Uma vez que, o fator de rajadas, referente ao intervalo de tempo atual (slot $k$ ), tenha sido obtido e o algoritmo tenha coletado as medidas monitoradas nos servidores, no slot $k$, relacionadas à vazão, à utilização de CPU e ao tempo de serviço, o algoritmo faz uma predição da vazão para o próximo slot $k+1$ nos servidores.

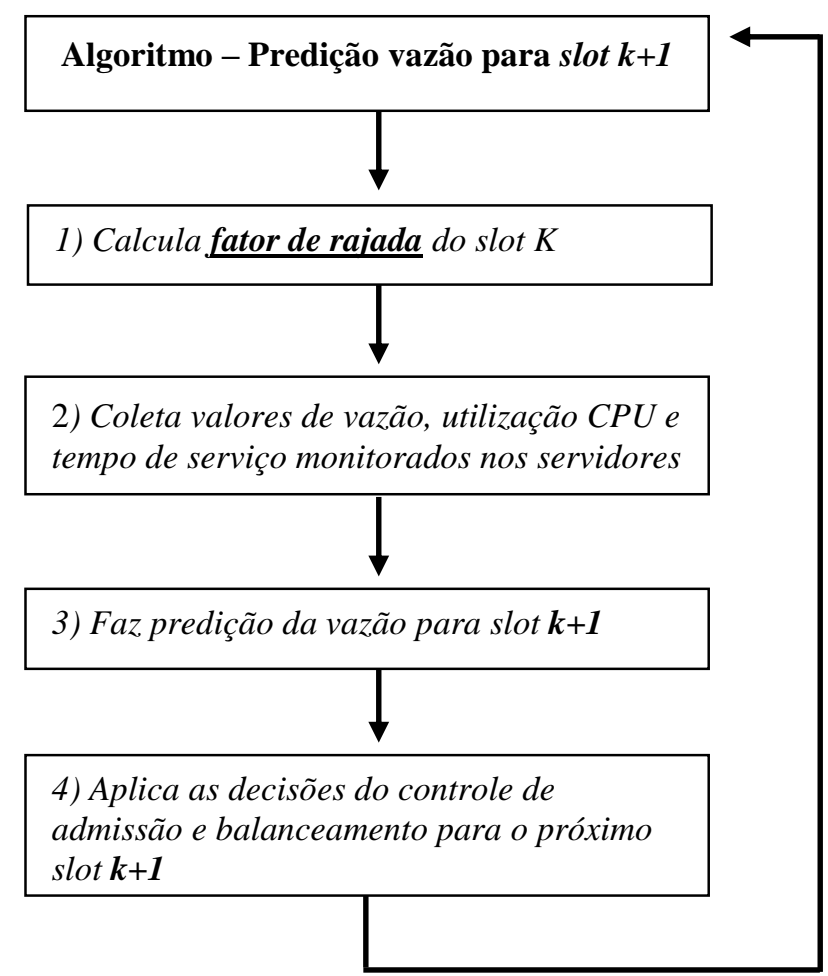

Figura 7.1 - Exemplo do algoritmo e modelo preditivo proposto por Gilly et al. (2012) 
O fator de rajada (BF - Burstiness Factor), conforme apresentado na Seção 4.5 do Capítulo 4, é uma medida importante que determina a ocorrência de rajadas em cargas de trabalho, podendo assumir valores entre [0,1]. Quanto maior o valor de BF mais intensa será a rajada observada na taxa de chegada de requisições. O BF tem sido utilizado em alguns trabalhos (Menascé e Almeida, 2001) (Menascé et al., 2004) (Gilly et al., 2009) (Suchacka, 2011) (Al-Ghamdi et al., 2011) (Gilly et al.,2012) como uma das métricas consideradas em modelos preditivos de desempenho para dar uma estimativa da tendência da taxa de chegada de requisições no sistema em relação à taxa de chegada média.

A definição do fator de rajadas, nesses trabalhos, requer o conhecimento da taxa de chegada média $(\lambda)$ das requisições durante $n$ intervalos de tempo ou slots de $0,1,2, \ldots, k-1$, de duração fixa (Menascé e Almeida, 2001) ou variável (Gilly et al., 2012), onde para cada slot $k$ é calculado a taxa de chegada desse slot $\left(\lambda_{\mathrm{k}}\right)$. A taxa de chegada do slot $k$ é então comparada com a taxa de chegada média $(\lambda)$ e caso $\lambda_{k}$ seja superior à $\lambda$, o slot é considerando um slot com rajadas. O modelo matemático proposto por Menascé e Almeida (2001), considera que o fator de rajada de um slot pode ser obtido pela relação entre o número acumulativo de slots com rajadas $\left(k^{+}\right)$e o número atual do slot, ou seja, $k$. Esse modelo também é considerado no trabalho de Gilly et al. (2009) (2012), incluindo mais outros cinco diferentes modelos. A descrição detalhada desses modelos encontra-se na Seção 4.5.

De modo geral, os modelos matemáticos para o fator de rajada propostos nesses trabalhos, consideram apenas a taxa de chegada das requisições. No entanto, as rajadas também podem se manifestar nas demandas de serviços impostas aos recursos do sistema. Como pôde ser observado nos resultados obtidos nas avaliações de desempenho apresentadas no Capítulo 6 , as rajadas originadas tanto no processo de chegada das requisições como nas demandas imposta aos recursos da nuvem, podem afetar severamente o desempenho dos serviços e do sistema e desta forma, precisam ser levadas em consideração não apenas na modelagem de cargas de trabalho, como também na implementação de modelos preditivos de desempenho.

Este Capítulo tem como objetivo apresentar uma nova abordagem desenvolvida para a obtenção do fator de rajada, considerando a ocorrência de rajadas nas chegadas de requisições e nas demandas de serviços. É importante salientar que o foco não é propor um modelo preditivo de desempenho, mas sim propor um modelo matemático para o fator de rajada que possa ser adotado para determinar rajadas de diferentes origens. Para tanto, nas próximas Seções, serão apresentadas a metodologia proposta (Seção 7.3) e uma análise comparativa do modelo desenvolvido com os fatores de rajadas propostos na literatura (Seção 7.4). 


\subsection{Metodologia Proposta para o Fator de Rajada}

Nesta Seção é apresentada a metodologia adotada para obtenção de duas medidas para fator de rajada proposto neste projeto. Uma das medidas refere-se ao $\mathrm{BF}_{\text {cloud_AR }}$ (Burstiness Factor for Cloud Arrival Rate) que determina a ocorrência de rajadas no processo de chegada de requisições. A outra medida corresponde ao BF cloud_DR ((Burstiness Factor for Cloud Demand Rate), que determina a presença de rajadas nas demandas de serviços. Essas duas medidas referentes ao fator de rajada podem ser utilizadas em modelos preditivos de desempenho, em cenários onde a carga de trabalho se apresenta em rajadas, e desta forma, contribui para as áreas de pesquisas voltadas à avaliação de desempenho de sistemas computacionais.

O componente da arquitetura desenvolvida, apresentada na Seção 5.3.2 do Capítulo 5, responsável pela tarefa de monitoramento das requisições e demandas de serviços submetidas ao Broker corresponde ao monitor de carga de trabalho. Esse monitor tem a função de calcular as taxas de chegadas de requisições (em requisições por segundo) e de demandas de serviços (em MIPs) e encaminhá-las ao método responsável em calcular o fator de rajada para a obtenção de $\mathrm{BF}_{\text {cloud_AR }}$ e de $\mathrm{BF}_{\text {cloud_DR. }}$ A Figura 7.2 apresenta uma visão geral das operações realizadas por esses componentes.

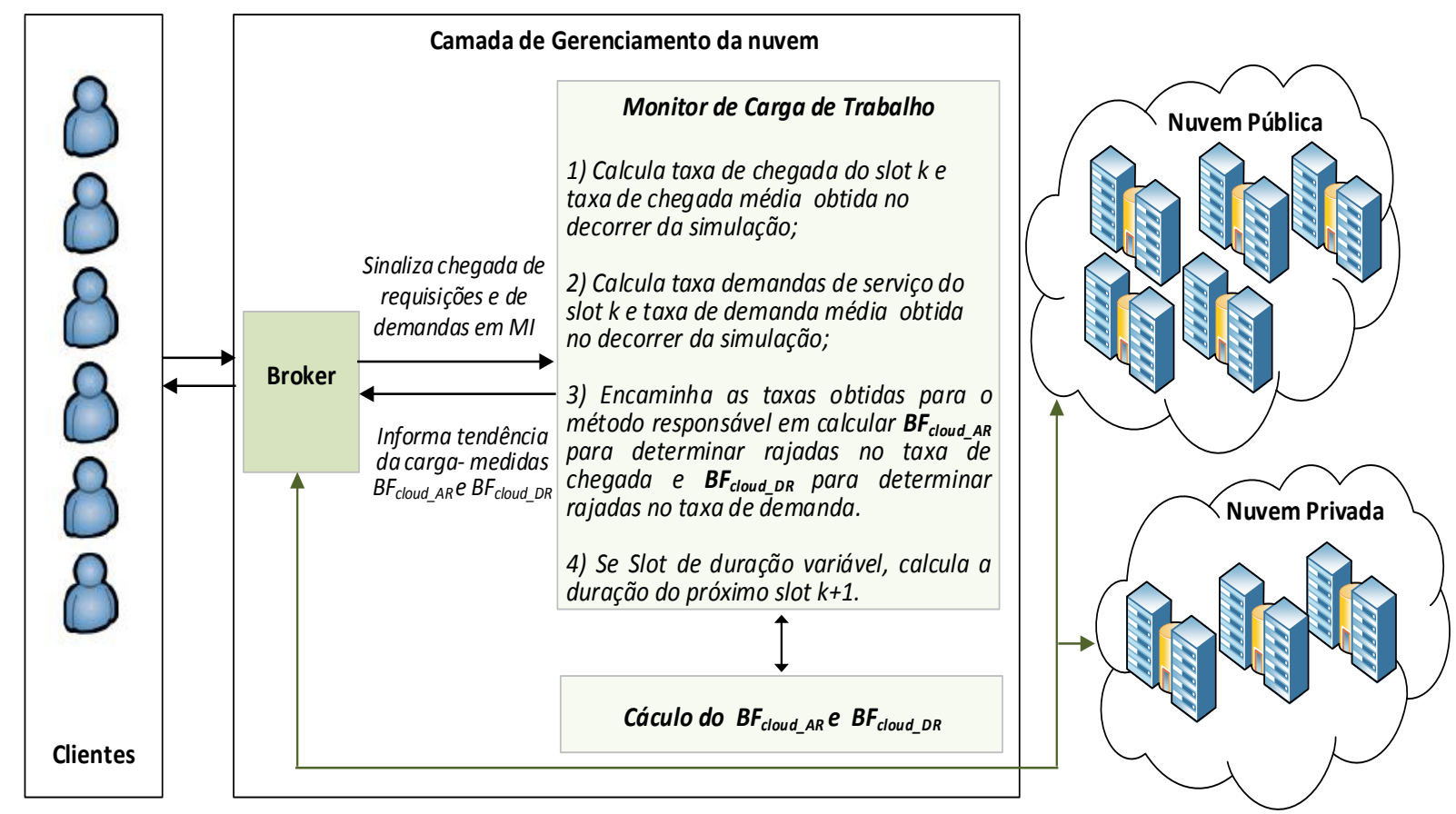

Figura 7.2 - Monitoramento das cargas de trabalho e cálculo do fator de rajada. 
Conforme ilustrado na Figura 7.2, as requisições e demandas de serviços em MI submetidas ao Broker são sinalizadas ao monitor de carga de trabalho para que este determine a quantidade de requisições e demandas de serviços que chegam, durante um intervalo de tempo (slot), no decorrer da simulação. Baseado nesses dados, o monitor de carga de trabalho realiza o cálculo da taxa de chegada de requisições $\left(\lambda_{k}\right)$ e da taxa de chegada de demandas de serviços $\left(\mu_{\mathrm{k}}\right)$ correspondentes ao slot $k$ e verifica a quantidade total de requisições e demandas de serviços que chegam no decorrer do período de simulação até o instante de tempo final do slot $k$ para calcular a taxa média de chegada de requisições $(\lambda)$ e a taxa média de demandas de serviços $(\mu)$. Essas informações são então passadas para o método responsável em obter as medidas relacionadas ao fator de rajadas.

Considerando que o fator de rajada representa uma das métricas que pode ser considerada em um modelo preditivo de desempenho, é importante definir a duração dos slots (intervalos de tempo) em que as taxas de chegadas e demandas serão monitoradas, visto que a sobrecarga imposta ao sistema pode ser maior ou menor, dependendo da frequência em que esses monitoramentos ocorrem. Neste sentido, o monitoramento pode ocorrer de três formas:

i) A cada instante de tempo em que as requisições chegam no Broker;

ii) Durante instantes de tempos fixos, através da definição de slots estáticos, com duração fixa, como proposto nas metodologias apresentadas em Menascé e Almeida (2001) e em Suchacka (2011);

iii) Durante instantes de tempos variáveis, por meio da definição de slots dinâmicos, com duração variável, que segue a abordagem utilizada no trabalho de Gilly et al. (2009) (2012) e Al-Ghamdi et al. (2011).

Segundo Gilly et al. (2009), a sobrecarga imposta pela opção (i) é maior, em virtude do monitoramento ser feito a cada momento em que uma requisição chega ao sistema. Enquanto que a opção (ii) apresenta uma sobrecarga constante no sistema e a opção (iii) apresenta um nível de sobrecarga que irá depender da frequência dos intervalos (slots) de tempo em que o sistema será monitorado.

Desta forma, na metodologia proposta neste projeto considera as duas últimas opções, ou seja, (ii) e (iii), para definição da duração dos slots. Para tanto, foram implementadas duas formas de definição de slots: uma seguindo a opção (ii) onde os slots possuem uma duração fixa e a segunda baseada na opção (iii), onde os slots possuem uma duração variável ou ajustada de maneira dinâmica, dependendo do comportamento da carga de trabalho observada nos dois 
últimos slots. A opção que será ativada no monitor de requisições é um parâmetro de entrada para o modelo e que pode ser facilmente alterado no início da execução da simulação. Quando a opção correspondente à definição de slots estáticos é ativada antes da simulação iniciar, devese informar também a duração, em segundos, que deverá ser considerado. Para a opção de slots dinâmicos, é especificado apenas a duração, em segundos, do primeiro slot, sendo que a duração dos próximos slots é definida durante a simulação, pelo próprio monitor de carga de trabalho, como mostra a Figura 7.2 (item 4).

A definição da duração dos slots dinâmicos, depende da taxa de chegada obtida nos dois slots prévios, de acordo com a equação 7.1, que pode ser aplicada tanto para definição dos slots utilizadas para o cálculo do fator de rajada $\mathrm{BF}_{\text {cloud_AR }}$ como para o cálculo do fator de rajada BF cloud_DR.

$$
\begin{array}{r}
\operatorname{Para~BFcloud}_{\mathrm{AR}}: \quad \text { se } \lambda_{k} \geq \lambda_{k-1}, \quad d(k+1)=d(k)-\frac{k^{+}}{k} \\
\operatorname{Para~BFcloud}_{\mathrm{DR}}: \quad \text { se } \mu_{k} \geq \mu_{k-1}
\end{array} \quad \begin{aligned}
& \mathrm{B}^{+} \\
& \text {caso contrário, }
\end{aligned}
$$

onde $\mathrm{K}^{+}$é o número acumulativo de slots que satisfaçam a condição $\lambda_{k} \geq \lambda$ considerado para BFcloud_AR ou a condição $\mu_{k} \geq \mu$ considerado para BFcloud_DR e k é o slot atual.

Como a duração do próximo slot $k+1$ é definido baseando-se nas taxas de chegadas dos dois slots prévios, caso seja observado um aumento da taxa no slot $k$ em relação ao slot $k$ - 1 , então a duração do slot $k+1$ diminui, para que o monitoramento seja executado com maior frequência, caso contrário, a duração do slot $k+1$ torna-se maior que o slot anterior e consequentemente, os intervalos em que o sistema é monitorado são mais espaçados.

A partir da definição dos slots estáticos ou dinâmicos, os fatores de rajadas BFcloud_AR e BFcloud_DR para cada slot $k$, podem ser obtidos pelas equações 7.2 e 7.3 respectivamente.

$$
\begin{aligned}
& b f_{\text {cloud }_{A R}}(k)=\left(\frac{K^{+}}{K}\right)\left(\frac{\lambda_{K}}{\lambda}\right) \\
& b f_{\text {cloud }_{D R}}(k)=\left(\frac{K^{+}}{K}\right)\left(\frac{\mu_{K}}{\mu}\right)
\end{aligned}
$$

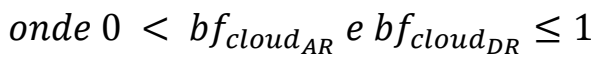


As duas medidas, portanto, consideram uma modificação da equação do fator de rajadas $\mathrm{BF}_{1}$ proposta por Menascé e Almeida (2001), $b f_{l}=k^{+} / k$, incluindo a relação entre a taxa de chegada (de requisições $-\lambda_{\mathrm{k}}$ ou de demandas de serviços $-\mu_{\mathrm{k}}$ ) do slot $k$ e a taxa de chegada média $(\lambda$ ou $\mu$ ) obtida no decorrer da simulação até o instante de tempo final do slot $k$. Conforme mencionado na Seção 7.2, os fatores de rajadas podem assumir valores entre [0,1]. No entanto, nas equações apresentadas para o fator de rajada, pode acontecer do valor obtido ser maior do que 1. Quando isto acontece, com base no trabalho de Gilly et al. (2009), o valor é definido para 1, de forma a cumprir com a restrição: $0<b f_{\text {cloud }_{A R}} e b f_{\text {cloud }_{D R}} \leq 1$.

\subsection{Análise Comparativa dos Fatores de Rajada}

Nesta Seção é apresentada uma análise comparativa entre os modelos propostos para o fator de rajada disponíveis em literatura e o modelo proposto neste projeto de doutorado, considerando slots estáticos e dinâmicos. Na Tabela 7.1 são apresentados os modelos considerados nessa avaliação, incluindo as equações e uma breve descrição a respeito dos modelos matemáticos considerados para cada modelo (e que foram apresentados na Seção 4.5).

Para avaliar os modelos definidos para o fator de rajada, considerando-se intervalos de tempo fixos (slots estáticos), foram utilizados os experimentos realizados e apresentados na Seção 6.6 do Capítulo 6, com as mesmas configurações descritas para esses experimentos. Assim, para analisar os fatores de rajada baseados na taxa de chegada de requisições, foram considerados os resultados obtidos no experimento voltado para avaliar rajadas originadas no

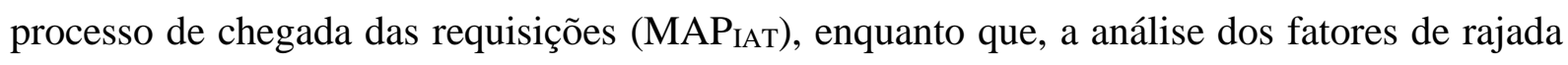
definidos para determinar a ocorrência de rajadas nas demandas de serviços, considerou-se os resultados obtidos na execução do experimento onde as demandas de serviços foram modelas pelo MAPSD. Ambos experimentos consideraram rajadas de intensidades severas (com índice de dispersão igual a 4000), porém com variabilidades diferentes, ou seja, para o experimento que adotou o modelo MAP $\mathrm{IAT}_{\mathrm{T}}$ considerou-se os resultados obtidos para rajadas de variabilidade alta (com SCV igual a 7), enquanto que, para o experimento que adotou o modelo MAPSD considerou-se rajadas de variabilidade moderada (com SCV igual a 3). Desta forma, é possível analisar o comportamento dos modelos propostos para o fator de rajada, considerando não apenas rajadas de origens distintas, mas também rajadas com diferentes níveis de variabilidade. Para esses experimentos a duração dos slots foi definida em 14 segundos, o mesmo intervalo de tempo considerado nos monitoramentos da taxa de chegada das requisições e demandas, utilizado no Capítulo 6. 
Tabela 7.1 - Modelos de fator de rajada considerados nas avaliações.

\begin{tabular}{|c|c|c|}
\hline $\begin{array}{c}\text { Fator de } \\
\text { Rajada }\end{array}$ & Equação & Descrição \\
\hline $\mathbf{B F}_{1}$ & $b f_{1}(k)=\left(\frac{K^{+}}{K}\right)$ & $\begin{array}{l}\text { Proposta definida por Menascé e Almeida } \\
(2002) \text {. }\end{array}$ \\
\hline $\mathrm{BF}_{2}$ & $b f_{2}(k)=\left(\frac{K^{+}}{K}\right)\left(1+\frac{\lambda_{K}-\lambda_{k-1}}{\lambda_{k-1}}\right)$ & $\begin{array}{l}\text { Considera } \mathrm{BF}_{1} \text {, incluindo a diferença } \\
\text { relativa da taxa de chegada dos dois slots } \\
\text { prévios (Gilly et al., 2012) }\end{array}$ \\
\hline $\mathbf{B F}_{3}$ & $\begin{array}{l}\quad b f_{3}(k)=\left(\frac{K^{+}}{K}\right)(1+\alpha) \\
\text { onde } \alpha=0,1 . \mathrm{j} \text {, para } \mathrm{j} \in 1,2, \ldots, 10 \text {. }\end{array}$ & $\begin{array}{l}\text { Considera } \mathrm{BF}_{1} \text {, incluindo um acréscimo no } \\
\text { fator de rajada na presença de } \boldsymbol{j} \text { slots } \\
\text { consecutivos com rajadas (Gilly et al., } \\
\text { 2012). }\end{array}$ \\
\hline $\mathrm{BF}_{4}$ & $b f_{4}(k)=\left(\frac{K^{+}}{K}\right)\left(1+\frac{\lambda_{K}-\lambda_{k-1}}{\lambda_{k-1}}+\alpha\right)$ & $\begin{array}{l}\text { Considera } \mathrm{BF}_{1} \text {, incluindo a diferença } \\
\text { relativa da taxa de chegada dos dois slots } \\
\text { prévios e o acréscimo no fator na presença } \\
\text { de } j \text { slots consecutivos com rajadas (Gilly et } \\
\text { al., 2012). }\end{array}$ \\
\hline $\mathrm{BF}_{5}$ & $\begin{array}{c}\qquad b f_{5}(k)=\left(\frac{K^{+}}{K}\right) \\
\text { Onde } k^{+} \text {é o número acumulativo de slots } \\
\text { que satisfaçam } \lambda_{k}>\lambda_{k}^{\wedge}, \text { sendo } \lambda_{k}^{\wedge} \text { a } \\
\text { previsão da taxa de chegada do slot } k \text { : } \\
\lambda_{k}^{\hat{n}}=\lambda_{k-2}+\left(\frac{t_{k}-t_{k-2}}{t_{k-1}-t_{k-2}}\right)\left(\lambda_{k-1}-\lambda_{k-2}\right), \\
\text { sendo } \mathrm{t}_{\mathrm{k}} \text { o tempo final do slot } \mathrm{k} .\end{array}$ & $\begin{array}{l}\text { Neste modelo, é feita uma previsão da taxa } \\
\text { de chegada do slot } \mathrm{k}\left(\lambda_{\mathrm{k}}{ }_{\mathrm{k}}\right) \text {, baseada no } \\
\text { trabalho de Baryshnikov et al.(2002). O slot } \\
\text { é considerado com rajadas quando } \lambda_{k}> \\
\lambda_{k}^{\wedge} \text { e então é aplicada a equação } \mathrm{BF}_{1}, \\
\text { considerando } \mathrm{k}^{+} \text {como o número de slots } \\
\text { com rajadas e k o número do slot corrente } \\
\text { (Gilly et al., 2012). }\end{array}$ \\
\hline BFcloud_AR & $\begin{aligned} b f_{\text {cloud }_{A R}}(k) & =\left(\frac{K^{+}}{K}\right)\left(\frac{\lambda_{K}}{\lambda}\right) \\
b f_{\text {cloud }_{D R}}(k) & =\left(\frac{K^{+}}{K}\right)\left(\frac{\mu_{K}}{\mu}\right)\end{aligned}$ & $\begin{array}{l}\text { Modelo proposto, considerando } \mathrm{BF}_{1}, \\
\text { multiplicado pela relação entre a taxa de } \\
\text { chegada do slot } \mathrm{k} \text { e a taxa média. }\end{array}$ \\
\hline
\end{tabular}

Em relação à análise dos fatores de rajadas, considerando slots dinâmicos, foram executadas novas repetições dos mesmos experimentos considerados para a situação dos slots estáticos, porém habilitando a opção de slots dinâmicos, para que a duração dos slots fosse definida durante a simulação, pelo monitor de carga de trabalho. Para esse cenário, a duração inicial do primeiro slot foi definida em 28 segundos, sendo a duração dos próximos slots definida dependendo da taxa de chegada obtida nos dois slots prévios. Optou-se em definir uma duração inicial do primeiro slot maior (28s) do que o slot estático (14s), para evitar intervalos de tempos de monitoramento muito curtos, uma vez que a duração dos slots é variável durante a simulação. 
Nas Seções a seguir, 7.4.1 e 7.4.2, serão apresentados os resultados obtidos na análise comparativa dos modelos de fatores de rajadas com o objetivo de avaliar como cada um deles se comporta em relação à taxa de chegada (de requisições ou demandas), ou seja, se possuem a capacidade de acompanhar com precisão as mudanças e as rápidas variações da carga de trabalho e se conseguem detectar a presença de rajadas no processo de chegada de requisições ou nas demandas de serviços submetidas ao sistema.

Para validar os resultados obtidos, também é apresentado um estudo da correlação obtida entre as taxas de chegadas e os fatores de rajadas, usando o método estatístico que visa estudar a associação entre duas variáveis aleatórias X e Y, conhecido como coeficiente de correlação de Pearson, $\rho_{\mathrm{x}, \mathrm{y}}$ (Moore, 2010). Nesse método duas variáveis apresentam uma correlação linear quando os pontos do diagrama de dispersão se aproximam de uma reta. Essa correlação pode ser positiva (para valores crescentes de $\mathrm{X}$, há uma tendência também crescente de Y) ou negativa (para valores crescentes de $\mathrm{X}$, observa-se uma tendência de valores decrescentes de Y) e assumir valores entre [-1,1], onde $\rho_{\mathrm{x}, \mathrm{y}}=1$ ou -1 representa uma correlação perfeita positiva e perfeita negativa respectivamente. Quando mais próximo o valor de $\rho_{x, y}$ for de 1, mais forte será a correlação entre as variáveis X e Y. O coeficiente de correlação linear é expresso por (Moore, 2010):

$$
\rho_{X, Y}=\frac{\operatorname{cov}_{X, Y}}{\sigma_{X} \sigma_{Y}}
$$

onde $\operatorname{COV}_{\mathrm{X}, \mathrm{Y}}$ é a covariância entre as variáveis $\mathrm{X}$ e $\mathrm{Y}$ e $\sigma_{\mathrm{x}}$ e $\sigma_{\mathrm{y}}$ são os desvio-padrão das variáveis $\mathrm{X}$ e $\mathrm{Y}$, respectivamente. Neste estudo, portanto, a variável $\mathrm{X}$ corresponde à amostra de taxas de chegadas e $\mathrm{Y}$ à amostra dos fatores de rajadas obtidos durante a simulação. $\mathrm{O}$ valor do coeficiente de correlação determina, portanto, se a relação entre as amostras é fraca, moderada ou forte. Existem diferentes classificações encontradas na literatura para definir o grau da correlação entre duas amostras. Santos (2007) propõe uma classificação dos valores dos coeficientes de correlação da seguinte forma: correlação nula: $\rho_{x, y}=0$; correlação ínfima: 0 $<\rho_{\mathrm{x}, \mathrm{y}}<0,1$; correlação fraca: $0,1 \leq \rho_{\mathrm{x}, \mathrm{y}}<0,5$; correlação moderada: $0,5 \leq \rho_{\mathrm{x}, \mathrm{y}}<0,8$; correlação forte: $0,8 \leq \rho_{\mathrm{x}, \mathrm{y}}<1$ e correlação perfeita $\rho_{\mathrm{x}, \mathrm{y}}=1$. No estudo apresentado neste Capítulo, para interpretar os resultados obtidos, é considerada essa classificação. 


\subsubsection{Fator de rajadas - BFcloud_AR}

Nesta Seção são apresentados os resultados obtidos no estudo comparativo dos modelos de fator de rajada para determinar rajadas na taxa de chegada de requisições (requisições/s), considerando slots estáticos e dinâmicos. Os gráficos da Figura 7.3 apresentam o comportamento da taxa de chegada de requisições em relação ao fator de rajada calculado para cada slot estático, de duração fixa, durante a simulação. Do mesmo modo, na Figura 7.4 são apresentados os resultados considerando slots dinâmicos, com duração variável.

Nos gráficos das Figuras 7.3 e 7.4 as taxas de chegadas de requisições são representadas pela linha verde e os valores obtidos para o fator de rajada corresponde à linha laranja. A Figura 7.3(a) e 7.4 (a), mostram o comportamento de $\mathrm{BF}_{1}$ em relação à taxa de chegada de requisições. Observa-se que esse modelo não tem a habilidade de detectar as rápidas variações da carga de trabalho e nem capturar os picos de chegadas e as flutuações dentro de um mesmo pico. Além disso, percebe-se também que esse fator de rajada suaviza a curva da taxa de chegada. Esse comportamento foi semelhante nas duas análises consideradas, ou seja, tanto com slots estáticos como dinâmicos.

Os modelos propostos por Gilly et al. (2009) (2012), $\mathrm{BF}_{2}$ a $\mathrm{BF}_{5}$, são apresentadas na Figura 7.3(b-e), para cenários onde considerou-se slots estáticos e a na Figura 7.4 (b-e), para slots dinâmicos. Percebe-se que os fatores de rajadas $\mathrm{BF}_{2}, \mathrm{BF}_{3}$ e $\mathrm{BF}_{4}$ (considerando para esses dois últimos o valor de $j$ igual a 4), apresentadas nas Figuras 7.3 e 7.4 (b-d), tentam acompanhar as rápidas variações das cargas de trabalho que chegam ao Broker, mas ainda não conseguem representar com exatidão os picos que surgem nas taxas de chegadas das requisições no decorrer do período de simulação. $\mathrm{O}$ fator $\mathrm{BF}_{5}$, no entanto, assim como o $\mathrm{BF}_{1}$ mostra-se ineficiente para representar as mudanças das taxas de chegadas, como pode ser observado nas Figuras 7.3(e) e 7.4(e).

Em relação ao fator de rajada proposto neste projeto, o BFcloud_AR, para as duas opções de definição de duração dos slots, os resultados se mostraram melhores do que os obtidos para os outros modelos analisados, conforme mostram as Figuras 7.3(f), para slots estáticos e 7.4(f), para slots dinâmicos. Observa-se que esse modelo consegue acompanhar com maior exatidão as variações da taxa de chegada que ocorrem durantes os slots e também têm a habilidade de detectar o surgimento de picos e as flutuações das taxas de chegada inseridas nos próprios picos.

Os gráficos das Figuras 7.3 e 7.4 dão uma percepção visual dos resultados. Para confirmar e validar os resultados analisados e apresentados nesta Seção, é importante também fazer uma análise de correlação entre as taxas de chegadas de requisições e os fatores de rajadas. Neste 
sentido, a Tabela 7.2 apresenta a correlação obtida entre as duas variáveis consideradas (taxa de chegada de requisições e fator de rajada). Na segunda coluna da Tabela encontra-se a correlação obtida para os resultados obtidos com a adoção de slots estáticos e na terceira coluna é apresentada a correlação resultante, considerando os resultados obtidos com a utilização de slots dinâmicos.

(a)

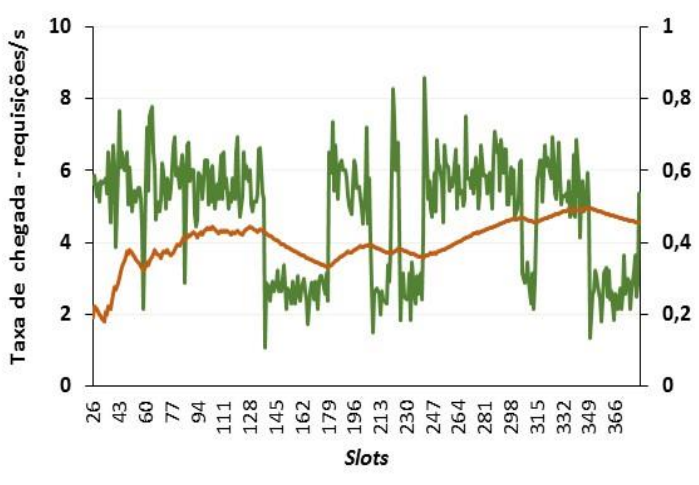

—Taxa de Chegada de Requisições

(c)

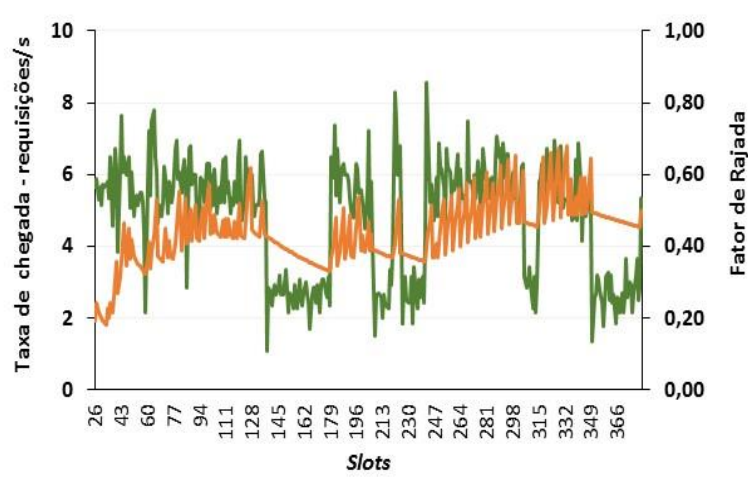

—Taxa de Chegada de Requisições

(e)

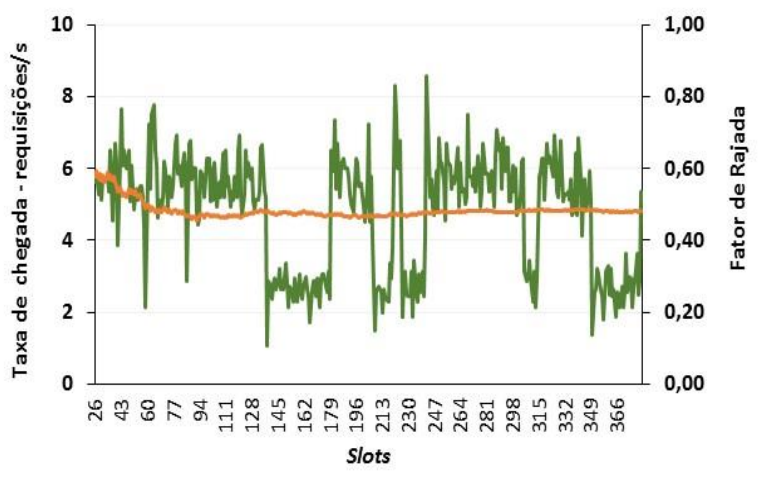

—Taxa de Chegada de Requisições (b)

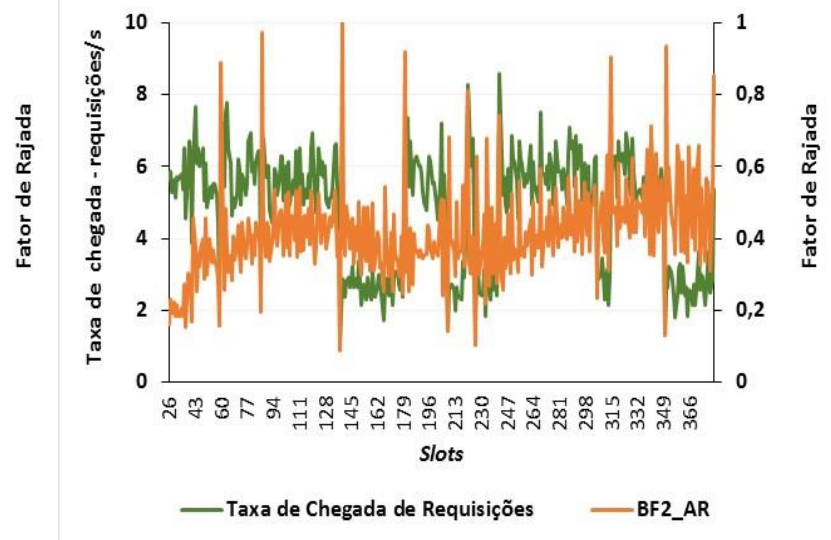

(d)

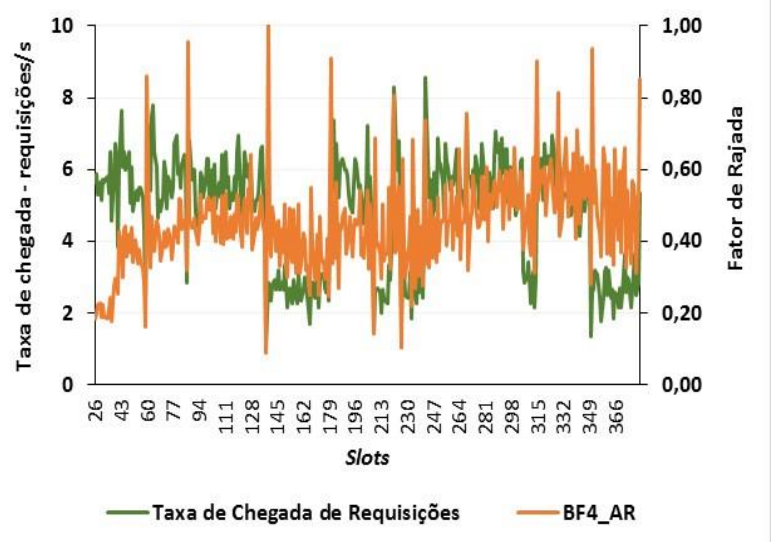

(f)

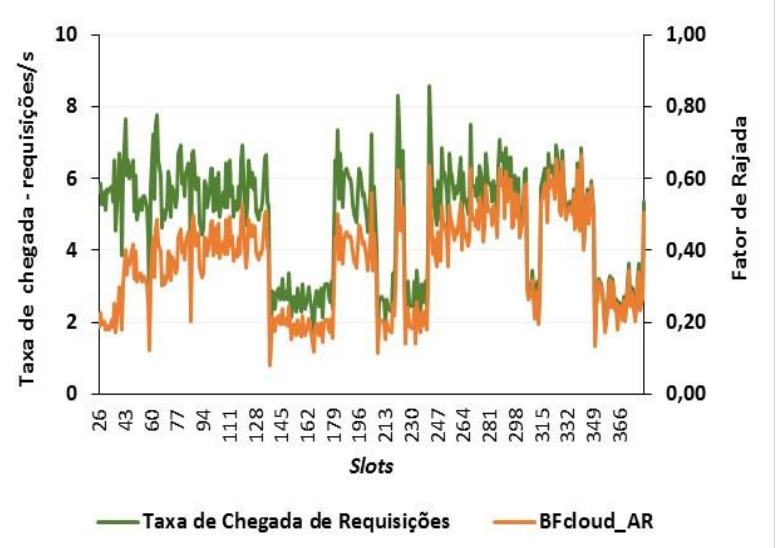

Figura 7.3 - Taxa de chegada de requisições e fatores de rajadas, considerando slots estáticos: a) BF1_AR; b) BF2_AR; c) BF3_AR com j=4; d) BF4_AR com j=4; e) BF5_AR; f) BF cloud_AR. 
(a) BF1_AR

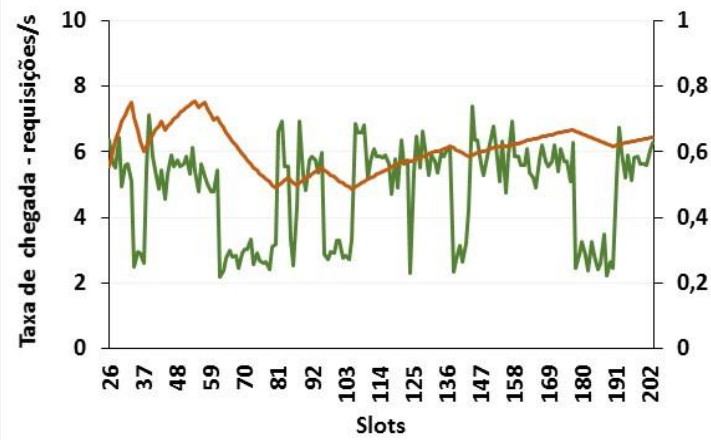

—Taxa de Chegada de Requisições —BF1_AR

(c) BF3_AR com j=4

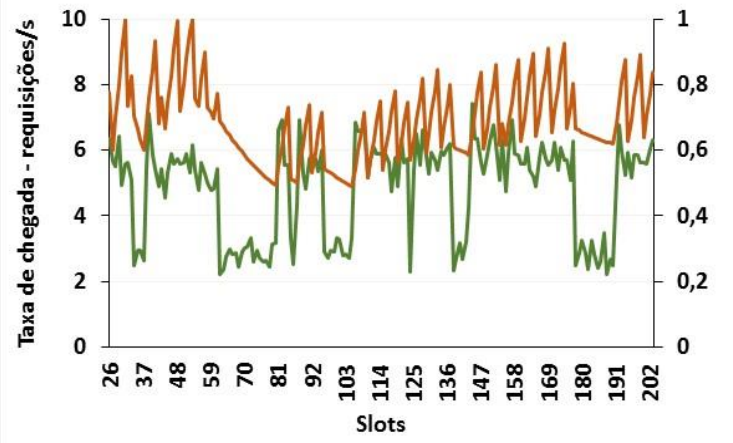

—Taxa de Chegada de Requisições —BF3_AR

(e) BF5_AR

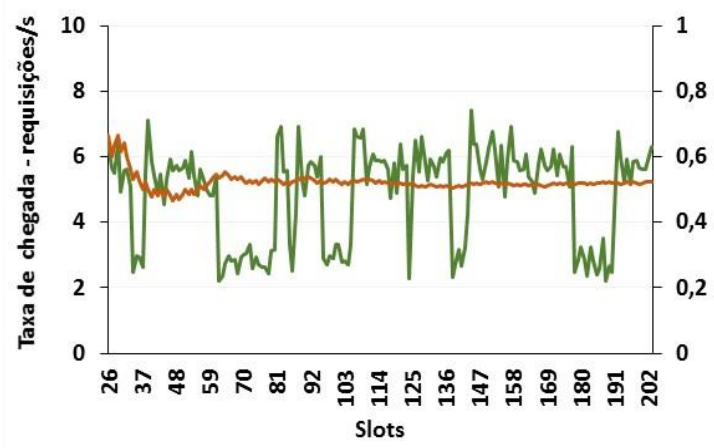

- Taxa de Chegada de Requisições —BF_AR (b) BF2_AR

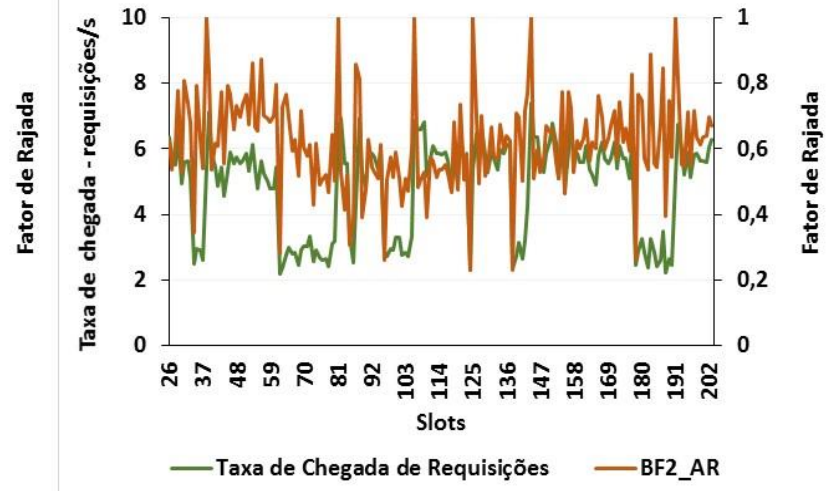

(d) BF4_AR com j=4

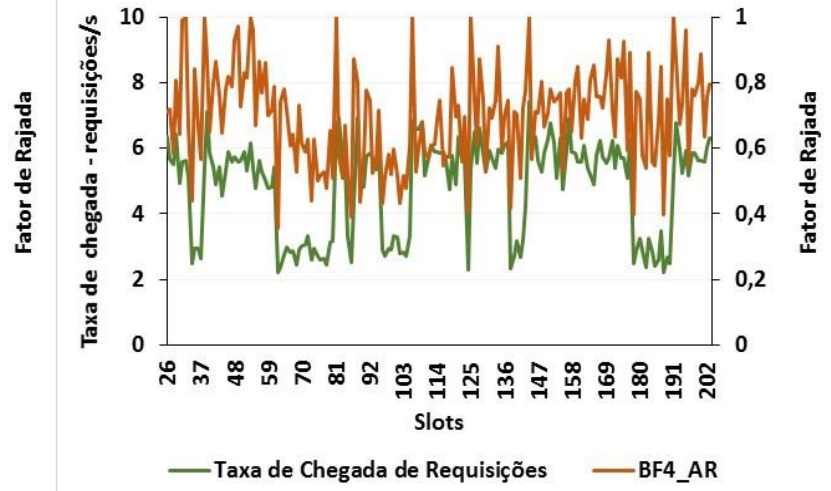

(f) BFcloud_AR

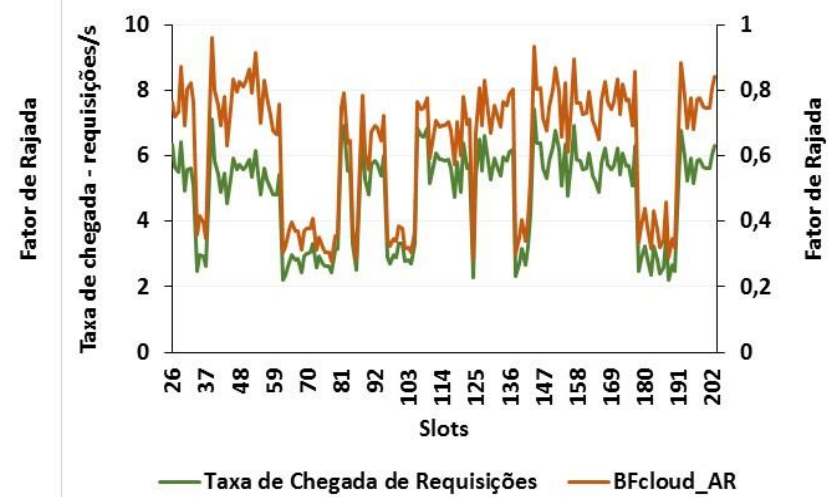

Figura 7.4 - Taxa de chegada de requisições e fatores de rajadas, considerando slots dinâmicos: a) BF1_AR; b) BF2_AR; c) BF3_AR com j=4; d) BF4_AR com j=4; e) BF5_AR; f) BF cloud_AR.

Confirmando os resultados observados nas Figuras 7.3 e 7.4, o fator de rajada $\mathrm{BF}_{1}$ é o que apresenta uma correlação mais baixa em relação aos demais fatores de rajadas. $\mathrm{O}_{\mathrm{BF}}$ também apresenta uma correlação fraca em relação à taxa de chegada. Percebe-se ainda que para esse fator, a correlação é negativa, quando considera-se slots dinâmicos. Isso indica que esse fator apresenta uma tendência de diminuição dos valores do fator de rajada quando observa-se uma tendência de aumento da taxa de chegada. $\mathrm{O} \mathrm{BF}_{2}$ apesar de apresentar uma 
correlação maior em relação aos dois fatores de rajadas anteriores, ainda assim, apresenta uma correlação fraca. Os fatores de rajadas $\mathrm{BF}_{4}, \mathrm{BF}_{3}$ apresentam resultados melhores quando se adota slots dinâmicos, com valores de coeficiente de correlação em torno de 0,5 , o que corresponde a uma correlação moderada.

Tabela 7.2 - Correlação entre o fator de rajada e taxa de chegada de requisições

\begin{tabular}{|l|cc|}
\cline { 2 - 3 } \multicolumn{1}{c|}{} & Slots estáticos & Slots dinâmicos \\
\cline { 2 - 3 } \multicolumn{1}{c|}{ BF $_{1 \_A R}$} & 0,0078 & 0,1189 \\
\hline BF $_{2 \_A R}$ & 0,2425 & 0,3686 \\
\hline BF $_{\text {3_AR }}(\mathbf{j}=\mathbf{4})$ & 0,3960 & 0,5340 \\
\hline $\mathbf{B F}_{4 \_A R}(\mathbf{j}=\mathbf{4})$ & 0,3813 & 0,5467 \\
\hline $\mathbf{B F}_{\text {5_AR }}$ & 0,1798 & $-0,2083$ \\
\hline BF $_{\text {cloud_AR }}$ & 0,9057 & 0,9697 \\
\hline
\end{tabular}

O modelo de fator de rajada proposto neste projeto, o BFcloud_AR, é apresentado na última linha da Tabela 7.2. Como pode ser observado, os valores obtidos para esse fator de rajada e as taxas de chegadas no decorrer da simulação apresentam uma correlação muito forte, especialmente quando considera-se slots dinâmicos. Este resultado reflete o comportamento desse modelo observado nos gráficos das Figuras 7.3 e 7.4 e mostram que o modelo proposto consegue representar com maior exatidão as variações que surgem nas taxas de chegadas de requisições. A relação entre a taxa de chegada e o fator de rajada BFcloud_AR também é mostrada nos diagramas de dispersão da Figura 7.5.
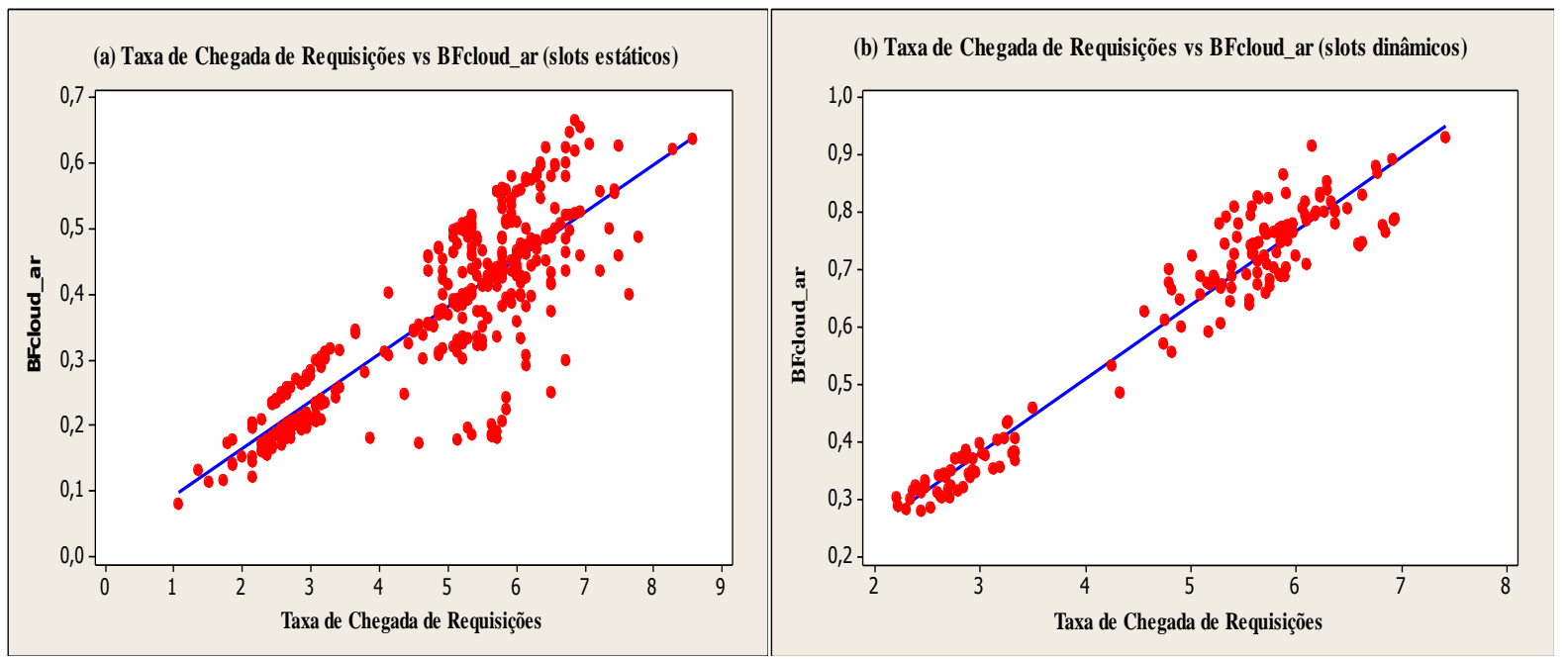

Figura 7.5 - Relacionamento entre as variáveis: taxa de chegada de requisições e BFcloud_AR, considerando: (a) slots estáticos e (b) slots dinâmicos 
O gráfico de dispersão permite visualizar o relacionamento entre duas variáveis $(\mathrm{X}, \mathrm{Y})$, sendo que a correlação linear existe quando os pontos do diagrama de dispersão se aproximam da reta. Além disso, quanto maior a correlação, mais próxima de uma reta a $45^{\circ}$ (graus), para uma correlação positiva ou a $135^{\circ}$ (graus), para correlação negativa, será a distribuição. Pelos diagramas, observa-se que existe uma forte correlação linear entre o modelo proposto e a taxa de chegada, sendo ainda mais correlacionados quando os slots são definidos de forma dinâmica.

\subsubsection{Fator de Rajadas - BFcloud_DR}

Os resultados obtidos na análise comparativa dos modelos de fator de rajada para determinar rajadas na taxa de chegada de demandas de serviços (MIPs), são apresentados nos gráficos 7.6 e 7.7. Na Figura 7.6 é ilustrado como cada modelo se comporta em relação à taxa de chegada de demanda de serviços, considerando slots estáticos, com duração fixa, enquanto que na Figura 7.7, é apresentado os resultados quando considerou-se slots dinâmicos, com duração variável. O eixo principal vertical dos gráficos corresponde à taxa de chegada das demandas, sendo representadas nos gráficos pela linha azul e o eixo secundário vertical dos gráficos corresponde ao fator de rajada e são representados nos gráficos pela linha laranja.

Observa-se que os modelos de fator de rajadas em relação à taxa de chegada de demandas de serviços se comporta de maneira semelhante ao observado para a taxa de chegada de requisições, apresentado na Seção 7.4.1. Da mesma forma o $\mathrm{BF}_{1}$, Figuras 7.6(a) para slots estáticos e 7.7(a) para slots dinâmicos, não consegue seguir as variações da carga de trabalho e nem detectar a presença de picos de chegadas durante o período monitorado. $\mathrm{O}$ fator de rajada $\mathrm{BF}_{5}$, Figuras 7.6(e) e 7.7(e), assim como o $\mathrm{BF}_{1}$, mostra-se também incapaz de acompanhar a taxa de chegada de demandas de serviços e a variabilidade da taxa nos diferentes slots.

Os modelos $\mathrm{BF}_{2}, \mathrm{BF}_{3}$ e $\mathrm{BF}_{4}$, considerando para esses dois últimos o valor de $j$ igual a 4, (Figuras 7.6 e 7.7 (b-d)) apresentam melhores resultados quando considera-se slots dinâmicos e da mesma forma que observado na Seção 7.4.1, tentam seguir as mudanças da taxa de chegada de demandas de serviços no decorrer do tempo simulado, porém também não tem a habilidade de representar com precisão a presença de picos irregulares nas taxas de chegadas de demandas.

O modelo proposto neste projeto, o BFcloud_DR, é apresentado na Figura 7.6(f), considerando a opção de slots estáticos e 7.7(f), considerando a opção de slots dinâmicos. Para este estudo referente à taxa de demandas de serviços, é possível observar que esse modelo, do mesmo modo que para o estudo que envolveu a taxa de chegada de requisições, consegue seguir as rápidas variações da taxa de chegada de demandas e também é capaz de representar com 
maior exatidão os picos das taxas de demandas de serviços que surgem ao longo do período, assim como as flutuações que ocorrem dentro dele.

(a) BF1_DR

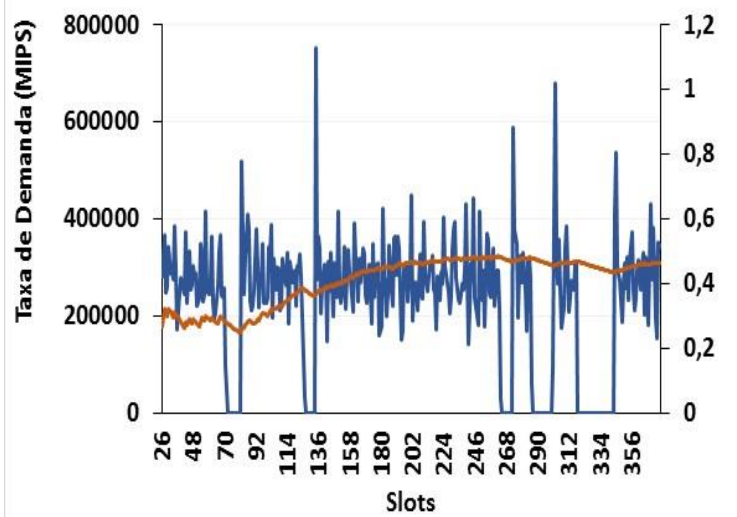

— Taxa de Chegada de Demanda de Serviço —BF1_DR

(c) BF3_DR COm j=4

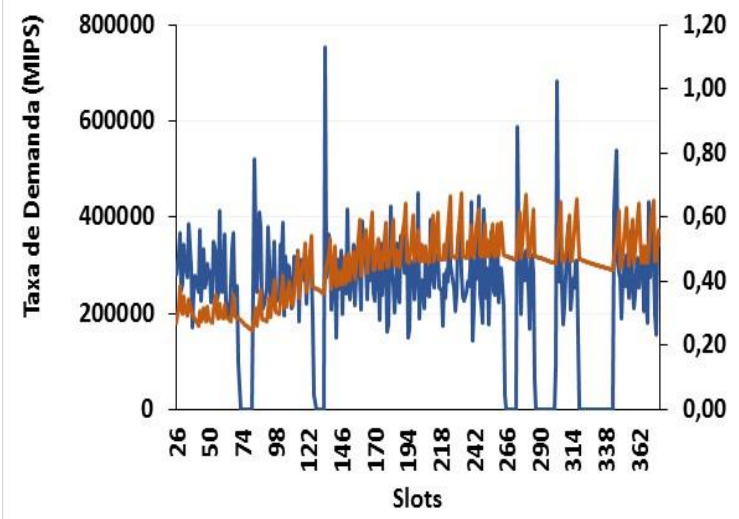

— Taxa de Chegada de Demanda de Serviço —BF3_DR

(e) BF5_DR

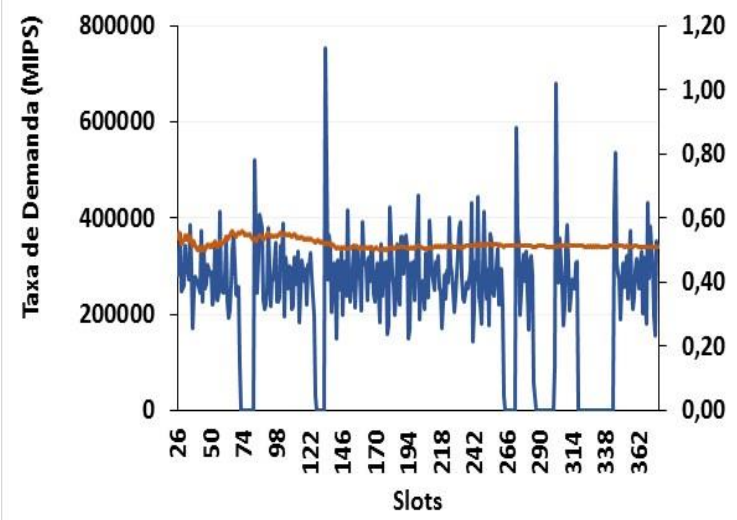

— Taxa de Chegada de Demanda de Serviço —BF5_DR (b) BF2

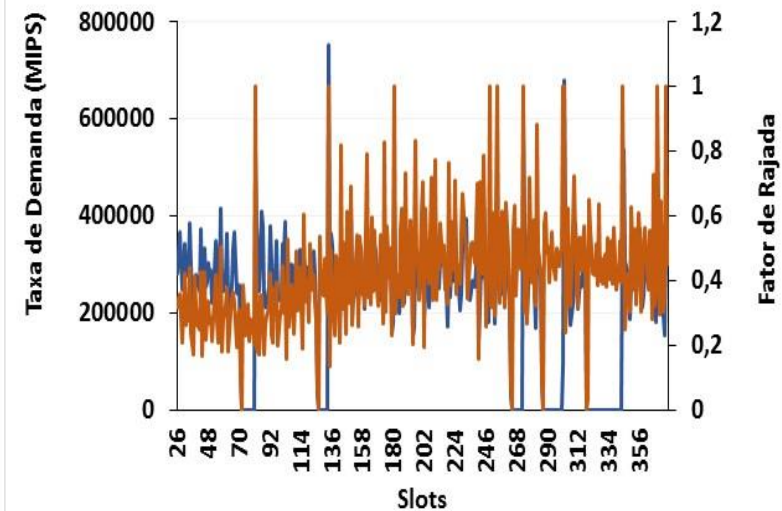

— Taxa de Chegada de Demanda de Serviço — BF2_DR

(d) BF4_DR com je4

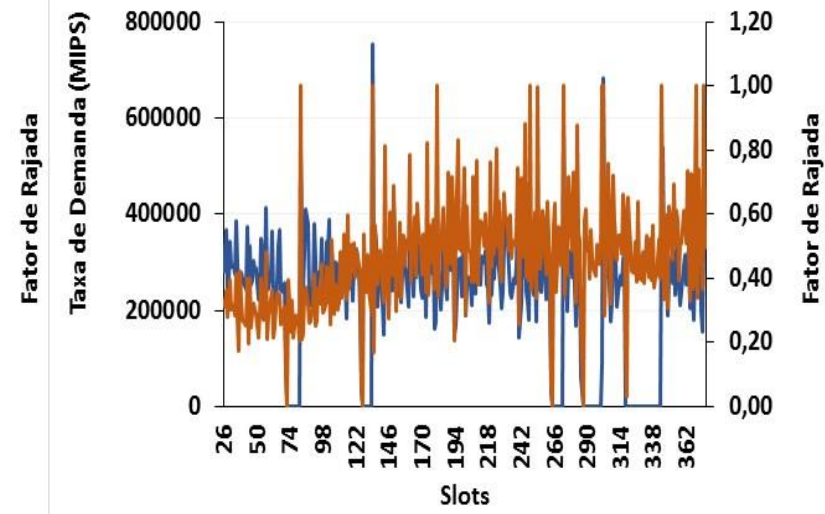

—Taxa de Chegada de Demanda de Serviço —BF4_DR

(f) BFcloud_DR

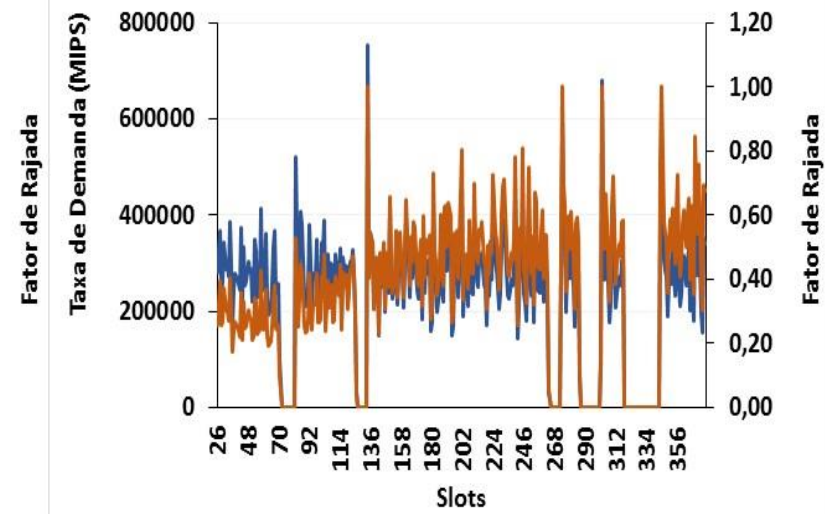

—Taxa de Chegada de Demanda de Serviço —BFcloud_DR

Figura 7.6 - Taxa de chegada de demanda de Serviço e fatores de rajadas, considerando slots estáticos: a) BF1_DR; b) BF2_DR; c) BF3_DR com j=4; d) BF4_DR com j=4; e) BF5_DR; f) $\mathrm{BF}_{\text {cloud_DR. }}$ 
(a)

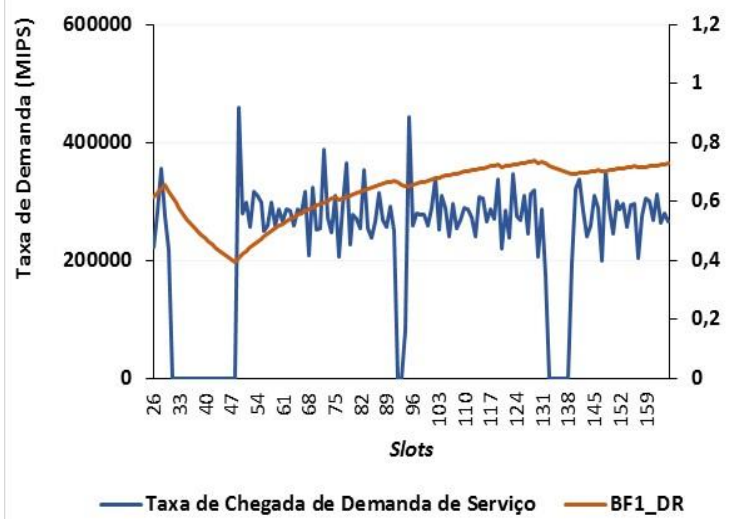

(c)

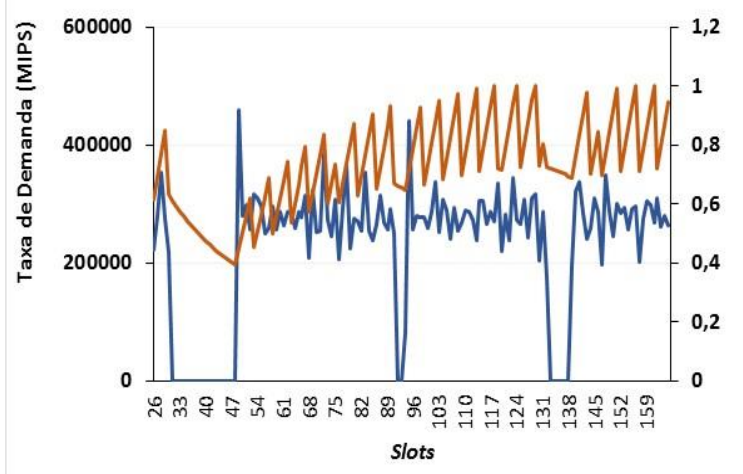

— Taxa de Chegada de Demanda de Serviço —BF_DR

(d)

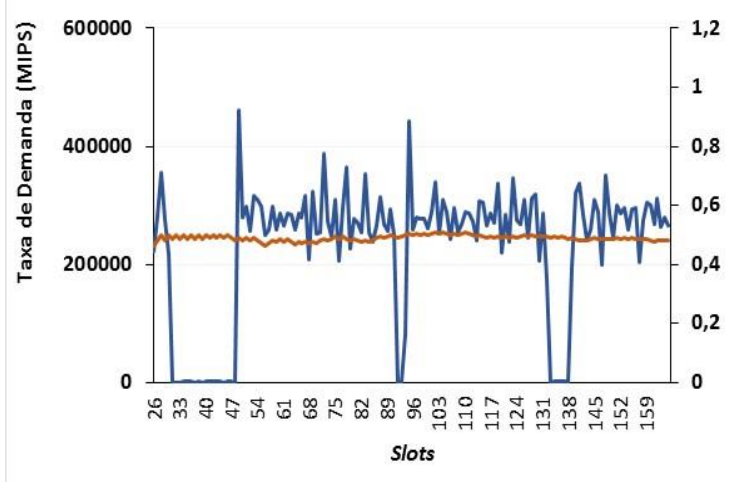

—Taxa de Chegada de Demanda de Serviço _ _ BF5_DR (b)

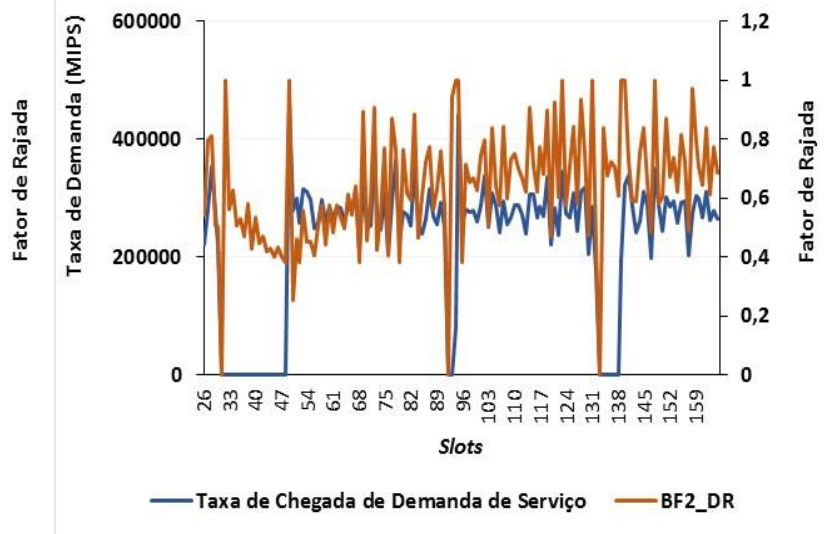

(d)

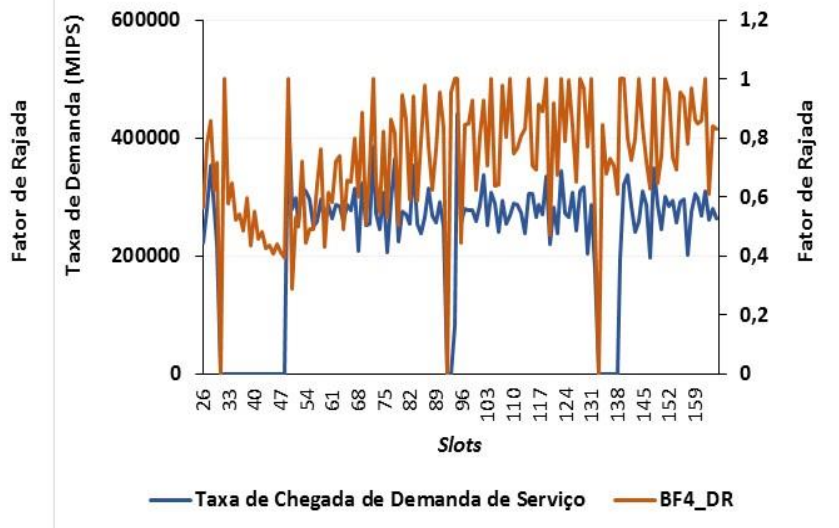

(f)

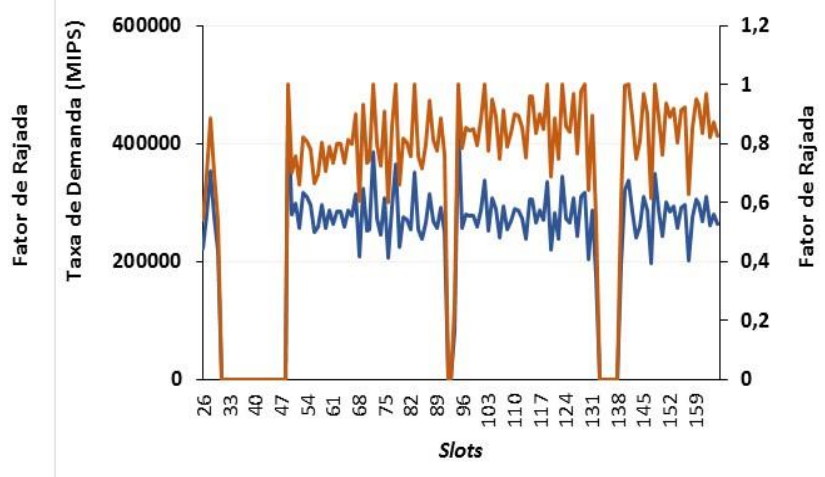

—Taxa de Chegada de Demanda de Serviço _ BFcloud_DR

Figura 7.7 - Taxa de chegada de demanda de Serviço e fatores de rajadas, considerando slots dinâmicos: a) BF1_DR; b) BF2_DR; c) BF3_DR com j=4; d) BF4_DR com j=4; e) BF5_DR; f) BF

A Tabela 7.3 apresenta a correlação obtida entre os fatores de rajadas considerados neste estudo e a taxa de chegada de demandas de serviços monitoradas no tempo de simulação. Observa-se que todos os fatores de rajadas apresentam resultados ligeiramente melhores quando são considerados slots dinâmicos. Entretanto, mesmo para esse cenário com slots dinâmicos, os 
modelos propostos em literatura ainda apresentam uma correlação fraca em relação à taxa de chegada de demandas de serviços. No entanto, os resultados apresentados na Tabela 7.3 mostram uma forte correlação linear existente entre o modelo BFcloud_DR e a taxa de chegada de demandas de serviços, chegando a um coeficiente de correlação de 0,96.

Tabela 7.3 - Correlação entre o fator de rajada e taxa de demanda de serviço

\begin{tabular}{|l|cc|}
\cline { 2 - 3 } \multicolumn{1}{c|}{} & Slots estáticos & Slots dinâmicos \\
\cline { 2 - 3 } \multicolumn{1}{c|}{$\mathbf{B F}_{1 \_D R}$} & $-0,0617$ & 0,2356 \\
\hline $\mathbf{B F}_{\text {2_DR }}$ & 0,3728 & 0,4013 \\
\hline $\mathbf{B F}_{\text {3_DR }}(\mathbf{j}=\mathbf{4})$ & 0,2213 & 0,4357 \\
\hline $\mathbf{B F}_{4 \_D R}(\mathbf{j}=\mathbf{4})$ & 0,4306 & 0,4859 \\
\hline $\mathbf{B F}_{5 \_D R}$ & 0,0265 & $-0,1502$ \\
\hline $\mathbf{B F}_{\text {cloud_DR }}$ & 0,9182 & 0,9567 \\
\hline
\end{tabular}

A Figura 7.8 ilustra os diagramas de dispersão para as duas variáveis consideradas: a taxa de chegada de demandas de serviços e o fator de rajada BFcloud_DR. Observa-se que tanto na Figura 7.8(a) como 7.8(b), os pontos do diagrama estão bem próximos da reta e ainda que, a reta apresenta uma inclinação em torno de 45 graus, o que indica uma forte correlação linear.

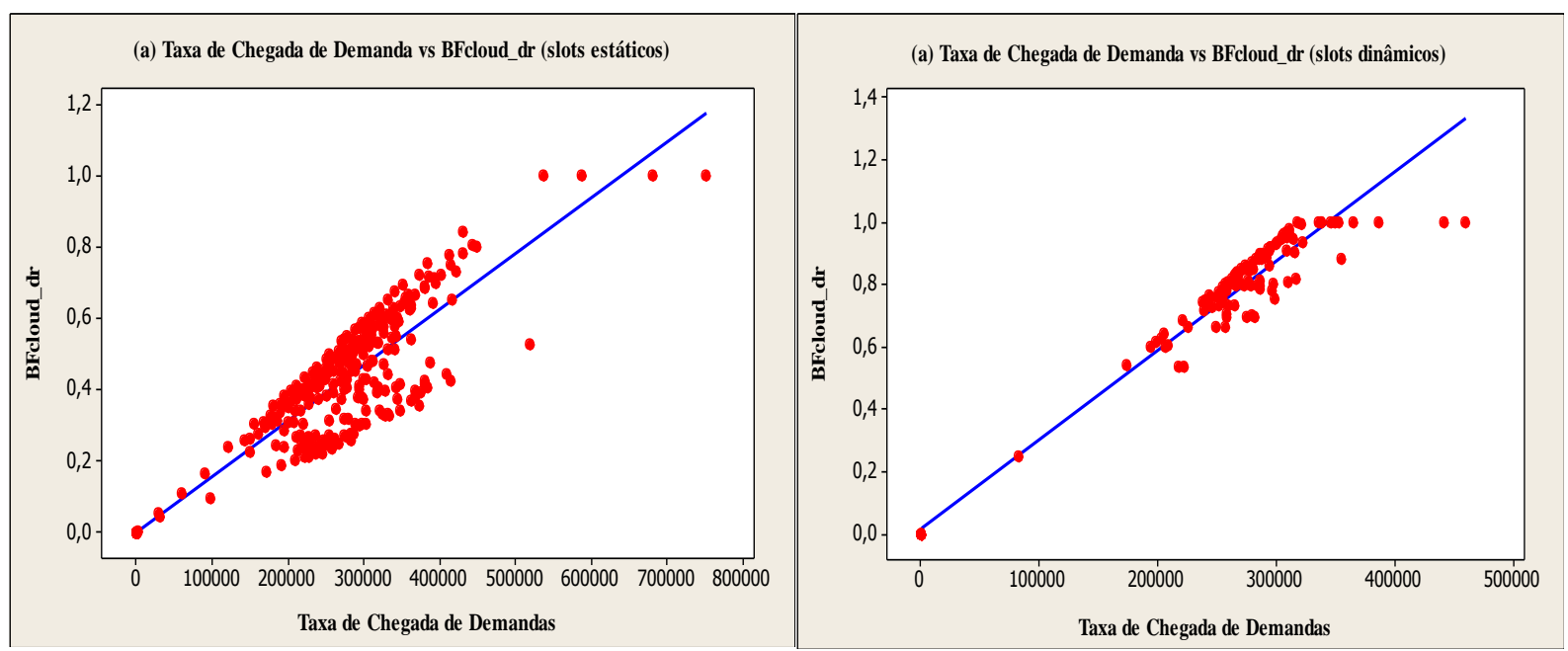

Figura 7.8 - Relacionamento entre as variáveis: taxa de chegada demandas de Serviços e BFcloud_DR, considerando: (a) slots estáticos e (b) slots dinâmicos.

\subsection{Considerações Finais}


Este Capítulo apresentou uma metodologia proposta para determinar a ocorrência de rajadas nas taxas de chegadas de requisições e nas taxas de chegadas de demandas de serviços, através da construção de um modelo matemático para a medida fator de rajadas. Nessa metodologia também foi proposto um modelo para definir estaticamente ou dinamicamente a duração dos slots de monitoramento, durante a simulação.

Além disso, foi apresentada uma análise comparativa do modelo proposto com outros cinco modelos para o fator de rajadas disponíveis em literatura, a fim de analisar não apenas o comportamento de cada um deles, mas também como eles se relacionam com as taxas de chegadas (requisições e demandas) nos períodos de tempos observados ao longo da simulação. Os resultados obtidos nesse estudo mostram que o modelo proposto neste projeto consegue acompanhar com maior exatidão as variações da taxa de chegada, tanto de requisições como de demandas de serviços, do que foi observado para os outros modelos propostos em literatura. Esses resultados foram confirmados também no estudo de correlações entre os modelos e taxas de chegadas, através da análise do coeficiente de correlação de Pearson, onde mostrou uma forte correlação linear entre o modelo proposto neste projeto (BFcloud_AR e BFcloud_DR) e a taxa de chegada de requisições e de demandas de serviços, indicando assim que o modelo proposto é eficiente para determinar a ocorrência de rajadas de diferentes origens e com níveis de variabilidade distintas. 


\section{Conclusão}

O trabalho desenvolvido nesta tese aborda a lacuna que diz respeito ao estudo e caracterização de rajadas nas cargas de trabalho voltadas para computação em nuvem e à avaliação do impacto das rajadas no desempenho dos serviços executados em ambientes de nuvens.

Três objetivos específicos coordenam a definição de uma metodologia para a confirmação da hipótese de que as rajadas influenciam no desempenho dos serviços executados em ambientes de nuvens e de que é necessária a definição de uma metodologia para detectar rajadas em uma carga de trabalho e para prever as rajadas. Todas as avaliações de desempenho executadas neste estudo, assim como a proposição de uma arquitetura que permita caracterizar o desempenho dos serviços considerando diferentes modelos de cargas de trabalho, possibilitaram que os objetivos fossem alcançados.

O primeiro objetivo, apresentado na introdução desta tese, refere-se à definição de um modelo de carga de trabalho que represente adequadamente as características e propriedades do fenômeno de rajadas. Por meio dos experimentos realizados na Seção 6.6, pode-se concluir que as diferentes cargas de trabalho com rajadas modeladas pelo processo Markovian Arrival Process e parametrizados com diferentes níveis de variabilidade e intensidades, têm a habilidade de representar adequadamente as propriedades específicas desse tipo de carga, como localidade temporal, variabilidade em diferentes escalas e agregação.

O segundo objetivo refere-se à caracterização do desempenho dos serviços quando são consideradas rajadas, de diferentes origens, intensidades e variabilidades, nas cargas de trabalho. Para atingir esse objeto foi proposta e implementada uma arquitetura, CloudSimBEQoS, integrada aos diferentes modelos de carga de trabalho com e sem rajadas desenvolvidos, que permitisse avaliar o impacto das rajadas no desempenho dos serviços quando executados em uma nuvem privada e uma nuvem híbrida. Os resultados obtidos e 
apresentados na Seção 6.6, mostram, considerando os fatores, níveis e experimentos adotados neste estudo, que a presença de rajadas no processo de chegada das requisições e/ou nas demandas de serviços, mesmo quando elas chegam de forma mais suave e com variabilidade moderada ocasiona uma considerável degradação de desempenho do serviço executado em uma nuvem privada. Como um exemplo, pode-se citar que para uma carga com rajadas leves apenas no processo de chegada das requisições, obtém-se um aumento de $44 \%$ no tempo de resposta, quando comparado com a carga sem rajada. Para cargas pesadas essa porcentagem chega a 78\%. As medidas de desempenho consideradas no estudo, como tempo médio de resposta, tempo médio do sistema e vazão, são ainda mais afetadas negativamente quando as rajadas de diferentes origens (nos intervalos de chegadas e demandas de serviços) e com intensidades mais rigorosas, chegam de maneira sincronizada ao longo do tempo, levando a um aumento de até $118 \%$ no tempo de resposta observado nos experimentos realizados. Os resultados também revelaram que o impacto no desempenho dos serviços, causado pelas rajadas, quando se considera o modelo de nuvem híbrido não é tão intenso quanto observado para situações em que modelo de nuvem privada é adotado, porém o impacto também é significativo. A vazão, mesmo considerando uma nuvem híbrida com maior capacidade de processamento, é afetada negativamente quando as demandas de serviços se apresentam em rajadas. Além disso, constatou-se que quando são criadas condições de rajadas, a quantidade de VMs públicas necessárias para atender todas as requisições submetidas à nuvem, torna-se significativamente maior, impondo ao provedor de nuvem um custo mais elevado para garantir que o desempenho não seja tão afetado pelas rajadas.

Finalmente, o terceiro objetivo refere-se à proposta de uma metodologia que permita monitorar e determinar a ocorrência de rajadas no processo de chegada de requisições e na demanda de serviços. A análise comparativa do modelo proposto, apresentado na Seção 7.4, mostrou que o modelo desenvolvido (BFcloud_AR e BFcloud_DR) consegue acompanhar as rápidas variações da taxa de chegada, tanto de requisições como de demandas de serviços, com maior precisão do que foi observado para os outros modelos propostos em literatura. Constatouse ainda uma forte correlação linear entre o modelo proposto e a taxa de chegada de requisições e de demandas de serviços, validando a sua eficiência para determinar a ocorrência de rajadas de diferentes origens e com níveis de variabilidade distintas.

Assim, os resultados obtidos neste estudo mostraram que os objetivos descritos na introdução desta tese foram alcançados e comprovam a hipótese defendida neste trabalho de doutorado. Ou seja, pode-se considerar correta a seguinte afirmação: “As rajadas presentes em cargas de trabalhos influenciam no desempenho dos serviços executados em ambientes em 
nuvens e, portanto, devem ser consideradas nos modelos de cargas de trabalhos e nas atividades voltadas para avaliações de desempenho em computação em nuvem". Foi ainda proposta e validada uma metodologia que permite monitorar uma carga de trabalho e prever a ocorrência de rajadas, comprovando a segunda parte da hipótese defendida que diz que "É possível definirse uma metodologia que permita monitorar uma carga de trabalho e determinar a ocorrência de rajadas".

\subsection{Contribuições}

A realização deste projeto propiciou algumas contribuições diretamente relacionadas com a hipótese do doutorado e algumas outras que foram alcançadas no decorrer da realização do projeto, relacionadas principalmente com a metodologia desenvolvida para alcançar os objetivos definidos.

Desta forma, como contribuições principais diretamente ligadas a hipótese desta tese temse:

- Caracterização da influência das rajadas no desempenho dos serviços executados em nuvens privada e híbrida.

O estudo apresentado nesta tese contribui com diversas áreas de pesquisas ligadas ao desenvolvimento de novas soluções voltadas para computação em nuvem que precisam estar atentos à imprevisibilidade e variabilidade da carga de trabalho, à construção de benchmarks e modelos de desempenho. Além disso, a disponibilização de uma caracterização de desempenho dos serviços em nuvem quando são consideradas cargas de trabalho com rajadas poderá contribuir em vários outros projetos de pesquisas voltados à avaliação de desempenho em computação em nuvem.

\section{- Presença de rajadas na chegada das requisições e na demanda de serviços.}

Os modelos de cargas de trabalho propostos nesta tese, consideram rajadas originadas tanto na chegada de requisições como nas demandas de serviços. Esses modelos podem ser instanciados em benchmarks para avaliar ou comparar desempenho de diversos aspectos envolvidos em computação em nuvem, como técnicas voltadas para alocação das requisições das VMs, consolidação de carga para otimização dos recursos, técnicas voltadas para controle de admissão e ainda em modelos de predição de desempenho. 
- Proposta e avaliação de um fator de rajada que determine a ocorrência de rajadas tanto na taxa de chegada, como na taxa de demanda de serviço.

O modelo de fator de rajadas proposto pode ser incorporado em modelos preditivos de desempenho, em cenários onde a carga de trabalho se apresenta em rajadas, e desta forma, contribui para as áreas de pesquisas relacionadas aos modelos de predição de desempenho e avaliação de desempenho de sistemas computacionais.

Cabe ainda destacar as seguintes contribuições alcançadas durante a realização desta tese:

- Desenvolvimento de uma arquitetura que permite a avaliação de desempenho quando cargas de trabalho são submetidas às nuvens.

A CloudSim-BEQoS por ser projetada utilizando a API do CloudSim e agregar funcionalidades importantes como cargas de trabalhos que consideram diferentes perfis de rajadas e políticas de escalonamento orientadas à QoS e eficiência energética, contribui não apenas com os projetos realizados no LaSDPC, mas também e principalmente com as áreas de pesquisas voltadas para simulação e avaliação de desempenho de sistemas computacionais em nuvem.

- Construção de diferentes modelos de carga de trabalho que considerem rajadas.

A construção de diferentes modelos de cargas de trabalho que representem o fenômeno de rajadas é uma contribuição importante para várias áreas de pesquisa como planejamento de capacidade de sistemas e avaliações de desempenho, uma vez que essas atividades precisam levar em conta fatores que afetam o desempenho do serviço e do sistema.

- Definição de uma metodologia para parametrização dos modelos MAPs com diferentes intensidades e variabilidades.

A definição dos parâmetros do MAP é um importante passo para construção de um modelo de carga de trabalho que represente adequadamente o fenômeno de rajadas. Metodologias voltadas para definição dos parâmetros do modelo MAP têm sido propostas na literatura recentemente e é um tema que continua sendo um desafio para a comunidade científica pela complexidade envolvida na parametrização de processos estocásticos. Desta forma, a metodologia proposta para parametrização dos modelos MAPs com diferentes níveis de variabilidade e intensidade contribui com várias pesquisas voltadas para modelagem de cargas de trabalho que utilizam diferentes classes de processos estocásticos.

- Estudo do impacto das rajadas no desempenho de serviços Web.

Durante o desenvolvimento deste projeto de doutorado, foi realizada uma avaliação de desempenho voltada para Serviços Web, considerando diferentes características das cargas 
de trabalho. Dentre essas características destacou-se o fenômeno de rajadas. Esse estudo deu origem a um artigo apresentado e publicado nos anais do XXX Simpósio Brasileiro de Redes de Computadores e Sistemas Distribuídos - SBRC, 2012:

Centurion, A.M.; Santana, R. H. C.; Santana, M. J.; Bruschi, S. M.

Impacto da Carga de Trabalho com Rajadas no Desempenho de Serviços Web. In: XXX Simpósio Brasileiro de Redes de Computadores e Sistemas Distribuídos, 2012, Ouro Preto/MG. Anais do SBRC2012, p. 422-435, 2012.

\subsection{Trabalhos Futuros}

O presente trabalho de doutorado não finaliza as possibilidades de estudo relacionadas às avaliações de desempenho dos serviços em situações em que a carga de trabalho se apresenta em rajadas. Outros estudos devem ser conduzidos a partir dos resultados e constatações encontradas durante o desenvolvimento desta tese. Dentre os possíveis trabalhos futuros, destacam-se os seguintes estudos:

- Avaliação de Desempenho considerando Eficiência Energética e QoS: avaliar o comportamento do sistema na presença de rajadas, considerando políticas de escalonamento com garantia de QoS e eficiência energética, a fim de evitar picos de demandas de energia. Embora a CloudSim-BEQoS tenha implementado essas políticas de escalonamento, um estudo de caso utilizando esses requisitos não foi realizado. Esse estudo permitirá analisar qual o impacto das rajadas em relação à quantidade de requisições que foram atendidas de acordo com os critérios de QoS negociados com os clientes e qual o impacto no desempenho do serviço quando medidas de consumo eficiente de energia são considerados.

- Avaliação do impacto das rajadas considerando um planejamento de experimentos com diferentes fatores e níveis: realizar novos experimentos considerando diferentes fatores como: diferentes quantidades de clientes, modos de submissão em grupo, adoção de modelos de nuvens composta de vários data centers interconectados, entre outros. Esse estudo poderá quantificar a influência das rajadas no desempenho dos serviços, em 
condições diferentes das que foram analisadas e considerar ainda um estudo para determinar a influência dos fatores e verificar as interações entre eles.

- Consideração de modelos de cargas de trabalho com rajadas com diferentes parametrizações: realizar um estudo da influência das rajadas no desempenho dos serviços, onde os processos de chegadas e demandas de serviços modeladas por MAPs sejam parametrizados por uma metodologia baseada em traces. No entanto, para que seja possível essa parametrização deve-se obter um log real de um data center em nuvem que contenha grande quantidade de registros (como intervalos de chegadas ou tempos de serviços), de modo que seja possível capturar com exatidão medidas utilizadas por essas metodologias, como momentos e coeficiente de autocorrelação, na estrutura desse log real.

- Incluir políticas de alocação de recursos considerando os modelos de fator de rajadas: A CloudSim-BEQoS implementa a técnica híbrida para provisionamento de aplicações, onde as requisições são direcionadas à nuvem pública contratada, quando os recursos da nuvem privada são insuficientes para atender tal demanda. Ou seja, caso o percentual de consumo dos recursos do data center privado atinja um limite especificado, o Broker passa a encaminhar as requisições para a nuvem pública. Porém, quando as cargas se apresentam em rajadas, este limite, em várias ocasiões, é ultrapassado. Esse mecanismo pode ser otimizado para considerar também, além do consumo dos recursos, os fatores de rajadas da taxa de chegada e demanda de serviço propostos neste trabalho. Assim, dependendo do fator de rajada obtido para um intervalo de chegada monitorado, a política de escalonamento pode adotar a melhor estratégia de alocação das cargas de trabalhos nos recursos da nuvem.

- Adição de novos módulos à arquitetura CloudSim-BEQoS: a implementação da arquitetura CloudSim-BEQoS, apresentada no Capítulo 5, pode ser estendida para atender outras funcionalidades como modelos de custos que considerem rajadas na utilização e cobrança dos serviços. Além disso, outros módulos podem ser criados para o monitoramento de outros parâmetros de qualidade de serviço como confiabilidade e segurança. Esses requisitos são importantes no contexto de computação em nuvem. Assim, avaliações de desempenho que considerem a adição de mecanismos de segurança ou 
confiabilidade podem ser conduzidas com o objetivo de analisar o impacto desses tipos de requisitos, aliado à presença de rajadas nas cargas de trabalho, no desempenho dos serviços. 


\section{Referências}

Alam, M.; Shakil, K. A.; Sethi, S. Analysis and Clustering of Workload in Google Cluster Trace based on Resource Usage. arXiv preprint arXiv:1501.01426, 2015.

Al-Ghamdi, M.; Chester, A. P.; He, L.; Jarvis, S. A.; Xue, J. W. J. Dynamic active window management: a method for improving revenue generation in dynamic enterprise systems. In Computer and Information Technology (CIT), 2011 IEEE 11 th International Conference on, p. 23-28, 2011.

Ali-Eldin, A.; Seleznjev, O.; Sjostedt-de Luna, S.; Tordsson, J.; Elmroth, E. Measuring Cloud Workload Burstiness. In Utility and Cloud Computing (UCC), 2014 IEEE/ACM 7th International Conference on p. 566-572, 2014.

Arlitt, M. F.; Williamson, C. L. Web server Workload characterization: the search for invariants. SIGMETRICS Perform. Eval. Rev., 24(1), p. 126-137, 1996.

Armbrust, M.; Fox, A.; Griffith, R.; Joseph, A. D.; Katz, R. H.; Konwinski, A.; Lee, G.; Patterson, D. A.; Rabkin, A.; Stoica, I.; Zaharia, M. Above the clouds: A Berkeley view of cloud computing. Relatório Técnico UCB/EECS-2009-28, EECS Department, University of California, Berkeley, 2009.

Barford, P.; Crovella, M. Generating Representative Web Workloads for Network and Server Performance Evaluation. In Proceedings of the 1998 ACM SIGMETRICS International Conference on Measurement and Modeling of Computer Systems, p. 151-160, 1998.

Baryshnikov, Y.; Coffman, E.; Rubenstein, D.; Yimwadsana, T. Traffic prediction on the internet. Technical report ee200514-1, Computer Networking Research Center Columbia University, 2002.

Batista, B. G; Estrella, J. C.; Santana, M. J.; Santana, R. H.; Reiff-Marganiec, S. Performance Evaluation in a Cloud with the Provisioning of Different Resources Configurations. In Services (SERVICES), 2014 IEEE World Congress on, p. 309-316, 2014.

Bause, F.; Buchholz, P.; Kriege, J. A comparison of Markovian Arrival and ARMA/ARTA processes for the modeling of correlated input processes. In Winter Simulation Conference, p. 634-645, Winter Simulation Conference, 2009. 
Bertolino, A.; De Angelis, G.; Frantzen, Al.; Polini, A. Model-Based Generation of Testbeds for Web Services. In: Testing of Communicating Systems and Formal Approaches to Software Testing - TESTCOM/FATES 2008. Lecture Notes in Computer Science, Springer, p. 266-282, 2008 .

Bhatt, M. T. P; Patel, A. P. P. J. Survey On Virtualization With Xen Hypervisor. In International Journal of Engineering Research and Technology Vol. 1, No. 8, 2012.

Bolch, G.; Greiner, S.; de Meer, H.; Trivedi, K. S. Queueing networks and Markov chains: modeling and performance evaluation with computer science applications. John Wiley \& Sons, 2006.

Bozkurt, M.; Harman, M.; Hassoun, Y. Testing Web Services: A Survey. Technical Report TR-10-01, Department of Computer Science, King's College London, 2010.

Breuer, L. An EM algorithm for batch Markovian arrival processes and its comparison to a simpler estimation procedure. Annals of Operations Research 112, p. 123-138, 2002.

Buchholz, P.; Kemper, P.; Kriege, J. Multi-class Markovian arrival processes and their parameter fitting. Performance Evaluation, 67(11), p. 1092-1106, 2010.

Buyya, R.; Yeo, C. S.; Venugopal, S.; Broberg, J.; and Brandic, I. Cloud computing and emerging it platforms: Vision, hype, and reality for delivering computing as the 5th utility. Future Gener. Comput. Syst.em, 25(6), p. 599-616, 2009.

Cao, B.Q.; Li, B.; Xia, Q.M. A service-oriented qos-assured and multi-agent cloud computing architecture. In: Proceedings of the 1st International Conference on Cloud Computing, CloudCom '09, Berlin, Heidelberg: Springer-Verlag, p. 644-649. 2009.

Calheiros, R.N.; Ramjan, R; Beloglazov, A., Rose, C.A.F.; Buyya, R. CloudSim: a toolkit for modeling and simulation of cloud Computing environments and evaluation of resource provisioning algorithms. Wiley Online Library (wileyonlinelibrary.com), 2011.

Calheiros, R. N.; Ranjan, R.; De Rose, C. A.; Buyya, R. Cloudsim: A novel framework for modeling and simulation of cloud computing infrastructures and services. arXiv preprint arXiv:0903.2525, 2009.

Calzarossa M.; Massari L.; Tessera D. Workload Characterization - Issues and Methodologies. Lecture Notes in Computer Science: Performance Evaluation, v. 1769, p. 459$482,2000$. 
Casale, G.; Zhang, E.Z.; Smirni, E. KPC-Toolbox: Simple Yet Effective Trace Fitting Using Markovian Arrival Processes. IEEE Computer Society, Los Alamitos, p. 83-92, 2008.

Casale, G.; Smirni, E. MAP-AMVA: Approximate mean value analysis of bursty systems. In Dependable Systems \& Networks, 2009. DSN'09. IEEE/IFIP International Conference on, p. 409-418, 2009.

Casale, G.; Kalbasi, A.; Krishnamurthy, D.; Rolia, J. Automatic stress testing of multi-tier systemsby dynamic bottleneck switch generation. In To appear in Proc. of USENIX Middleware, 2009.

Casale, G.; Kalbasi, A.; Krishnamurthy, D.; Rolia, J. BURN: Enabling Workload Burstiness in Customized Service Benchmarks. Software Engineering, IEEE Transactions, 2012.

Casale G.; Mi N.; Cherkasova L.; Smirni E. Dealing with Burstiness in Multi-Tier Applications: Models and Their Parameterization, IEEE Transactions on Software Engineering, v. 38, 2013.

Centurion, A. M.; Santana, M.J.; Santana, R. C. S.; Bruschi, S. M. Impacto da Carga de Trabalho com Rajadas no Desempenho de Serviços Web. In: XXX SBRC 2012, Ouro Preto/MG, 2012.

Deka, G. C.; Prashanta K. D. An Overview on the Virtualization Technology. Handbook of Research on Cloud Infrastructures for Big Data Analytics, 2014.

Di, S.; Kondo, D.; Cappello, F. Characterizing cloud applications on a Google data center. In Parallel Processing (ICPP), 2013 42nd International Conference on, p. 468-473, 2013.

Dick, S.; Yazdanbaksh, O.; Tang, X., Huynh, T.; Miller, J. An empirical investigation of Web session workloads: Can self-similarity be explained by deterministic chaos? Information Processing \& Management, 50(1), p. 41-53, 2014.

Falko, B.; Buchholz, P.; Kriege, J. A comparison of Markovian Arrival and ARMA/ARTA processes for the modeling of correlated input processes. Winter Simulation Conference, 2009.

Feitelson, D. G. Workload Modeling for Computer Systems Performance Evaluation. School of Computer Science and Engineering, versão 1.0.1, editado em 2014. Versão disponível em: http://www.cs.huji.ac.il/ feit/wlmod/wlmod.pdf. Último acesso: 25/02/2015. 
Fischer, W.; Kathleen, M. The Markov-modulated Poisson process (MMPP) cookbook. Performance Evaluation, v. 18, n. 2, p. 149-171, 1993.

Galindo, H. E. S. Geração de Carga Sintética para o Planejamento de Capacidade em Ambientes Virtuais. Dissertação de Mestrado, UFPE, 2010.

Ghorbani, M.; Wang; Y., Xue, Y.; Pedram, M.; \& Bogdan, P. Prediction and control of bursty cloud workloads: a fractal framework. In Proceedings of the 2014 International Conference on Hardware/Software Codesign and System Synthesis, ACM, 2014.

Gilly, K.; Brosig, F.; Nou, R.; Kounev, S.; Juiz, C. Online prediction: four case studies. In Resilience Assessment and Evaluation of Computing Systems, p. 185-202, Springer Berlin Heidelberg, 2012.

Gilly, K.; Alcaraz, S.; Juiz, C.; Puigjaner, R. Analysis of burstiness monitoring and detection in an adaptive web system. Computer Networks, 53(5), p. 668-679, 2009.

Gmach, D.; Rolia, J.; Cherkasova, L. Selling T-shirts and Time Shares in the Cloud. In Cluster, Cloud and Grid Computing (CCGrid), 12th IEEE/ACM International Symposium, p. 539-546, 2012.

Gonçalves, G.; Drago, I.; da Silva, A. P. C.; de Almeida, J. M.; Vieira, A. B. Caracterização e Modelagem da Carga de Trabalho do Dropbox. $32^{\circ}$ Simpósio Brasileiro de Redes de Computadores e Sistemas Distribuídos, SBRC, 2014.

Gusella, R. Characterizing the variability of Arrival Process with Indexes of Dispersion. IEEE JSAC, p. 203-211, 1991.

Guo, t.; Sharma, U.; Wood, T.; Sahu, S.; Shenoy, P. Seagull: Intelligent Cloud Bursting for Enterprise Applications. Proceedings of USENIX Conference on Annual Technical Conference, 2012.

Habib, S. M.; Ries, S.; Muhlhauser, M. Cloud computing landscape and research challenges regarding trust and reputation. In Ubiquitous Intelligence \& Computing and 7th International Conference on Autonomic \& Trusted Computing (UIC/ATC), pp. 410-415, 2010.

Heffes, H.; Lucantoni, D. A Markov Modulated Characterization of Packetized Voice and Data Traffic and Related Statistical Multiplexer Performance. IEEE Journal on Selected Areas in Communications SAC-4, p., 856-868, 1986. 
Jain, R. The art of computer systems performance analysis: Techniques for experimental design, measurement, simulation, and modeling. Wiley, 1991.

Johnson, B.; Perkins, B.; Chambers, J.; Garber, D., Malik, J.; Fazio, A. Windows Azure Developer's E-Book Bundle. John Wiley \& Sons, 2013.

Johnson, T.; Margalho, J. Avaliação de desempenho de sistemas computacionais. LTC, Rio de Janeiro, RJ, 2011.

Khan, A.; Yan, X.; Tao, S.; Anerousis, N. Workload characterization and prediction in the cloud: A multiple time series approach. In Network Operations and Management Symposium (NOMS), p. 1287-1294, 2012.

Kleinrock, L. Computer-Communication Networks: Measurements, Flow Control, and ARPANET Traps, in Queueing Systems, v. 2: Computer Applications, Wiley and Sons, 1976.

Klemm, A.; Lindemann, C.; Lohmann, M. Modeling IP traffic using the batch markovian arrival process. Perform. Eval. 54(2), p. 149-173, 2003

Kriege, J.; Buchholz, P. An empirical comparison of MAP fitting algorithms. Measurement, Modelling, and Evaluation of Computing Systems and Dependability and Fault Tolerance, Springer Berlin Heidelberg, p. 259-273, 2010.

Krishnamurthy, D. Rolia, J. Xu, M. The Weighted Average Method for Predicting the Performance of Systems with Bursts of Customer Sessions. Software Engineering, IEEE Transactions, 2009.

Li, H; Lee, W.C; Sivasubramaniam, A.; Giles, C. L. Workload analysis for scientific literature digital libraries. International Journal on Digital Libraries, p. 139-149, 2008.

Liu, Z., \& Cho, S. Characterizing machines and workloads on a Google cluster. In Parallel Processing Workshops (ICPPW), 2012 41st International Conference on, p. 397-403, 2012.

Lu, L.; Cherkasova, L.; Personè, V. N.; Mi, N.; Smirni, E. AWAIT: Efficient overload management for busy multi-tier web services under bursty workloads. Proceeding ICWE'10 Proceedings of the 10th international conference on Web engineering, Springer-Verlag Berlin, Heidelberg, 2010.

Lu, X.; Yin, J.; Chen, H.; Zhao, X. An Approach for Bursty and Self-similar Workload Generation. In Web Information Systems Engineering-WISE, pp. 347-360, Springer Berlin Heidelberg, 2013. 
Luo, Z.; Qian, Z. Burstiness-aware Server Consolidation via Queuing Theory Approach in a Computing Cloud. In Parallel \& Distributed Processing (IPDPS), IEEE 27th International Symposium, p. 332-341, 2013.

Malawski, M.; Kuzniar, M., Wojcik, P.; Bubak, M. How to use google app engine for free computing. Internet Computing, IEEE, 17(1), p. 50-59, 2013.

Mell, P.; Grance, T. The NIST Definition of Cloud Computing. US Nat'l Inst. of Science and Technology, 2011.

Menascé, D.; Ribeiro, F., Almeida, V.; Fonseca, R.; Meira, R.R.W. In Search of Invariants for E-Business Workloads. In second ACM conference on Electronic Commerce, Minneapolis, 2000 .

Menascé, D. A.; Almeida, A. F. Capacity Planning for Web Services: Metrics, Models, and Methods. Prentice Hall, 2001.

Menascé, D. A.; Almeida, V. A.; Dowdy, L. W.; Dowdy, L. Performance by design: computer capacity planning by example. Prentice Hall Professional, 2004.

Mi, N.; Casale, G.; Cherkasova, L.; Smirni, E. Burstiness in multi-tier applications: Symptoms, causes, and new models. Proc. Of Middleware, 2008.

Mi, N.; Casale, G.; Cherkasova, L.; Smirni, E. Injecting Realistic Burstiness to a Traditional Client-Server Benchmark. Proceedings of the 6th International Conference on Autonomic Computing, p. 149-158, Barcelona, Espanha, 2009.

Mi, N.; Casale, G.; Cherkasova, L.; Smirni, E. Sizing multi-tier systems with temporal dependence: benchmarks and analytic models. Journal of Internet Services and Application (JISA), p. 117-134, 2010.

Moore, D. S. The basic practice of statistics. Palgrave Macmillan, 2010.

Murta, C. D.; Nascimento, A.M. Caracterização de Carga e Desempenho de um servidor de Software. WPerformance, Anais do XXVII Congresso da SBC, p. 543-558, 2007.

Nakamura, L. H. V. Mecanismos de autoconfiguração e auto-otimização para arquiteturas virtualizadas que visam a provisão de qualidade de serviço. Monografia de qualificação de doutorado, 2013.

Nelson, B. L. Stochastic modelling analysis and simulation. Courier Dover Publications, 2012. 
Obaidat, M. S.; Boudriga, N. A. Fundamentals of Performance Evaluation of Computer and Telecommunications Systems. Wiley-Interscience, 2009.

Overman, E. A MATLAB Tutorial. Department of Mathematics. The Ohio State University, Columbus, 2011.

Pacheco-Sanchez, S.; Casale G.; Scotney B.W.; McClean S.; Parr, G; Dawson, S. Markovian Workload Characterization for QoS Prediction in the Cloud, IEEE CLOUD, IEEE, p. 147-154, 2011.

Pedroso, C.C; Fonseca, K. Um modelo para geração de carga de servidores Web utilizando classificação de conteúdo. CEFET-PR, Brazil, SBRC, 2006.

Quiroz A; Kim H; Parashar M; Gnanasambandam N; Sharma N. Towards autonomic workload provisioning for enterprise grids and clouds. Proceedings of the 10th IEEE/ACM International Conference on Grid Computing, Banf, AB, IEEE Computer Society: Silver Spring, MD, p. 50-57, 2009.

Rasheduzzaman, M.; Islam, M.; Islam, T.; Hossain, T.; Rahman, R. M. Task shape classification and workload characterization of google cluster trace. In Advance Computing Conference (IACC), 2014 IEEE International, p. 893-898, 2014.

Rolia, J.; Krishnamurthy, D.; Casale, G; Dawson, S. BAP: a benchmark-driven algebraic method for the performance engineering of customized services. Proceedings of the first joint WOSP/SIPEW international conference on Performance engineering, San Jose, California, 2010.

Sakellari, G.; Loukas, G. A survey of mathematical models, simulation approaches and testbeds used for research in cloud computing. Simulation Modeling Practice and Theory, 39, p. 92-103, 2013.

SANTOS, C. Estatística descritiva: manual de auto-aprendizagem. Lisboa: Silabo, 2007.

Silva, L. H. C. Caracterização de Cargas de Trabalho para Testes de Modelos de Servidores Web. Dissertação de Mestrado, ICMC - USP, São Carlos, 2006.

Shoch, J. F.; Hupp, J. A. Measured performance of an Ethernet local network. Communications of the ACM, 23(12), p. 711-721, 1980. 
Sobel, W.; Subramanyam, S.; Sucharitakul, A.; Nguyen, J.; Wong, H., Klepchukov, A.; Patil, S.; Fox, A.; Patterson, D. Cloudstone: Multi-platform, multi-language benchmark and measurement tools for web 2.0. In Proc. of CCA, v. 8, 2008.

Suchacka, G. Generating Bursty Web Traffic for a B2C Web Server. In Computer Networks, Springer Berlin Heidelberg, p. 183-190, 2011.

Suleiman, B.; Sakr, S.; Jeffery, R.; Liu, A. On understanding the economics and elasticity challenges of deploying business applications on public cloud infrastructure. Journal of Internet Services and Applications, 3(2), p. 173-193, 2012.

Tai, J.; Zhang, J.; Li, J.; Meleis, W.; Mi, N. ArA: Adaptive resource allocation for cloud computing environments under bursty workloads. In Performance Computing and Communications Conference (IPCCC), IEEE 30th International, p. 1-8, 2011.

Tavares, T. C. Caracterização de Cargas de Trabalho para Avaliação de Desempenho em Web Services. Dissertação de Mestrado, ICMC - USP, São Carlos, 2009.

Telek, M.; Horváth, G. A minimal representation of Markov arrival processes and a moments matching method. Perform. Eval. 64(9-12), p. 1153-1168, 2007.

Unuvar, M.; Doganata, Y.; Steinder, M., Tantawi, A.; Tosi, S. A predictive method for identifying optimum cloud availability zones. In Cloud Computing (CLOUD), 2014 IEEE 7th International Conference on, p. 72-79), 2014.

ur Rehman, Z.; Hussain, O. K.; Hussain, F. K.; Chang, E.; Dillon, T. User-side QoS forecasting and management of cloud services. WWW: Internet and Web Information Systems, p. 1-40, 2015.

Voorsluys, W.; Broberg, J.; Buyya, R. Introduction to cloud computing. Cloud computing: Principles and paradigms, p. 3-37, 2011.

Wang, K.; Lin, M.; Ciucu, F.; Wierman, A.; Lin, C. Characterizing the impact of the workload on the value of dynamic resizing in data centers. Performance Evaluation, 2014.

Wang, Z.; Crowcroft, J. Analysis of burstiness and jitter in realtime communications, in: Proceedings of the SIGCOMM, p. 13-19, 1993.

Wang, Q.; Makaroff, D. J.; Edwards, H. K.; Thompson, R. Workload Characterization for an E-commerce Web Site. In: Proceedings of the 2003 Conference of the Centre for Advanced Studies on Collaborative research, p. 313-327, Toronto, Ontario, Canada: IBM Press, 2003. 
Wang, J.; Hua, R.; Zhu, Y.; Wan, J.; Xie C.; Chen, Y. Ro-burst: A robust virtualization cost model for workload consolidation over clouds. In Proceedings of the 12th IEEE/ACM International Symposium on Cluster, Cloud and Grid Computing, p. 490-497, 2012.

Weber, S.; Hariharan, R. A. New Synthetic Web Server Trace Generation Methodology. In: IEEE International Symposium on Performance Analysis of Systems and Software, p. 80-90 Austin, Texas: IEEE, 2003.

Williams, A.; Arlitt, M.; Williamson, C.; Barker, K. Web Workload Characterization: Ten years later. In Web Content Delivery, volume 2, p. 3-21, 2005.

Wu, Y.; Offutt, J. Modeling and Testing Web-Based Applications. GMU ISE Technical ISETR-02-08, 2002

Yin, J.; Lu, X.; Chen, H.; Zhao, X.; Xiong, N. N. System resource utilization analysis and prediction for cloud-based applications under bursty workloads. Information Sciences, 279, p. 338-357, 2014.

Zhang, Q.; Cheng, L.; Boutaba, R. Cloud computing: state-of-the-art and research challenges.Journal of Internet Services and Applications, v. 1, p. 7-18, 10.1007/s13174-0100007-6, 2010. 